\title{
COMBINED TURBULENT \\ CONVECTION HEAT TRANSFER \\ TO NEAR CRITICAL WATER
}

by

R. F. Touba

P. W. McFadden

January 1966

PURDUE UNIVERSITY

School of Mechanical Engineering

Lafayette, Indiana
PURDUE RESEARCH FOUNDATION

Project 3312 


\section{DISCLAIMER}

This report was prepared as an account of work sponsored by an agency of the United States Government. Neither the United States Government nor any agency Thereof, nor any of their employees, makes any warranty, express or implied, or assumes any legal liability or responsibility for the accuracy, completeness, or usefulness of any information, apparatus, product, or process disclosed, or represents that its use would not infringe privately owned rights. Reference herein to any specific commercial product, process, or service by trade name, trademark, manufacturer, or otherwise does not necessarily constitute or imply its endorsement, recommendation, or favoring by the United States Government or any agency thereof. The views and opinions of authors expressed herein do not necessarily state or reflect those of the United States Government or any agency thereof. 


\section{DISCLAIMER}

Portions of this document may be illegible in electronic image products. Images are produced from the best available original document. 


\section{RELLEAASED FIOR ANNOUNCEMENT}

IN NUCLEAAR SCIENCE ABSTRRACTS

COMBINED TURBULENT CONVECTION HEAT TRANSFER

TO

NEAR CRITICAL WATER *

\section{- LEGAL NOTICE}

This report was prepared as an account of Government sponsored work. Neither. the United Ge of the Commission:

A. Hakes any warranty or representation, expressed or implied, with respect to the accuA. Makes any warranty or usefulness of the information contained in this report, or that the use racy, complenes opparatus, method, or process disclosed in this report may not infringe of any informallon, apparat

a the of, or for damages resulting from the

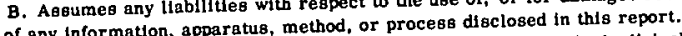

use of any Information, apparatus, method, or process dhe Commission" includes any em-

As used in the above. "person acting on benalf of the such contractor, to the extent that ployee or contractor of the Com such employee or contractor of the Cony informetion pursuant to his employment or contract diseeminates, or provides access to, any informathen pontractor.

by

R. F. Touba

P. W. McFadden

Purdue Research Foundation

Lafayette, Indiana

Technical Report No. 18

Contract No. AT $(11-1)-1177$

$\therefore \therefore$

January 1966

*

Research reported herein was taken from the $\mathrm{Ph}$. D. Thesis of R. F. Touba. 


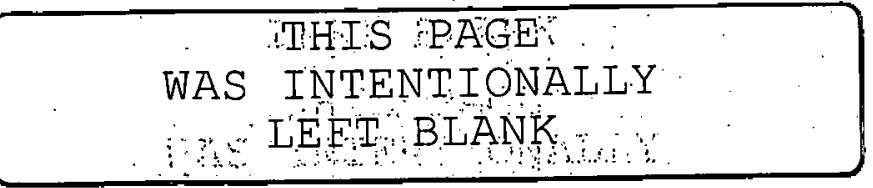




\section{THIS PAGE}

\section{WAS INTENTIONALLY LEFT BLANK}




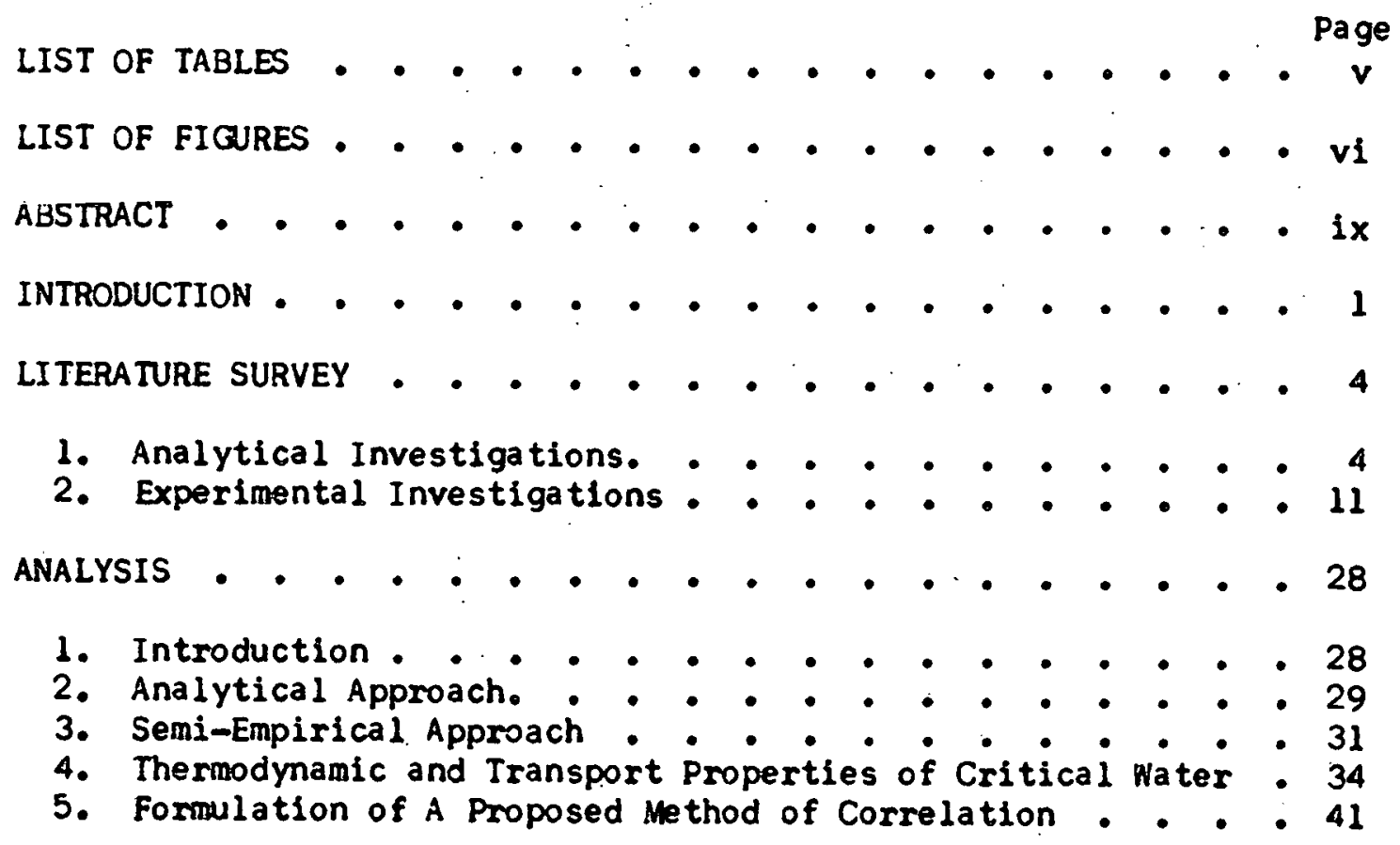

DESCRIPTION OF APPARATUS • . . . . . . . . . . . 50

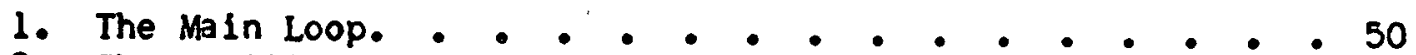

2. The Auxiliary Loop - . - . . . . • . . . . . 56

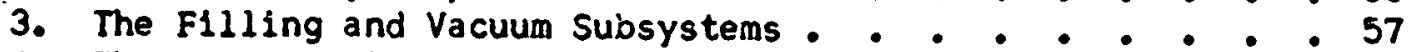

4. The Test Section. - . . . - . . . . . . . . . 60

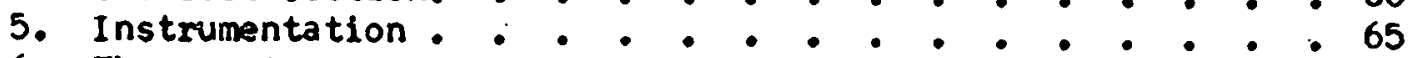

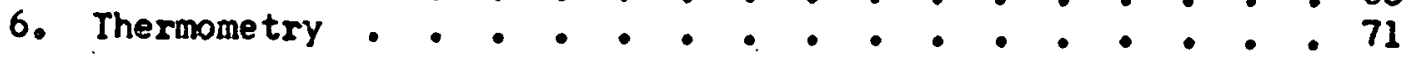

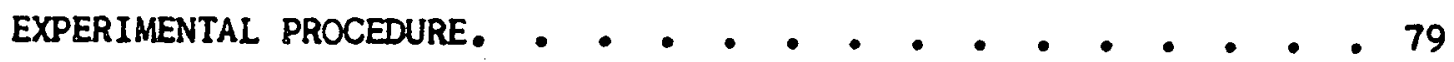

EXPERIMENTAL OBSERVATIONS. • • • • • • • • • • • • •.

REDUCTION OF DATA • • • • • • • • • • • • • • $\bullet 95$

1. Flow Rate Calculations. - • • . . - • . . . 95

2. Test Section Pressure Drop $-\bullet^{-} \cdot \bullet^{-} \cdot \bullet^{-} \cdot \bullet^{-} \cdot \bullet^{-} \cdot 96$

3. Calculation of the Inside Wall Temperature $\bullet \cdot \bullet^{-} \cdot \bullet^{-} \cdot \bullet^{-} 99$

4. Calculation of Local Wall Heat Flux . • • • • •.$~ 104$

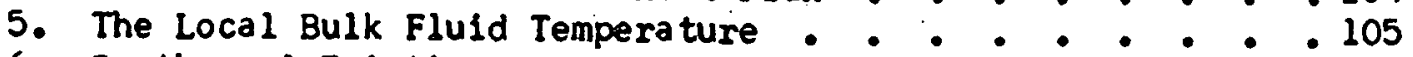

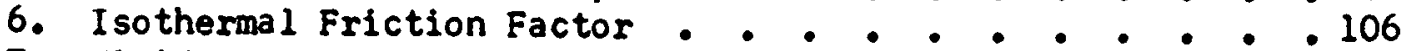

7. Fluid Properties Used In This Work. $\bullet_{\bullet} \cdot \bullet^{-} \cdot \bullet^{-} \cdot \bullet^{-} \cdot 106$

8. Computer Reduction of Experimental Data . . . . . . 111 
EXPERIMENTAL RESULTS, CORRELATIONS, AND DISCUSSIÓN • - . - 113 CONCLUSIONS AND RECOMMENDATIONS. . . . . . . . . . . . 146

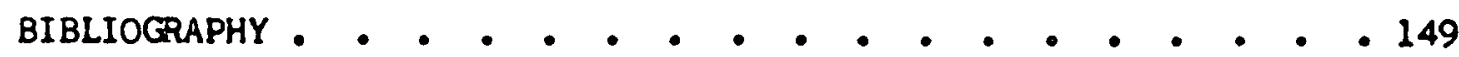
APPENDICES. . . . . . . . . . . . . . . . 153

APPENDIX A, LIST OF SYMBOLS. . . . . . . . . . . . 153

APPENDIX B\& DENSITY CORRECTION IN THE TEST SECTION

PRESSURE DROP MEASUREMENTS •.$\cdot \cdot \cdot \cdot \cdot \cdot \cdot 158$

APPENDIX C: POSSIBLE SOURCES OF UNCERTAINTIES AND THEIR

EFFECI ON THE CALCULATION OF INSIDE WALL

TEMPERATURE. • • • • • • . . . . . . 160

APPENDIX D\& ELECTRICAL RESISTIVITY MEASUREMENT . • • • • 165

APPENDIX E: ENTHALPY-PRESSURE-TEMPERATURE TABLES FOR

NEAR CRITICAL WATER . . . . . . . . . . 171

APPENDIX F\& CALCULATIONS FOR PEAK ENTHALPY. . • • • • • 175

APPENDIX G: IBM 7094 FORTRAN II COMPUTER PROGRAMS • • • • 179

2. Heat Balance Program. . . . . . . . 180

2. Data Reduction and Analysis Program. . . . . 184

APPENDIX H8 SAMPLE COMPUTATIONS . . . . . . . . . . . 190

APPENDIX I: EXPERIMENTAL DATA . . . . . . . ...... 213

APPENDIX J\& POSSIBLE UNCERTAINTIES IN THE COMPUTED

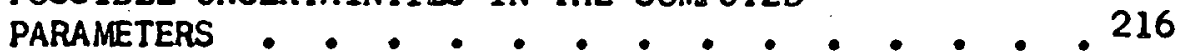

APPENDIX K: A DISCUSSION OF FLUID VIBRATIONS $\bullet \cdot{ }^{\circ} \cdot{ }^{-} \cdot 218$

1. Experimental thods. . . . . . . . 218

2. Analytical and Statistical Methods. . . . 229

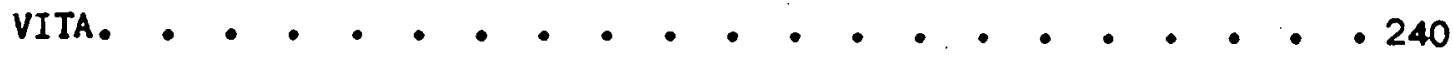




\section{LIST OF TABLES}

Table

I. Eckert-Deissler Rule for Reference Temperature • - - 21

II. Possible Uncertainties in the Thermodynamic

Properties for Water in the Critical Region. . . . 41

III. Test Sections Used in This Work . . . . . . . 60

IV. Discrepancy in the Heat Balances. - . . . . - . 92

V. Sumnary of Electrical Resistivities and Thermal

Conductivity for the Test Sections . . . . . . . 102

C-I. Estimates of Uncertainty in the Variables. . . . - 162

C-II. Estimates of Possible Uncertainty Introduced

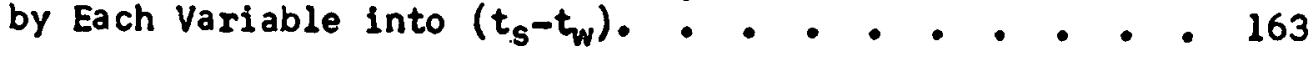




\section{LIST OF FIQURES}

Figure

Pạge

1. Region of Interest to This Investigation . . . . . 3

2. Comparison of Equatioin 25 with Analytical Studies . . 20

3. Specific Volume, Enthalpy, and Volume Expansion Coefficient for Water Near the Peak Temperature

at 3300 psia Pressure. . . . . . . . . . 37

4. Specific Heat, Viscosity, and Thermal Conductivity

for Water Near the Peak Temperature at 3300 psia

Pressure • . . . . . . . . . . . . 38

5. Thermodynamic and Transport Properties of Carbon

Dioxide at 1100 psia . . • . . • . • . . 39

6. Thermal Conductivity of Stainless Steel Type 347. . . . 43

7. Schematic Arrangement of the High Flux Heat Transfer Loop. 51

8. Lower Flange Assembly. . . . . . . . . . . 53

9. Schematic of the Filling System - . . . . . . 58

10. Comparison of Old and New Test Section Designs . - . 63

11. Test Section outlet . . . . . . . . . 64

12. Overall View of $1 / 2$ inch $0 . D$. (XF) Test Section . • 73

13. Overall View of $3 / 8$ inch O.D. (XE) Test Section . . . 74

14. Thermocouple Wiring Detail - . . . . . - 76

15. View of the Instrument and Control Panel - . . . - 77

16. View of the Main Loop and Test Section. . . . . 78

17. Dynograph Traces of Pressure Drop Fluctuations at 300 F, 1900 psia . • . . . . . . . . . 88

18. Test Section Pressure Drop Fluctuations for Iest XE 28. - 89 
vii

Figure

Page

19. Flow Coefficients for Large and Small. Venturis • • . 97

20. Venturi Thermal Expansion Factor - . • • • • . 98

21. Electrical Resistivities of Test Sections XE and XF. - . 103

22. I sobaric Enthalpy-Temperature Curves for Water in the Critical Region . . . . . . . . . . 109

23. Pressure and Temperature Corresponding to $c_{p_{\max }}$ along Isobars . . . . . . . . . . 110

24. Isothermal Friction Factor for Test Sections . . . . 114

25. Low Temperature Heat Transfer Results • • • • • 116

26. Comparison of Low Temperature Data with the Equation of Swenson et al. . . . . . . . . . 118

27. Heat Transfer Results for Run XF 10 • • . • . . 119

28. Heat Transfer Results for Run XE 4. . . . . . . 121

29. Stanton Number Profiles Along the Tube. Wall for Runs XE 4, XF 10, XF 31 . . . . . . . . . . 123

30. Heat Transfer Results for Run XE 7 . . . . . . 124

31. Heat Transfer Results for Run XE 31 - • • • • • 126

32. Heat Transfer Results for Run XF 42 - . • • • . . 127

33. Heat Transfer Results for Run XF 39 . - . • - . 128

34. Heat Transfer Results for Run XF 40 . . . . . . 129

35. Stanton Number Profiles for Runs $X E 7, X E 28$, XE 31, XF 36, XF 39, XF 40, XF 42. . . . . . . 130

36. Comparison of Data with the Dittus-Boelter Correlation. 132

37. Comparison of High Temperature Data with the

Correlation of Swenson et al. - . . . . . . 133

38. Nusselt Number Comparison . . . . . . . . . . 134

39. Heat Transfer Results for Run XF 18 . - . • . . . 136

40. Heat Transfer Results for Run XE 25 . . . . . . 137 
41. Stanton Number Profiles for Runs XE 25, XF 18. - - . - 138

42. Average Stanton Number Versus Reduced Bulk Fluid

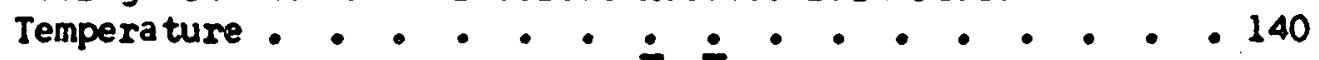

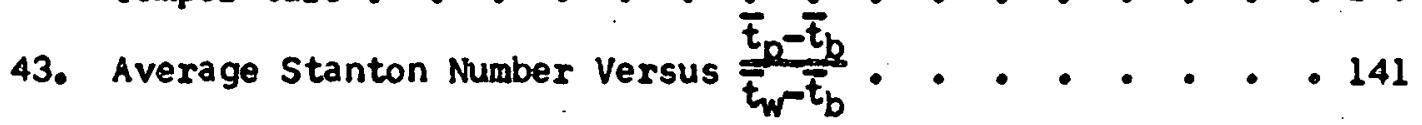

44. Correlation of Near Critical Heat Transfer Data . • . 143

45. Dependence of $\xi_{b}$ Upon the Prandtl Number . . . . . 145

B-1. Simple Schematic of Transducer Circult . . . . . . 159

D-1. Details of Test Section - . - . - . - • 166

D2. Circuit for the Measurement of Electrical Resistivity • 168

D-3. Electrical Resistivity of Stainless Steel Type 347 v/s Temperature. . . . . . . . . . . . 170

F-1. Pressure and Enthalpy Corresponding to Peak Enthalpy Along Isobars . . . . . . . . . . 177

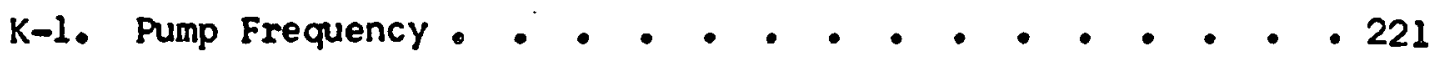

K-2. Velocity Pick Up and Transducer Records. - . . . . 222

K-3. Equipment Used in Dynamic Analysis . . . . . . . . 223

K-4. Experimental Set Up for Accumulator Tests . . . . . 226

K-5. Some Records of the Accumulator Experiments . . . '. 228

K-6. Liquid Mass. Entrapped Between Iwo Gas Volumes. . . . . 230

K-7. Pressure Dependence of the Frequency. . . . . . . . 235

K-8. Power Spectral Density Function . . . . . . . . . 236

K-9. Recorded Effect of the Displacement Pump Action . . . . 238 


\section{ABSTRACT}

Touba, Riza Feredj, Ph.D., Purdue University, June 1965. Combined Turbulent Convection Heat Transfer to Near Critical Water. Major Professors: Richard J. Grosh and Peter W. McFadden.

The experimental study reported herein deals with an investigation of heat transfer to near critical water flowing through a heated vertical tube. Turbulent free and forced convection flow was present. The study utilized the facilities of the High Flux Heat Transfer Research of the School of Mechanical Engineering, Purdue University, sponsored by the United States Atomic Energy Commission. Two AISI type 304 seamless stainless steel tubes of 0.245 and 0.370 inch inside diameter served as joulean heated test sections.

The range of variables covered was as follows:

$\begin{array}{ll}\text { Test Section Bulk Fluid Temperature } & 610-716 \mathrm{~F} \\ \text { Pressure } & 3220-3400 \mathrm{psia} \\ \text { Mass Flux } & 0.849-3.86 \times 10^{6} \frac{\mathrm{lb}_{\mathrm{m}}}{\mathrm{hr} \mathrm{ft}^{2}} \\ \text { Heat Flux } & 176,000-523,000 \frac{\mathrm{B}}{\mathrm{hr} \mathrm{ft}^{2}} \\ \text { Wall Temperature } & 621-835 \mathrm{~F}\end{array}$

Wall to Bulk Fluid Temperature Differences $1.28-117 \mathrm{~F}$

Local heat transfer and Stanton numbers were computed from the data. The data was checked against the Dittus-Boelter equation and good agreement was obtained for temperatures below $650 \mathrm{~F}$ or Prandtl number, based on the bulk fluid temperature, not exceeding 1.20. 
The new correlation of Swenson, Carver, and Kakarala was also tested, which proved satisfactory up to a temperature of around $690 \mathrm{~F}$. Beyond that range agreement deteriorated rapidly with proximity to the peak temperature. The peak temperature was defined as the temperature at which the isobaric specific heat curve peaked.

The effect upon heat transfer of the proximity of both the wall and/or fluid temperatures to the peak temperature was tested. However, the range of the equipment did not allow testing with the bulk fluid temperature above the peak temperature. Very large heat transfer coefficients were obtained for conditions where the wall and/or fluid temperatures approached the peak temperature.

Significant fluctuations were detected in the pressure drop across the test section. These perturbations were present during all isothermal and heating operations at all temperature and pressure levels. The amplitude of the fluctuations magnified at the near critical operations. The cause and the effect of the vibrations could not be determined accurately.

The data is presented in the form of the Stanton number modified to remove the difficulty with the specific heat term. It was possible to correlate the near critical data in the form of

$$
s t_{e} \operatorname{Re}_{b}^{a}=c e^{\frac{b \frac{H_{b}}{H_{p}}}{p}}
$$

to within $\$ 16$ per cent.

Data below $t_{b} / t_{p}$ of 0.93 could be correlated in the form of $\overline{s t}=$ constant

for limited ranges of mass and heat fluxes. 


\section{INTRODUCT ION}

The engineer's everlasting desire for greater efficiencies and economy has tempted him towards higher and higher temperatures. This thrust has taxed both science and technology. From the heat transfer point of view, the recent interests in the developments of supercritical steam power plants, nuclear reactor technology, cooling of computers, and rocket engines have been most demanding. Efficient methods of heat transfer are being sought. One such method is the use of fluids in the proximity of their critical point; where investigations have revealed very sharp increases in the heat transfer rates. Complexity of the process and the characteristics of the fluids in the near critical region pose a great difficulty to both the analytical worker and the experimentalist. The basic equations that describe such a process are vastly complicated, and present the analyst challenge and many hardships. The experimental investigations are hampered not only by the very difficult task of obtaining reliable information, but also by the unavailability of vast and accurate information on thermodynamic and transport properties.

The critical pressure and temperature specify a limit above which a l1quid and saturated vapor can not coexist together in thermodynamic equilibrium. Thus, above the critical point there is no distinction between a liquid and vapor. The critical pressure, temperature, 
and enthalpy for water are believed to be $3208 \mathrm{psia}, 705.5 \mathrm{~F}$, and $900 \mathrm{~B} / 1 \mathrm{~b}_{\mathrm{m}}$ respectively.

The correlation of the experimental data for heat transfer has been another major difficulty with near critical fluids. From a practical standpoint it is essential to obtain simple yet general correlations. Many such attempts have been unsuccessful in the critical region partly due to the large changes in the fluid properties. The properties also present a massive obstacle to the theoretical studies. Besides obtaining experimental data, this work was also an attempt to find a simple method of correlation of data.

The facilities of the High Flux Heat Transfer Loop of the School of Mechanical Engineering, sponsored by the United States Atomic Energy Comnission, were used. The study concerned itself primarily with turbulent forced convection heat transfer to near critical water, exploring a region where previously little or no data had been available. Figure 1 describes the area of interest based on the bulk fluid properties. In the succeeding sections of this thesis a literature survey, a description of the test equipment, an analysis of the problem, and the results of the investigations are presented. 


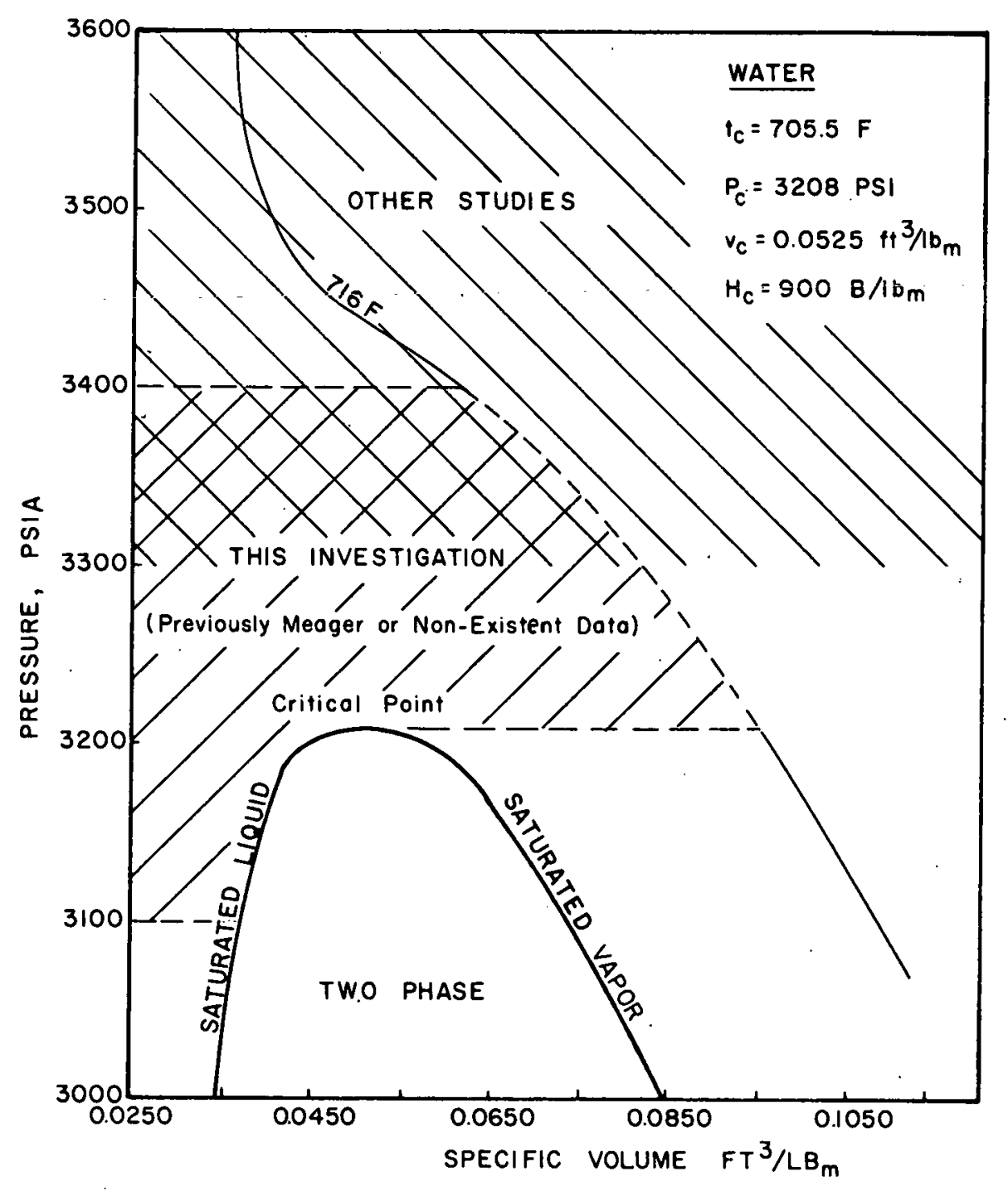

FIGURE I. REGION OF INTEREST TO THIS INVESTIGATION 


\section{LITERA TURE SURVEY}

The literature dealing with the subject of heat transfer to near critical fluids is scarce. This can be attributed primarily to the complexity of both analytical and experimental investigations in this region. While the solution of the most simplified equations, roughly describing the process of heat transfer near the critical region of a fluid, involves laborious numerical methods, the experimentalist faces the most difficult task of obtaining rellable data and processing it satisfactorily. Briefly, it is the complex nature of the physical process that has denied the investigators a full understanding into this mode of heat transfer.

The high-lights of several analytical and experimental investigations in the regions below and above the critical point are described in the following. The problem of heat transfer to near critical fluids under the effect of combined forced and free turbulent convection is far from solved and understood.

\section{Analytical Investigations}

Deissler $(\underline{1}) *$ has generalized a previous analysis for fully developed turbulent variable property flow and heat transfer in smooth tubes to make it applicable to air and supercritical water.

\footnotetext{
*Underlined numbers in parentheses designate References in the Bibliography.
} 
Large variations with temperature of the physical properties of supercritical water were recognized and the following assumptions were made:

1. The eddy diffusivity for momentum, $\epsilon$, and heat transfer, $\epsilon$, were assumed equal. For $\operatorname{Re}>15,000$, the ratio of. $\epsilon_{h}$ to $\epsilon$ was nearly constant.

2. The variation across the tube of the shear stress and the heat flux was considered to have a negligible effect on the velocity and temperature distributions.

3. The static pressure across the tube was considered constant.

4. $\frac{\epsilon}{\nu_{w}}=\kappa^{2} \frac{\left(\frac{d u^{+}}{\left.d y^{+}\right)^{3}}\right.}{\left.\frac{d^{2} u^{+}}{d y^{+2}}\right)^{2}}$, away from the wall, and $\frac{\epsilon}{\nu_{w}}=n^{2} u^{+} y^{+}$ close to the wall. 5. $\frac{\mu}{\mu}=a\left(\frac{I}{I_{w}}\right)^{b}$, where $a$ and $b$ are constants.

The following equations for the computation of Reynolds number, Nusselt number, and friction factor were then obtained.

$$
\begin{aligned}
& N u_{w}=2 \stackrel{r_{0}}{+\frac{P r_{w}}{I_{b}}} \\
& R e_{w}=2 \bar{U} r_{0}^{+} \\
& f_{w}=\frac{2}{\bar{U} \leftarrow 2} .
\end{aligned}
$$

* For description of symbols refer to Appendix $A$. 
A plot of Nusselt number against Reynolds number for a pressure of 5000 psia and a wall temperature of $900 \mathrm{~F}$ with $\Omega=\frac{q_{w}^{n} \sqrt{\tau} w_{w}}{c_{p_{w}} g_{w} T_{w}}$ as a parameter was presented. The variation of Nusselt number with $\Omega$ proved to be rather complex, and a single reference temperature which could be used in evaluating the properties (independent of $\Omega$ ) could not be obtained. Thus, a plot of the reference temperature Iref versus $\frac{T_{w}}{T_{b}}$ with $T_{w}$ as a parameter was given for use in the determination of Nusselt and Reynolds parameters. A similar plot gave the reference temperature for use in the determination of the friction factor. For better results it was recommended that Nuref determined from a plot of $\mathrm{Nu}_{\text {ref }}$ versus Re ref with $\mathrm{Pr}=1$ as a parameter be multiplied by $\mathrm{Pr}_{\mathrm{w}}^{0.45}$. A similar analysis for air showed substantial agreement between experimental results and analytically predicted heat transfer and friction correlations.

E. R. G. Eckert (2), in discussing the above work of Deissler, gave a plot of $\sigma=\frac{t_{\text {ref }}-t_{b}}{t_{w}-t_{b}}$ versus $\frac{t_{p}-t_{b}}{t_{w}-t_{b}}$ with $t_{w}$ as a parameter. The parameter $t_{w}$ became quite insignificant as all curves for different $t_{w}$ values aligned well along a single curve. Eckert showed that for

$$
\frac{t_{p}-t_{b}}{t_{w}-t_{b}} \leq 0, \quad \sigma \approx 0
$$

hence $t_{\text {ref }} \approx t_{b} ;$ and for

$$
\frac{t_{p}-t_{b}}{t_{w}-t_{b}} \geq \text { unity, } \sigma \approx \text { unity, }
$$

hence $t_{\text {ref }} \approx t_{w^{*}}$ 
It was reported that the influence of $t_{p}$ on the location of $t_{\text {ref(friction) }}$ to be used in the calculation of friction was weaker than for heat transfer.

In his closure, Deissler concluded that the properties in the Nusselt and Reynolds number could be calculated at $t_{p}$ as long as $t_{p}$ remained between $t_{w}$ and $t_{b}$. If $t_{p}$ was higher than $t_{w}$ the properties should be evaluated at $t_{w}$. If $t_{p}$ was lower than $t_{b}$ then they should be evaluated at approximately $t_{b}$. The Prandtl number was to be evaluated at $t_{w}$ rather than $t_{r e f}, i_{. e .}$

$$
N u_{\text {ref }}=C \operatorname{Re}_{\text {ref }}^{\mathrm{a}} \mathrm{Pr}_{\mathrm{w}}^{\mathrm{b}}
$$

Goldmann $(\underline{3}, 4)$ has presented a method of analysis to predict heat transfer and pressure drop characteristics for fluids with temperature dependent properties in fully developed turbulent flow. It was a further extension of the Reynolds analogy between turbulent momentum exchange and heat transfer. Results were shown to be in good agreement with experimental data available for air under high heat fluxes. Heat transfer and pressure drop characteristics for water at 5000 psia as predicted by this method were given in graphical form. The essential difference between Goldmann's and Deissler's analyses was that Goldmann avoided the assumption of the constancy of $k$ and $n$. Instead, the assumption was made that the turbulent mixing process at any point was a function of fluid properties at that point but was not affected by small property changes in the neighborhood of that point. 
Plots of the heat flux parameter $\left(\frac{q^{\prime \prime}, D^{0.2}}{G 0.8}\right)$ versus wall temperature with bulk temperature as a second parameter, and shear stress. parameter $\left(\frac{\tau\left(g P_{b}\right) D 0.3}{G l .7}\right)$ versus bulk temperature with wall temperature as a second parameter, were presented in references $(\underline{3}, 4)$ for water at 5000 psia.

Such a correlation followed from a consideration that for convective heat transfer the following relations are usually employed;

$$
\frac{\mathrm{hD}}{\mathrm{k}}=\mathrm{C}\left(\frac{\mathrm{GD}}{\mathrm{H}}\right)^{\mathrm{m}}(\mathrm{Pr})^{\mathrm{b}}
$$

and

$$
h \equiv \frac{q_{w}^{\prime \prime}}{t_{w}-t_{b}}
$$

For isothermal shear stress the following relation is applied:

$$
\frac{\tau_{w}}{P_{u}^{2}}=\frac{f}{2}=\frac{C}{\left(\frac{G D}{\mu}\right)^{1-n}}
$$

These relations have led to

$$
\frac{q_{w}^{\prime \prime} D^{1-m}}{G^{m}}=f\left(t_{w}, t_{b}\right), m=0.8
$$

and

$$
\frac{\tau p^{1-n}}{G^{l+n}}=g\left(t_{w}, t_{b}\right), \quad n=0.7
$$

Usually $m$ and $n$ are functions of Reynolds and Prandtl numbers.

Eckert (2) gave the following theoretically founded equation for forced convection heat transfer in a tube with turbulent flow:

$$
S t=\frac{\mathrm{Nu}}{\operatorname{Re} \operatorname{Pr}}=\frac{0.0384(\mathrm{Re})^{-0.25}}{1 \cdot \mathrm{A}(\mathrm{Re})^{-0.125}(\mathrm{Pr}-1)}
$$


The value of $A$ may be obtained from a curve by $W$. Bühne presented in reference (2), page 207 or calculated from the following equation given by E. Hoffman (2, page 207):

$$
A=1.5 \operatorname{Pr}^{-\frac{1}{6}}
$$

The property values to be used in the above equations must be computed at a reference temperature

$$
t_{\text {ref }}=t_{b}+\frac{0.1 \operatorname{Pr}+40}{\operatorname{Pr}+72}\left(t_{w}-t_{b}\right)
$$

Hsu and Smith (ㅁ) have presented a study in which the effect of large density changes (in the radial direction) upon heat transfer within a tube was investigated analytically. Deissler's work did not take into account the influence of density variations on the radial transfer of momentum and heat between adjacent fluid elements, and the radial variation of the force of gravity on the fluid. Hsu and Smith attempted this objective, and employed Deissler's expressions for the eddy diffusivity in solving the equations for heat and momentum transfer. The effect of free convection on heat transfer coefficient for turbulent flow was predicted.

The results indicated that the effect was significant only for relatively high Grashof numbers and low Reynolds numbers. The ratio $\frac{\mathrm{Gr}}{\mathrm{Re}_{\mathrm{w}}^{3}}$, obtained in the analysis, showed the influence of variable density upon the shear stress profile. $G r<<e_{w}$ signified the negligible effect of body force.

Velocity and temperature profiles were computed. The results for heating showed that including the density variation flattened both 
the temperature and velocity curves and increased the heat transfer coefficient at a given Reynolds number.

The computated heat transfer results for near critical $\mathrm{CO}_{2}$ at 1200 psia were compared with the experimental determinations of Bringer (6). It was observed that taking into account the affect of density variations improved the agreement with the experimental data. However, the Grashof number at Bringer's operating conditions was too low for natural convection to be significant.

Recently, Ojalvo (7) has presented an analytical study of turbulent heat transfer in a vertical circular tube under the conditions of combined forced and free convection with uniform wall heat flux. Three linear integro-differential equations which contained Prandtl, Rayleigh, and friction Reynolds parameters were obtained from the basic conservation equations. A numerical solution yielded fully developed velocity profile, temperature profile and pressure drop for fixed values of the above parameters. Nusselt and Reynolds parameters together with mixedmean-to-wall temperature difference were also computed.

Ojalvo's assumptions which are of interest in this work are presented below:

1. All fluid properties were assumed constant except density in the expression for body force. A mean density was used for all other density terms.

2. Viscous dissipation and axial heat conduction were considered negligible compared to the heat conduction in the radial direction.

3. The eddy diffusivities of momentum and heat were assumed to be in constant proportion, and given by an equation presented by Lykoudis ( $(8)$ in his study of heat transfer to liquid metals, viz.

$$
\epsilon_{h}=\frac{6}{\pi^{2}} \sum_{n=1}^{\infty} \frac{1}{n^{2} \exp \left(0.01 \frac{n^{2}}{P r}\right)}
$$


4. The equation giving the eddy diffusivity of momentum was a modification of Reichardt's equation and was based on various avallable experimental data. Thus,

$$
\begin{array}{ll}
\frac{\epsilon}{\nu}=0.0667 \operatorname{Re}^{*}\left(0.5 * \eta^{2}\right)\left(1-\eta^{2}\right) \\
\text { for } 0 \leq \eta \leq\left(1-\frac{10}{\operatorname{Re} *}\right) \\
\frac{\epsilon}{\nu}=0 \quad \text { for }\left(1-\frac{10}{\operatorname{Re}^{*}}\right) \leq \eta \leq 1
\end{array}
$$

Certainly some of the assumptions of the analytical works presented above may not be valid for heat transfer near the critical region. Therefore, such solutions. must be regarded as limited in scope and valid only within the domain of their assumptions. In the section reviewing experimental investigations the inadequacy of some analytical results is presented.

\section{Experimental Investigations}

McAdams, et al. (9) have conducted experimental investigations on the problem of heat transfer to superheated steam at high pressures, and have determined local coefficients of heat transfer from surfaces to superheated steam at pressures up to 3500 psia and bulk temperatures from 430 to $1000 \mathrm{~F}$. Their experimental apparatus consisted of a vertical annulus with electrically heated inner wall and unheated outer wall. Steam flowed upward, with mass velocity restricted to $55,000-165,000$ $\frac{1 \mathrm{~b} m}{\mathrm{hr} \mathrm{ft}^{2}}$ - Wall and bulk fluid temperature differences were from 100 to $625 \mathrm{~F}$. 
The following correlation which must not be extrapolated outside the range of data was recommended:

$$
\left(\frac{h D_{e}}{k_{b}}\right)\left(\frac{c_{p} \mu}{k}\right)_{b}^{-\frac{1}{3}}\left(\frac{l}{D_{e}}\right)^{0.13}=0.0126\left(\frac{D_{e}^{G}}{\mu_{b}}\right)^{0.89}
$$

Based on thermal conductivity extrapolated from newer measurements of Keyes and Sandell $(\underline{9}) *$ the above equation became:

$$
\begin{gathered}
\left(\frac{h D_{e}}{k_{b}}\right)\left(\frac{c_{p} \mu^{-\frac{1}{3}}}{k}\right)_{b}\left(1-\frac{2.3}{L / D_{e}}\right)^{-1}=0.0214\left(\frac{D_{e}^{G}}{\mu_{b}}\right)^{0.80} \\
\quad \text { for } 6000 \leq \frac{D_{e}^{G}}{\mu_{b}} \leq 50,000
\end{gathered}
$$

It was reported that for a given Reynolds number the maximum deviation from measured values was 28 per cent, and the average deviation was seven per cent.

Kreith and Summerfield (10) have conducted an experimental study of heat transfer to water at high fluxes with and without surface boiling. Although they operated at low pressures, their results were worth noting. Surface coefficients of heat transfer, at heat fluxes up to $1.04 \times 10^{6} \frac{\mathrm{B}}{\mathrm{hr} \mathrm{ft}^{2}}$, were obtained for water flowing in stainless steel tubes at mass fluxes up to $2.8 \times 10^{6} \frac{\mathrm{lb}_{\mathrm{m}}}{\mathrm{hr} \mathrm{ft}^{2}}$. The non-boiling forced convection data were correlated by the Colburn equation

$$
N u_{f}=0.023 \operatorname{Re}_{f}^{0.8} \operatorname{Pr}_{f}^{1 / 3}
$$

within plus or minus. five per cent in the Reynolds number range from 50,000 to 350,000 . It was also concluded that when heat was transferred

\footnotetext{
Personal communications of McAdams.
} 
to water in turbulent flow without surface boiling in a tube, the friction coefficient at equal Reynolds numbers decreased according to the following equation:

$$
\frac{f(\text { heat transfer })}{f(\text { isotherma })}=\left(\frac{\mu_{w}}{\mu_{b}}\right) 0.13
$$

The authors also reported that the Colburn equation could not predict the heat transfer coefficient between a metal surface and water flowing in a tube when the surface temperature exceeded the boiling point of the fluid.

The Dittus-Boelter equation (2) for heat flow has been given as

$$
\mathrm{Nu}=0.0243(\mathrm{Re})^{0.8}(\mathrm{Pr})^{0.4} \text { * }
$$

where properties may be evaluated at the bulk fluid temperature. McAdams has proposed a rule by which heat transfer in mixed (i.e., combined free and forced convection) flow through a vertical tube could be determined as follows: The heat transfer coefficient is calculated from forced convection and free convection relations and the larger value is used. Eckert reported that measured values did not deviate by more than 25 per cent from the values calculated by McAdams' rule.

Russian investigators Miropolskii and Shitsman (11), working with a steel tube of $0.354 / 0.276$ inch diameter heated in an electrical radiation furnace, covered the following ranges of variables:

* (2) $, p, 211$.

+ Ibid, p. 332 . 


$$
\text { Pressure }=60-4200 \text { psia }
$$

Fluid temperature $=36.5-770 \mathrm{~F}$

Surface to fluid temperature diff $=16.2-387 \mathrm{~F}$

$$
\begin{aligned}
& \text { Mass flux }=0.125 \times 10^{6}-2.21 \times 10^{6} \frac{1 b_{m}}{\mathrm{hr} \mathrm{ft}^{2}} \\
& \text { Heat flux }=0.369 \times 10^{5}-7.38 \times 10^{5} \frac{\mathrm{B}}{\mathrm{hr} \mathrm{ft}^{2}}
\end{aligned}
$$

The fluid temperature at intermediate distances along the test section were determined by linear interpolation from inlet and outlet temperatures. Hydrodynamic stability was established before the inlet to the heated section.

Experimental results were compared with certain relations frequently used for heat transfer computations in conjunction with turbulent flow through a tube. It was concluded that the following relations,

$$
\begin{aligned}
& N u_{b}=0.023 \operatorname{Re}_{b}^{0.8} \operatorname{Pr}_{b}^{0.4} \\
& N u_{b}=0.021 \operatorname{Re}_{b}^{0.8} \operatorname{Pr}_{b}^{0.43}\left(\frac{\operatorname{Pr}_{b}}{\operatorname{Pr}_{w}}\right)^{0.25} \\
& N u_{b}=0.027 \operatorname{Re}_{b}^{0.8} \operatorname{Pr}_{b}^{0.33}\left(\frac{\mu_{b}}{\mu_{w}}\right)^{0.14}
\end{aligned}
$$

did not give satisfactory results. For heating superheated steam at given inlet temperature, pressure, and mass flux, equations (21) and (22) gave an increase in the calculated values of $h$, while the experimental results showed that heat transfer coefficients decreased with an increase in the wall-to-bulk fluid temperature difference. Also, the 
application of the above equations in the temperature ranges where the values of Prandtl number varied in connection with changes in the specific heat did not give satisfactory results.

Miropolskii and Shitsman proposed an equation containing the known parameters $\mathrm{Nu}, \mathrm{Re}, \mathrm{Pr}$ for the evaluation of local heat transfer coefficients to water and steam. They believed this to be advantageous for temperatures of the heat transfer medium above $300 \mathrm{~F}$. Their equation is:

$$
N u_{b}=0.023 \operatorname{Re}_{b}^{0.8} \operatorname{Pr}^{0.8}
$$

The bulk temperature of the fluid is assumed to be the determining factor in the calculation of $\mathrm{Nu}$ and $\mathrm{Re}$, but $\mathrm{Pr}$ is determined according to the following rules:

1. Use the wall temperature if $\mathrm{Pr}_{b}>\mathrm{Pr}_{w^{*}}$

2. Use the fluid temperature if $\operatorname{Pr}_{\mathrm{b}}<\operatorname{Pr}_{w^{*}}$.

The authors reported that, for water at subcritical pressures of $25-220$ atm., their data was predicted within plus or minus ten per cent by their proposed equation. The accuracy dropped down to \$ 15 per cent for pressures of $230-280 \mathrm{~atm}$. It was also reported that the standard correlations, equations (20) to (22), were suitable for the range of temperatures and pressures where $\operatorname{Pr}$ variations were associated with changes in the dynamic viscosity.

Dlckinson and Welch (12), working with a horizontal, electrically heated AISI Type 304 stainless steel tube having an inside diameter of 0.300 inch, covered the following range of variables: 


$$
\begin{aligned}
& \text { Pressure } 4500 \text { psia - some } 3500 \text { psia } \\
& \text { Fluid bulk temperature } 220-1000 \mathrm{~F} \\
& \text { Mass flux } 1.6-2.5 \times 10^{6} \frac{1 \mathrm{bm}_{\mathrm{m}}}{\mathrm{hr} \mathrm{ft}^{2}} \\
& \text { Heat flux } 28-58 \times 10^{4} \frac{\mathrm{B}}{\mathrm{hr} \mathrm{ft}^{2}} \\
& \text { Wall-to-steam temperature diff. }>40 \mathrm{~F}
\end{aligned}
$$

Data points having bulk temperatures below $660 \mathrm{~F}$ were compared with equation (20), viz.

$$
N u_{b}=0.023 \operatorname{Re}_{b}^{0.8} \operatorname{Pr}_{b}^{0.4}
$$

and were found to be approximately ten per cent below the values obtained from the above equation. Due to unavailability of adequate property values, no attempt was made to correlate the data using dimensionless parameters completely. Instead, film coefficlents were plotted against surface temperature for various values of mass flux. The authors reported that cross plots of the data indicated that the heat transfer coefficient varied approximately as $G^{0.8}$ for bulk temperatures below $660 \mathrm{~F}$ and as $\mathrm{G}^{1.0}$ for bulk temperatures above $800 \mathrm{~F}$. It was concluded that for surface temperatures within 800 to $1100 \mathrm{~F}$, the data could reliably be represented in the form of a constant Stanton number of 0.00189 for the range of mass fluxes tested. That is,

$$
s t .=\frac{h}{c_{p} G}=0.00189 \pm 10 \text { per cent. }
$$

where $c_{p}$ is evaluated at the wall temperature. For the range of 660-800 F heat transfer coefficients higher than those predicted by theoretical studies of Deissler and Goldmann were obtained. 
Touba (13) investigated the characteristics of heat transfer to near critical water (pressure-and-temperature-wise) in turbulent upward flow through an electrically heated Type 347 seamless stainless steel tube. The range of variables covered was as follows:

$\begin{aligned} \text { Pressure } & 3230-3300 \text { psia } \\ \text { Fluid bulk temperature } & 685-712 \mathrm{~F} \\ \text { Mass flux } & 1.87-2.69 \times 10^{6} \frac{1 \mathrm{~b}_{\mathrm{m}}}{\mathrm{hr} \mathrm{ft}^{2}} \\ \text { Heat flux } & 5 \times 10^{5} \frac{\mathrm{B}}{\mathrm{hr} \mathrm{ft}^{2}} \\ \text { Wall-to-fluid temperature diff. } & 2-37.1 \mathrm{~F} .\end{aligned}$

Local and average heat transfer coefficients for subcritical and supercritical (temperature-wise), water were determined. Dimensional analysis based on prevailing conditions in the test section led to the Stanton number as a major parameter, which was redefined to suit the needs of the work.

Heat transfer coefficients of more than $50,000 \mathrm{Btu}$ per hour per square foot per $F$ were reported. Large values occurred close to the temperature at which the specific heat corresponding to a given pressure reached its peak.

Plots of stanton number and the heat transfer coefficient versus bulk and wall temperatures were presented. A plot of Stanton number versus $\frac{t_{b}}{t_{p}}$ was given. This correlation helped reduce the scatter of data. The Dittus-Boelter equation failed to give adequate results. Recently Swenson, Kakarala, and Carver (14) published the results of their investigations in heat transfer to supercritical water in smooth-bore tubes. The range of variables covered was: 


$$
\text { Pressure } 3300 \text { - } 6000 \text { psia }
$$

Fluid bulk temperature $167-1068 \mathrm{~F}$

$$
\begin{array}{ll}
\text { Mass flux } & 4-15.85 \times 10^{5} \frac{\mathrm{lb}}{\mathrm{hr} \mathrm{ft}^{2}} \\
\text { Heat flux } & 6.5-57.8 \times 10^{4} \frac{\mathrm{B}}{\mathrm{hr} \mathrm{ft}^{2}}
\end{array}
$$

Wall-to-fluid temperature diff. $11-513 \mathrm{~F}$

An electric-resistance welded AISI Type 304 stainless steel tube 116 inches long, having a nominal 1/2-inch outer diameter and 0.371 inch inside diameter was used as the test section. The test section was installed vertically with the flow upward, and heated electrically along 72 inches of its length. An open-circuit heat transfer test apparatus was employed.

Local forced convection heat transfer coefficients for supercritical water were obtained. It was shown that conventional forced convection correlations for fully developed turbulent flow were inadequate and did not fit the data. A satisfactory equation, which correlated only the data from the downstream half of the tube, was obtained by modifying the conventional forced convection heat transfer relation. This relation is of the form:

$$
N u_{w}=a \operatorname{Re}_{w}^{b} \operatorname{Pr}_{w}^{c}\left(\frac{v_{b}}{v_{w}}\right)^{d}
$$

where

$$
\begin{aligned}
& a=0.00459 \\
& b=0.923 \\
& c=0.613 \\
& d=0.231
\end{aligned}
$$


All properties in the non-dimensional parameters are evaluated at the inside wall temperature, and the specific heat term in the Prandtl number is defined as

$$
c_{p_{h}}=\frac{H_{w}-H_{b}}{t_{w}-t_{b}} .
$$

The authors reported a good fit, indicating that 95 per cent of their data lay within $\$ 15$ per cent of the correlation. It was also found that the same equation correlated the supercritical heat transfer data of carbon dioxide, and predicted heat transfer coefficients in the regions where the constant property assumptions were valid. Furthermore, it was concluded that in the supercritical region heat transfer coefficient is strongly affected by heat flux - specifically, it decreases with increasing heat flux.

For the sake of completeness, a plot presented by Swenson, Kakarala and Carver in an attempt to compare their results with the analytical studies of Deissler $(\underline{1})$ and Goldmann $(\underline{3}, \underline{4})$ is reproduced in Figure 2. Since the property values used in the three works represented in this plot were not the same, the reader must be cautious as to the extent of his conclusions. It has already been stated that Hsu and Smith (ㅁ) modified Deissler's analysis, and obtained a better agreement with experimental data for carbon dioxide.

It is now appropriate to point out and survey some of the important experimental investigations dealing with the subject of heat transfer to supercritical $\mathrm{CO}_{2}$. Similar studies were reported for Hydrogen by Hess and Kunz (15), and for Oxygen by Powell (16). Powell's 


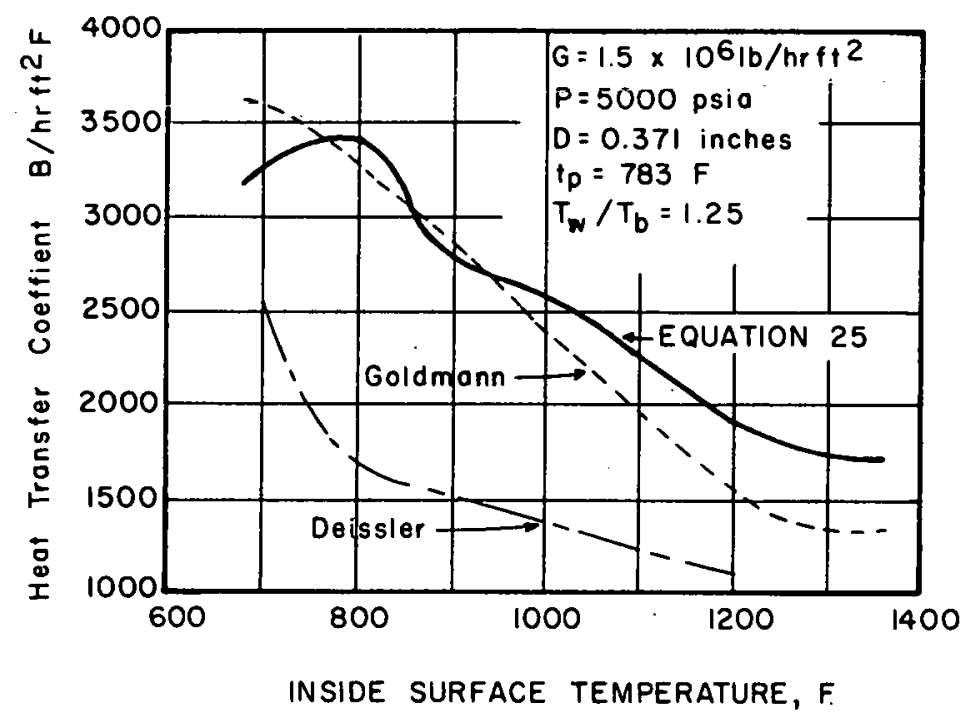

FIGURE 2. COMPARISON OF EQUATION 25 WITH ANALYTICAL STUDIES

(After Swenson et.al.) 
data showed a minimum for the heat transfer coefficient near the critical temperature.

Bringer and Smith (6) reported measurements of heat transfer coefficients for carbon dioxide in turbulent flow. The bulk temperature was varied from 70 to $120 \mathrm{~F}$ at a pressure of 1200 psia.* The heat transfer coefficients ranged from $300-2600 \frac{\mathrm{B}}{\mathrm{hr} \mathrm{ft}^{2} \mathrm{~F}}$ over a Reynolds number range of $3 \times 10^{4}-30 \times 10^{4}$. The test section was installed vertically with upward flow. Inadequacy of existing empirical and semitheoretical correlations was observed. Numerical computations for carbon dioxide based on Deissler's analytical method were found to fit the experimental data. A simplified procedure was proposed for estimating heat transfer coefficients in the critical region. The authors replaced Deissler's $\Omega$. 0 solution for water at 5000 psia by a conventional type heat transfer equation - namely,

$$
N u_{\text {ref }}=0.0266 \operatorname{Re}_{\text {ref }}^{0.77} \operatorname{Pr}_{w}^{0.55}
$$

and proposed to evaluate the property values in Nusselt and Reynolds parameters according to the rule given by Deissler (). Table 1 below restates this rule in a tabular form.

TABLE 1

Eckert-Deissler Rule for Reference Temperature

$$
\begin{array}{cc}
\frac{t_{p}-t_{b}}{t_{w}-t_{b}} & t_{\text {reference }} \\
0 t_{0} 1.0 & t_{p} \\
>1.0 & t_{w} \\
<1.0 & t_{b} .
\end{array}
$$

* $\mathrm{CO}_{2}$ critical conditions are: $\mathrm{P}_{\mathrm{c}}=1071$ psia, $t_{c}=87.8 \mathrm{~F}$. 
It was reported that the method worked satisfactorily when compared with the computed heat transfer coefficients of Deissler for supercritical water, but showed 30 per cent deviation when compared with the carbon dioxide results. The discrepancy was attributed to the fact that while the $\mathrm{CO}_{2}$ was very close to the critical point (reduced pressure $=1.1$ ), the water was further removed (reduced pressure $=1.6)$. The coefficient in equation (26) could be increased to obtain a better fit with an average deviation of $\div 16$ per cent.

Russian investigators Petukhov, Krasnoschekov, and Protopopov (17) have investigated experimentally the problem of heat transfer to supercritical carbon dioxide in turbulent flow through a horizontal tube. Mieasurements were carried out at pressures of 90,100 , and $110 \mathrm{~kg} / \mathrm{cm}^{2}$ and temperature differences from 4 to $50 \mathrm{C}$. Reynolds number ranged from $5 \times 10^{4}$ to $3 \times 10^{5}$.

An equation correlating the available experimental data on heat transfer. to carbon dioxide and water in the supercritical region was proposed. It was reported that the majority of their data was correlated within $₫ 15$ per cent, and only 6 per cent diverged slightly more than 20 per cent. The equation is:

$$
\left.N u_{b}=N u_{b}^{\prime} \frac{\mu_{b}}{\mu_{w}}\right)^{0.11}\left(\frac{k_{b}}{k_{w}}\right)^{-0.33}\left(\frac{{ }^{c} p_{h}}{c_{p_{b}}}\right)^{0.35}
$$

where $c_{p_{h}}=\frac{H_{w}-H_{b}}{t_{w}-t_{b}}$, as was defined previously.

$\mathrm{Nu}_{b}^{\prime}$ was reported to have been derived by Petukhov and Kirillov, by a theoretical computation, for heat transfer to turbulent pipe flow of 
fluids with constant physical properties.

$$
N u_{b}^{\prime}=\frac{\frac{N}{8} \operatorname{Re}_{b} \operatorname{Pr}_{b}}{12.7 \sqrt{\frac{N}{8}\left(\operatorname{Pr}_{b}^{2 / 3}-1\right)+1.07}}
$$

where

$$
N=\frac{1}{\left(1.82 \log R e_{b}-1.64\right)^{2}}
$$

Koppel and Smith (18) have carried out investigations on heat transfer to near critical carbon dioxide. A horizontal, electrically heated test section was employed. The range of the experiments was:

$$
\begin{aligned}
\text { Pressure } & 1071-1100 \mathrm{psia} \\
\text { Heat flux } & 2 \times 10^{4}-20 \times 10^{4} \frac{\mathrm{B}}{\mathrm{hr} \mathrm{ft}^{2}} \\
\text { Fluid temperature } & 65-120 \mathrm{~F} \\
\text { Reynolds number } & 3 \times 10^{4}-30 \times 10^{4}
\end{aligned}
$$

Unusual results were observed. One was a decrease in the wall temperature in the section of the tube imnediately after the entrance. The investigators reported that:

1. the phenomenon would not occur if the bulk fluid temperature at the tube inlet was above the peak temperature;

2. the transition was gradual with the wall temperature profile at the entrance first flattening and finally dipping as the flow rate was increased;

3. the flow rate necessary to cause the transition was an increasing function of the wall heat flux. 
Furthermore, they concluded that:

1. normal heat transfer results were obtained for fluid inlet temperatures above the peak temperature;

2. at inlet temperatures below the peak temperature unusual axial variations of the heat transfer coefficient were observed, which behavior was most pronounced at the critical pressure;

3. at low or moderate wall-to-fluid temperature differences, the fluid exhibited increasingly better heat transfer characteristics as the peak temperature was approached. An effort to correlate the data according to equation (23) and the rule proposed by Miropolskii and Shitsman (11), proved unsatisfactory. The authors indicated that a different approach was necessary to explain heat transfer near the critical point.

Recently Wood and Smith (19) measured temperature and velocity profiles and local heat transfer coefficients for turbulent flow of carbon dioxide in a tube at 1075 psia $\left(p_{c}=1071\right)$. Their results showed a maximum in the velocity profile between the wall and tube axis, a peak in the heat transfer coefficient, and an acute flattening of the temperature profile as the bulk fluid temperature passed through the peak temperature.

A closed loop circuit was used. The test section was a seamless Inconel tube. Inconel was selected for its very small temperature coefficient of resistivity. The tube outside diameter was 1.000 inch, the inside diameter 0.902 inch, and the total length of the tube 56.5 inches. The tube was installed vertically and heated along 30.1 
inches of its length by $A C$ power. The length of the tube upstream from the heated section was 21 inches. Temperature and velocity profiles were measured at 27.7 inches downstream from the beginning of the heated section,

The temperature and velocity profiles were obtained from separate runs as nearly similar as practically possible. The authors indicated that since the reproducibility was good, the measurements from two separate runs could be used as one.

Agreement between the electrical heat input and the measured fluid energy rise was reported to have been within two per cent at temperatures well below the peak temperature. However, for temperatures close to $t_{p}$ variations up to 20 per cent were reported as common. It was also noted that when the temperature profile included $t_{p}$, i.e., density was changing rapidly, the agreement between flow rates from the integrated velocity profile and the venturi meter was poor.

The authors concluded that:

1. velocity profiles with maxima at positions other than center were possible and existed;

2. the temperature profiles flattened acutely when the bulk temperature passed through $t_{p}$;

3. the maximum in the heat transfer coefficient was properly associated with the bulk fluid temperature and not the wall temperature;

4. at constant bulk temperature the heat transfer coefficient decreased with increasing heat flux. 
The authors attempted to account for the general effects by considering a two resistance concept, consisting of a region next to the wall where conduction was the dominant heat transfer mechanism and the turbulent core where the heat capacity or the product of the heat capacity and density was the significant variable. It was reasoned that:

1. As the fluid temperature approached the peak temperature, $c_{p}$ increased rapidly with temperature, heat transfer due to mixing was improved and temperature gradients in the core were lowered, resulting in the flattening of the temperature profile;

2. the peak in the heat transfer coefficient near the peak temperature resulted from better mixing in the core and a large increase in the thermal conductivity near the wall;

3. the sudden decrease in the heat transfer coefficient above the peak temperature was due to a large decrease in the fluid thermal conductivity accompanied by an increase in the core resistance;

4. the increase in the heat flux caused higher wall temperatures, thus lowering the thermal conductivity which in turn aggravated the situation resulting in lower heat transfer coefficients.

In concluding this section the following points must be recalled. Most of the works reported here dealt with the far supercritical region. In general only the investigations of Koppel and Smith (18), Wood and Smith (19), and Touba (13) were specifically intended to study the 
characteristics of heat transfer to the near critical fluids where the reduced pressure $\left(\frac{P}{P_{C}}\right)$ was less than 1.05 . Of these the first two dealt with carbon dioxide and the last with water. Some investigations have only approached this region within the course of other work. Presently there are no correlations that were devised for the near critical region. The analytical work of Hsu and Smith (5) was the only study Intended for the near critical region, while the works of Deissler ( 1 ) and Goldmann $(\underline{3}, 4)$ belong to the far supercritical region. Basically, investigations have been carried out under three different test section arrangements - namely, horizontal, vertical, and vertical annulus (9). In the near critical region the results for the horizontal and vertical tubes may not agree since there is a sharp contrast in the direction of the force fields.

Regarding the results, there is general agreement that the heat transfer coefficient increases appreciably as the peak temperature is reached. A sharp contrast was the results of Powell (16) which indicated a minimum near the critical temperature. Although the two resistance concept of hood and Smith substantiated their experimental results, it depends to some extent upon the controversial fact that the fluid thermal conductivity undergoes a sharp increase near the peak temperature. Such is not.true of the commonly used thermal conductivity values for water. 


\section{ANALYSIS}

\section{Introduction}

The problem of heat transfer to critical ter in steady flow through a heated vertical tube under the effects of combined forced and free convection is treated in the following. Emphasis is placed mainly on the presentation and definition of the problem and the variables involved therein.

The mixed or combined flow region is defined as the region where the effects of free and forced convection are of the same order of magnitude. It may also be defined as the region where heat transfer differs by more than ten per cent* from the value obtained with forced or free convection relations respectively.

It has been the general practice to express heat transfer results for convection in terms of certain non-dimensional parameters and/or combinations thereof. As long as the thermodynamic properties employed in these parameters remained constant or experienced very slow changes no major trouble with these correlations was encountered.

The relations and methods proposed for the supercritical region far from the critical environment cannot be expected to give proper

* (4), p. 332 . 
results for near critical conditions. Since in the far-supercritical states the thermodynamic properties no longer experience the large variations characteristic of the near critical region, the use of conventional type correlations may prove to be adequate.

Also, the concept of a "reference temperature" has been

introduced in an effort to make valid the use of conventional correlations in the regions where thermodynamic property changes may be present.

However, the validity of such rules for supercritical fluids has not been properly established. Also, it is not certain that these rules could be applied successfully in the irmediate vicinity of the critical region where more severe conditions prevail. One such rule is given by Deissler where the fluld properties should be evaluated at the peak temperature.

\section{Analytical Approach}

The essential features which must be considered in the analysis of the problem undertaken in this work are:

1. Forced and free convection single phase upward flow through a tube of circular cross section.

2. Highly variable fluid thermodynamic and transport properties.

3. Turbulent flow.

4. Uniform wall heat flux. 
Turbulent fluctuations may be introduced in the momentum, energy, and continuity equations in the conventional manner - 1.e., by substituting for a turbulent variable its mean and fluctuating components, for example, $u=\bar{u} \bullet u^{*}$. The resulting equations could then be simplified on the basts of various assumptions.

Whether any use could be made of the conventional boundary layer assumptions and techniques to simplify the equations further is doubtful. The difficulty is due to two facts. First, the common assumption for curved walls that the boundary layer thickness is small compared with the radius of curvature of the wall can not be satisfied for tubes of rather small diameter used in experimental investigations and in the practice. Second, no orders of magnitude can be easily assigned to the perturbation terms.

Presently, very little is known about such perturbation terms as $\rho^{\circ}$ and $\mu^{*}$ and thefr behavior. Also, the data available on velocity perturbation terms has been obtained mainly under isothermal flow conditions.

It can also be shown that in the case of variable fluld properties the eddy diffusivity for momentum, as it is known for constant property fully developed flow, can not basically satisfy the many requirements. The same conclusion is reached for eddy diffusivity for heat transfer. 
Another point to be considered is the question whether fully developed flow can be achieved in heat transfer to a fluid with rapidily varying thermodynamic properties. The continuity equation, after the application of various cormon assumptions, reads?

$$
\frac{1}{r} \frac{\partial}{\partial r}\left(r \bar{\rho} \bar{u}_{r}\right) \cdot \frac{\partial}{\partial z}\left(\bar{\rho} \bar{u}_{z}\right) \bullet \frac{1}{r} \frac{\partial}{\partial r}\left(\overline{r \rho^{0} u_{r}^{0}}\right)=0
$$

If by fully developed flow it is meant that the velocity and temperature profiles are developed and have become invariant, then that is not possible here. Contrary to constant property flow, $\frac{\partial}{\partial z}\left(\bar{u}_{z}\right)$ can not be set equal to zero since $\vec{u}_{z}$ varies not only in the radial direction, but also continuously in the axial direction as the fluid density is changed. Axial velocity is of course further influenced by the free convection effects which are also a function of density. The work of Wood and Smith (19) has clearly illustrated the dependence of temperature and velocity profiles upon bulk fluid temperature. It is quite possible that the heat flux or wall temperature also has significant influence upon the velocity and temperature profiles. The dependence of heat transfer coefficient on the heat flux, as reported by many investigators, substantiates this point.

Certainly the inability of many analytical findings to confirm experimental results for heat transfer to near critical fluids is partially rooted in the above mentioned difficulties.

\section{Semi-Empirical Approach}

An efficient method of making heat transfer data available to the designer of equipment has been the use of so-called non-dimensional parameters. 
Equations of the form

$$
\begin{array}{ll}
\mathrm{Nu}=f^{\prime}(\mathrm{Re}, \mathrm{Pr}) & \text { Forced Convection } \\
\mathrm{Nu}=g^{\prime}(G r, \mathrm{Pr}) & \text { Free Convection }
\end{array}
$$

have proved very successful in heat transfer work. However, Hallman (20), studying combined forced and free convection in a vertical tube in the laminar region, reported that the Rayleigh number, defined as

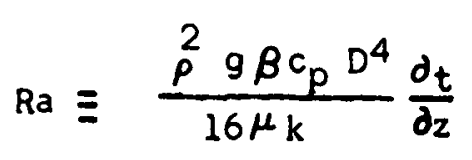

was significant as a measure of the influence of the free convection upon the forced convection. $\frac{\partial t}{\partial z}$ represents the axial temperature gradient. For upward flow with heating the fluid is hotter downstream, and thus the Rayleigh number is positive.

It is important to recognize that the Rayleigh number, as defined above, was no different than the product of Grashof, Prandtl, and $\frac{D}{\left(t_{w}-t_{b}\right)} \frac{\partial t}{\partial z}$

Sparrow et al. (21) in a paper on combined forced and free convection underlined the significance of the ratio $\frac{G_{b}}{\operatorname{Re}_{b}^{2}}$ as a measure of the influence of free convection on forced convection flow. They indicated that the ratio would approach unity as the affects of free and forced convection became equal in magnitude.

Hence, for combined forced and free convection it would seem logical to express the heat transfer results in the following form (or one similar to it): 


$$
N u=f\left(R e, P r, G r, \frac{D}{\left(t_{w}-t_{b}\right)} \frac{\partial t}{\partial z}\right) \text { Combined Convection }
$$

Relations of this form have been used by many authors in presenting their analytical findings. In the case of near critical fluids the evaluation of these parameters becomes. very difficult. Another school, among them Coldmann $(\underline{3}, 4)$, favor correlations of the form given by equation (8), viz.

$$
\frac{q_{w}^{2 s} D^{1-m}}{G^{m}}=f\left(t_{w}, t_{b}\right)
$$

Although such a correlation entirely removes the difficulty with the thermodynamic and transport properties, it restricts the validity of the results to the range of the experiments. Thus, not only the results of experiments with one fluid may not be applied to other fluids, but perhaps rather extensive experimentations with one fluid are required to cover all possible variables for that fluid.

The difficulty lies in the fact that equation ( 8 ) is highly empirical. The so-called heat flux parameter $\frac{q_{w}^{\prime \prime} p^{1-m}}{\sigma^{m}}$ has complicated dimensions and is also a function of another dimensional quantity. For. near critical fluids this correlation is pressure dependent.

Therefore, of the two methods considered here it may be said that: the one employing non-dimensional parameters is quite general, but strongly dependent on the fluid properties; the other, rather simple and not dependent on fluid properties, lacks necessary breadth. The last part of the present section is devoted to a brief development of a different method of correlation. 


\section{Thermodynamic and Transport Properties}

\section{of Critical Fluids}

From the heat transfer standpoint the behavior of thermodynamic and transport properties of fluids near their critical region is most interesting. It is to the rather large changes of these properties in the critieal regiun that a significant increase in the heat transfer coefficient may be attributed.

The critical region, as used in this work, is the area in close proximity to the critical point - more specifically, the region that is associated with most rapid and large changes in the properties. Thus, the above definition would exclude far-supercritical states such as $P=5000$ psia where the property changes are, relatively, neither rapid nor large. In more concrete terms, the area of interest here may be given as follows:

$$
\begin{aligned}
& 1.00 \leq \frac{P}{P_{c}} \leq 1.05 \rightarrow 1.10 * \\
& 0.95 \leq \frac{T_{b}}{T_{p}} \leq 1.05
\end{aligned}
$$

The critical pressure and temperature specify a limit above which a liquid and a saturated vapor cannot coexist together in thermodynamic equilibrium. In other words, above the critical point there is no distinction between a liquid and a vapor.** Mathematically stated,

* Recall that the present interest does not include two phase problems. ** (22), pp. 54-55. 


$$
\begin{aligned}
& \left.\frac{\partial p}{\partial v}\right|_{t_{c}}=0 \\
& \left.\frac{\partial^{2} p}{\partial v^{2}}\right|_{t_{c}}=0
\end{aligned}
$$

From general thermodynamic relations it follows that at the critical point

$$
\begin{aligned}
& c_{p} \rightarrow \infty \\
& \beta \rightarrow \infty
\end{aligned}
$$

A large change in $c_{p}$ in turn causes a rapid increase in the enthalpy through the critical temperature range. Little may be said of the exact behavior of viscosity and thermal conductivity, since a knowledge of thermodynamic properties is not sufficient for the determination of the transport properties.

At pressures above the critical pressure $\left.\frac{\partial p}{\partial v}\right|_{t}$ is finite, but the inflection point still occurs, though at respectively higher temperatures. For the lack of a better designation, this region is referred to (unproperly or properly) as the pseudo-critical or transposedcritical region. In the vicinity of the inflection point, where $\left.\frac{\partial^{2} p}{\partial v^{2}}\right|_{t}=0$ and $\left.\frac{\partial p}{\partial v}\right|_{t}$ attains its least magnitude, the specific heat and the volume expansion coefficient along isobars reach their maxima.

Thus, the interests of the present work are limited to a narrow region on both sides of the peak temperature. As the pressure is increased the magnitude of $\left.\frac{\partial p}{\partial v}\right|_{t}$ around the peak temperature increases. This helps lower the peak attained by the $\beta$ and $c_{p}$ curves, and also diminishes their rate of change with temperature. In other words, at higher pressures, the thermodynamic properties cease to exhibit the 
large variations characteristic of the near critical pressures. The maxima attained by the isobaric specific heat and volume expansion coefficient decrease rather rapidly with accompanying broadening of the curves.

Figures 3 and 4 give the thermodynamic and transport properties of water at 3300 psia. The speclfic volume, enthalpy, and volume expansion coefficient are shown in Figure 3 , while the specific heat, viscosity, and thermal conductivity appear in Figure 4. Large variations in the properties within a narrow band containing the peak temperature are observed. Due to the rapid changes in the properties their experimental deternination has posed exceedingly difficult problems. Hence, most of the present plots are based upon derived values, for example curves presented for $\beta$ and $c_{p}$ were adapted from (23).

In accordance with the Principle of Corresponding States it is expected that fluids will behave similarly at the same reduced states. Figure 5, adapted from Koppel and Smith (18), presents the thermodynamic and transport properties of carbon dioxide near the peak temperature corresponding to 1100 psia. The reduced pressures in Figures 3, 4. and 5 are 1.029 for water and 1.027 for carbon dioxide. Hence, the two fluids are in corresponding states. The transport properties are seen to be different. This is the real reason for presenting Figure 5 .

Thermal conductivity has been subject to many controversies. The presence of tremendous free convection currents near the peak temperatures close to the critical region have prevented its determination with certainty. The newer measurements for carbon dioxide 


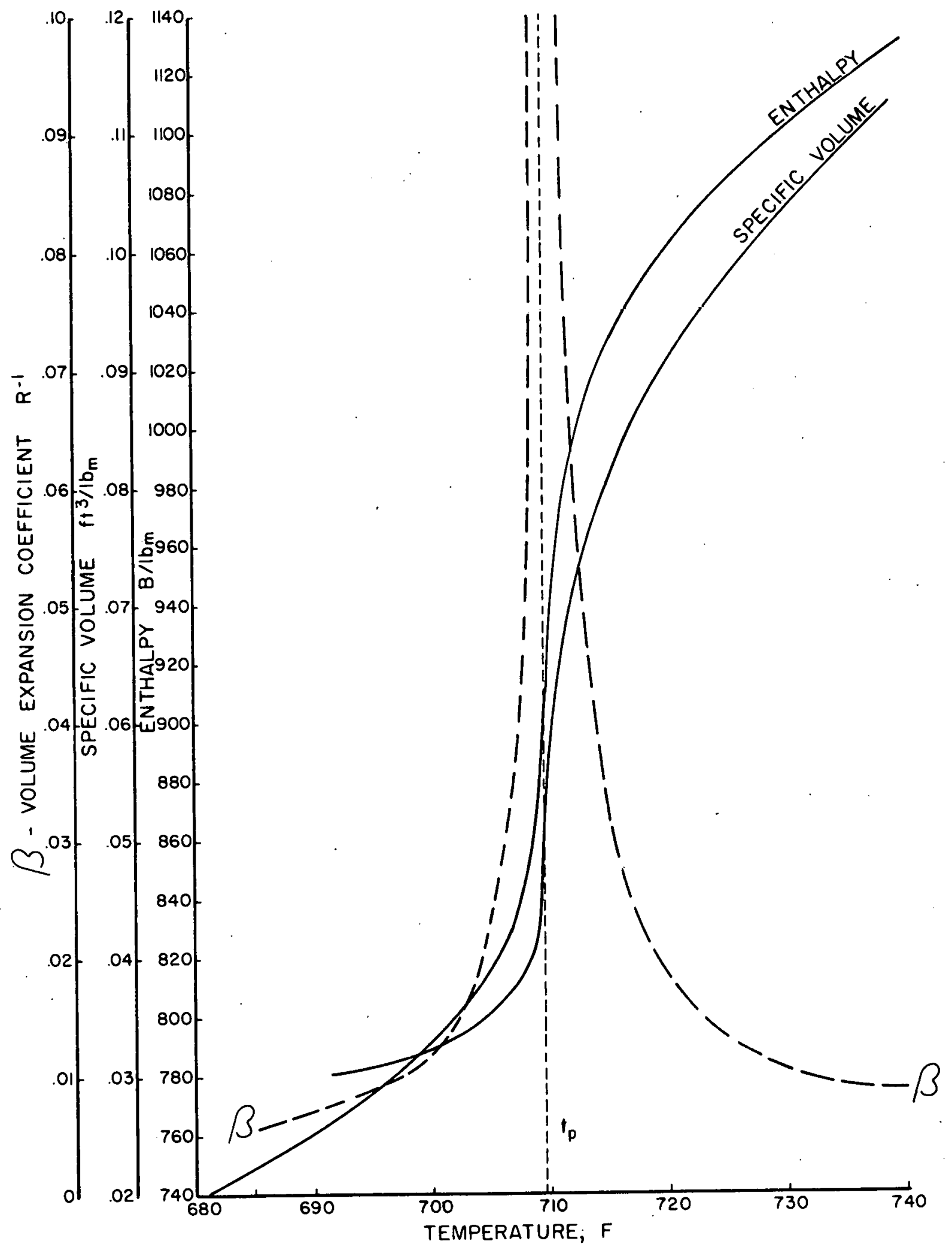

FIGURE 3. SPECIFIC VOLUME, ENTHALPY, AND VOLUME EXPANSION COEFFICIENT FOR WATER NEAR THE PEAK TEMPERATURE AT 3300 PSIA PRESSURE 


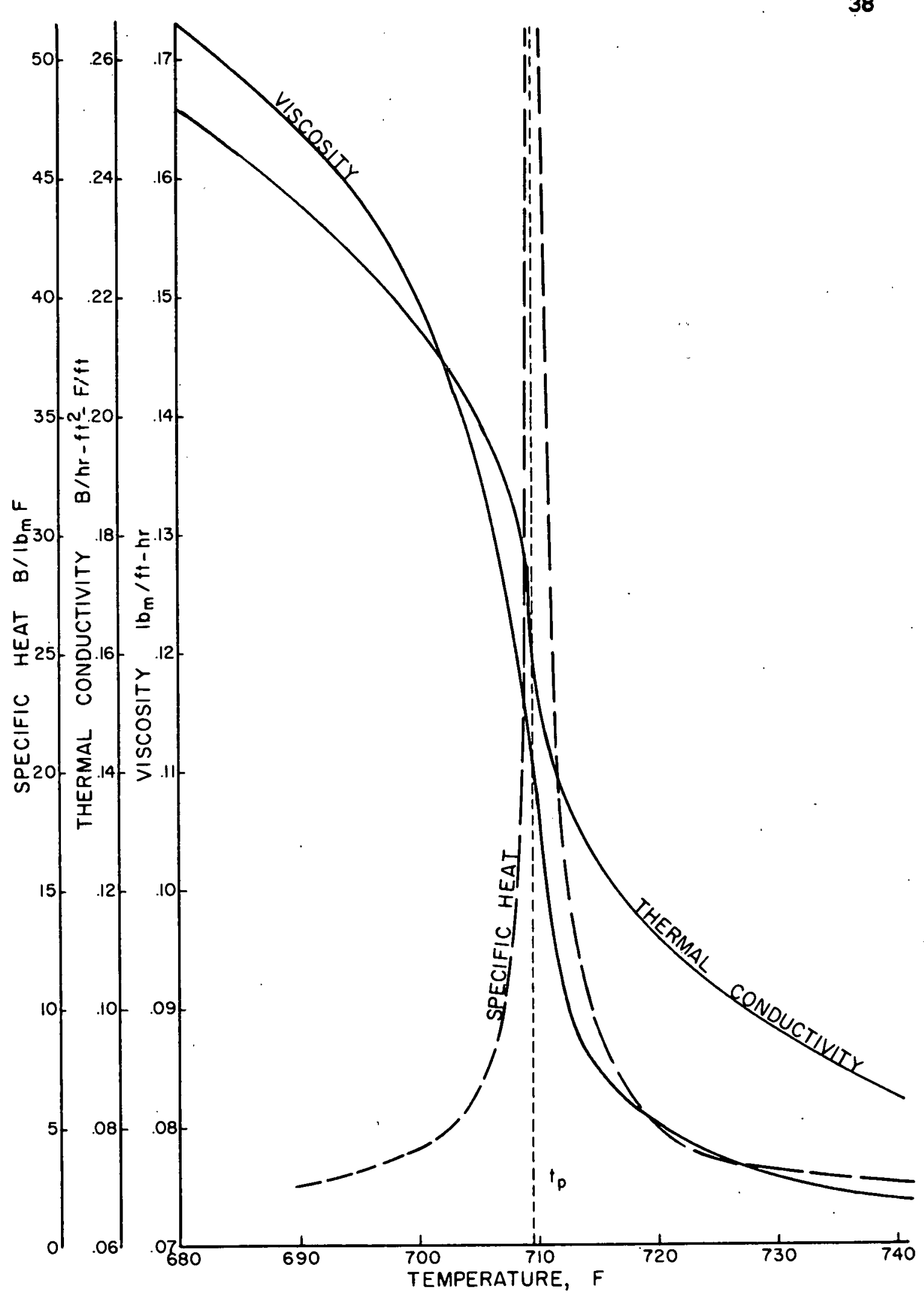

FIGURE 4. SPECIFIC HEAT, VISCOSITY, AND THERMAL CONDUCTIVITY FOR WATER NEAR THE PEAK TEMPERATURE AT 3300 PSIA PRESSURE 

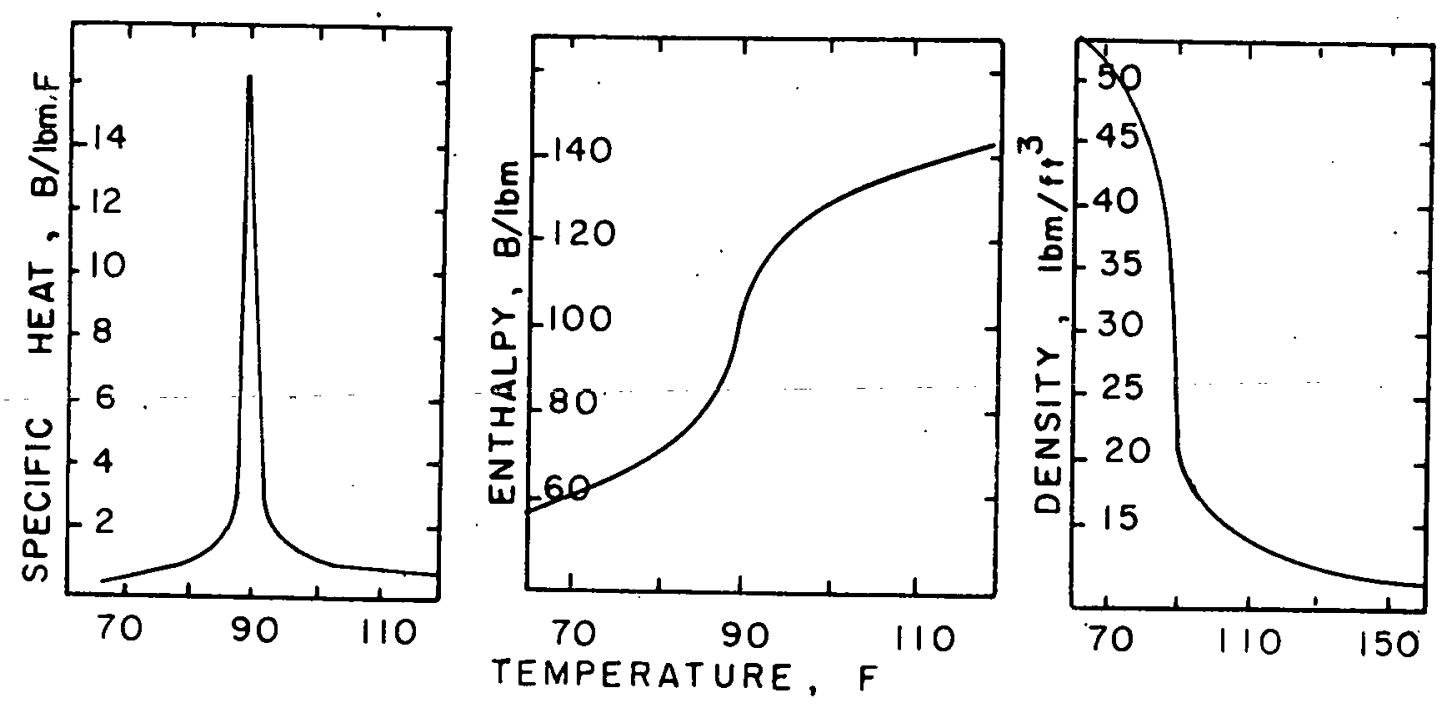

THERMODYNAMIC
CARBON
DIOXIDE
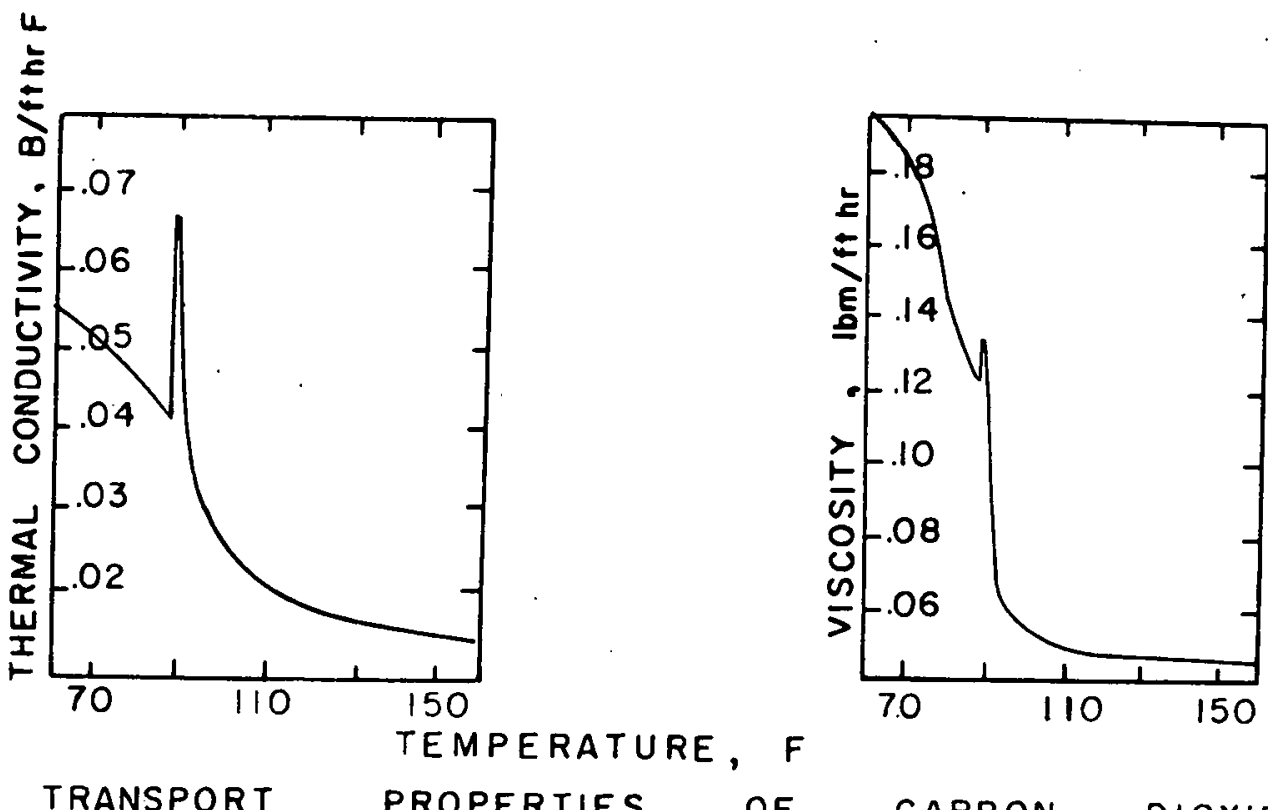

TRANSPORT PROPERTIES OF

CARBON DIOXIDE

FIGURE

5

THERMODYNAMIC

AND

TRANSPORT

PROPERTIES OF

CARBON

DIOXIDE

AT 1100 PSIA 
show that the thermal conductivity at the peak temperature increases rapidly and then decreases, somewhat like the specific heat curve. On the contrary, the recent recommendations for the thermal conductivity of near critical water specify a behavior as presented in Figure 4. Nowak and Grosh made a complete survey and study of the thermodynamic properties of water in the critical region. Their findings and recommendations were published in a series of reports $(\underline{24}, \underline{25}, \underline{26}, \underline{27})$, which at the time of publication represented the best available thermodynamic data for this region. Table II gives the extent of uncertainties in each of the thermodynamic properties derived, smoothed, and recommended by the authors. The data has been extracted from the above reports.

Fritsch and Grosh $(\underline{23}, \underline{28})$ surveyed the experimental investigations covering the thermal conductivity and dynamic viscosity of water. It was reported that no measurements for thermal conductivity were available very close to the critical point. Where available, experimental uncertainties in measurements were found to be around three per cent for thermal conductivity and six per cent for dynamic viscosity. Appropriate correlations for the critical range were suggested. The uncertainty in the values obtained from these correlation would probably be around fifteen per cent on the average.

The above review helps show that the thermodynamic and transport properties present perhaps the biggest obstacle to a successful correlation of the data for heat transfer in the near critical region. In a later section in conjunction with data reduction the actual values of the properties used in this work are discussed and presented. 


\section{TABLE II}

Possible Uncertainties in the Thermodynamic Properties

for Water in the Critical Region

(Based on Nowak-Grosh Recommendations)

Pmperty

Specific Volume

Volume Expansion

Coefficient

Specific Heat

Enthalpy
Uncertainty

$1-10 / 10,000$

$5 \%$

$5-30 \%$

$1-5 \%$

$20 \% 6+$

within $40 \%$

$2-3 / 1000$

within $1 / 1000$

$1-2 / 1000$
Comments

Experimental uncertainty of recent measurements is estimated at $20 / 10,000$.

$$
\text { 690-750 F range }
$$

$\boldsymbol{\beta}_{\max }$ region.

Majority of measurements. Near the critical point and the peak temperatures. Derived values.

Maximum deviations in mea surements.

Average deviation. Derived values.

5. Formulation of a Proposed Method of Correlation

In a situation where meager experimentally determined property values are available and most of the present plots are based upon derived values, presentation of the results of experiments in terms of parameters which depend on a number of rapidly varying properties would be hard to justify. Even if the thermodynamic and transport properties in the critical region were known precisely, temperature measurements 
and calculations would need to be accurate within a few tenths of a degree or better in order to stay within reasonable bounds of error in computing the values of the dimensionless parameters involved. Figures 3 to 5 support this conclusion. With the type of experimental set-ups discussed in the section on literature survey such an absolute accuracy is not realizable. In almost every case the inside wall temperature of a tube is calculated from measurements of the outside wall temperature. This involves an accurate knowledge of the tube dimensions together with pertinent thermophysical data - namely, electrical and thermal conductivities and their temperature coefficients. The tube wall thickness is subject to some variations along the axial and peripheral directions. The measured thermal conductivity of stainless steels, commonly used in high pressure and temperature experiments, is truly chaotic. Figure 6 , prepared by the author in 1962*, shows as an example the various measurements for the thermal conductivity of Type 347 stainless steel. The scatter is undoubtedly partly due to the quantities of various alloying elements in the specimen tested. At high heat flux levels considerable error may be introduced into the computations through faulty knowledge of such data. Appendix $C$ discusses the effect of possible error in the tube parameters upon the inside wall temperature computations.

Hence, it is very possible that the value of such parameters as Prandtl, Grashof, and Rayleigh numbers, which contain several thermodynamic and transport properties subject to relatively appreciable

* Data was obtained from the Thermophysical Properties Research Center (TPRC), Purdue University, Lafayette, Indiana.. 
uncertainties in the critical region, may be erroneously computed. To clarify this point, let a unit uncertainty be associated with each property. The uncertainties associated with each of the above parameters and the Reynolds number will then be:

$\begin{array}{ll}\text { Reynolds Number } & 1 \text { units } \\ \text { Prandtl Number } & 3 \\ \text { Grashof Number } & 5 \\ \text { Rayleigh Number } & 6\end{array}$

In the above it is assumed that the Reynolds number is computed from $\frac{G D}{\mu}$ where $G$ is known with mor e certainty. Briefly the method that is presented below is an attempt to accomplish the following:

1. simplicity and convenience of use in the near critical region;

2. satisfactory generality and range;

3. evaluation of the properties at a temperature which may be determined with higher accuracy.

The rate of heat transfer between a unit element of surface of a. tube of circular cross section and the fluid flowing past that surface, at a location sufficiently removed from the inlet, is determined by four factors, viz.

1. the flow field;

2. the temperature field;

3. the state of the fluid; and

4. the tube diameter. 
All the effects are interrelated or coupled. The thermodynamic state of the fluid may be described by two thermodynamic properties." However, this is not sufficient to describe the transport properties, which are also a function of the molecular structure and the molecular field forces. The work of Fritsch and Grosh (28) reported that it was possible to correlate the thermal conductivity and viscosity data for water in terms of the specific volume and temperature.

The specific heat, viscosity, temperature, and the peak temperature were selected to define the state of the fluid. The peak temperature serves to provide a reference state. The effects of the flow field and the temperature field may be expressed by the heat transfer coefficient, mass flux, and the state of the fluid. Therefore,

$$
\Phi\left(h, G, \mu_{b}, c_{p_{b}}, t_{b}, t_{p}, D, g\right)=0
$$

In applying dimensional analysis techniques to the above equation the method of Buckingham's $\mathrm{Pi}$ theorem was employed*. The basic dimensions consisted of the dimensions of temperature, mass, time, length, and heat. The result is as follows:

$$
\frac{h}{c_{p_{b} G}}=f\left(R e_{b}, \frac{t_{b}}{t_{p}}\right)
$$

It is recognized that the term $\frac{h}{c_{p_{b}} G}$ is the well-known stanton number. Although the above functional relationship seems to be a simple one, the inherent difficulty in it is the evaluation of ${ }^{c} \mathrm{p}_{\mathrm{b}}$.

* (29), pp. 42-55.

**Thermodynamic equilibrium is assumed. 
The reader may correctly question the justifiability of using the thermodynamic property $c_{p}$ in the above. The reasons are two fold. Firstly, specific heat plays an important role in heat transfer in the near critical region, secondly; it is an important element of the Prandtl number used in many correlations. In any case, the difficulty can be overcome: in three ways, two of which follow from the definition of the heat transfer coefficient, h. Conventionally the heat transfer coefficient is defined as

$$
h \equiv \frac{q_{w}^{\prime \prime}}{t_{w}-t_{b}}
$$

Another possible definition is to use the enthalpy difference, as has been done in the high speed heat transfer problems, instead of the temperature difference. The new coefficient $h_{\dot{e}}$ which has the dimensions of $\frac{h}{c_{p}}$ is given by

$$
h_{e}=\frac{q_{w}^{\prime \prime}}{H_{w}-H_{b}}
$$

The two heat transfer coefficients as defined above are related through an average specific heat function; thus

$$
\frac{h}{h_{e}} \equiv \frac{H_{w}-H_{b}}{t_{w}-t_{b}}=c_{p_{h}}
$$

It may be recalled that Swenson, et al. used $c_{p_{h}}$ in their Prandtl number.

In a previous work (13) the author suggested that the Stanton number appearing in equation (36) may be modified either by introducing $h_{e}$ to replace $\frac{h}{c_{p}}-v i z$. $s t_{e}=\frac{h_{e}}{G}$, or using an averaged stanton number 
between two points on the heated section. This required that the average values of $h$ and $c_{p}$ be used. These were defined in the following way:

$$
\begin{aligned}
& \bar{h} \equiv \frac{{\overline{w_{w}^{\prime \prime}}}_{\bar{t}_{w}-\bar{t}_{b}}^{\prime \prime}}{\overline{c_{p}} \equiv \frac{\Delta H_{b}}{\Delta t_{b}}=\frac{H_{b_{z+\Delta z}}-H_{b_{z}}}{t_{b_{z+\Delta z}}-t_{b_{z}}}}
\end{aligned}
$$

The superscript $(\overline{)}$ indicates averaged quantities within an interval $\Delta z$. A third method of disposing with the difficulty is to evaluate $c_{p}$ from the smoothed enthalpy data. This is done by computing the slope of an isobaric (Hxt) versus $H$ curve, since

$$
\left.\frac{\partial(H \times t)}{\partial H}\right|_{p}=t+\frac{H}{c_{p}}
$$

and using it to determine $c_{p}$ from the equation

$$
c_{p}=\frac{H}{\left.\frac{\partial(H x t)}{\partial H}\right|_{p}-t}
$$

The curve Hxt versus $H$ is sectionally nearly straight. If accurate isobaric enthalpy-temperature data is available, then the computation may be readily performed on a digital computer.

Hence, the relation ( 36 ) may be either used in its original form or in the form of one of the two modifications. The three forms are: 


$$
\begin{aligned}
& s t=f\left(R e_{b}, \frac{t_{b}}{t_{p}}\right) \\
& s t_{e}=f\left(R e_{b}, \frac{t_{b}}{t_{p}}\right) \\
& \overline{s t}=f\left(\overline{R e}_{b}, \frac{t_{b}}{\bar{t}_{p}}\right) \\
& .
\end{aligned}
$$

The specific heat used in (36a) may be obtained from appropriate tables or from a method outlined above and given by equation (39).

The Stanton number in $(36 b)$, defined by $s t_{e}=\frac{h_{e}}{G}$, would probably be accurate in most regions. However, in the immediate vicinity of the peak temperature where enthalpy has a very sharp temperature derivative good accuracy in the determination of the wall temperature is required. On the contrary, the Stanton number as used in equation (36c) is immune from such danger. The enthalpy difference is actually the amount of heat input to the fiuid in the interval $\Delta z$, and the fluid temperature can be evaluated from the measured (computed) fluid enthalpy. The process of calculating the temperature from the enthalpy in the region of rapid enthalpy variations is usually more accurate than the reverse process. It must be also noted that, while $\mathrm{c}_{\mathrm{Ph}_{\mathrm{h}}}$ used in equation (36b) has been limited in magnitude for all practical purposes by the very nature of its definition, there is nothing in equation (39) that may cause such a limitation.

Before closing, several interesting features of equation (36) should be discussed. The recent correlations of forced convection flow in the subcritical and supercritical regions, using some form of the basic Nusselt equation, viz. 


$$
N u=C \operatorname{Re}^{a} \operatorname{Pr}^{b}
$$

have given values of "a" higher than 0.8. McAdams found that a value of 0.89 best fitted his results and Swenson et al. used a value of 0.923 in their correlation. This indicates that the stanton number in equation (36) may be somewhat independent of the Reynolds number, or for restricted Reynolds number range

$$
s t=g\left(\frac{t_{b}}{t_{p}}\right)
$$

With $a=0.923$, an order of magnitude change in the Reynolds number may be reflected as 19.4 per cent in equation (360). Equation (36) is also compatible with other equations of the Nusselt type since it can be written as

$$
\text { St } \operatorname{Re}^{1-a}=f \cdot\left(\frac{t_{b}}{t_{p}}\right)
$$

where $f^{\prime}\left(\frac{t_{b}}{t_{p}}\right)$ replaces other property dependent functions in conventional correlations.

Another correlation where $f^{\prime}\left(\frac{t_{b}}{t_{p}}\right)$ was replaced by $g^{\circ} \cdot\left(\frac{H_{b}}{H_{p}}\right)$ was tried. The results appeared satisfactory. However, the main difficulty was the determination of $H_{p}$, the isobaric peak enthalpy corresponding to the peak temperature. This and other points are discussed in. a later section.

In the next section a general description of the experimental apparatus is given. 


\section{DESCRIPTION OF APPARATUS}

The high flux heat transfer loop of the School of Mechanical Engineering sponsored by the United States Atomic Energy Commission was used for the acquisition of the data reported in this work. In order to render this work self sufficient a general description of the equipment is given in the following. However, for additional details on various pieces of equipment the reader should consult references $(13,30,31,32$, and 33 ). The system is best described when various subsystems are treated separately.

\section{The Main Loop}

The essential constituents of the main circuit of the loop were a canned-motor centrifugal pump, obtained from the Chempump Corporation, a pump bypass, two venturi-meters, an electrically heated preheater, the test section proper, and an air-cooled heat exchangercondenser which was connected to the main loop through a three way Annin valve. The pump rotor and bearings were immersed in the test fluid for cooling and lubrication. In order to maintain the motor windings and the gaskets below a maximum operating temperature of $450 \mathrm{~F}$, cooling was provided through a shell in the pump housing. Figure 7 shows a schematic arrangement of the high flux heat transfer loop. The pump outflow was fed into either of the venturi-meters for flow rate measurements. The smaller venturi was used for flow rates 


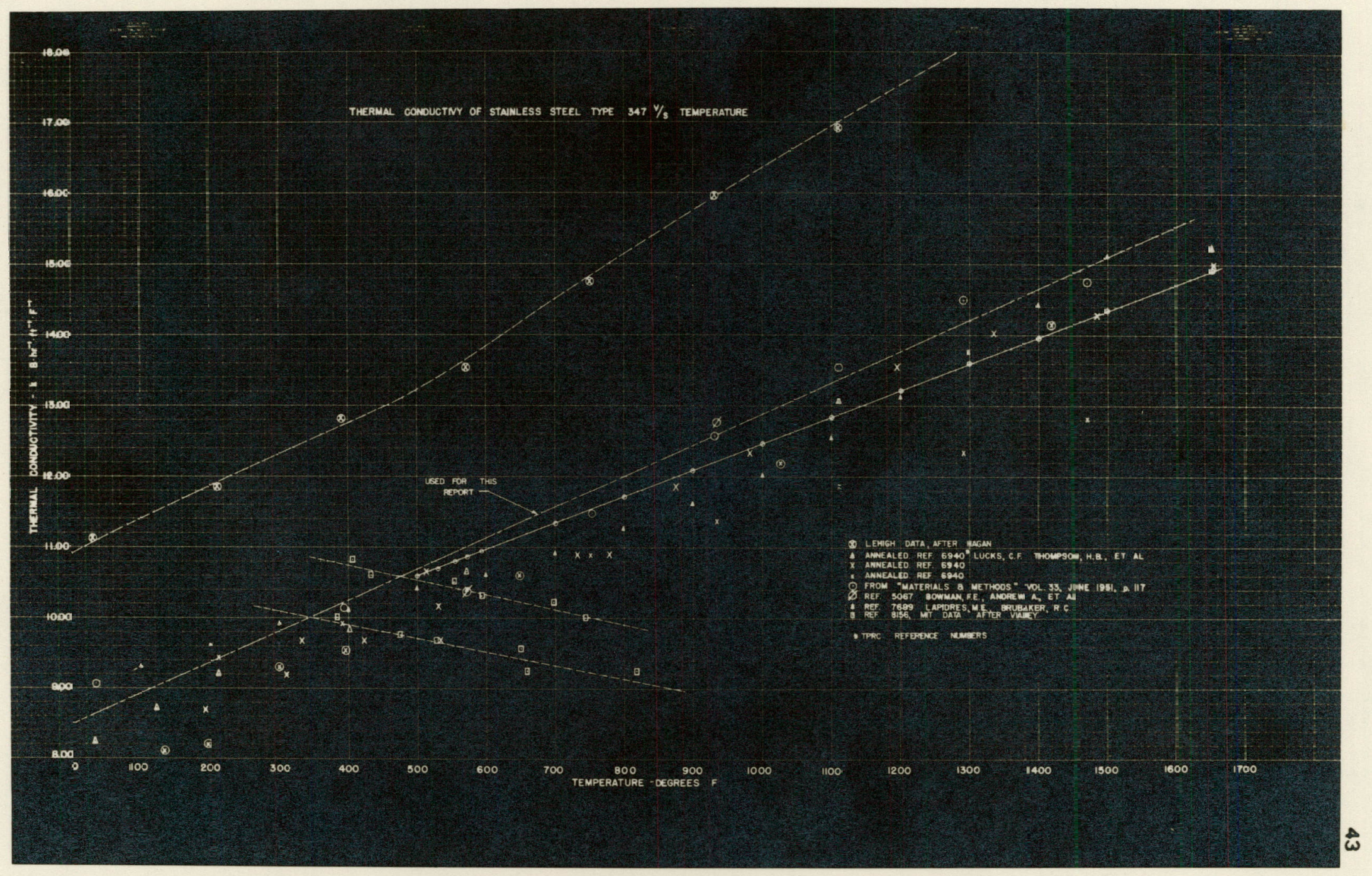

FIGURE 6. THERMAL CONDUCTIVITY OF STAINLESS STEEL TYPE 347 


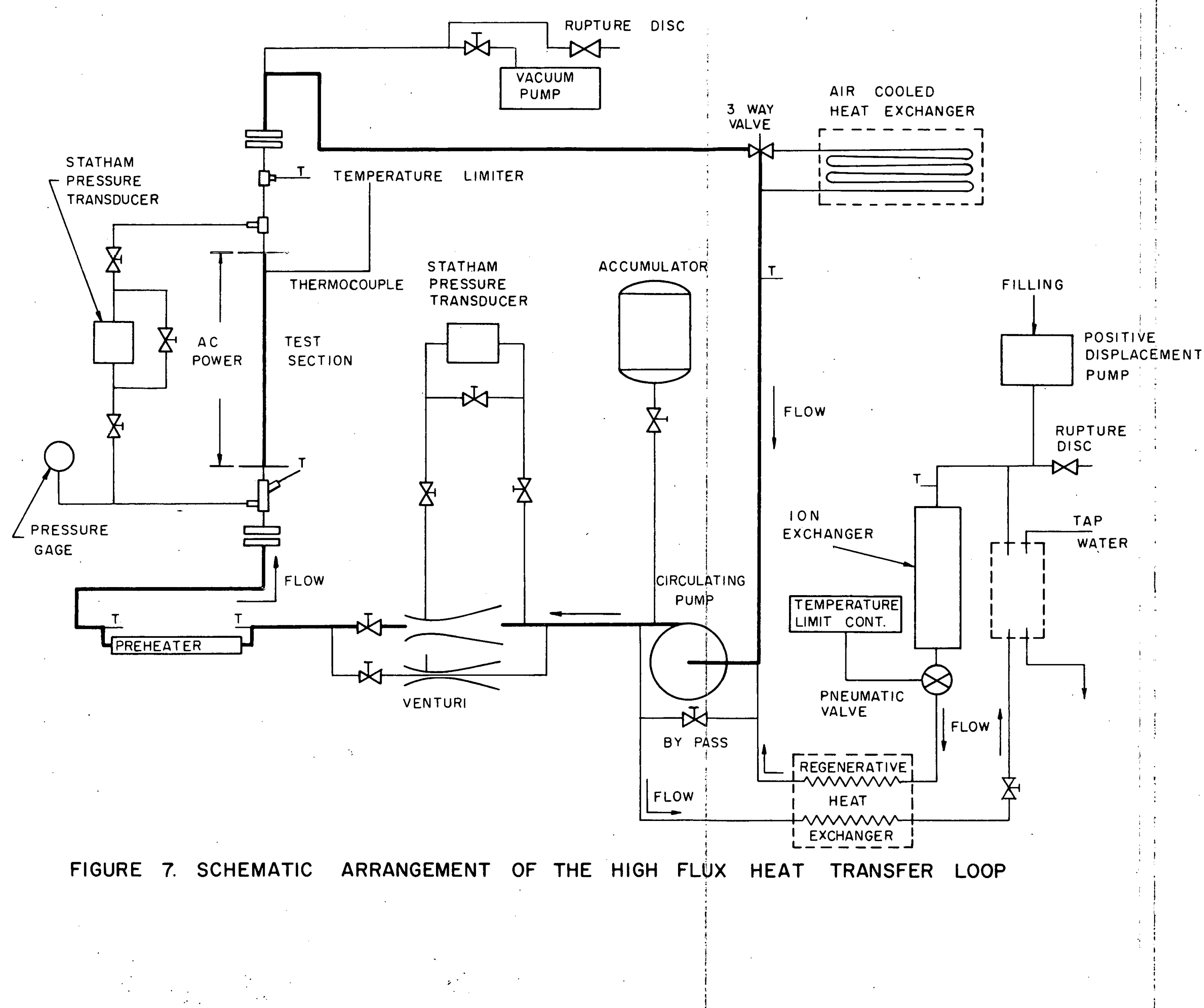


less than $0.8 \frac{1 \mathrm{bm}}{\mathrm{sec} .}$. Each venturi-meter was equipped with a valve which was used for regulating the flow rate or shutting off the flow through it. The valves did not provide good regulation since they were only effective near the closed position. Better flow regulation was obtained by manipulating the pump bypass valve together with the venturi-meter valves.

Leaving the venturis, the flow entered the preheater where it was heated to the required test section inlet temperature. The old preheater, designed in 1957 and used in the earlier experiments described by Dix (30), Van Putte (31), Tokar (32), and Touba (13), was inadequate. The present preheater, fully described in (33), has its cartridge heaters inserted into wells that are immersed in the test fluid. The metal separating each cartridge from the fluid is only $1 / 16$ inch thick. However, the contact resistance between a cartridge and its well, despite the close tolerances, was still large enough so that only about $15 \mathrm{kw}$ could be used without endangering the cartridge heaters. This design also offered a short response time. At high flow rates the preheater could raise the system temperature to $360 \mathrm{~F}$ only.

From the outlet of the preheater the flow was directed to the test section which was connected to the loop piping through a pair of electrically insulated, water-cooled, heavy.flanges. The lower flange assembly is shown in Figure 8. The flanges were designed to provide electrical insulation between the test section and the loop which was grounded. One of the flanges was welded to the system piping and the other, connected to the test section, was bolted to the first flange 


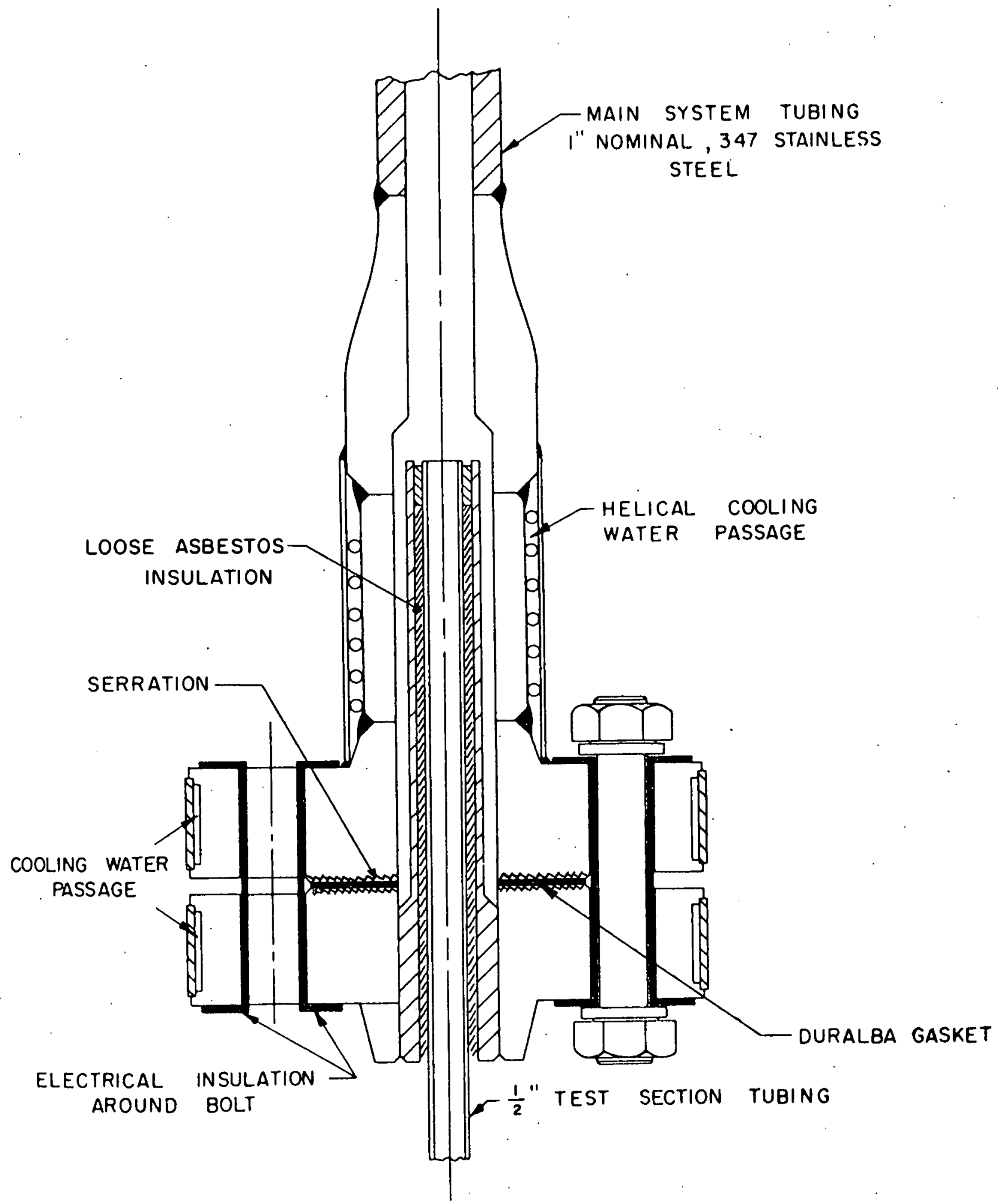

FIGURE 8. LOWER FLANGE ASSEMBLY 
with a sheet of "Duralba" high temperature asbestos gasket material inserted between them. The inner faces of the flanges in contact with the gasket were serrated to provide a strong grip. Insulation material was also inserted around the bolts and under the washers. To minimize heat loss from the hot test fluid to the heavy pressure flanges a standpipe was welded to the flange on the test section side. The test section tubing was then inserted into the standpipe and welded in concentric arrangement. The space between the tubes was filled with loose insulation. When assembled, the standpipe projected into the loop piping allowing a volume of stagnant water to form around it: This provided a further thermal insulation between the test section and the flange.

In his trial runs, Van putte (31) had encountered a severe problem with the flanges. During periods of warm-up, due to uneven thermal expansion rates of the flanges and their bolts, thermal stresses caused a failure in the gasket material between flanges leading to dangerous and damaging short circuits. Very long warm-up perlods of around 12 hours were required to eliminate the difficulty. To remedy this problem, water cooling was incorporated into the flange design and the standpipe arrangement mentioned above was used to reduce heat losses.

Any vertical test section, properly designed and instrumented, may be installed between the upper and lower flanges. The loop design also provides for easy conversion for use in conjunction with horizontal test sections. The details of the test section are discussed in part 4 of the present section. 
Downstream of the test section a three-way valve was provided for the purpose of regulating the pump and the test section inlet temperatures. Any portion of the test fluid could be channeled through the air cooled heat exchanger-condenser. The outflow of the heat exchanger joined the fluid which bypassed it via the valve, and the combined streams were directed into the pump inlet. Due to this arrangement relatively good control over the pump inlet temperature could be obtained. However, the operation of the heat exchangercondenser presented other problems, which are mentioned in the next section.

The heat exchanger was cooled by a motor driven blower capable of driving up to 10,000 CFM of air past its coils. Adjustable vanes and shutters were provided at the air intake and exhaust. At times, a fan placed close to the blower intake was used instead. The blower was rarely used.

The main loop also accommodated two bladder type accumulators of $2 \frac{1}{2}$ and 5 gallons capacity. The water side of one or both accumulators could be connected to the pump outlet or any other location in the loop. The gas side was charged with nitrogen to a pressure at least 25 per cent of the operating pressure. Pressurization on the nitrogen side could also be used to increase the system pressure. The line connecting the accumulator(s) to the pump outlet or system was made long in order that the hot fluid from the loop would reach it at a safe temperature. Otherwise, the Buna $N$ synthetic rubber bag could be damaged. For this reason the water line to the accumulator(s) was also connected to the cold test fluid in the auxiliary loop which is 
discussed next. A valve arrangement allowed switching to the cold fluid when rapid heating was in progress, while for steady state operations the connection to the pump outlet was preferried.

\section{The Auxiliary Loop}

In order to maintain the high purity of the test fluid an ion exchange circuit was incorporated into the system. This helped prevent scale formation and assures reproducibility of data. Approximately five per cent of the system flow continuously passed through an ion exchange bed. Water resistivity measurements could be taken at the inlet and outlet of the ion exchange bed.

The system water, bled at the circulating pump outlet, was passed through a regenerative heat exchanger which transferred heat from the hot water leaving the main loop to the deionized fluid returning to the pump inlet. After further cooling by a single-pass counterflow tap water heat exchanger, the fluid passed through a remote-controlled valve into the ion-exchange bed.' This system was made necessary by the fact that the ion-exchange resin operating temperature was limited to $140 \mathrm{~F}$. A Gardsman controller was used to guard against temperature excesses. If needed, the Gardsman unit, sensing the water temperature through a thermocouple located at the ion-exchange inlet, could automatically engage an air operated valve which would stop all flow through the ion exchanger.

Rupture disks were provided in both the hot and cold loops. Pressures exceeding the system design pressure were thus relieved. Finally, the loops were mainly constructed of one inch, schedule 160, type 347 stainless steel pipe, with proper consideration for thermal expansion. 


\section{The Filling and Vacuum Subsystems}

The purpose of the filling subsystem was two fold: (1) to remove the impurities in the tap water which cause scale formation and corrosion, and (2) to remove the dissolved gases from the water. Figure 9 shows a schematic of the filling system.

Two ion-exchange beds were provided. The function of each was to absorb the metallic and non-metallic ions present in tap water liberating the equivalent in hydrogen and hydroxyl ions respectively. Tap water entered the larger bed packed with a lower-melting point resin* $(105 \mathrm{~F})$ and flowed into a 30 -gallon stainless steel reservoir which was heated by a natural-gas flame.

The water to be admitted into the system was boiled for about two hours. It then passed through a tap-water cooled heat exchanger and into a smaller ion exchange bed with a melting point of around $140 \mathrm{~F}^{* *}$. This was to insure further purity and avoid possible mixing of degassed water with undegassed water in the larger ion-exchanger if the latter were used for the second purification pass. Another feature of the filling subsystem was an air-driven positive displacement pump. The pump was used for initial pressurization of the system, and for system pressure control during the experimental runs. The water from the second deionizer entered the system via the positive displacement pump.

\footnotetext{
* Monobed MB-3, Enley Products Inc., N. Y. * Monobed MB-1, Enley Products Inc., N. Y.
} 


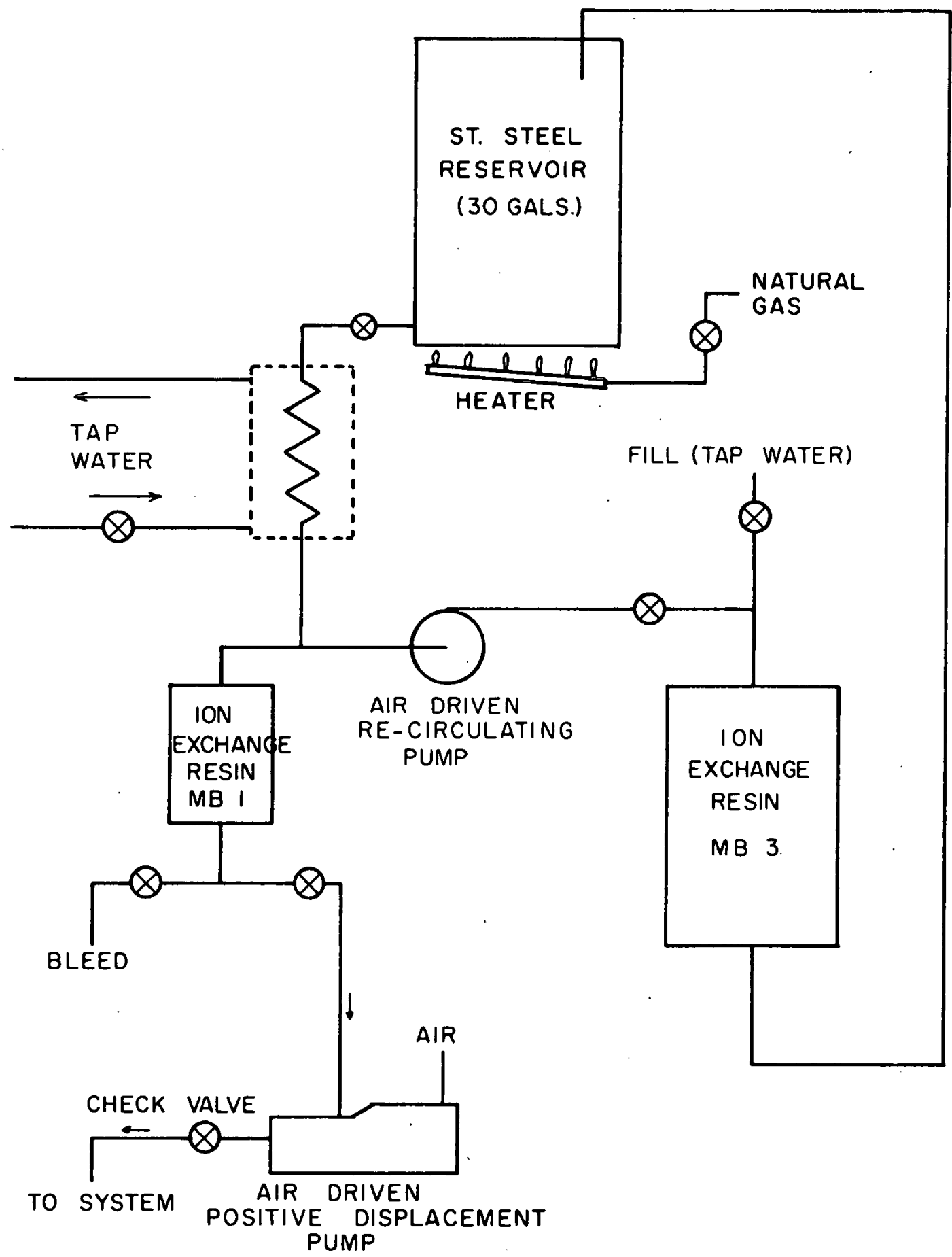

FIGURE 9. SCHEMATIC OF THE FILLING SYSTEM 
To obtain higher purity water an air-driven recirculation pump was incorporated into the filling subsystem. The pump was operated at all times except when water was being boiled. The water from the reservoir was drawn into the pump through the heat exchanger, and forced over the larger ion-exchange bed. Under this procedure, the resistivity of the water in the reservoir consistently measured at better than $3,000,000 \mathrm{ohm}-\mathrm{cm}$.

Prior to filling, the system was evacuated for about three hours. A vacuum pump was connected to the highest point in the system through a reservoir which received two lines from the system piping. One line ( $1 / 2$ inch $O D)$ was an integral part of the system and served both the vacuum subsystem and a rupture disk. The other line, an ordinary vacuum hose, was connected to a "Y-like" joint, installed at the highest point in the system, which also received the $1 / 2$ inch stainless steel line.

This arrangement accomplished two objectives: (1) it provided a sufficiently large passage to the vacuum pump, and (2) it insured against air pockets within the operational system. A satisfactory evacuation and filling manifested itself in the fact that only very few strokes of the positive displacement pump were needed to raise the system pressure above atmospheric. 
The vacuum pump was allowed to run while water was being admitted into the system. Rising water level in the reservoir indicated that the system and the $\frac{1}{2}$ inch stainless steel line were full. The valve connecting this line to the pump was then shut off, while the pump operation through the vacuum hose continued. An instant later the hose was also disconnected and the vacuum pump was switched off. It should be noted that since the system could never be drained completely a vacuum of better than 29.3 inches of mercury was rarely obtained.

\section{The Test Section}

For the purposes of the experimental study reported here two test sections were prepared and instrumented. TableIII supplies some pertinent information on these test sections. Tube wall thickness was measured by cutting axially through a six inch length of the tube, cut from one end of the test section tubing, and taking micrometer readings on each half.

TABLE III

Test Sections Used in This Work

\begin{tabular}{|c|c|c|}
\hline & Small & Large \\
\hline Code Name & $X E$ & $\mathrm{XF}$ \\
\hline Outside Diameter & 0.3762 inch & 0.5010 inch \\
\hline Inside Diameter & $0.2446 "$ & $0.3698 \quad 12$ \\
\hline Wall Thickness & $0.0658 "$ & $0.0656 "$ \\
\hline Heated Length & $52.0 \quad 1$ & 56.0 \\
\hline Distance between pressure taps & 71.0 & $72.0-74.0^{\prime \prime}$ \\
\hline $\begin{array}{l}\text { Material } \\
\text { Manufactured }\end{array}$ & $\begin{array}{l}\text { SS. Type } 304 \\
\text { Drawn Seamless }\end{array}$ & $\begin{array}{l}\text { SS. Type } 304 \\
\text { Drawn Seamless }\end{array}$ \\
\hline
\end{tabular}


Circular current flanges were silver-soldered to the test section. The current flanges measured 7 inches in diameter and had two symmetrically located wings to which heavy flexible power leads were bolted. Two circular guard heaters, producing 1250 watts together, were concentrically clamped to the outer face of each flange. Short pieces of Nichrome wire were used for power connection to the heaters since copper wires became badly corroded at elevated temperatures.

In early operations of the high flux heat transfer loop the test section was an integral part of the heavy, water cooled, isolation flanges. This meant that every test section change required a reconstruction of the heavy flanges, the cooling system, the pressure taps, and the immersed thermocouples used for bulk fluid temperature measurements. Since in conjunction with the above a number of silver-soldered joints were also used, many frustrating leaks developed. During the work of (13) a new and efficient design was adopted and carried to the present work.

The water cooled flanges, the primary function of which was to provide electrical insulation between the test section and the rest of the loop, together with the pressure taps and the immersed thermocouples were installed on a permanent basis.

The above arrangement served two important functions as follows:

1. The test section could be dismounted or mounted readily;

2. different test sections could be prepared and installed without any welding or soldering.

Welded joints were used throughout the system since most soldered joints failed after several hours of operation giving rise to many difficulties. It is likely that this was due to the formation of some 
hydrogen atoms which penetrated the weak points of the solder and. caused the formation of miniature holes.

Figure 10 allows a comparison of an early test section and the small diameter test section (XE) of this investigation. The older test section is seen with heavy, uncooled isolation flanges, pressure taps, large square current flanges, and guard heaters installed on both faces of the current flanges. It is bulky and end-heavy. The test section $X E$ is seen with its current flanges and thermocouples installed. The dark spots on the current flanges indicate the location of the guard heaters. The center thermocouple was removed for post-testing calibration.

A special fitting which housed a $1 / 16$ inch Conoclad stainless steel sheathed chromel-alumel thermocouple and a pressure tap was installed at the test section inlet. Inlet pressure and temperature data were obtained through this unit. Another pressure tap was installed immediately at the test section outlet. However, in order to obtain a better mixing cup temperature, the test section exit temperature was measured at a distance of about twelve inches from the exit. To stimulate mixing a coiled length of stainless steel wire was inserted in the tube.

Figure 11 shows the test section outlet. The guard heaters clamped in position on the current flange, the outlet pressure tap, the immersed thermocouple fitting, and the water-cooled isolation flanges are seen. Part of the vacuum and electrical systems are pictured to the left. 


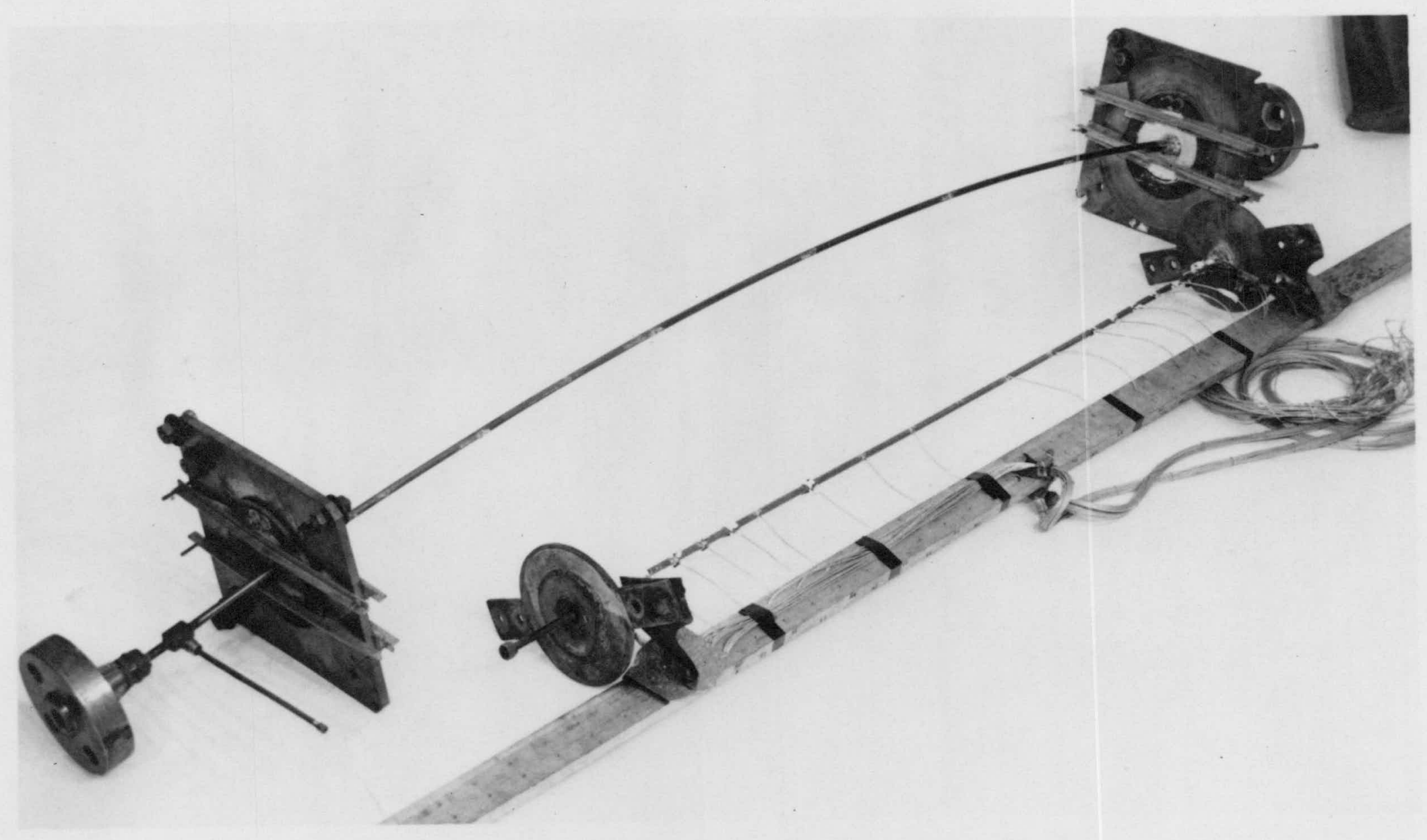

FIGURE 10. COMPARISON OF OLD AND NEW TEST SECTION DESIGNS 

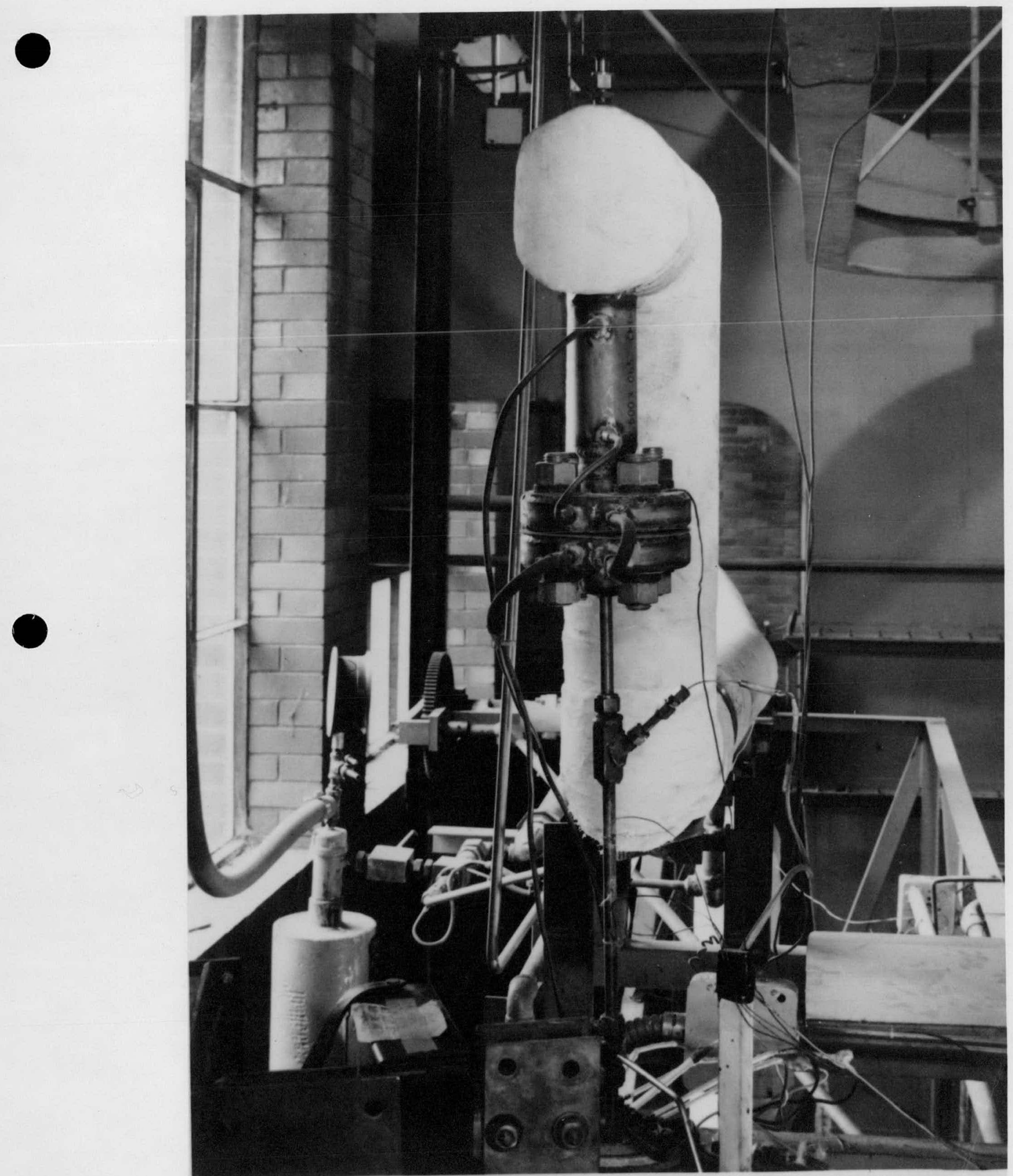

FIGURE II. TEST SECTION OUTLET 
The system and the test section were insulated with double layers of Johns Manville high temperature insulation. Glass wool insulation was used around guard heaters and elsewhere.

\section{Instrumentation}

The instrumentation of the system may be grouped under three broad categories of power supply and control, the safety interlock circuits, and the measurement devices. Thermometry is discussed in part 6.

Two independent power supplies were available. Single phase, 60 cycle, 2400 volt electrical power was supplied to the test area and stepped down to 240 volts by a power distribution transformer. This voltage was delivered to a water-cooled welding transformer, capable of supplying the test section with voltage from 4.2 to 50.7 volts via a saturable core reactor-transformer. The reactor-transformer was controlled by a magnetic amplifier with which the output could be varied from 10 to 95 per cent of the line voltage.

The saturable core reactor-magnetic amplifier combination, used in conjunction with a Leeds and Northrup Type H Speedomax Recorder, was used to maintain constant power delivery to the test section. The controller worked through a thermal converter to which the test section voltage and current were delivered via appropriate potential and current transformers. The actual working was as follows. The thermal converter signal was evaluated by the Speedomax Recorder which fed a Current Adjusting Type Controller a signal proportional to the difference between the actual and the "set" powers. A DC signal from the 
controller to the magnetic amplifier was amplified and delivered to the reactor-transformer. Therefore, the test section power was controlled by the DC current which determined the degree of core saturation in the reactor-transformer. Power available for test section use was 167 KVA.

The preheater was supplied with 230 volt, 3 phase power. Maximum available preheater power was $22.5 \mathrm{KVA}$. A separate control system similar to the test section power regulation was also available. This, however, was designed to control the test section inlet temperature. The essential difference between the test section and the preheater controls was the fact that the thermocouple in the preheater control system replaced the thermal converter used in the test section power control.

Both systems operated satisfactorily, but the lack of preheater power and the temperature limit on its cartridge heaters did not allow extensive use of the preheater controller. This system, in conjunction with a joulean heated preheater, would give very satisfactory results. Copper buss bars and heavy braided copper leads connected the welding transformer to the test section. The power input to the main saturable core reactor-transformer was via a 2 pole, 800 ampere, 50,000 amperes interrupting, air circuit breaker.

The safety interlock system was designed to prevent injury to personnel and damage to the test apparatus. It consisted of an electrical circuit which had a set of relays in series with the holding coils on the preheater and test section power supply lines. When any relay in the interlock system was opened, both power supply circuits were 
disconnected and a light on the panel turned off to indicate the trouble spot. The components of the system were as follows.

1. A Gardsman* high limit controller, activated by a thermocouple, monitored the test section outside wall temperature. If the temperature exceeded a preset value, test section power was interrupted.

2. The power lines in the circulating pump were wired with two relays in the interlock system. Thus, the test section power is disconnected in the case of pump power failure or pump motor temperature excess. The relays could be disconnected for pure free convection experiments.

3. A micro-switch, activated by a vane in the air cooled heat exchanger and wired to a relay, provided safety against failure in the blower. When air flow was not required, a switch on the instrument panel disarmed this safety.

4. A Weston 705 relay was available for use in conjunction with the preheater. This device could be set to interrupt the system power when cartridges exceeded $1000 \mathrm{~F}$. Instead, in the present investigation a chromel-alumel thermocouple installed in a groove cut into a cartridge was connected to a Micro-Max recorder and the cartridge temperature was monitored by the operators. This eliminated power interruptions under maximum safe preheater power which resulted in cartridge temperatures of a little over $1000 \mathrm{~F}$.

* West Instrument Corporation. 
5. A high-low pressure limit gage* wired to a relay interrupted power when the system pressure reached a preset maximum or minimum allowable pressure. This gage could be used to prevent overpressures above the system design pressure, or underpressure which could lead to burn-out.

6. A big, red switch on the instrument panel served as a "panic button". It, too, was wired to a relay which interrupted all heating power.

A six channel Micro-Max recorder was wired to provide constant monitoring of certain critical temperatures. Three channels, every alternate one, were connected to a thermocouple immersed in the test fluid near the pump inlet. Other channels were assigned to lower and upper water-cooled insulation flanges, and to the pump motor casing. These insured against accidental cooling-water failure to these areas. The measurement devices may be divided into power (current and voltage), pressure, and temperature measuring equipment. Below, a short account of related devices used in this investigation is presented. Previously, power measurements were made by GE P3 type volt, ampere and watt meters. The test section power supply speedomax Recorder readings could also be used for comparison. However, when during the work of reference $(\underline{13})$ the test section power voltage wave form was photographed, it was discovered that the input voltage was not sinusoidal. This could be attributed to the presence of the saturable core reactor-transformer in the power circuit. A Fourier analysis of

* Obtained from the United States Gage Co. 
photographs taken at a power input of $45.7 \mathrm{kw}$ revealed that the voltage wave contained 10.4 per cent third harmonic and 19.0 per cent fifth harmonic with respect to the first harmonic. It was concluded that the meters designed for sinusoidal wave forms and for a frequency range of up to $133 \mathrm{cps}$ could be in error.

Later a Greibach Model 700 AC-DC volt-ammeter was installed which was guaranteed to give true RMS voltage and current readings within one half of one per cent. Comparison of the measurements taken from the older meters and the new indicated that the voltmeter was the only source of error.

The Greibach volt-ammeter was connected across the test section for. voltage measurements and across a $240 / 1$ ratio Weston Model 347 current transformer for current measurements. The P3 volt and watt meters and the Speedomax Recorder were connected across the test section through a potential transformer which allowed meters to be operated within their midscales. Current was supplied by a separate $240 / 1$ ratio current transformer. A current transformer of $600 / 1$ ratio was available for higher current measurements.

- For pressure measurements two large pressure gages, twó differential pressure transducers, and a specially designed high pressure manometer were used.

A Crosby 0 -4000 psia Hydrostatic test gage was connected to the gas side of the accumulator(s). The accumulator pressure could then be always monitored whether or not it was connected to the loop. A $0-5000$ psia Heise gage with a least count of 10 psia was connected 
to the system at the circulation pump output line and the test section inlet. A valve arrangement allowed selection of either location. Two Statham* $\$ 40$ psi differential transducers were used in the system. One was permanently connected across the test section. The other, and an especially designed mercury manometer, could be connected across both the large and small venturi-meters and the test section through an arrangement of Aminco high pressure needle valves. The transducers were operated by Model BAM-1 Bridge Amplifier Meter supplied by Ellis Associates. Bridge output was monitored by its own meter or auxiliary equipment - including a two channel Beckman offner Type RS Dynograph or a Type 502 duel beam Tektronix oscilloscope equipped with Polaroid camera attachment. Pressure lines were connected to the test section pressure taps through two isolation flanges using mica sheets.

The high pressure manometer, designed and fabricated at Purdue University, employed stainless steel tubes which contained the mercury. The mercury level was determined by locating a steel ball that floated on the mercury column. For this a special centering coil energized by a Hewlett Packard Model 200AB Audio-Oscillator was used. A Hewlett Packard Model 400D Vacuum Tube Voltmeter indicated the output. The manometer scale was engraved at 0.01 inch intervals.

The pressure gages and one transducer were calibrated with a dead weight tester. The test section pressure drop transducer was checked against the calibrated transducer. The transducers were also

* Operational pressure: 0-5000 psi; temperature compensation: 0-200 F. 
calibrated against the manometer. Excellent agreement to better than 0.03 inch of mercury existed. The calibration of all equipment was checked regularly, and all exhibited near perfect stability. The Heise gage scale permitted readings with an accuracy of 5 psi.

For temperature measurements a Leeds and Northrup Type $\mathrm{K} 3$ Universal Potentiometer in conjunction with a Leeds and Northrup D.C. Null Detector and 099034 Constant Voltage Supply by Dynage was used. . The thermocouples were connected to the potentiometer by Leeds and Northrup switches.

\section{Thermometry}

Each test section was instrumented with a number of thermocouples. Test sections $X E$ and $X F$ had respectively 29 and 27 thermocouples attached to their heated span. Furthermore, two thermocouples were mounted on the collar of each current flange. These were used to regulate the guard heaters. All thermocouples were 28 gage chromel-alumel wires with double fiberglass insulation, covered by a braided tinned-copper shield, and jacketed in Nylon. Premium grade Thermo-Electric wires were used.

The thermocouples were installed by forming each wire around the tube wall and carefully spot welding it to the tube metal. Therefore, the junction of the thermocouple was made through the metal and heat conduction was eliminated by the isothermal length. Previous experience had shown that this was a safe method. The junction was then wrapped with glass tape and the wires were led out to a wooden bar to which they were fastened. See Figure 10. 
Additional wires were installed on the two isothermal sections of the tube at the inlet and outlet. These were used to provide a check for the immersed thermocouples; $1 / 16$ inch conoclad stainless steel sheathed chromel-alumel thermocouples were also installed at the inlet and outlet of the preheater. Other thermocouples were attached to the large venturi outer wall.

All thermocouples were properly shielded and led into an isothermal junction box. From the box to the thermocouple switches copper wire was used. All wires were shielded and all shields were grounded.

A cold junction was made by inserting a spot welded thermocouple wire into kerosene in a thin glass tube. The tube was placed in a continuously stirred içe bath.

Figures 12 and 13 show an overall view of test sections $X F$ and XE respectively. The location and number of thermocouples is properly indicated. Figure 12 also illustrates the cooled flanges and the special fluid temperature and pressure measuring units at inlet and outlet. The details of the wiring of a thermocouple are shown in Figure 14.

Thermocouples were calibrated against the freezing points of tin, lead, and zinc. The metals were standard samples obtained from the National Bureau of Standards. They were placed in graphite crucibles and were covered by a layer of graphite powder. A bored graphite rod inserted through a hole in the lid contained the thermocouple. The crucible was heated in an electrical radiation furnace. Two test section thermocouples together with preheater and test section inlet and outlet immersed thermocouples were calibrated. The 


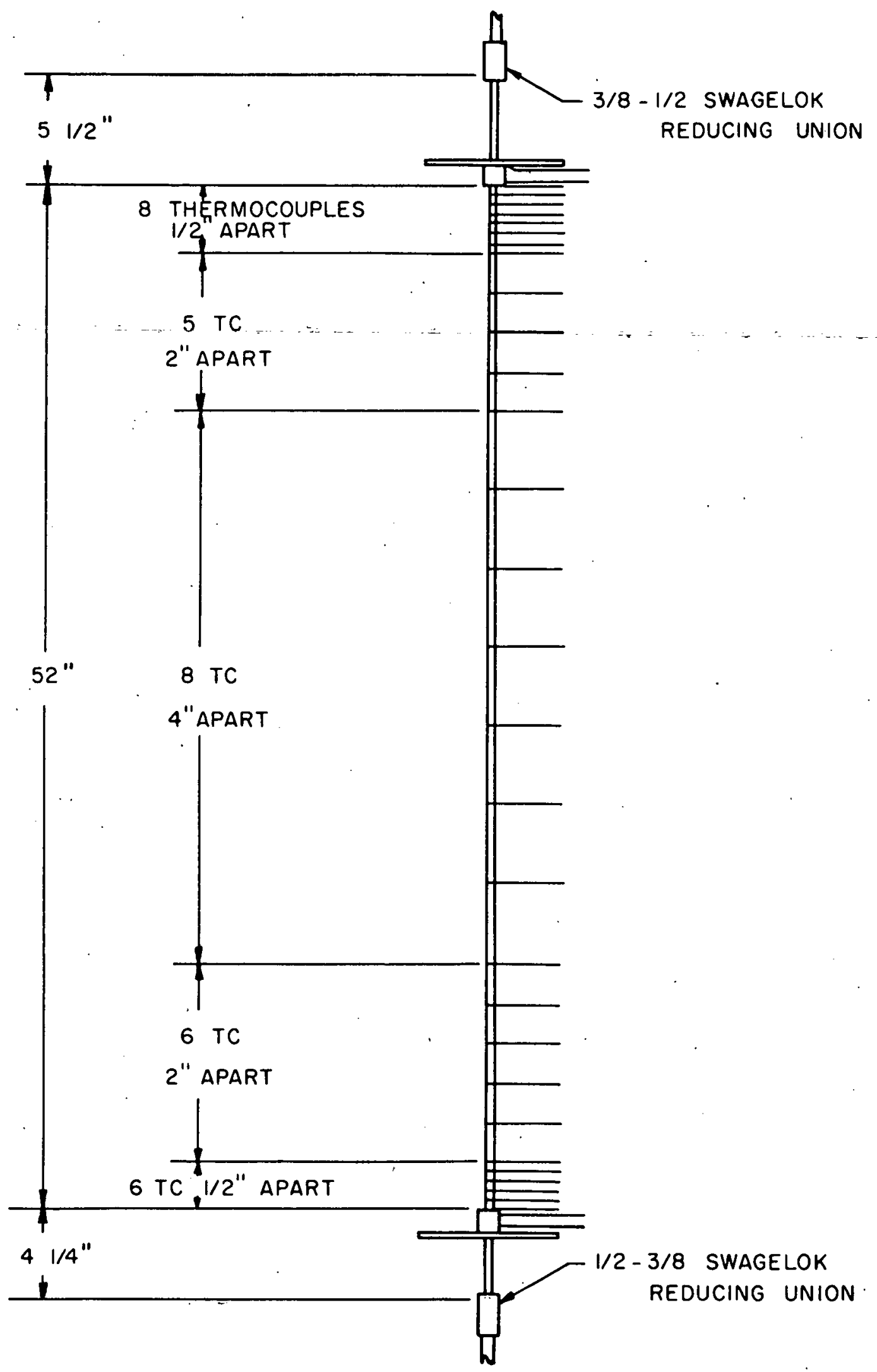

FIGURE 13. OVERALL VIEW OF 3/8" O.D. (XE) TEST SECTION 
THERMO ELECTRIC 28 GAGE

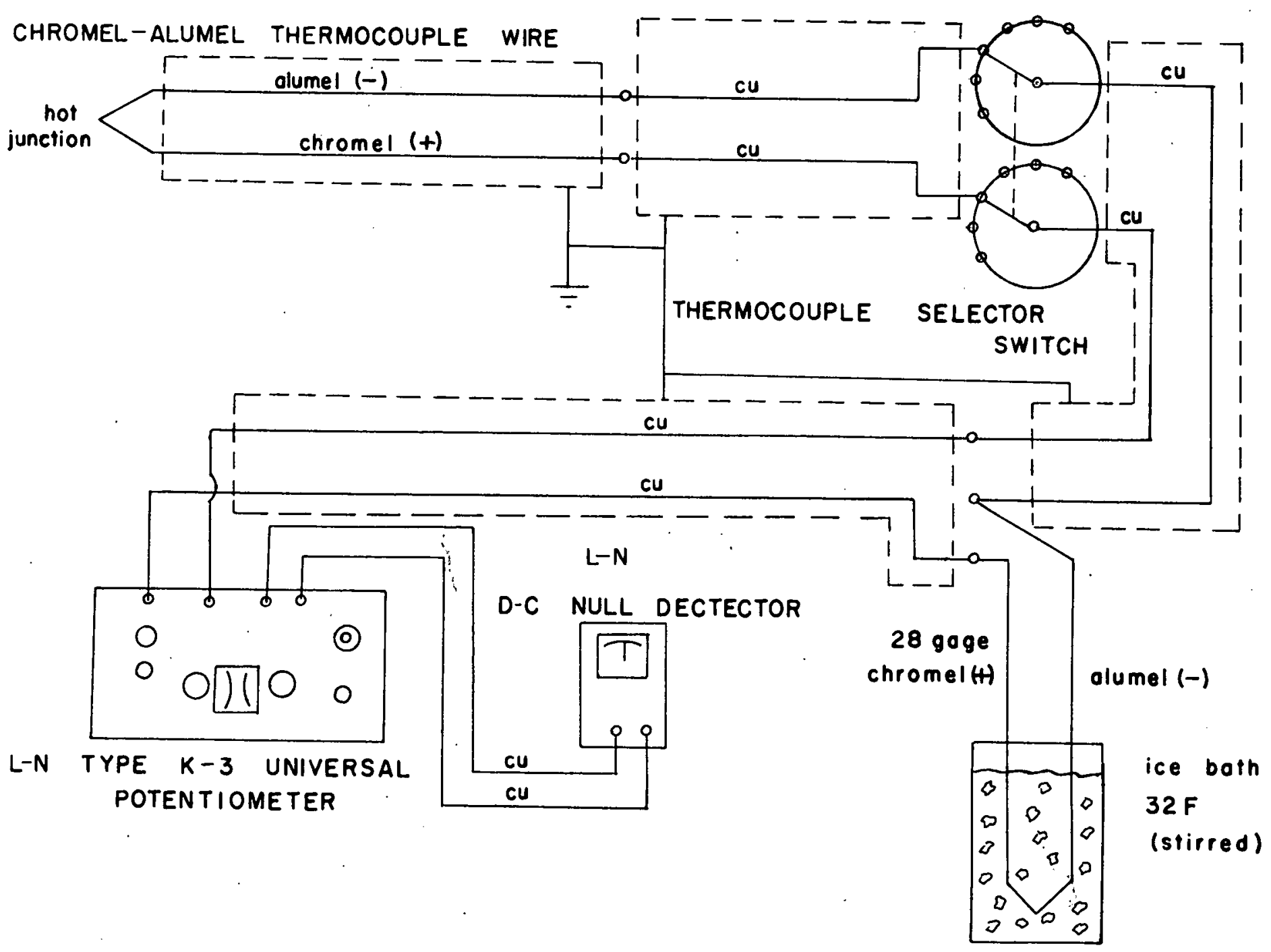

FIGURE IA THERMOCOUPLE WIRING DETAIL 
latter were found to be indicating up to $6.85 \mathrm{~F}$ higher than the true temperature. The test section thermocouples were off by less than $1 F$.

Finally, Figure 15 gives a view of the instrument and control panel, and Figure 16 shows the loop with the test section installed. In Figure 16 the installation of the test section, the thermocouples, pressure taps, and the water-cooled isolation flanges may be seen. Power supply equipment is to the left. In the background the aircooled heat exchanger, and the large flanges and the tube of the system ion-exchanger are visible. 


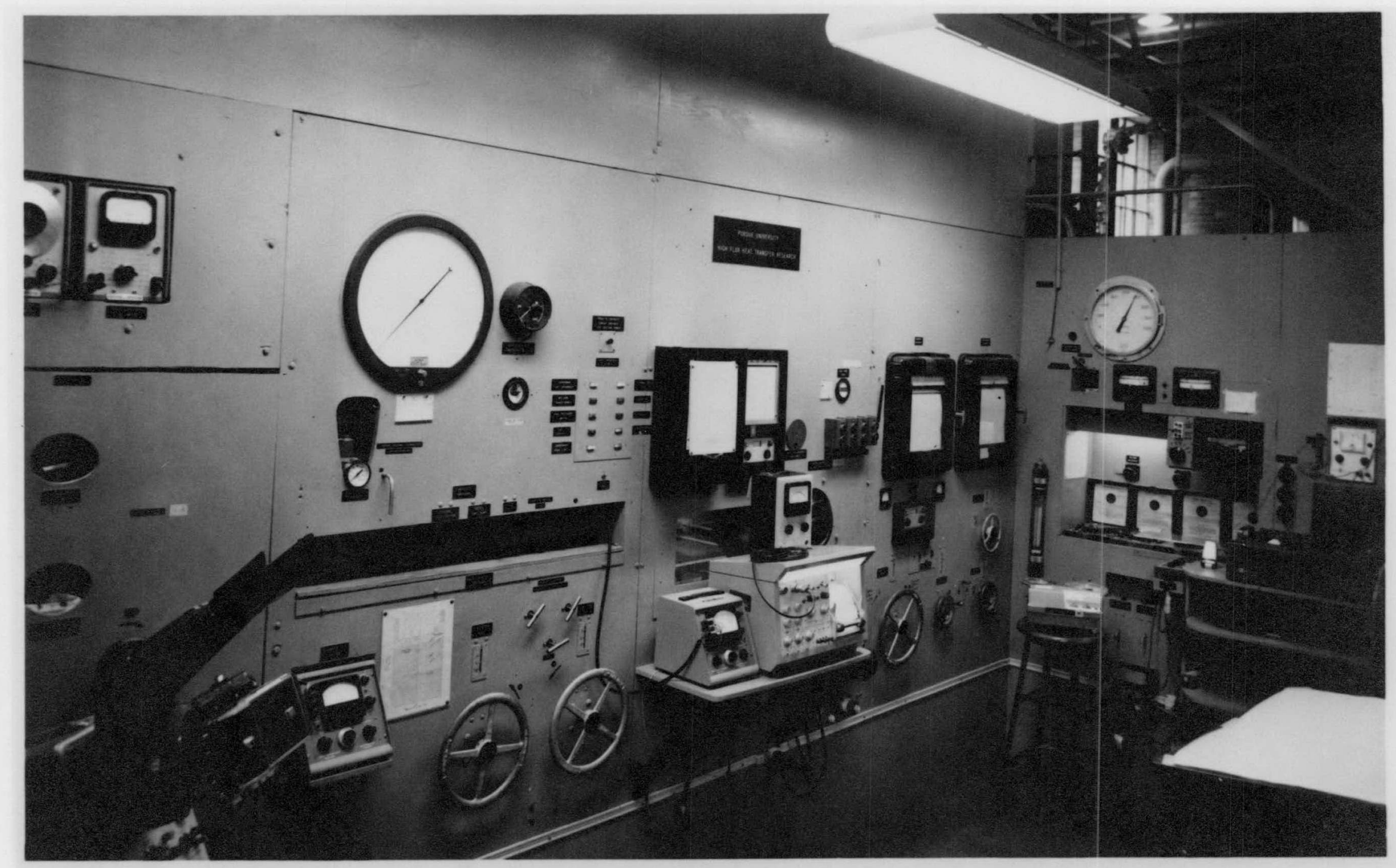

FIGURE 15. VIEW OF THE INSTRUMENT AND CONTROL PANEL 

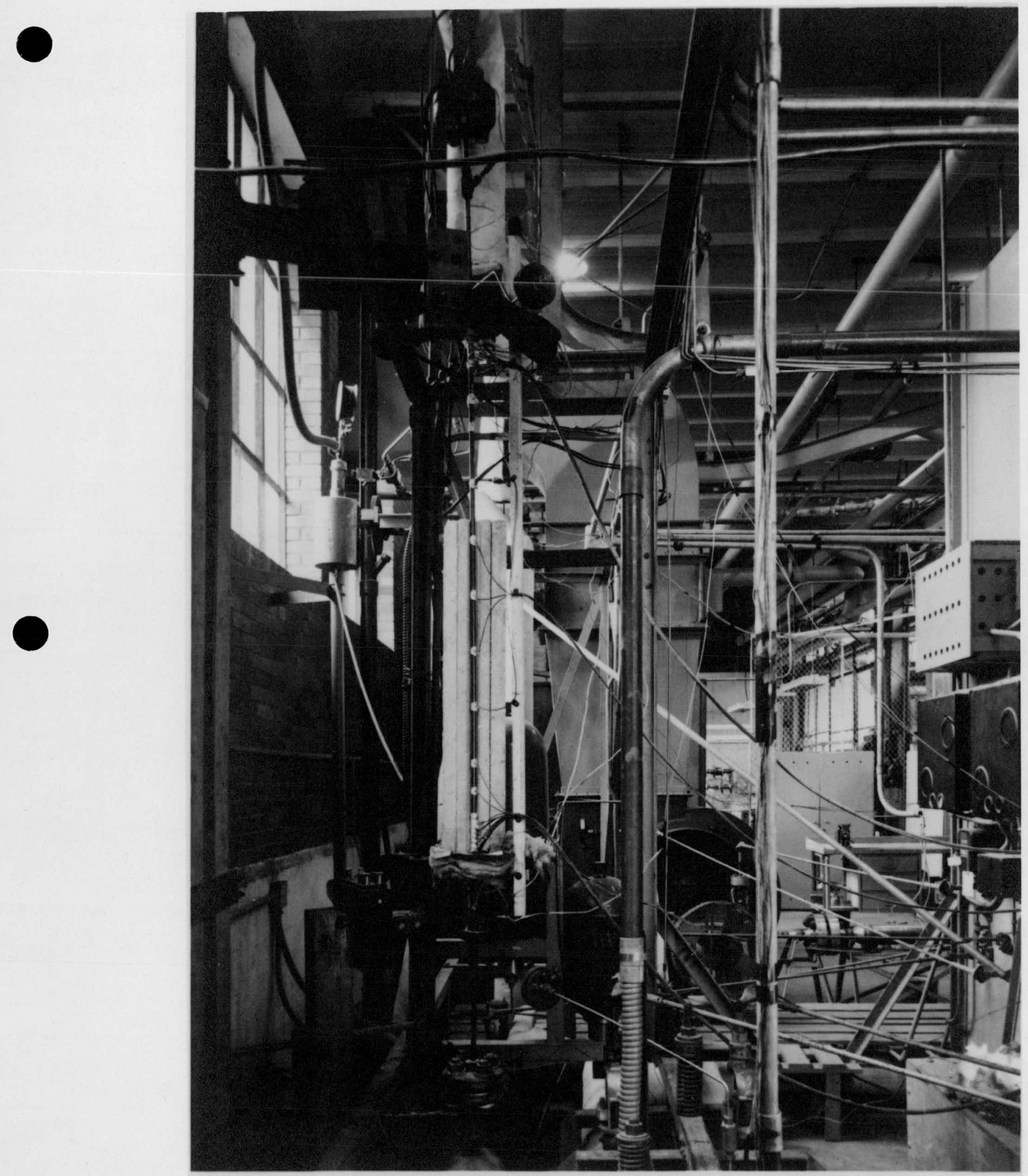

FIGURE 16. VIEW OF THE MAIN LOOP AND TEST SECTION 


\section{EXPERIMENTAL PROCEDURE}

Experiments were conducted to determine the characteristics of heat transfer to near critical water flowing turbulently through an electrically heated tube. Upward forced convection flow was produced by the system circulation pump. Free convection effects were expected to be present in the regions where the density gradient with temperature became large.

At the start of a series of tests, the system was evacuated and filled with de-ionized, degassified water. The accumulator was charged with nitrogen to a pressure ranging from 1500 to 2000 psia depending upon the supply pressure available. The system pressure was then raised to around 1500 psia by the positive displacement.pump.

Before power was activated, all system components such as the safety relay circuits, recorders, thermocouples, and the interlock system were carefully checked and calibrated where necessary. A strict start-up and shut-down procedure was followed. Every step on a special check list was carried out. These checks included:

1. The test section resistance to ground was measured to insure against possible shorts.

2. All electrical equipment and auxiliaries were turned on to allow a sufficient warm-up period.

3. All cooling water was turned on. 
4. The system circulation pump was started, and the flow rate and test section pressure drop were measured using the appropriate pressure transducers.

5. Current transformer leads were checked.

6. All equipment was standardized.

7. The panic button was reset, and the preheater was activated and adjusted to a safe initial power.

8. Finally, the test section power was activated, the magnetic amplifier was turned on, and the automatic control system was switched on to maintain a constant power input to the test section.

All personnel participating in the test runs were trained and instructed as to the conduct of the test and the necessary action to be taken in the event of an emergency.

The system pressure was usually maintained at a value above the saturation pressure of the prevailing highest test section temperature to prevent possible burnmout. Only when it was desired to get into the boiling range to check thermocouples was the pressure lowered to the saturation value. The system temperature was raised gradually in order to avoid leaks in certain units such as the valves. However, the problem of leaks was more serious during the shut-down phase. The three way valve almost always let off steam when temperatures were being lowered.

The power input to the test section was gradually increased until the pressure reached the test range. The needle valve of the line connecting the cooler section of the auxiliary loop and the accumulator was then adjusted so that excess water due to volumetric expansion 
flowed into the accumulator while the system pressure was maintained at an almost constant value. When the temperature approached the desired range, the flow through the air cooled heat exchanger and the power input at the preheater were adjusted to obtain the desired fluid temperature at the test section inlet. Heat flux could be adjusted easily; however, regulation of the flow rate and the test section inlet temperature was not as easy. The system pressure was maintained by occasional bleeding of water from the system or pumping water into the system by the positive displacement pump. The controls for these units were located near the Heise pressure gage. System pressure control by bleeding from or adding nitrogen to the accumulator was not practical for the reason that commercial nitrogen cylinders are pressurized to only about $2300 \mathrm{psi}$, and that no. such fine pressure regulation was needed.

An effort was made to minimize bleeding of water from the system at elevated temperatures. This would not only save the pure water in the system, but would also help the positive displacement pump to maintain the system pressure in the event of rapid temperature decreases. This could be realized by starting with a partially pressurized accumulator and system such that very little bleeding would be necessary as the system reached its operating temperature. Further small increases in the system pressure could be adjusted by additional cooling in the heat exchanger and heating in the preheater. The scheme was satisfactory only when such adjustments could be made with rather limited preheater power. However, the regulation of the system pressure did not actually present much difficulty. 
The main difficulties were the regulation of the flow rate through the test section, and the test section inlet temperature. Due to the construction of the venturi valves very little flow regulation was possible. However, a combined operation of the circulation pump bypass valve and the venturi valves could produce the desired effect.

The fluid inlet temperature at the test section was controlled by several variables - namely, the rate of flow through the heat exchanger, changes in the ambient temperature, drafts in the test area, and the power capacity of the preheater. The heat exchanger with its large surface area and exposed exterior was extremely sensitive to drafts and ambient temperature changes. A small decrease in the room temperature or a draft caused rapid pressure drops as the density of the fluid in the heat exchanger increased. This was also followed by a simultaneous drop in the test section inlet temperature. The test area was located in the vicinity of a gate and very close to traffic. During the winter months attaining of a steady state in operations was extremely difficult since an opening of the gate caused an inrush of cold air and subsequent rapid drop in system pressure and temperature. This ruined many otherwise good experimental runs. At other times, steady state was difficult to maintain during some period after the sunset.

With the heat exchanger blower in operation steady state was difficult to maintain. Also, the blower produced too much cooling. Hence, the heat exchanger was operated with natural air circulation, or rather by using a small fan to produce a steady draft. 
Due to the insufficient capacity of the preheater the test section heat flux was governed by the inlet temperature desired. For this reason heat fluxes lower than about $150,000 \frac{\mathrm{B}}{\mathrm{hr} \mathrm{ft}^{2}}$ could not be permitted since lower heat fluxes would not give sufficiently high inlet temperatures. Another element in favor of high heat fluxes was the necessity to obtain sufficiently large surface-to-fluid temperature differences such that the percentage of error would be decreased. This point is taken up in Appendices $C$ and $J$.

The system reached steady state conditions at near the critical point around three to four hours after start-up. For reasons discussed before, faster heating was avoided. The heat flux was set for automatic regulation, and the flow rate was adjusted. The operators then undertook to attain the desired inlet temperature by manipulation of the preheater. The heat exchanger was not used unless its use became necessary. The system pressure was also regulated at the desired level.

A data run was initiated when the existence of steady state conditions was assured through the following observations:

1. The test section inlet and outlet temperatures remained constant for at least five minutes.

2. The venturi pressure drop remained constant with time.

3. The fluid temperature at preheater exit and the pump inlet remained steady.

In the absence of a rapid potential measuring device, a Wollensak tape recorder equipped with foot-controls was used to speed data acquisition. This also afforded considerable savings in part time 
help, and decreased confusion by reducing the number of operators to two. Another feature was that verbal information describing the condition of various variables during the test runs could be fed into the tape, to be used in a later evaluation of the test. Operator A was assigned only the duty of reading the thermocouples and operating the tape recorder in conjunction with that. Operator $B$ was in charge of maintaining the system pressure, and making power, flow rate, and pressure drop measurements. In between data runs operator A regulated the test section guard heaters.

When the conditions were favorable the data run was started by reading into the magnetic tape the test run number, date and the time. Operator A then followed the following sequence in measuring and recording the thermocouple potentials:

1. all thermocouples associated with the run, but not needed for computations;

2. the venturi, preheater and test section inlet and outlet thermocouples;

3. all thermocouples installed on the heated span of the test section;

4. repeated section 2 and recorded the finish time.

In the meantime operator $B$ measured and recorded in writing the test section and preheater voltage and current, speedomax power reading, preheater outlet temperature as it appeared on the recorder, the test section pressure drop, guard heater settings, system pressure at the test section inlet, and the venturi pressure drop as indicated by the 
transducer. If the venturi pressure drop was less than 10 psi*, it was also measured by the manometer. Additionally, later it became necessary to obtain a time record of the test section and venturi pressure drops indicated by the transducers. For this the offner recorder was used. This subject is introduced in the section entitled Experimental observations.

The average time required for a data run was around 17 minutes. If the system had not maintained its steady state condition during this period of time the data were discarded. Otherwise, the system parameters were changed and a new steady state was awaited. One half to one hour or more was required, depending upon the many variables which determined the process.

Altogether 73 sets of data were collected, 31 of which were taken with the XE test section and 42 with the XF. In order to check the measurements against the well established correlations some data were taken at 3000 psia and a bulk fluid temperature range of 400-530 F. Separate experiments were conducted for isothermal friction drop measurements. Most of the data were taken at pressures ranging from 3220-3400 psia, and heat fluxes of 150,000 to $525,000 \mathrm{~B} / \mathrm{hr} \mathrm{ft}^{2}$.

At the end of a series of data runs the system was shut down. This involved a reversal of the start-up procedures. Flow of cooling water to the welding transformer, isolation flanges, and the pump casing was maintained for about three hours after shut-down. System pressure was allowed to decrease to atmospheric pressure. The time elapsed between start-up and shut-down ranged from 10 to 22 hours.

* The manometer did not accomnodate higher pressure drops. 


\section{EXPERIMENTAL OBSERVATIONS}

During the course of the work various trial experiments were performed to check the operational integrity and reliability of the system. These tests included the determination of isothermal friction factor for the test sections, heat balance tests, and low temperature (400-560 F) runs where agreement with well established heat transfer equations could be checked. Such basic tests are a prerequisite to any investigation of this kind.

The isothermal friction factor tests led to two strange effects as follows:

1. the pressure transducer connected across the test section indicated that the pressure drop across the test section was not steady;

2. the results of the friction factor measurements indicated that the friction factor for the large tube (XF) leveled off at around $\operatorname{Re}=1.5 \times 10^{5}$, a trend characteristic of rough tubes.

Similar behavior as in " $l$ " above was also observed on the differential pressure transducer connected to the large venturi, al though the amplitude of the fluctuations was smaller. Since these observations were made at arourid the $400 \mathrm{~F}$ level, it was decided to check the behavior at room temperatures with absolutely no heating, and with heating at temperatures where future experiments were to be run. 
The result of these observations created great concern. It was found that the fluctuations in the pressure drops across both the test section and the venturi persisted at room temperatures and that their frequency increased with pressure. In the near critical condition the test section pressure drop fluctuations amplified several times. Figures 17 and 18 show Dynograph traces of the pressure drop fluctuations. No fluctuations were observed in the static system pressure at any time. Undoubtedly, the nature of fluctuations in the near critical region was greatly influenced by the fluid density as water became more compressible.

Several months were spent trying to determine the origin of the fluctuations and/or to remedy the difficulty. Although some insight was gained, the fluctuations could not be stopped. Appendix $K$ is devoted to this matter where the procedures and the results of the endeavor are briefly outlined and discussed.

At this point the reader must be cautioned against hasty conclusions. Similar fluctuations may have been present in a great many investigations, and may have gone undetected. Neither the Bourdon tube pressure gage nor the mercury manometer were capable of detecting the fluctuations. Their construction did not allow for sufficient dynamic response. In investigations where such devices are used for monitoring pressure drops, fluctuations of the type reported here can not be observed. Hence, the situation is probably not unique to this investigation. In the section discussing the results it is shown that despite these perturbations there was good agreement between heat 


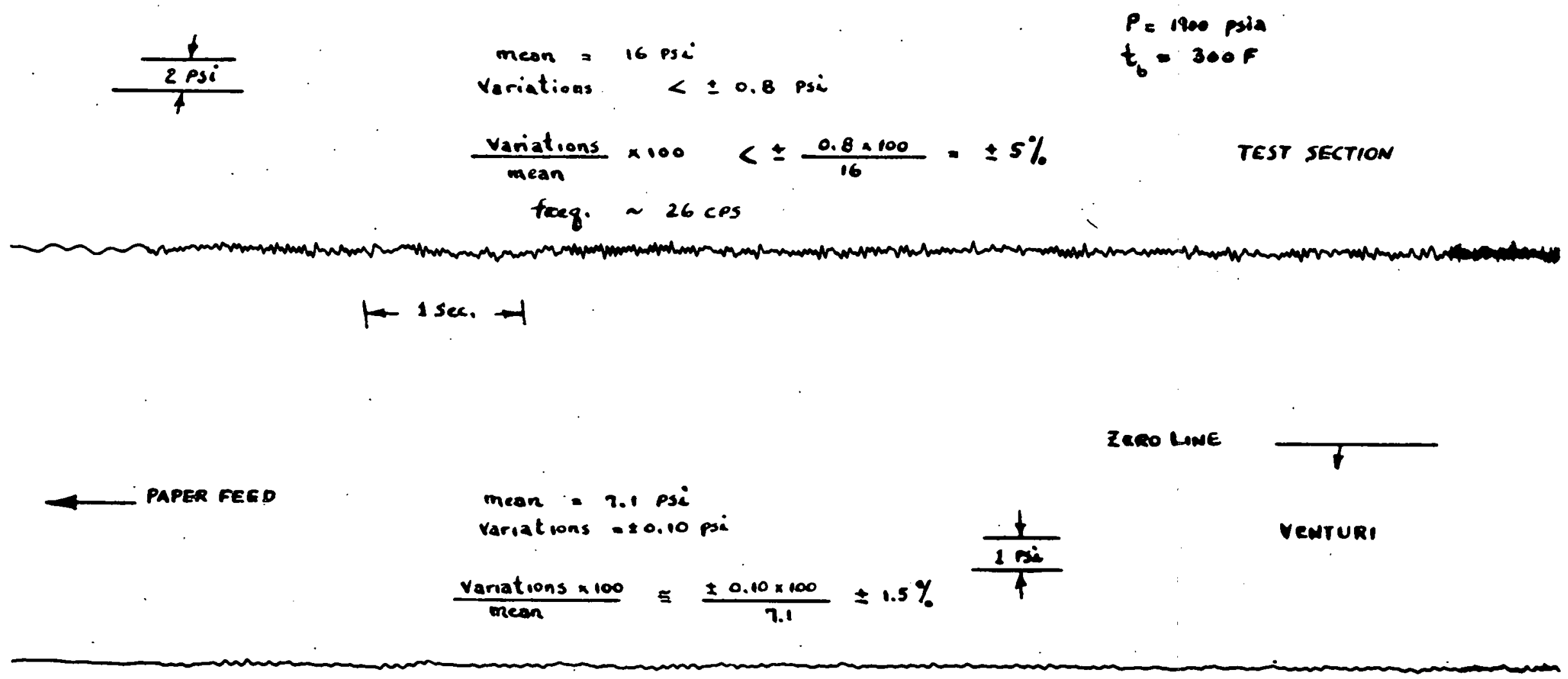

FIGURE 17. DYNOGRAPH TRACES OF PRESSURE DROP FLUCTUATIONS AT $300 \mathrm{~F}, 1900$ PSIA 

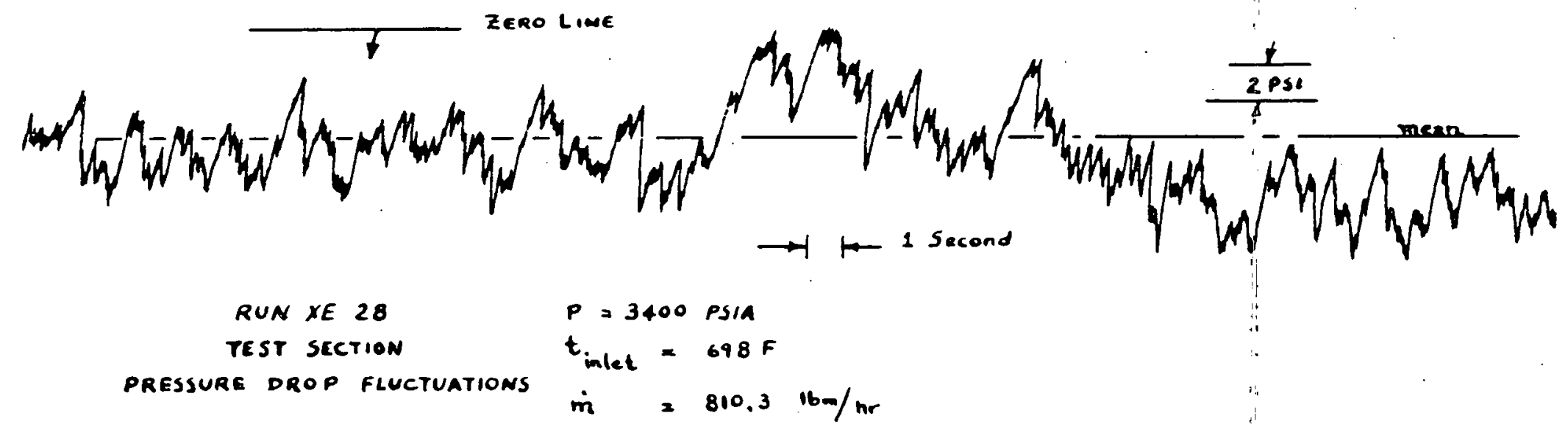

FIGURE 18. TEST SECTION PRESSURE DROP FLUCTUATIONS FOR TEST XE 28 
transfer measurements at $3000 \mathrm{psia}$, in the $400-560 \mathrm{~F}$ range, and the Dittus-Boelter equation.

Returning to the case of the friction factor measurements, at first it was thought that the leveling off could be attributed to the pressure drop fluctuations on the hypothesis that the perturbations may have caused the tube to become hydraulically rough. To check the instrumentation and the computations a separate set-up was arranged. for friction coefficient measurements in a tube similar to the XE test section. The flow rate was computed from time and weight measurements. The pressure drop across the tube was obtained from both a mercury-in-glass manometer and the differential pressure transducer. These readings were always in complete agreement. Since the tap-water line pressure was not constant and could not be depended upon, a pressurized water reservoir arrangement. was employed. The tank held about eight gallons of water and was pressurized with air. Two to four gallons were allowed to flow for each run. The arrangement was found to give very steady flow. Further, the pressure drop across the tube as monitored by the transducer and recorded by the Dynograph did not show any fluctuations or drift.

The results of these measurements fell in the range $\operatorname{Re}=1$ $5 \times 10^{4}$ and were in good agreement with the Prandtl universal friction factor curve for smooth tubes. Although the limited range did not allow for any conclusions to be drawn in regards to the flattening effect, the correctness and the reliability of the transducer measurements were indeed established. 
Low temperature heat transfer experiments showed a deterioration in the heat balances as the flow rate was decreased. The same trend was, also observed when the experimental heat transfer coefficients were. compared with values computed from the Dittus-Boelter equation. The trouble was successfully linked to the Annin valve on the small venturi meter. It was found that the leak was caused by the thermal expansion of the valve and increased linearly with temperature.

With this difficulty removed, very good heat balances were obtained and the low temperature data agreed well with the DittusBoelter equation at all flow rates.

Expecting that the valve leakage had also influenced the computations for the tube friction factor, further tests were carried out, some with flow straighteners (described in Appendix $K$ ) installed and the lower pressure tap located on the test section proper, downstream from the straighteners. However, no improvements were noted but all measurements showed excellent reproducibility of the measured friction factors. There is, therefore, no doubt that the XF test section tube did act rough. The results of the measurements and an. explanation for this behavior is presented in a later section.

Another problem encountered during the investigations was the general deterioration in the heat balances near the critical region. Table IV gives a general appraisal of the heat balances for various inlet and outlet temperatures. Up to $650 \mathrm{~F}$ at the inlet good heat balances, within one and one half per cent, were obtained. The situation deteriorated to ten per cent for the inlet and outlet temperatures below $675 \mathrm{~F}$ and $700 \mathrm{~F}$, respectively. At higher temperatures the situation immediately grew worse giving very poor heat balances in the 700-710 F 
TABLE IV

Discrepancy in the Heat Balances

\begin{tabular}{ll}
\hline Inlet & Condition \\
$t_{b} \leq 650 \mathrm{~F}$ & $t_{b} \leq 675$ \\
$650 \leq t_{b} \leq 675$ & $675 \leq t_{b} \leq 700$ \\
$675<t_{b}$ & $700<t_{b}$. \\
$706<t_{b}$ & $715 \leq t_{b}$.
\end{tabular}

Heat Balance

Error

(less than 1.5 per cent)

(within 10 per cent)

(some more than +50 per

cent)

$706<t_{b}$

$715 \leq t_{b}$

poor

(negative errors)

range for the exit fluid temperature. Some heat balances were off by more than 50 per cent, with the generated heat exceeding the product of the flow rate and the enthalpy rise between the inlet and outlet. At the inlet temperatures above approximately $706 \mathrm{~F}$ the discrepancy was in the opposite direction.

A general deterioration of the heat balances with the approach to the near critical region has been reported by many investigators. This seems to be another riddle associated with the problem of heat transfer to near critical fluids. Koppel's results were an exception primarily.because the same equipment and set-up were used to measure the enthalpy of carbon dioxide in the critical region prior to the heat transfer tests. 
There are essentially four basic factors which may influence the heat balances:

1. Error in the flow rate.

2. Thermocouple calibration error.

3. Thermocouple not measuring the correct bulk fluid temperature.

4. Discrepancy in the enthalpy tables.

The fluid specific volume appears in the venturi equation and is the only element of that equation which may possibly cause an abrupt discrepancy in the flow rate. However, for the flow rate to be, for example, twenty per cent off, the value of the specific volume must be off by over forty per cent. Even close to the steepest section of the isobaric specific volume-temperature curve, this would require 2 to $3 \mathrm{~F}$ error in the temperature. Since the fluid immersed thermocouples were calibrated at the lead and zinc points, such a large temperature error was improbable.

The more probable causes of the discrepancy were items 3 and 4 above. Despite the fact that a twelve inch length of tube was provided at the outlet from the heated section to insure proper fluid mixing, it was still quite possible that the centrally located thermocouple did not measure the true mixing-cup temperature. It is also possible that the presently available enthalpy data have a major discrepancy in the immediate vicinity of the critical region. Since the test section inlet temperature was known with better certainty, all computations were based on the inlet temperature. The presence of three fluid immersed thermocouples, two of which belonged to the preheater, together with several other thermocouples mounted on the piping 
and undoubtedly better opportunity for fluid mixing contributed to this decision. Furthermore, considering the facts that fair heat balances were obtained up to $700 \mathrm{~F}$ at the exit, and that the fluid inlet temperature was usually less than $700 \mathrm{~F}$, it was felt that the use of the inlet temperature was the safer of the two.

Certain instabilities were noted in the thermocouple readings. It appeared that the temperatures fluctuated within a few tenths of a degree from the mean value. The fluctuations in the wall temperatures were believed to be due both to the test section power fluctuations and probably to the fluid fluctuations discussed previously. The fluid temperature fluctuations were due to the latter. The fluctuations seemed to decrease as the critical region was approached. No system pressure instabilities of the type reported for free convection studies were observed. It may be hypothesized that these instabilities have their origin in the small flow fluctuations observed in this work. However, at lower fluid flow rates, as is the case in free convection flows, there is insufficient damping and the perturbations grow. As the fluid becomes more compressible, the amplitude grows and the lower frequencies become more distinct. An , example of such a behavior is given in Figure 18 where large differential pressure drop drifts may be seen. It was also observed that at higher flow rates there was a damping effect and much lower amplitudes prevailed. Hence, at low flow rates the amplitudes may become quite large. 


\section{REDUCTION OF DATA}

All satisfactory experimental data obtained during the course of the investigation were reduced to obtain the system flow rate, local wall and bulk fluid temperatures and enthalpies, and local heat fluxes. From these basic data the local heat transfer coefficients and other parameters of interest were computed. In the following the equations and procedure used in the reduction of data, and other calculations of interest, are outlined.

\section{Flow Rate Calculations}

The small and large venturi flow rates were computed from the general venturi equation, viz.

$$
\dot{m}=A K E \sqrt{\frac{2 g \Delta P_{v}}{v}}
$$

- Upon substituting the proper constants in equation (41) and accounting for the water leg in the manometer specific equations for each venturi were obtained. Thus,

$$
\begin{aligned}
& \dot{m}_{s}=0.00435 k_{s} E \sqrt{\frac{\Delta z v s}{v}} \cdot \frac{1 b_{m}}{s e c} \\
& \dot{m}_{1}=0.01489 k_{l} E \sqrt{\frac{\Delta z v l}{v}} \cdot \frac{1 b_{m}}{s e c}
\end{aligned}
$$

In the above equations $\Delta z_{v}$ represents venturi pressure drop in inches of mercury, whereas $v$ is given in cubic feet per pound of mass. When 
venturi pressure drop is measured on the transducer a correction must be applied to eliminate the effect of the water leg introduced in equations $(42 a, 42 b)$. It can be easily shown that

$$
\Delta z_{v}=\frac{\Delta P_{v}}{0.455}
$$

where $\Delta P_{v}$ represents the venturi pressure drop in "psi" as measured by the transducer.

The flow coefficient $K$ for each venturi and the thermal expansion coefficient $E$ are given in Figures 19 and 20 respectively. The venturis were built at Purdue University and calibrated by the Argonne National Laboratory at the time of their manufacture. In conjunction with the computer work the flow coefficients and the thermal expansion factor were approximated by simple equations which appear in the figures. The Reynolds number for each venturi was computed from the equation given below:

$$
\begin{aligned}
& \operatorname{Re}_{\mathrm{s}}=268300 \frac{\dot{\mathrm{m}}}{\boldsymbol{\mu}_{\mathrm{b}}} \\
& \operatorname{Re}_{1}=496100 \frac{\dot{m}}{\mu_{\mathrm{b}}}
\end{aligned}
$$

where viscosity is expressed in units of $\frac{1 b_{m}}{h r f t}$

\section{Test Section Pressure Drop}

The test section pressure drop was measured with a differential transducer. However, the difference in the density of the fluid in the test section and in the cold leg of the circuit required a correction. 

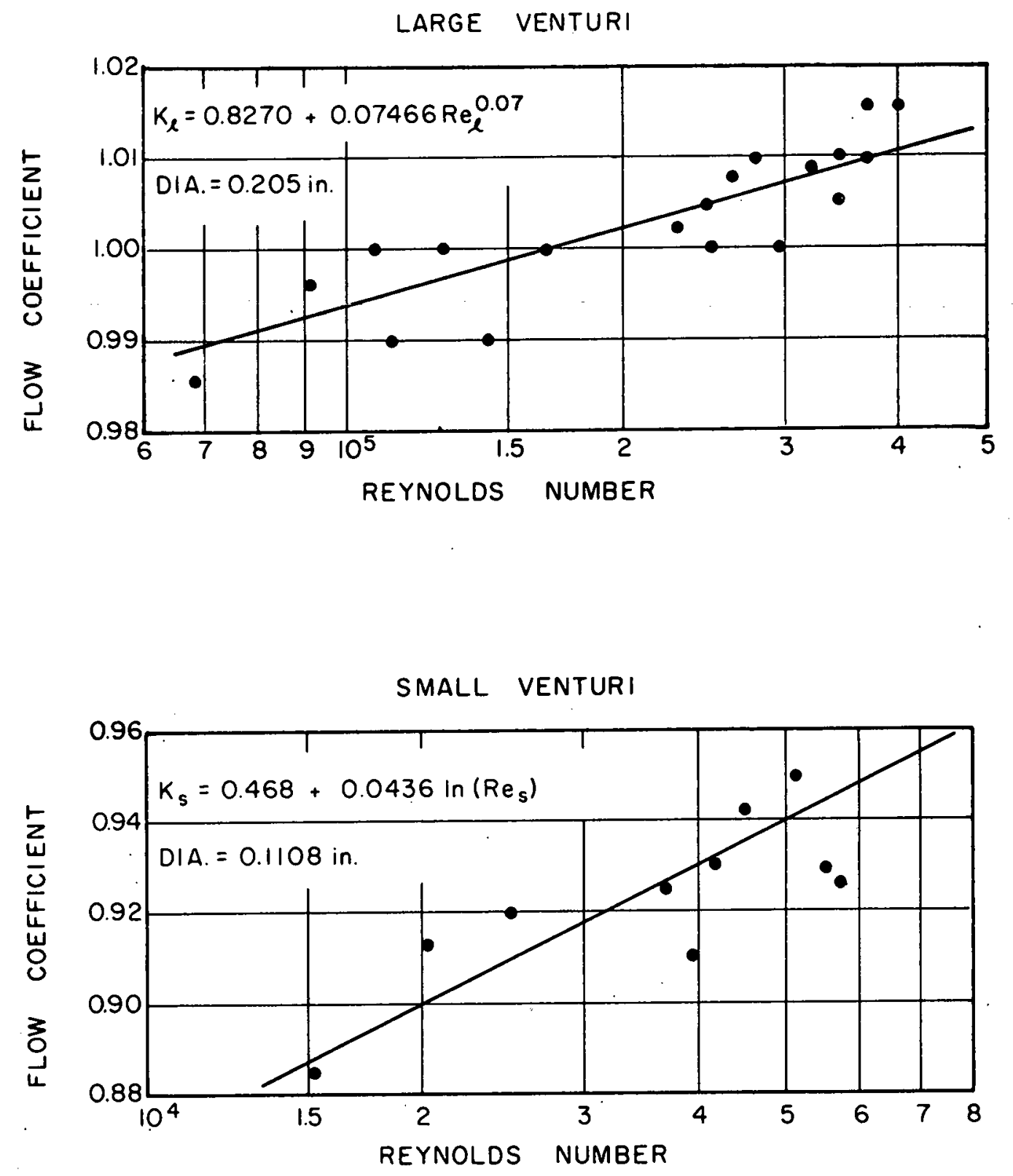

FIGURE 19. FLOW COEFFICIENTS FOR LARGE - AND SMALL VENTURIS 


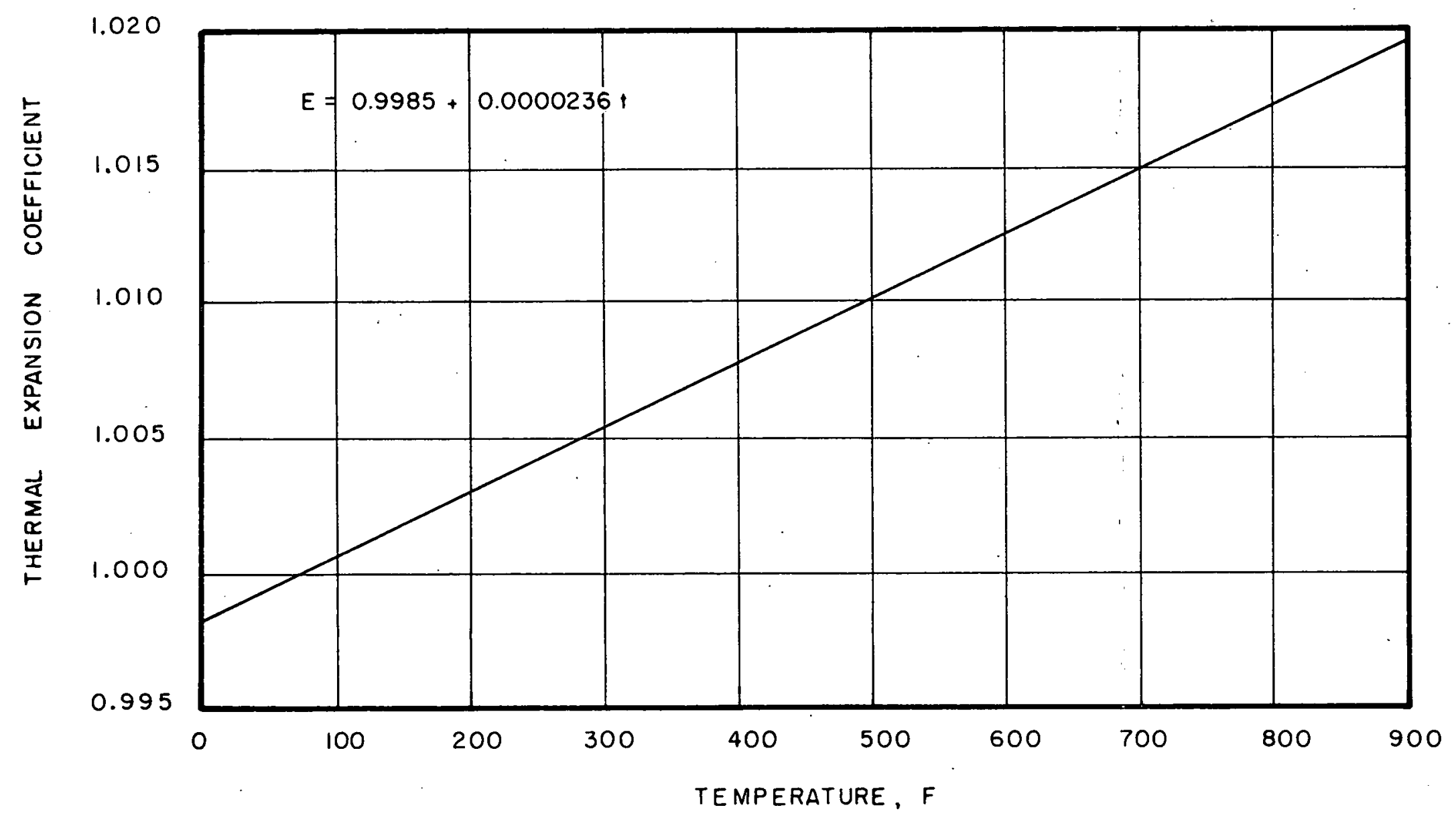

FIGURE 20. VENTURI THERMAL EXPANSION FACTOR 
When the fluid temperature in the test section was high and small pressure differences were being measured, the correction was quite significant and often larger than the measured quantity.

In Appendix B it is shown that the correction is given by the following equation:

$$
\Delta P_{f}=\Delta p_{t}+\Delta z_{p}\left(p-\bar{p}_{b}\right)
$$

where $\overline{\boldsymbol{P}}_{\mathrm{b}}$ is the mean fluid density between the pressure taps in the test section. $\Delta P_{f}$ and $\Delta P_{t}$ indicate test section frictional pressure drop and the pressure differential registered by the transducer, respectively.

\section{Calculation of the Inside Wall Iemperature}

Inside wall temperatures were computed from the first four terms of a series solution given by Kreith and Summerfield (34) using the measurements of outside wall temperatures and the current flowing through the section. The equation is as follows:

$$
\begin{aligned}
\Delta t=t_{s}-t_{w} & =\frac{M \Delta x^{2}}{\left(1+\gamma t_{s}\right)\left(1+a t_{s}\right)}\left[1+\frac{\Delta x}{3 r_{0}}+\frac{\Delta x^{2}}{4 r_{0}^{2}}\right. \\
& \left.+\frac{M}{\left(1+\gamma t_{s}\right)\left(1+a t_{s}\right)} \frac{\left(3 a+4 a \gamma t_{s}+\gamma\right)}{6\left(1+\gamma t_{s}\right)\left(1+a t_{s}\right)}\right] \\
M= & \frac{I^{2} \rho_{e m z}^{2}}{2 J k_{0} P_{e o} A c^{2}}
\end{aligned}
$$

where 


$$
\rho_{\text {einz }}=\rho_{\text {eo }}\left[1+\frac{a}{r_{0}-r_{i}} \int_{r_{i}}^{r_{0}} t(r) d r\right] \approx \rho_{e o}\left(1+a t_{m}\right)
$$

and

$$
t_{m}=\frac{t_{s}+t_{w}}{2}
$$

It is observed that an accurate determination of the inside wall temperature of the tube depends to a great extent on a precise knowledge of the variables appearing in equation (46). This subject is taken up in Appendix $C$ where the influence of each variable upon the computed value of $\Delta t$ is considered. Since the thermal conductivity of stainless steels is subject to considerable controversy (see Figure 4), an apparatus was designed and measurements were carried out with a piece from a similar tube with the same heat number as the XF test section. The result of measurements was in fair agreement with an equation used by Dickinson and Welch (12) who gave the National Bureau of Standards for the source. The thermal conductivity, computed from an equation obtained by fitting a linear least squares curve to the experimental data, was on the average 2.5 per cent less than the value given by the N.B.S. originated equation in the 650-950 F range.

The equation given by Dickinson and welch, viz.

$$
k=8.50\left(1+5.17 \times 10^{-4} t\right) \frac{B}{\mathrm{hr} \mathrm{ft} \mathrm{F}}
$$


was used in conjunction with equation (46) for the computations of the inside wall temperature. Since time did not allow measurements with the tube material of the XE test section, the use of two different relations would have been unwise from the point of view of data correlation and comparison.

Furthermore, the value of the measurements lies in the fact that they gave some indication of the extent of uncertainty in the thermal conductivity computed from equation (47).

Comparison of the electrical resistivities of the test sections revealed that they differed by about 3.4 per cent at the $800 \mathrm{~F}$ temperature level. It is possible that the thermal conductivities were also different. Computations of the electrical resistivity of the $\mathrm{XF}$ test section from voltage and current measurements showed that the results were in excellent agreement with previous, unreported, precision measurements of the author with a Type 347 stainless steel tube. Appendix $D$ briefly describes the method, and Figure D-3 shows a comparison with other measurements reported in the literature. A Kelvin bridge arrangement with a measurement accuracy of $10^{-6} \mathrm{ohm}$ was used. The $\mathrm{XF}$ test section resistivities as computed from the voltage and current readings taken during the experimental runs had rms deviations of less than 0.16 per cent in the 600-850 F range and less than 0.21 per cent in the 400-850 F range as found from a second degree least squares curve fitted to the data of the above mentioned electrical resistivity measurements. In the light of the fact that the least squares fit had a normalized absolute deviation of 0.083 per cent from the measured data the agreement is obviously quite satisfactory. 
The $\mathrm{XE}$ test section electrical resistivity compared very well with an equation given by Dickinson and Welch (12). The rms deviation was less than 0.20 per cent in the $600-800 \mathrm{~F}$ range. Table $V$ summarizes the thermal conductivities and electrical resistivities together with their linearized forms (where applicable) used for each test section and in conjunction with equation (46). Figure 21 is a graph of various electrical resistivities.

\section{TABLE $V$}

\section{Summary of Electrical Resistivities and Thermal} Conductivity for the Test Sections

Thermal Conductivity*

$$
k=8.50\left(1+5.17 \times 10^{-4} t\right) \quad X E \text { and } X F
$$

Electrical Resistivity**

$$
\begin{aligned}
& P_{e}=30.18\left(1+3.71 \times 10^{-4} t\right) 10^{-6} \quad \begin{array}{rr}
X E \\
t
\end{array} \\
& P_{e}=28.46\left(1+6.49 \times 10^{-4} t-1.52 \times 10^{-7} t^{2}\right) 10^{-6} . \quad \text { XF } \\
& \text { linearized } P_{e} \quad 31.75\left(1+3.42 \times 10^{-4} t\right) 10^{-6} \\
& \begin{array}{c}
X F \\
650<t<1000
\end{array} \\
& \text { linearized } P_{\text {e }} 29.45\left(1-4.84 \times 10^{-4} t\right) 10^{-6} \\
& \begin{array}{c}
X F \\
400<t<600
\end{array}
\end{aligned}
$$

* Units are in $B / h r$ ft $F$. ** Units are in Ohm-inches. 


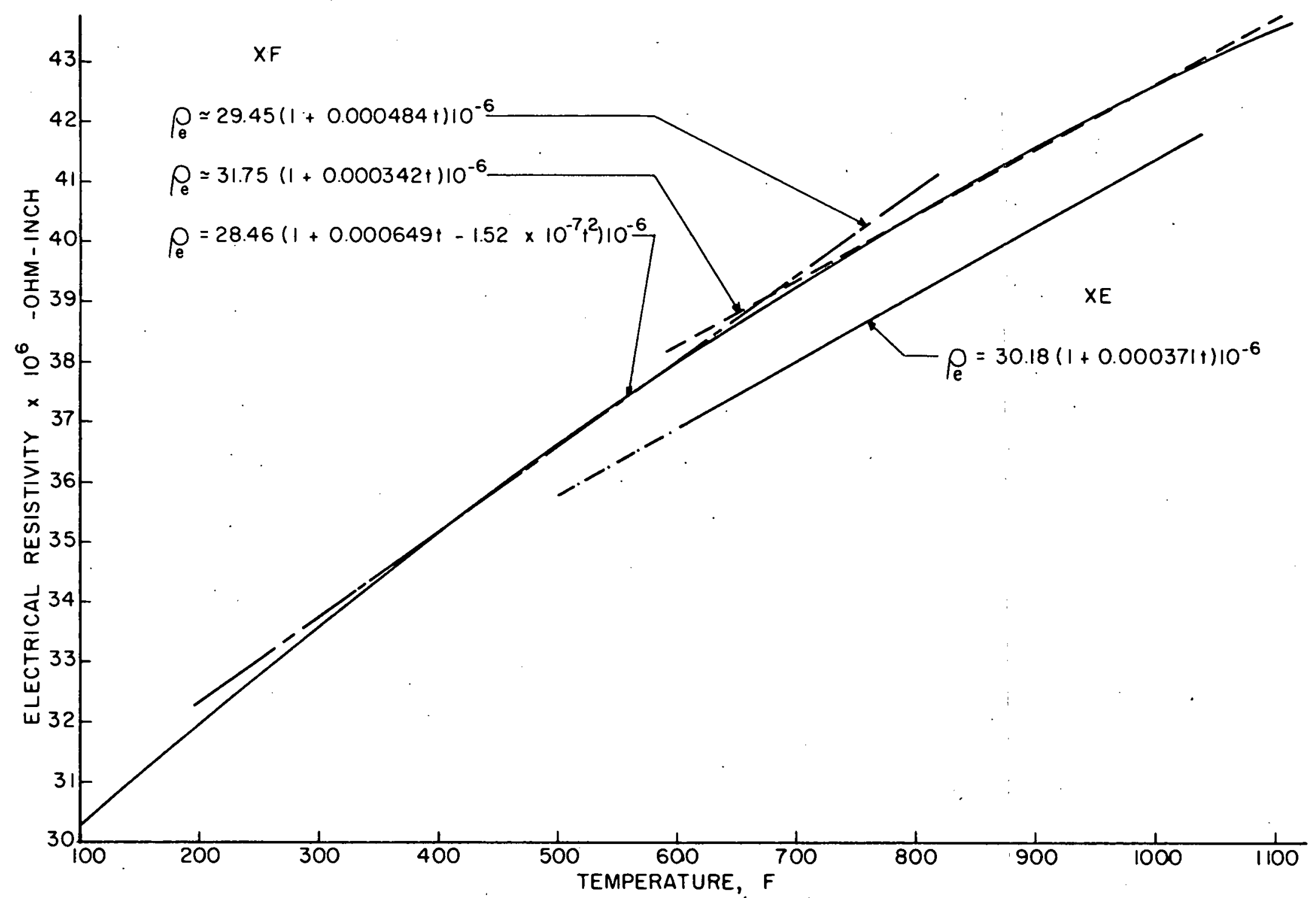

FIGURE 21. ELECTRICAL RESISTIVITIES OF TEST SECTIONS XE AND XF 
4. Calculation of Local Wall Heat Flux

The heat generation in a differential length of the test section is given by

$$
Q=\frac{I^{2} P_{e m z} \Delta z}{A_{c}} \times 3.4128 \frac{B}{h r}
$$

The heat flux at the inside wall was computed by dividing the heat rate by the inside area of the differential element under consideration. Therefore,

$$
\frac{Q}{A_{1}}=3.4128 \frac{I^{2} P_{e m z}}{\pi D_{i} A_{c}}
$$

where $P_{\text {emz }}$ is the local mean value of the electrical resistivity. In order to account for the deviation of the actual value of the electrical resistivity from that computed from an appropriate equation, the wall heat flux was multiplied by the ratio of measured resistivity to the average calculated resistivity. Thus,

$$
q_{w}^{\prime \prime}=3.4128 \frac{I^{2} \boldsymbol{p}_{\mathrm{emz}}}{\pi D_{i} A_{c}} \cdot \frac{\overline{\boldsymbol{p}}_{e}}{\boldsymbol{p}_{\mathrm{em}}} \frac{\mathrm{B}}{\mathrm{hr} \mathrm{ft}^{2}}
$$

where

$$
p_{\mathrm{em}}=\frac{1}{\mathrm{~L}} \cdot \int_{0}^{\mathrm{L}} \boldsymbol{\rho}_{\mathrm{emz}} \mathrm{dz}
$$

$P_{\text {emz }}$ was computed from equations (48) or (49) depending on the test section. 


\section{The Local Bulk Fluid Temperature}

The bulk fluid temperature was determined from tabulated enthalpytemperature-pressure data taken from smoothed curves. The bulk enthalpy at a point in the test section was determined by adding to the inlet bulk enthalpy the total heat delivered to the water from the entrance to the point in question. Thus,

$$
: H_{z}=H_{0} \cdot \frac{\pi D_{j} X}{\dot{m}} \int_{0}^{z} q_{w}^{\prime \prime} d z
$$

In the above equation $x$ is the ratio of the heat input to the fluid over that generated.

Both integrals in equations (55) and (56) were evaluated by the trapezoidal rule, viz.

$$
\int_{z}^{z+\Delta z} y d z=\frac{\Delta z}{2}\left(y_{z}+y_{z+\Delta z}\right)
$$

The bulk fluid pressure was determined by linear interpolation of the pressure drop between the entrance and exit, which was obtained from differential pressure transducer readings. Therefore,

$$
P_{z}=P_{0}-\frac{z}{\Delta z p} \Delta P_{f}
$$

From the computed values of the wall temperature and flux, the bulk fluid enthalpy and the bulk temperature various parameters of interest were calculated. 


\section{Isothermal Friction Factor}

The isothermal friction factor for the test section, defined by the equation

$$
f \equiv \frac{\Delta P_{f}}{\frac{\Delta z_{p} \rho}{D_{i}} \frac{v^{2}}{2 g}}
$$

was computed for a series of isothermal pressure drop measurements with the XE, XF, and another test section. For calculation purposes equation (58) was expressed in terms of the flow rate instead of the velocity, viz.

$$
f \equiv \frac{18 \pi^{2} g D_{i}^{5}}{\Delta z p} \frac{\Delta P_{f}}{v \dot{m}^{2}}
$$

The above relation also shows that the tube inside diameter must be determined with good accuracy.

\section{Fluid Properties Used in This Work}

For temperatures above $600 \mathrm{~F}$ the dynamic viscosity and thermal conductivity sere evaluated from equations adapted from Fritsch and Grosh (28), viz.

$$
\begin{aligned}
& \mu=\left(37.94 \times 10^{-10} \times\left(\frac{1}{v}\right)^{1.57} \cdot 4.788 \times 10^{-10} t+14.79 \times 10^{-8}\right) 115920 \\
& k=26.6 \times 10^{-4} \times\left(\frac{1}{v}\right)^{1.24} \cdot 4.0 \times 10^{-5}(t-550)+0.0246
\end{aligned}
$$

The units are $\frac{1 b_{m}}{h r f t}$ and $\frac{B}{h r f t F}$ respectively. The values obtained from the above equations for 3300 psia pressure and temperatures from 
600 to $750 \mathrm{~F}$ were compared to values taken from large plots and tables made available by the Babcock and Wilcox Co. Research Center*. In general good agreement existed except at near the peak temperature where the thermal conductivity showed a large discrepancy of about 25. per cent. At other temperatures the agreement was well within . four per cent. For the 400-560 F temperature'region the abnve mentioned plots and tables were useo.

Since no experimental thermal conductivity values are available for water in the near critical region, both the equations and the plots give interpolated values. The former were preferred since they were easier for machine computations.

All thermodynamic properties for the critical region were obtained from the recommended values of Nowak and Grosh. The specific heat, required in the Dittus-Boelter equation, was taken from Keenan and Keyes steam tables ( $\underline{36}$ ) at temperatures below those covered by (26). otherwise, the use was limited to the modified forms presented earlier. The specific volume was obtained from references (26), where available, and ( $\underline{36})$. Its use was in conjunction with the flow rate computations and various correlations where the specific volume, dynamic viscosity, and thermal conductivity were required.

Data from various tables were put together and.cross plotted several times to obtain a set of smoothed, consistent enthalpy-temperature-pressure plots and tables for a region extending from about 600 to $830 \mathrm{~F}$, and 2900 to $3400 \mathrm{psia}$. Special emphasis was placed in the

\footnotetext{
Personal communications.
} 
near critical region where the data was spaced every 20 psi from 3200-3300 psia. Tables contained temperature as a function of pressure and enthalpy, which was spaced every $5.0 \mathrm{~B} / 1 \mathrm{~b}_{\mathrm{m}}$.

Data in the critical region were mostly obtained from Nowak and Grosh (27). Other data taken from references (주, $\underline{37}, \underline{38}, \underline{39}, \underline{40})$ were used in conjunction with, and beyond the range of (27). Isenthalpic and isobaric plots were prepared. The smoothness of the isobaric enthalpy-temperature values in the critical region was checked by plotting the product of enthalpy and temperature versus enthalpy. Indeed, the results showed very smooth, sectionally linear curves. Appendix E presents the enthalpy-pressure-temperature tables as described above and used in this work. The enthalpy range extends from 600 to $1300 \mathrm{~B} / 1 \mathrm{~b}_{\mathrm{m}}$ and is spaced every $5.0 \mathrm{~B} / 1 \mathrm{~b}_{\mathrm{m}}$. Figure 22 illustrates the isobaric enthalpy-temperature curves for water in the critical region.

The values of the peak temperature versus pressure were adapted from reference (26), and are expressed by the equation:

$$
t_{p}=705.50 \cdot 0.044643(P-3208)
$$

which is valid up to around 3750 psia. Nowak has given the critical pressure and temperature as 3208.0 psia and $705.5 \mathrm{~F}$. A plot of $t_{p}$ versus pressure is given in Figure 23.

An effort was made to obtain the value of the enthalpy corresponding to the peak temperature (or the peak enthalpy), but despite the use of several methods no consistent results could be obtained. This probably presents the toughest demand from any temperature- 


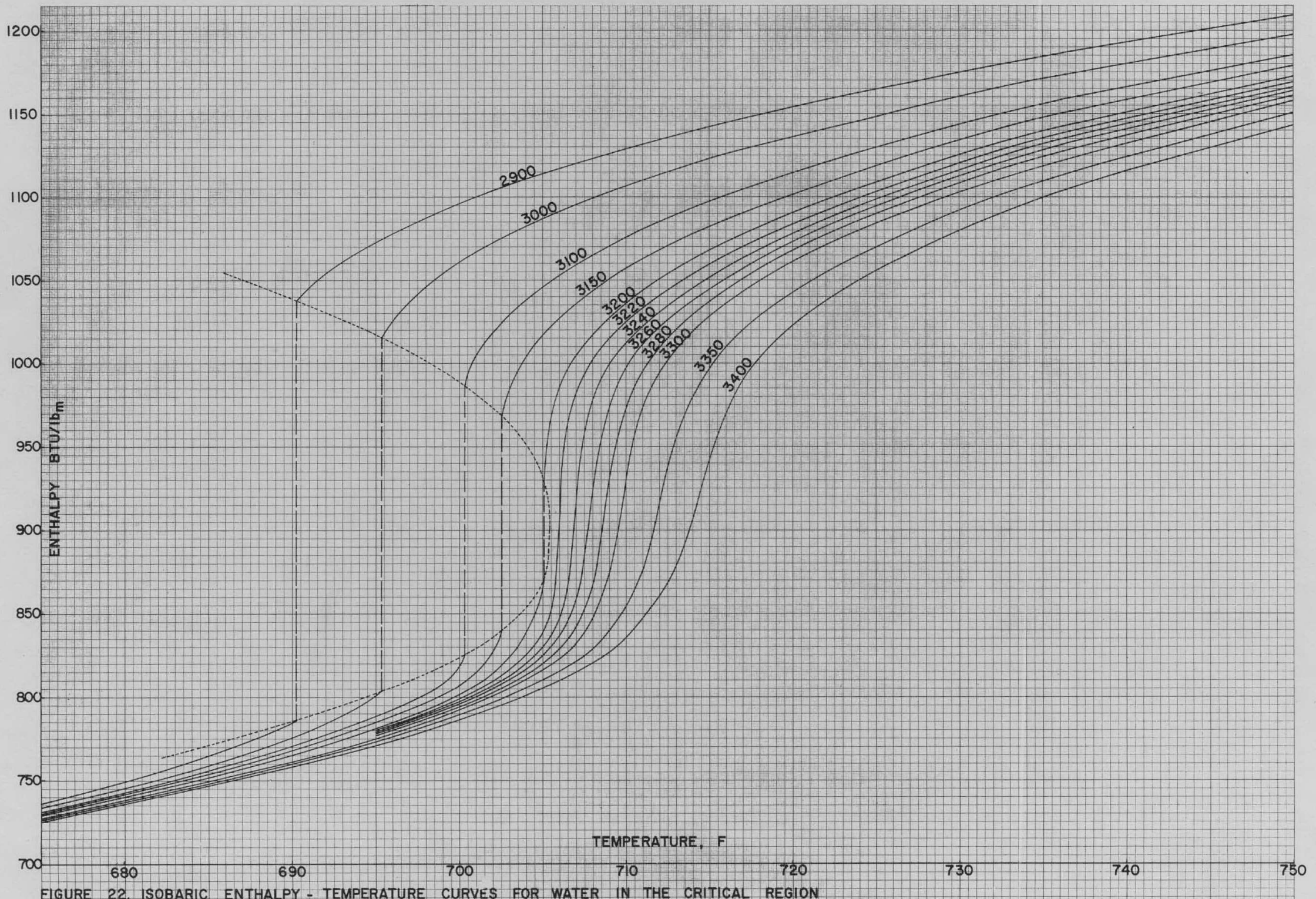




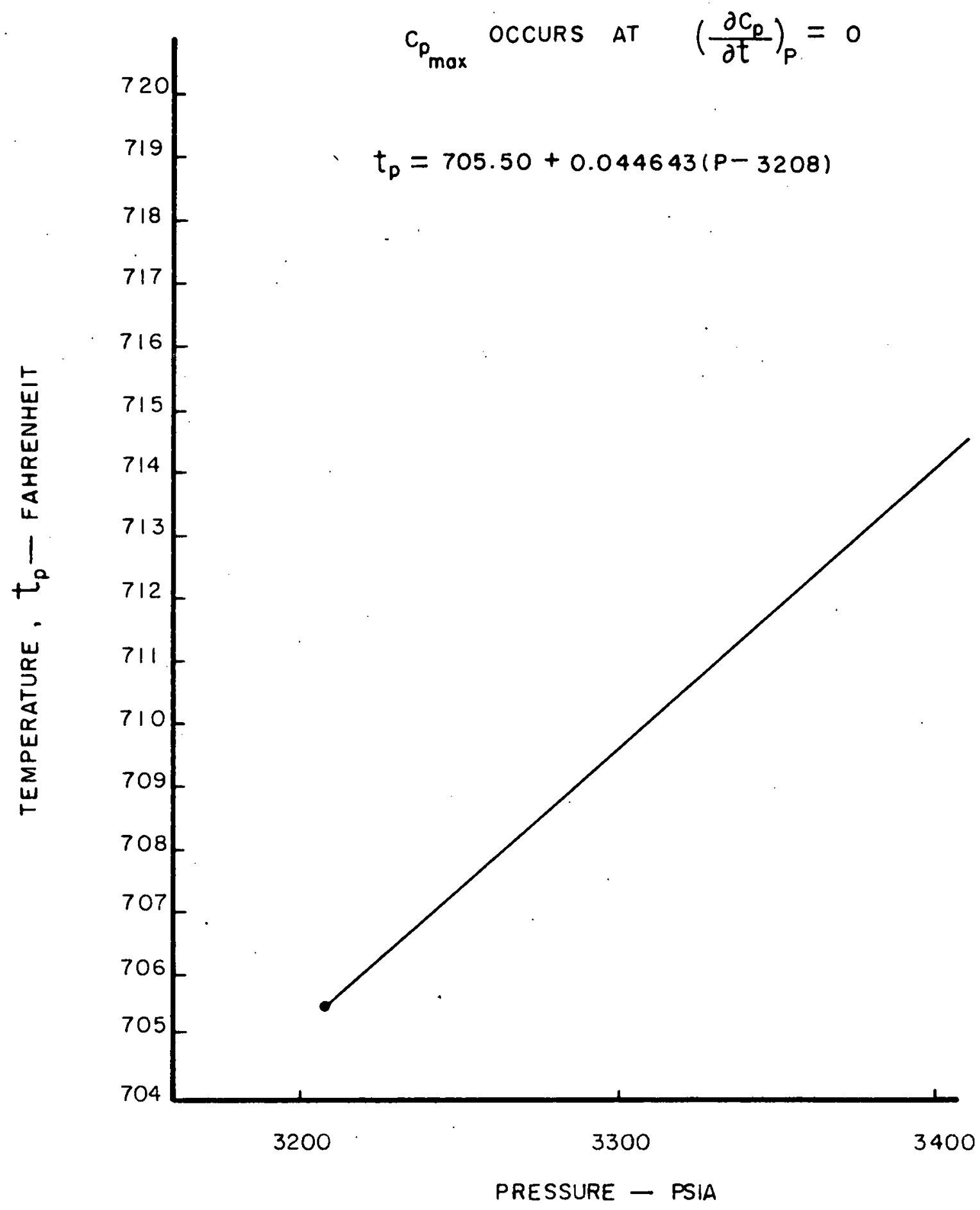

FIGURE 23 PRESSURE AND TEMPERATURE CORRESPONDING TO $C_{P_{\max }}$ ALONG ISOBARS 
enthalpy-pressure data for the critical region. Appendix $F$ discusses this point a little further.

\section{Computer Reduction of Experimental Data}

The Purdue University IBM 7094 digital computer was programmed to reduce sets of data and to compute various parameters of interest. The program was written in FORTRAN II compiler language and is presented in Appendix G.

The program consisted of two sections, run separately. The first part was designed to compute heat balances on the experimental runs. The heat balance program performed related computations and on the output described the various parameters of importance to heat balance computations such as the flow rate, heat generated, heat absorbed, and the heat balance error.

If the heat balance results were satisfactory, the entire wall thermocouple potentials and other data needed for reduction and analysis were fed into the second section. This program computed the inside wall temperatures, iterating for the correct mean temperature for the Kreith-Summerfield equation, the local wall heat fluxes, local fluid and wall enthalpies, local fluid temperatures; and many other parameters of interest for correlations. The ratio of the measured test section electrical resistivity over the average computed value was also calculated. Test section pressure drop, though not significant in some runs, was entered into the computations as a matter of routine.

Every effort was made to reduce man-handling of data reduction to eliminate mistakes and possibly some prejudice. All punched cards were 
double checked for accuracy. Thermocouple calibrations were also done on the computer.

Sample data reductions from $X E$ and $X F$ series are given in Appendix $\mathrm{H}$ together with an explanation of various computer input and output codes and symbols. Several sets of raw data are presented in Appendix I. However, space does not permit including all data. 
EXPERIMENTAL RESULTS, CORRELATIONS, AND DISCUSSION

The purpose of this section is to present and discuss the experimental findings and the correlations used in this work. To establish the validity and the integrity of the results for the near critical experiments, the isothermal friction factor and low temperature heat transfer results are presented first.

Isothermal measurements of the test section pressure drop, from which the friction factor was computed, were carried out at 50 psia, 61-89 F; 2000 psia, 297-425 F; and 3000 psia, 367-437 F. The results of these tests are presented in Figure 24, together with Prandtl's universal law of friction for smooth pipes. It is observed that, for the methods employed, there was very good agreement at Reynolds numbers less than $10^{5}$. The small discrepancy could be easily due to a small uncertainty in the test section diameter. In the section on data reduction it was pointed out that the fifth power of the diameter entered the computation. Thus, a one per cent error in the diameter would reflect as five per cent in the friction factor. At Reynolds numbers above $10^{5}$ the $X E$ test section still showed good agreement, but had a tendency to flatten out at a round $3 \times 10^{5}$. The $\mathrm{XF}$ test section demonstrated the characteristics of a rough tube, its friction factor having leveled off at the value of 0.018 . This should not be disturbing. Referring to the Moody chart for comnercial pipes 


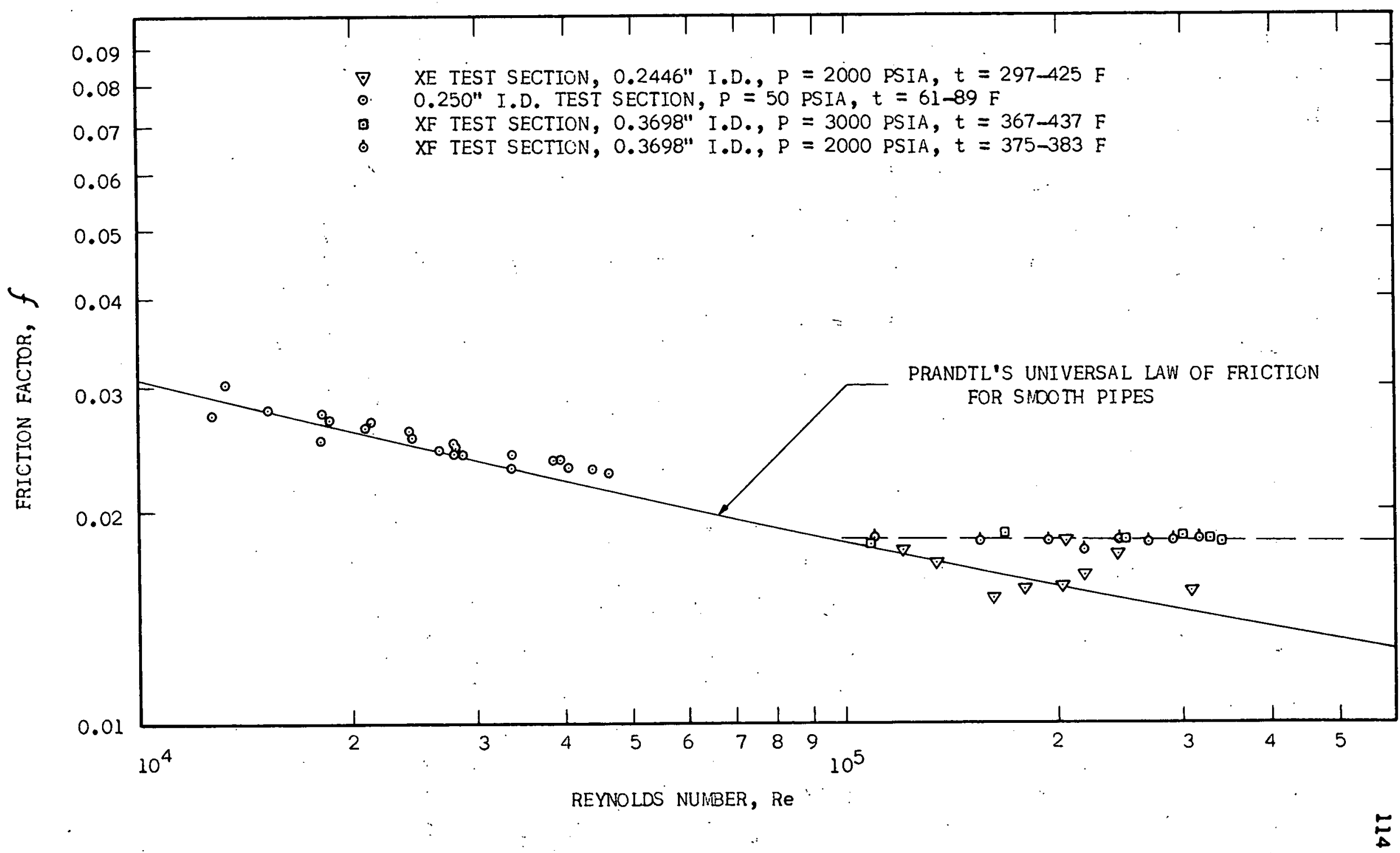

FIGURE 24. ISOTHERMAL FRICTION FACTOR FOR TEST SECTIONS 
It Is seen that the above corresponds to a relative roughness of 0.0007 , which upon multiplication by the diameter gives a roughness of 0.0003 inch. It is quite doubtful that the tube wall was any smoother. The measurements of the tube wall indicated that it had up to 0.0008 inch variations from the mean and that it was not axisymmetric. In the light of the above information the flattening in the friction factor mlght be expected. Thus, the results that are presented in the following apply to semi-smooth tubes.

The results of the heat transfer measurements at 3000 psia and 400-560 F tomperature range were compared with the Dittus-Boelter equation and showed good agreement. Figure 25 shows a typical case of the inside wall temperature, bulk fluid temperature, and the heat transfer coefficient distribution along the heated length of the tube. A large scale was employed to show the behavior of the variables. It is observed that the inside wall temperature increased smoothly except for a dip at a distance of 22 inches (or 59.5 length to diameter rat10) from the on-set of heating. The maximum varlation of the local heat transfer coefficients from the mean value along the tube did not exceed 10.5 per cent. This magnitude is nearly the same as the estimated experimental uncertainty. Such data, without any smoothing, were used in the evaluation of other parameters of interest. The low temperature data mere also compared with the equation suggested by Swenson et al., viz. 


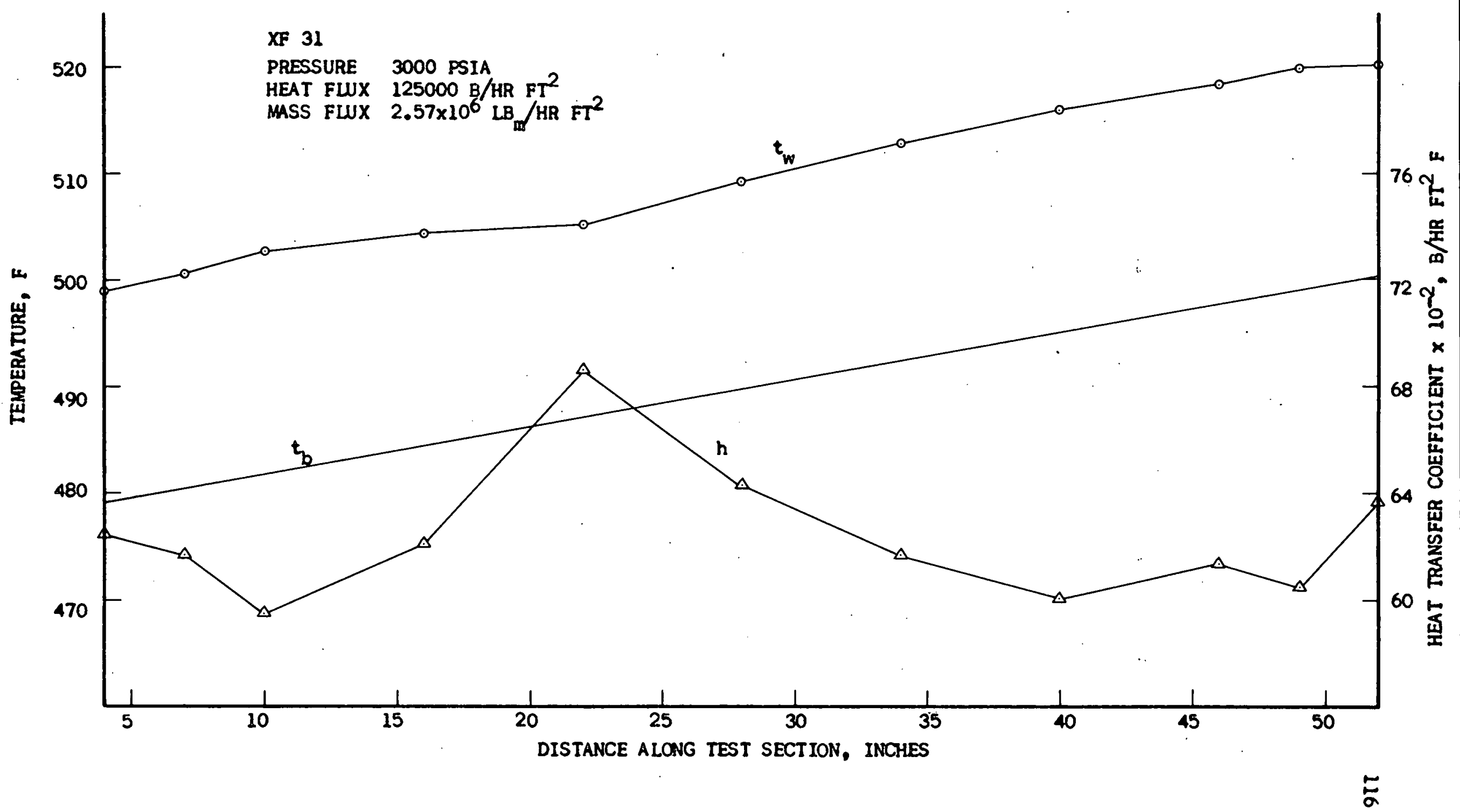

FIGURE 25. LOW IEMPERATURE HEAT TRANSFER RESULTS 


$$
N u_{w}=0.00453 \operatorname{Re}_{w}^{0.923}\left(\frac{\mu_{w}\left(H_{w}-H_{b}\right)}{\left(t_{w}-t_{b}\right) k_{w}}\right) 0.613\left(\frac{v_{b}}{v_{w}}\right)^{0.231}
$$

Figure 26 shows the comparison. Most of the data fell above the correlation line, but within 15 per cent of it. This was not as good as the Dittus-Boelter correlation where the rms deviation was around seven per cent. However, the above equation was not basically intended for pressures below 3300 psia.

The agreement of the low temperature data with the above correlations indicated that the operation of the equipment was satisfactory and that higher temperature data could be obtained and reduced with some confidence. Also, it appeared that the fluid vibrations present in the system did not have a significant influence upon the heat transfer coefficient. This is certainly correct if other data used in the correlations were obtained under conditions where such perturbations were not present. Otherwise, the above conclusion is not valid.

The behavior of the wall temperature and the heat transfer coefficient along the length of the XF test section with inlet temperature of around $665 \mathrm{~F}$ is shown in Figure 27. It is observed that there is little difference between the shape of the heat transfer coefficient in the central portion of the tube for this run and the lower temperature run depicted in Figure 25. Except for the different pressures, the mass flux was nearly constant and the heat flux was increased by about fifteen per cent to provide the higher temperature at the inlet. However, the shape of the " $h$ " profile close to the inlet and the outlet 


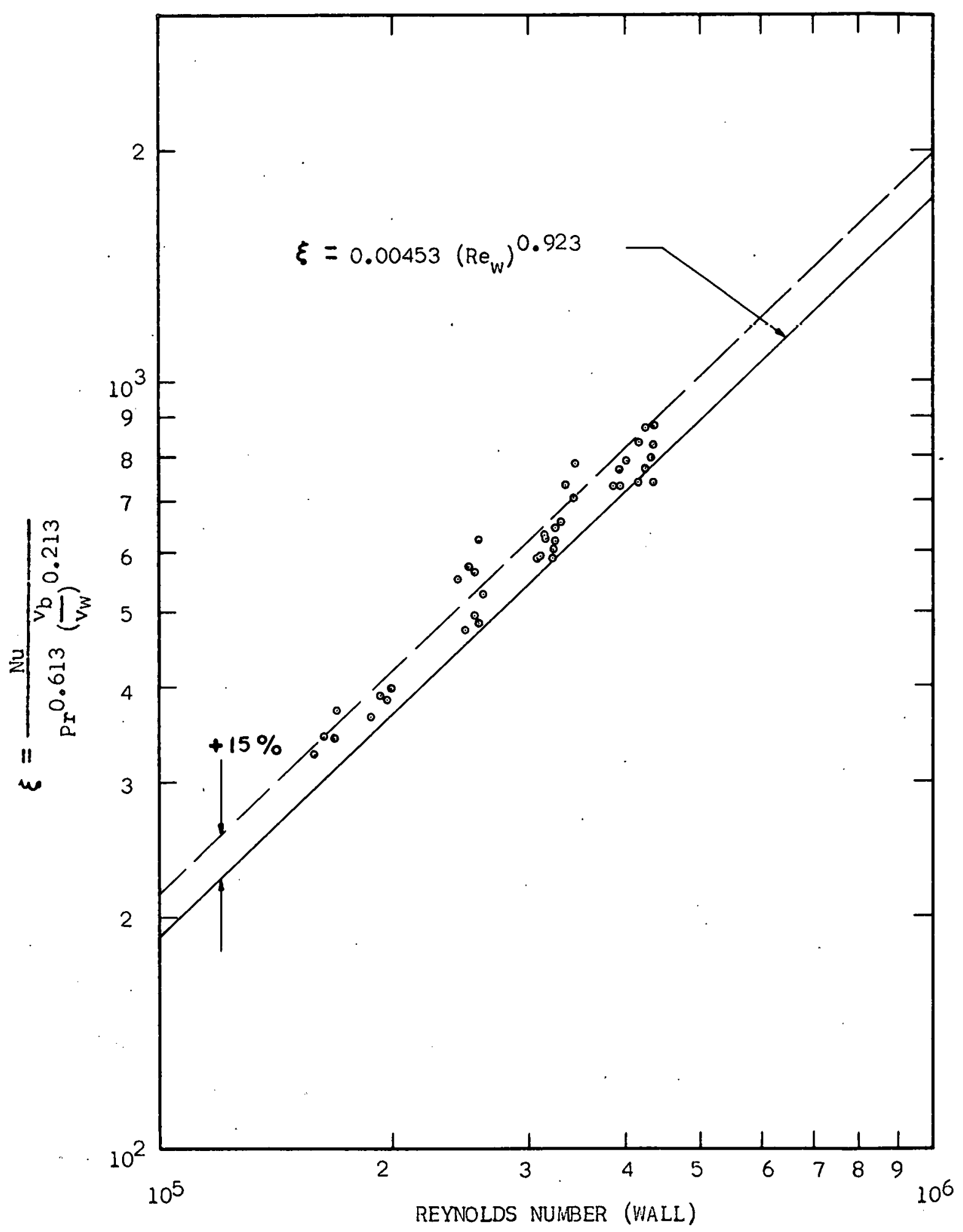

FIGURE 26. COMPARISON OF LOW TEMPERATURE DATA WITH THE EQUATION OF SWENSON ET AL. 


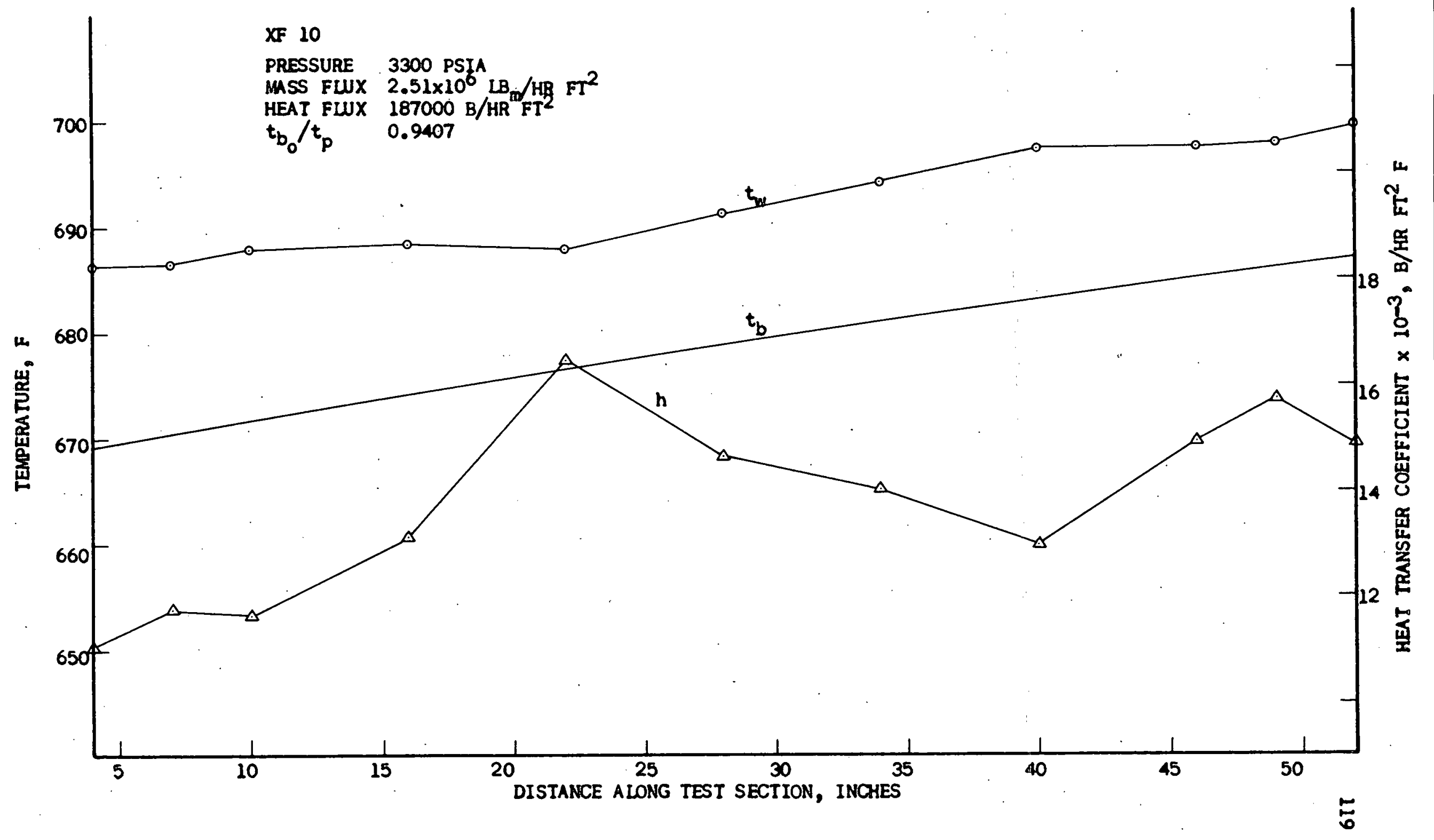

FIGURE 27. HEAT IRANSFER RESULTS FOR RUN XF 10 
was somewhat different. It appeared that such a behavior was characteristic of low surface to bulk temperature differences. Figure 28 shows similar results for run $X E 4$ where large heat and mass fluxes were imposed. The fluid inlet temperature in reduced $\left(t_{b} / t_{p}\right)$ form was 0.8532 as compared to 0.9407 for run $X F 10$. It is observed that the "h" profile was distinctly different. The wall to bulk temperature differences for run XE 4 were more than twice as much as for runs XF 31 and XF 10. The larger heat transfer coefficients in Figure 27 were undoubtedly due to the small temperature differences. The increase in the heat transfer coefficient close to the outlet seemed to be due to the wall temperature reaching closer to the peak temperature.

When the wall temperature is near the peak temperature, the fluid in contact with it becomes a better heat transfer medium and the heat transfer coefficient is increased to the extent that the wall temperature tends to flatten out. This point is well demonstrated in Figure 28 where, despite the very high heat flux, the wall temperature gradient along the tube becomes very small. This effect could not be attributed to the fluid since the bulk fluid temperature was still quite remote from the peak temperature. The reader must be reminded that this study.concerned itself also with wall temperatures near the peak temperature.

A plot of the Stanton parameter $S t_{e}$, previously defined as

$$
s t_{e}=\frac{q_{w}^{\prime \prime}}{\left(H_{w}-H_{b}\right) G}
$$




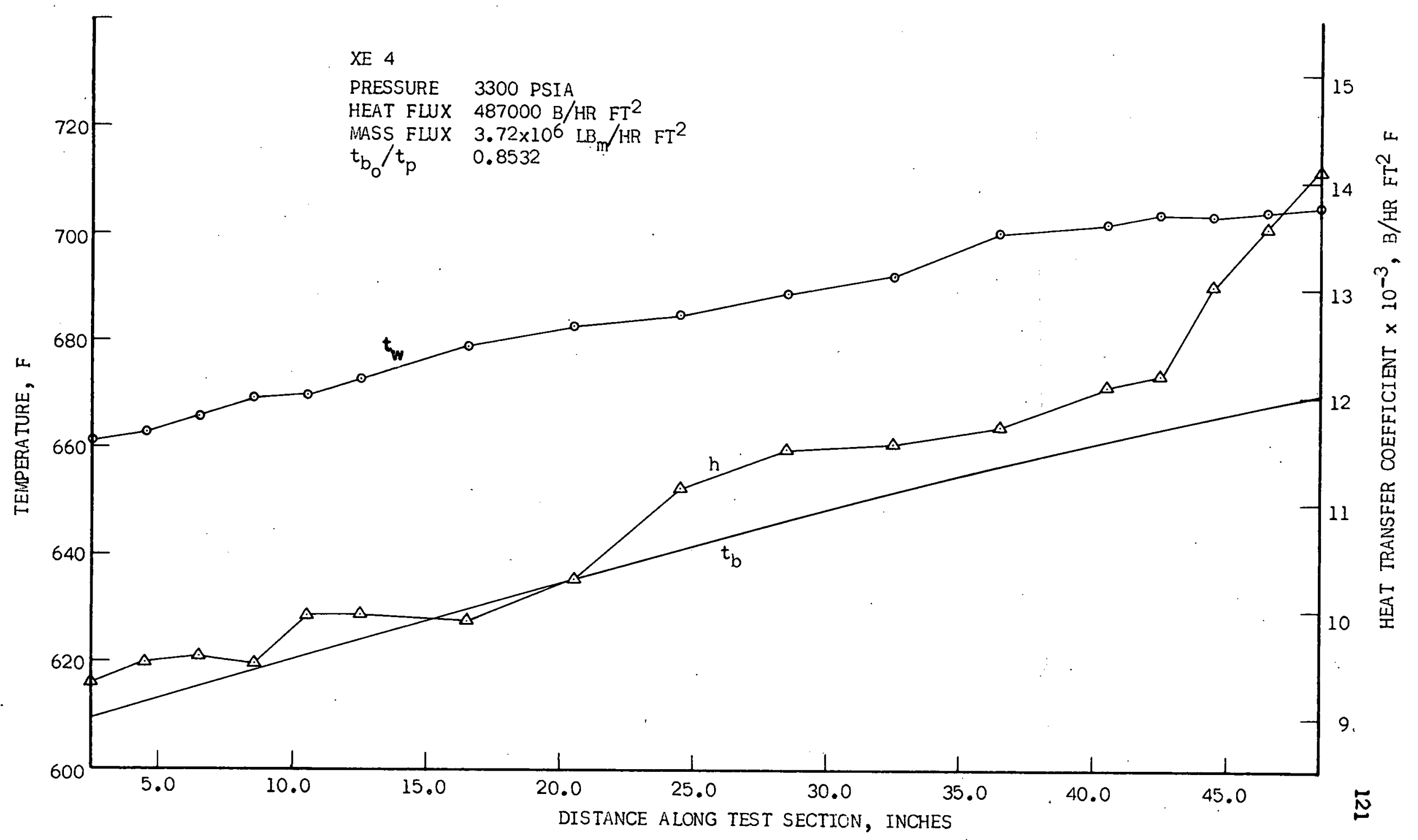

FIGURE 28. HEAT TRANSFER RESULTS FOR RUN XE 4 
versus tube length-over-diameter ratio is presented in Figure 29 for the runs discussed above. The very distinct behavior of XE 4 as compared with XF 10 and XF 31 is observed. The effect of wall to bulk fluid temperature is well illustrated. As $\left(t_{w}-t_{b}\right)$ is increased the Stanton number levels off. On the average the film temperature difference for the runs $X F 10, X F 31$, and $X E 4$ were 14,20 , and $41 \mathrm{~F}$ respectively. It must also be noted that the effect presented in Figure 29 was by no means associated with the proximity of fluid and/or surface temperature to the peak temperature since the fluid and wall temperatures for runs $X E 4$ and $X F 10$ were in the same range and XF 31 was a low temperature run. An estimate of the uncertainty in the film temperature difference, and hence in the heat transfer coefficient and the various parameters employed in this work, is presented in Appendix $\mathrm{J}$.

The next series of plots show the behavior of the bulk and wall temperatures and the heat transfer coefficient under near critical operations. The effect of various parameters upon the heat transfer coefficient is illustrated. - In contrast to Figure 28, Figure 30 shows a hump in the heat transfer coefficient profile around the center section of the tube. The heat flux may be considered as constant since the change in it was less than four per cent. Because in general the effect of the lower mass flux should be a decrease in the heat transfer coefficient, it may be concluded that the higher heat transfer coefficient and the hump were due to the proximity of the fluid temperature to the peak temperature. It may be hypothesized that the hump occurs where the optimum conditions for the transfer of heat from the 


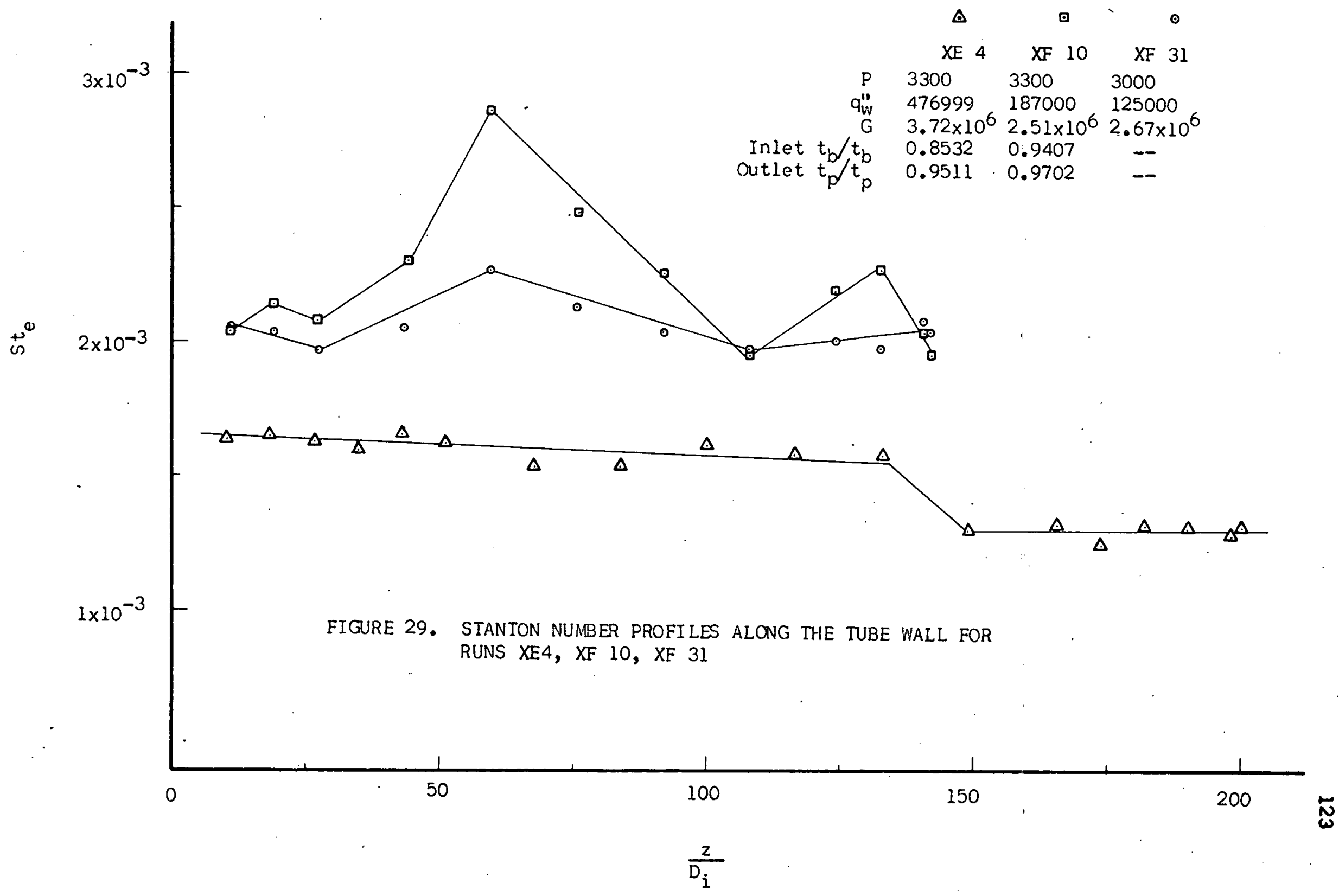




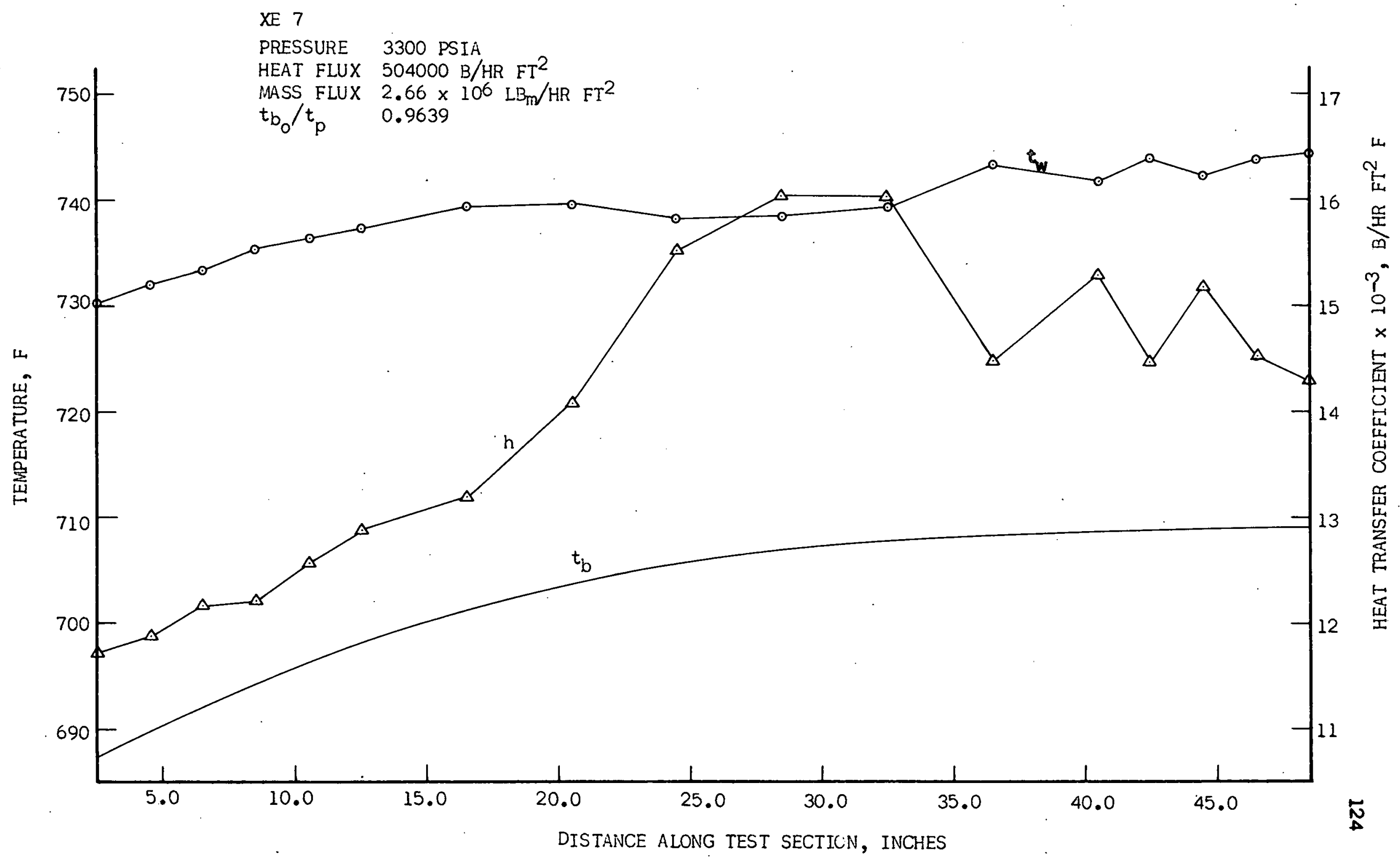

FIGJRE 30. HEAT TRANSFER RESULTS FOR RUN XE 7 
wall to the fluid stream are reached. Figure 31 shows a widening of the hump as the inlet fluid temperature gets closer to the peak temperature. The hump also moved left where conditions were optimum. The widening could be also attributed to the decrease in the heat flux which allowed a slower increase in the fluid and wall temperatures. A reduction in the magnitude of the heat transfer coefficient was also observed. Since the wall temperature in Figures 30 and 31 remained. virtually constant, the decrease in the heat flux may be cited as the reason. However, the flow rate may be thought to have contributed to the decrease also.

Figures 32,33 , and 34 illustrate further the effect of the ratio $t_{b} / t_{p}$ upon the heat transfer coefficient profile along the tube. The heat flux and the mass flux were maintained nearly constant. As $t_{b} / t_{p}$ approached unity the hump in the heat transfer coefficient curve flattened out and moved to the left. Figure 34 shows a decreasing $h$ curve along the entire tube length. It should also be observed that the wall temperature, being now further away from the peak temperature, has a smooth increasing gradient.

Stanton number profiles for the above runs together with several other typical runs are shown in Figure 35. The conditions for each run are summarized in the accompanying table. The illustration provides for easy determination of the effect of various independent variables upon the Stanton number. A comparison of XF 42 and $X F 39$ revealed that a larger $t_{b} / t_{p}$ ratio at the inlet tended to increase the stanton number; or comparison of XF 39, XF 36, and XE 28 showed that for nearly constant $t_{b} / t_{p}$ the stanton number decreased non-linearly with decreasing $\frac{q_{w}^{\prime \prime}}{G}$ ratio. 


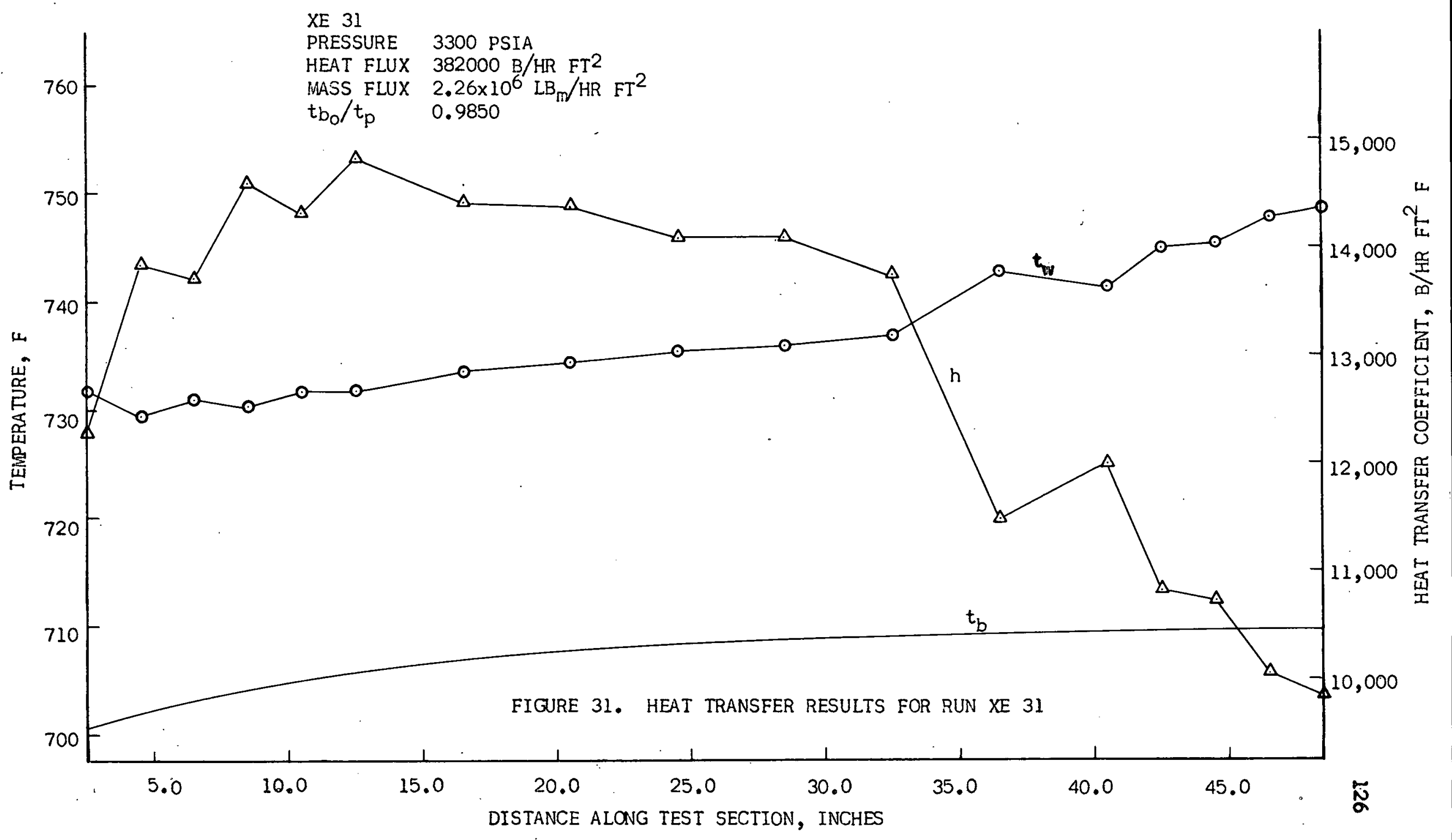




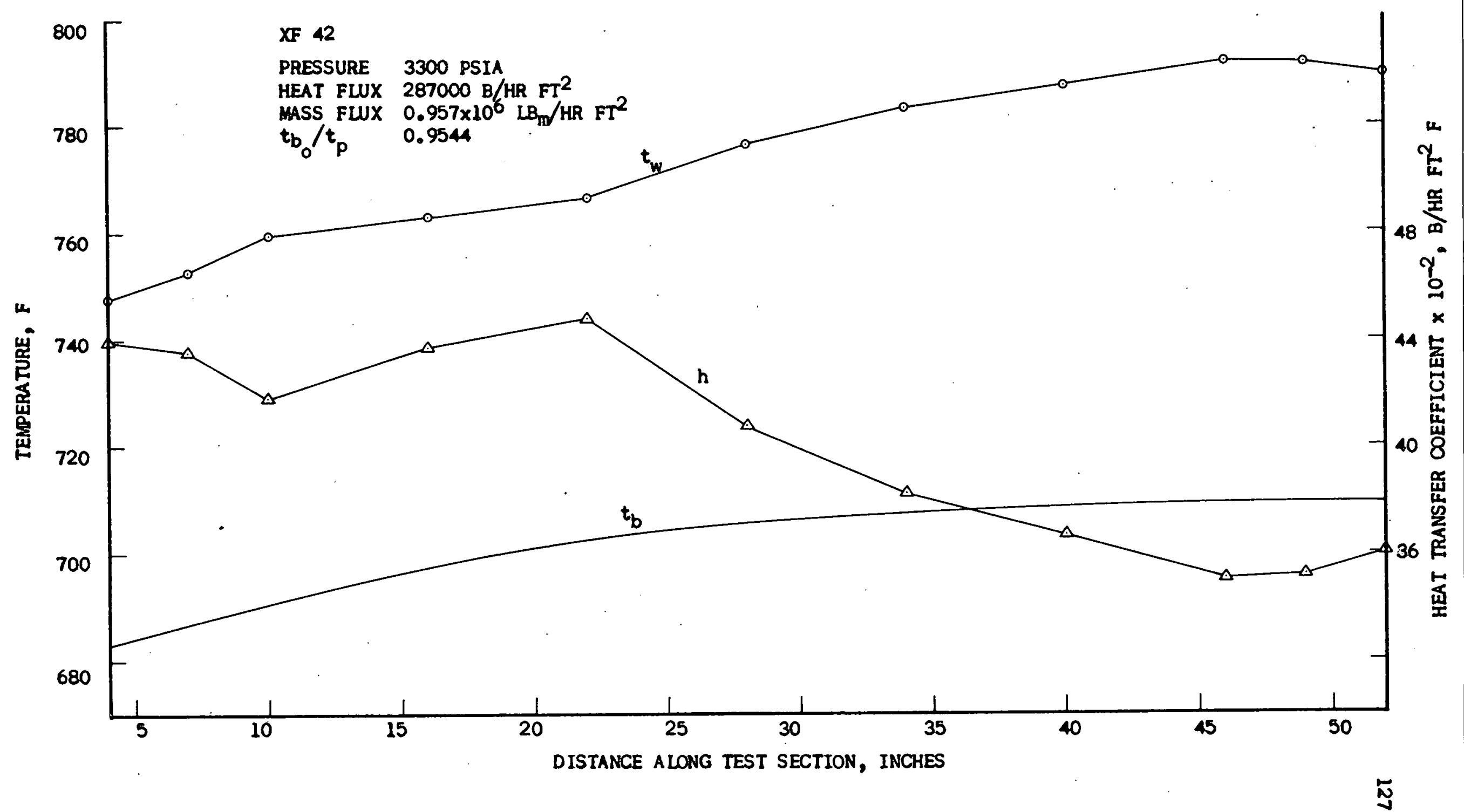

FIGURE 32. HEAT TRANSFER RESULTS FOR RUN XF 12 


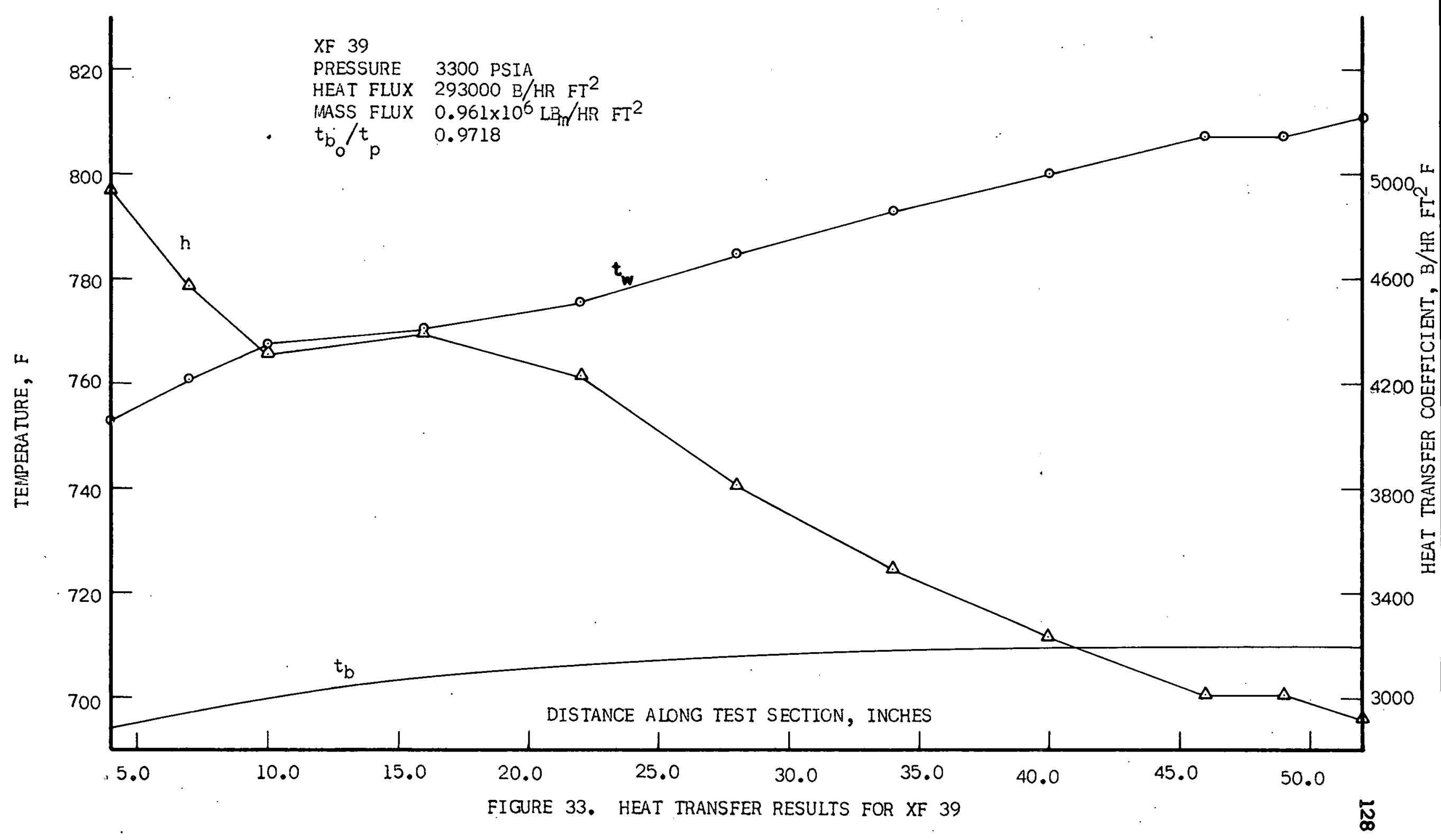




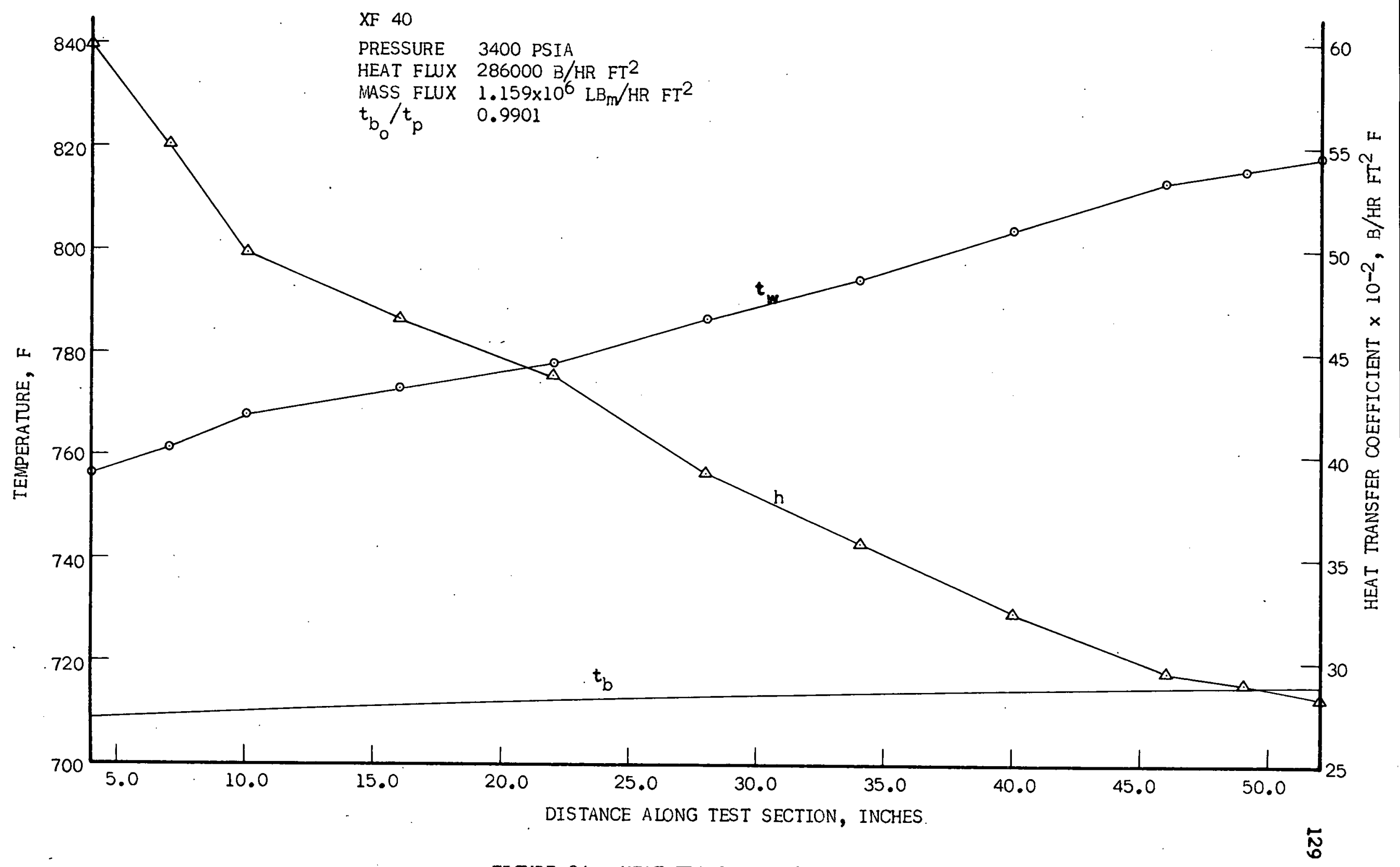

FIQURE 34. HEAT TRANSFER RESULTS FOR XF 40 


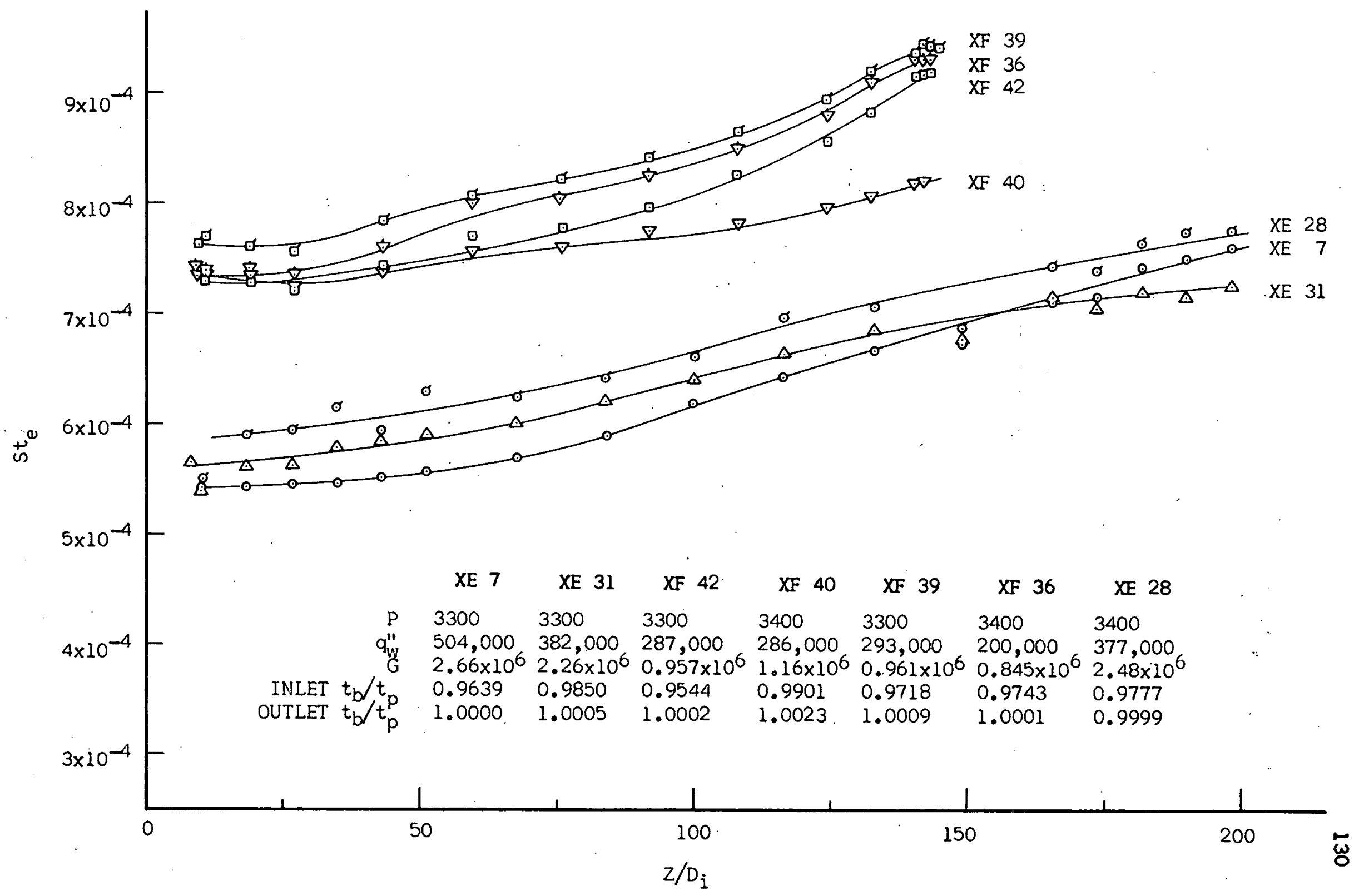

FIGURE 35. STANTON NUPABER PROFILES FOR.RUNS XE 7, XE 28, XE 3i; XF 36, XF 39, XF 40, XF 42 
In concluding this part of the presentation of the results, it should be stated that the data of this investigation did not substantiate the findings of Swenson et a1. (14) in regard to the general behavior of the heat transfer coefficient. Their data showed a decrease in the heat transfer coefficient along the tube length followed by continuous increase starting at 57 diameters down-stream from the on-set of heating for inlet temperatures below the peak temperature. No such behavior was observed in the present investigation. The data were compared with the correlations of Dittus-Boelter and Swenson et a1. Figure 36 shows the comparison of both the low and high temperature data with the Dittus-Boelter equation. It was found that good agreement was obtained for the low temperature data together with other test data up to a temperature of $650 \mathrm{~F}$ or $\mathrm{Pr}_{\mathrm{b}}=1.20$. Beyond this limit a rather rapid disagreement was in evidence.

Figure 37 gives a comparison of the high temperature data with the correlation of Swenson et al. Good agreement existed even beyond the tested range of the correlation. However, a rapid deterioration at the near critical temperatures was observed. Figure 38 shows a plot of the Nusselt number as computed from equation (25) versus the Nusselt number obtained from the measurements. No fixed point for the beginning of the disagreement may be given in terms of the Nusselt number. Experience showed that discrepancy started at the near critical temperatures, more specifically above $690 \mathrm{~F}$. Figure 38 shows deviation starting at around $\mathrm{Nu}_{w}=1500$ for bulk fluid temperatures close to the peak temperature, but the wall temperature well above the peak temperature. Larger deviations occurred at higher 


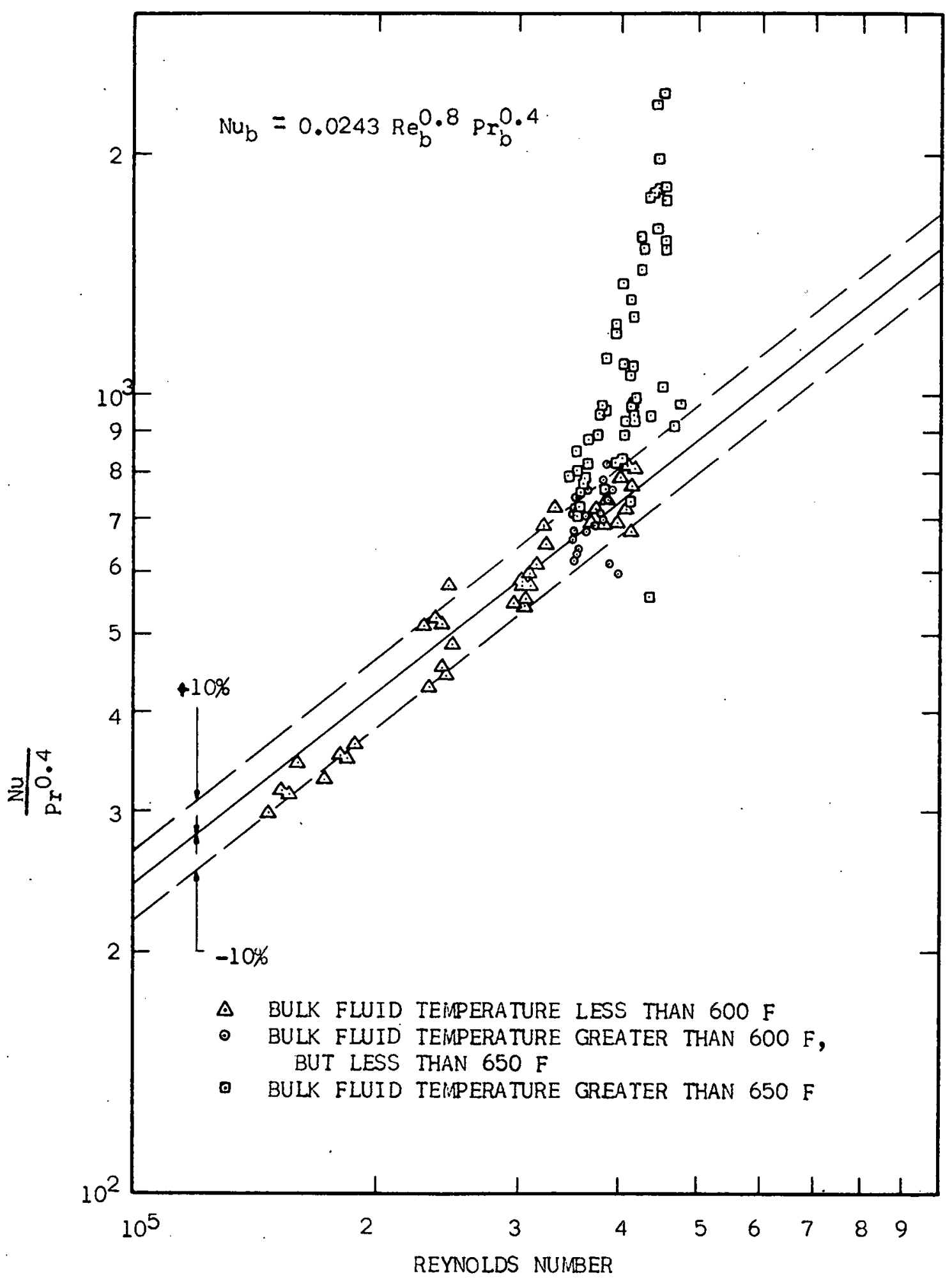

FIGURE 36. COMPARISON OF DATA WITH THE DITTUS-BOELTER CORRELATION 


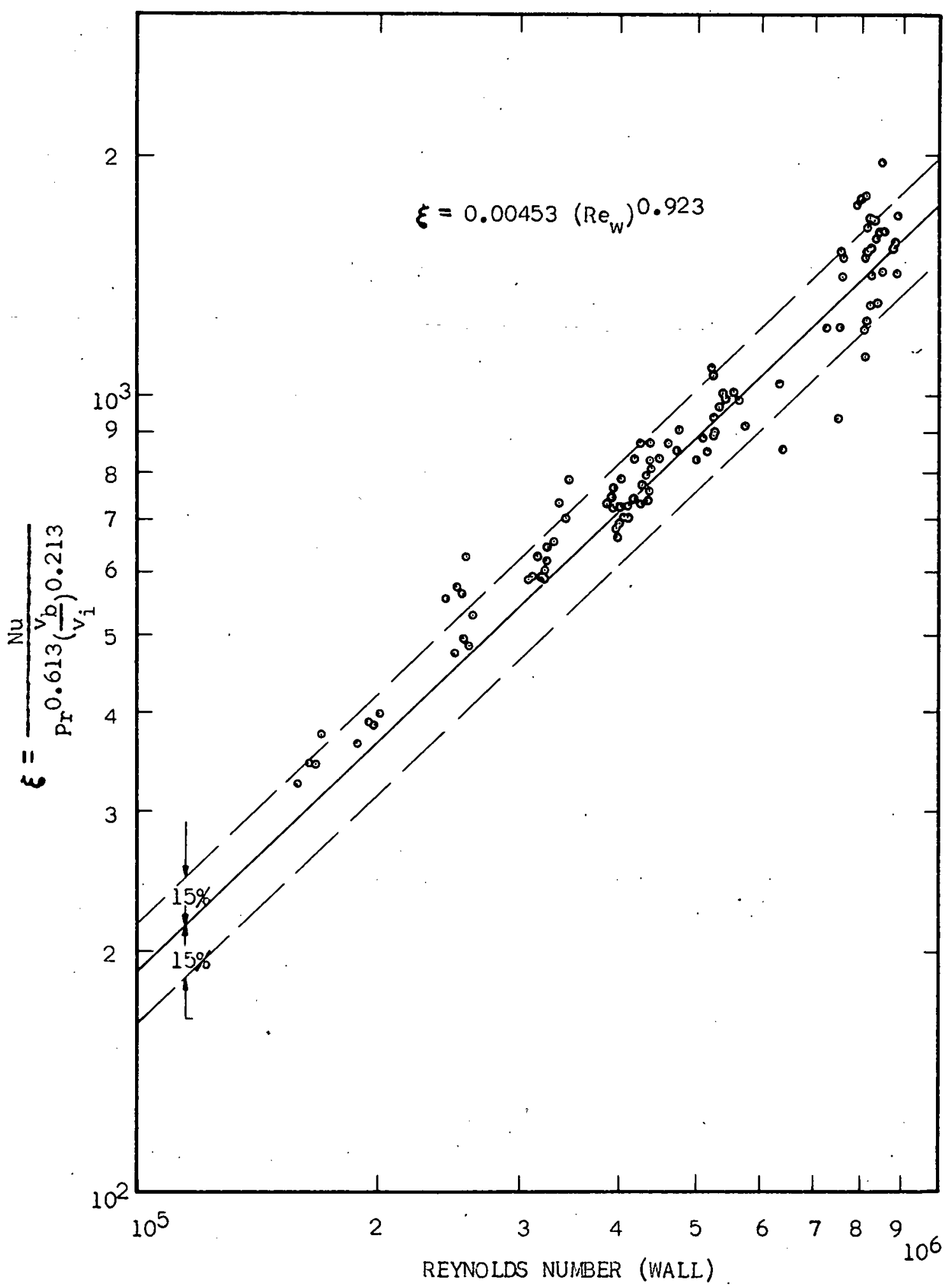

FIGURE 37. COMPARISON OF HIGH TEMPERATURE DATA WITH THE CORRELATION CF SWENSON ET AL. 


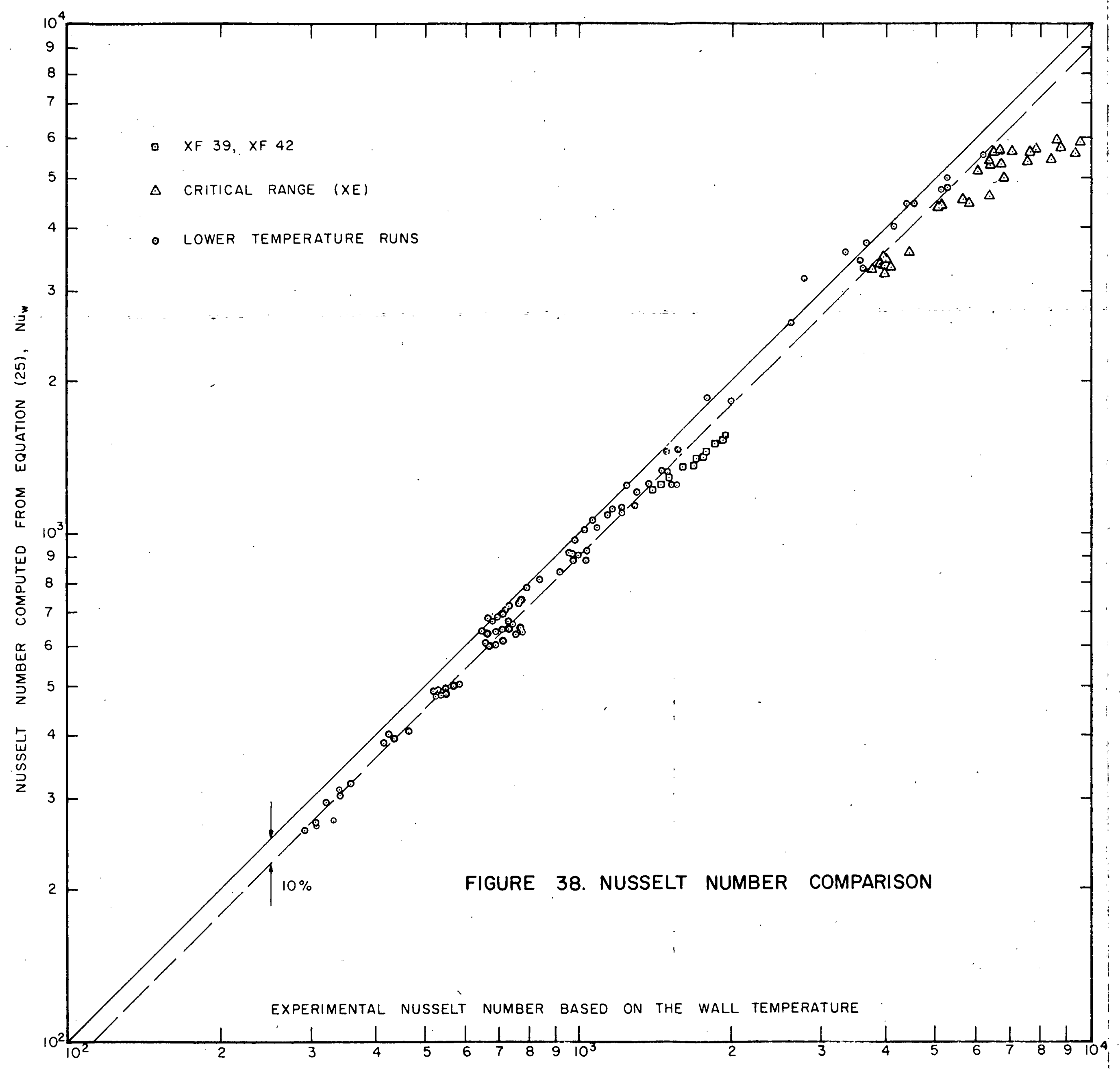


Nusselt numbers. resulting from conditions where both the bulk fluid and the wall temperatures were in the proximity of the peak temperature. The data used in conjunction with the correlation of Swenson et al. were taken from the downstream half of the tube as the correlation called for.

Figures 39 and 40 show an example of the behavior of the wall temperature and the heat transfer coefficient for small wall to bulk fluid temperature differences in the critical region. It is observed that the wall temperature gradient along the tube was very small. The heat transfer coefficient showed an increasing trend as the fluid temperature approached the peak temperature. It is evident that the heat transfer process becomes more efficient when both the wall and fluid temperatures are near the peak temperature. The experimental heat transfer coefficients obtained under such conditions were generally more than one and one half times as large as the values computed from the available correlations.

The stanton number profiles along the tube length for runs $X F 18$ and XE 25 are shown in Figure 41. The profile for run XF 18 may be compared with the profile for run XE 7 shown in Figure 35 . Except for the heat flux all other pertinent variables were nearly constant. Once again the influence of small wall to fluid temperature differences upon the heat transfer coefficient and the Stanton number is evident.

Several correlations of the data of this investigation are presented in the following. In general the data for which the estimated uncertainty in the heat transfer coefficient exceeded 25 per cent 


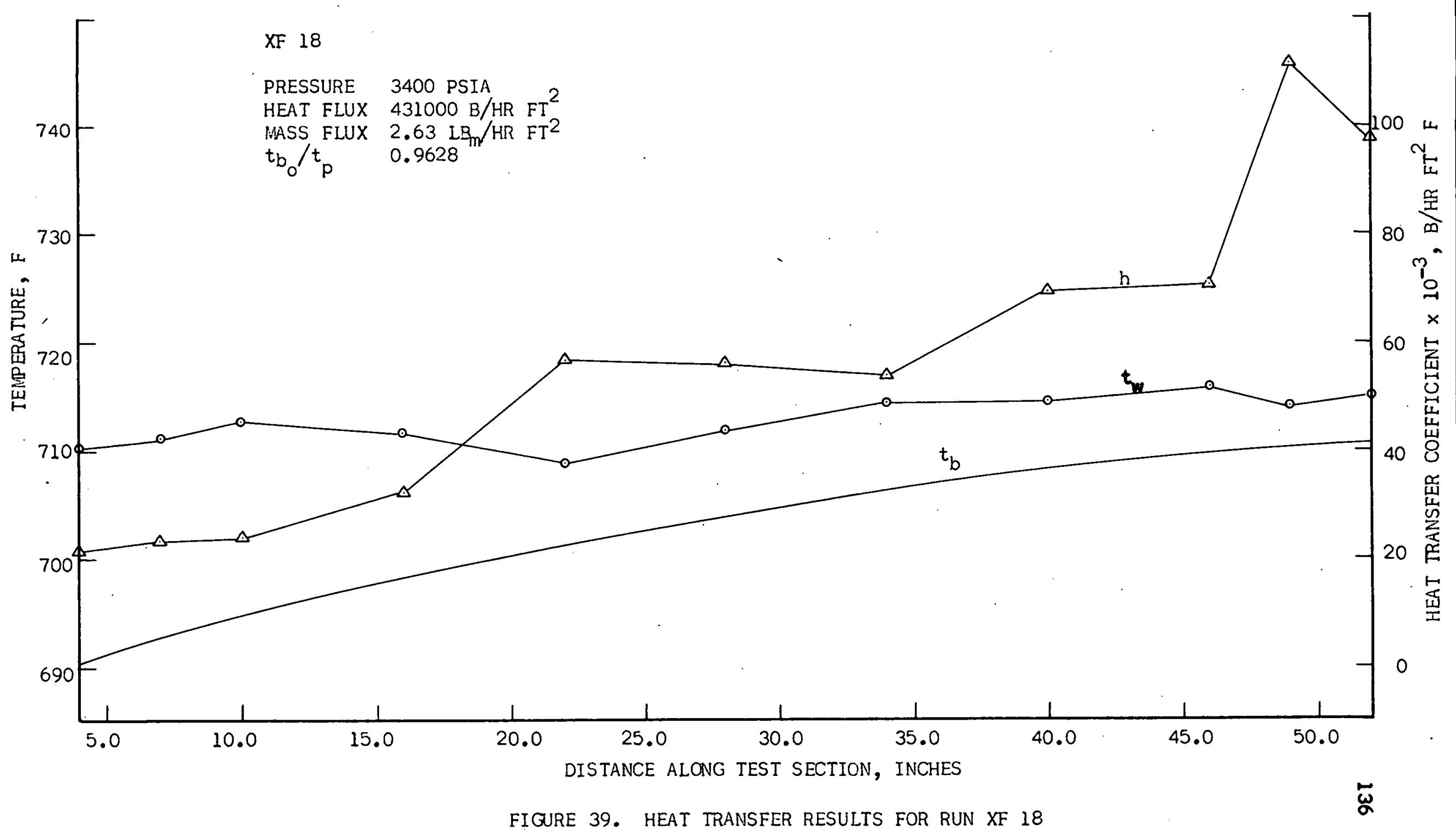




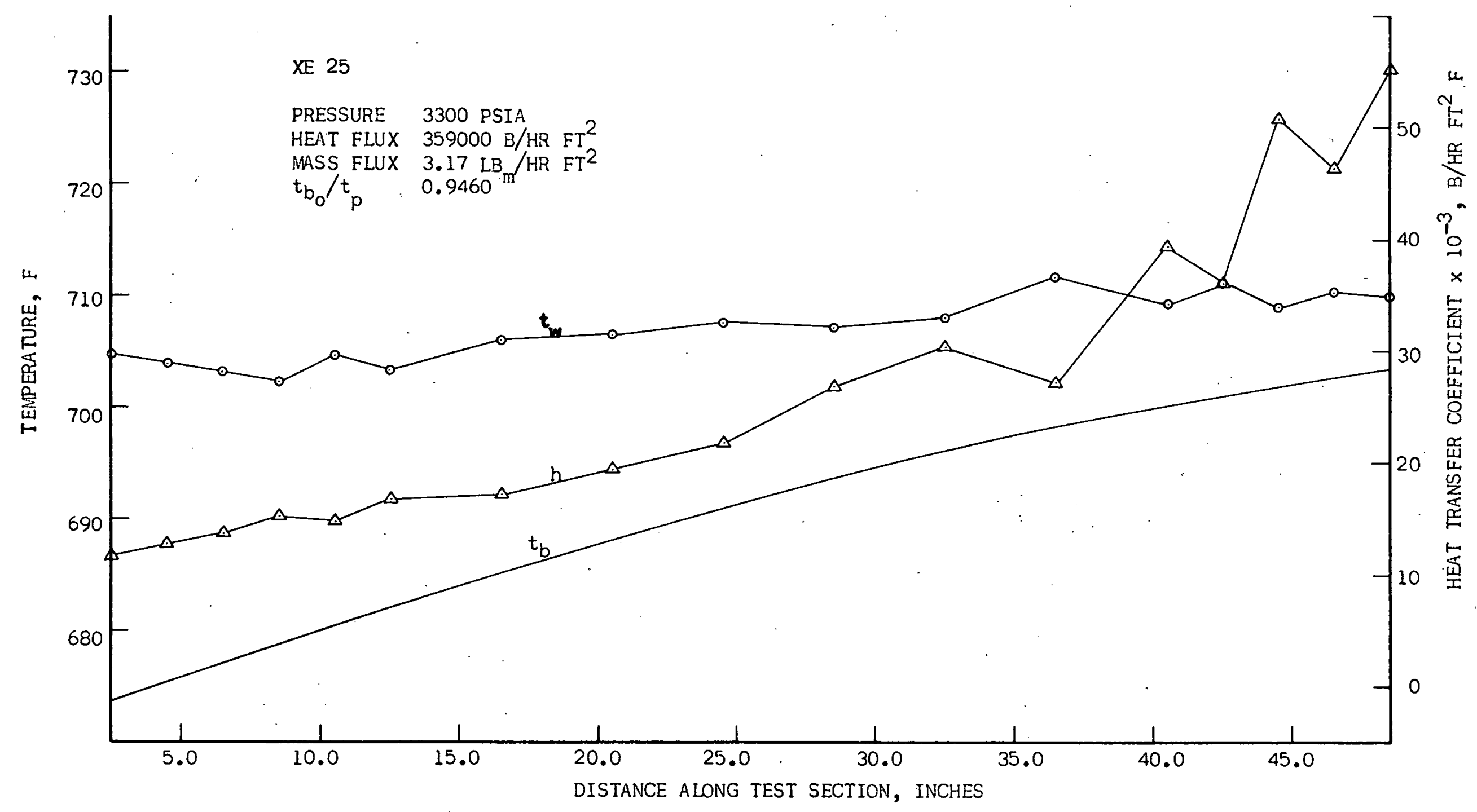

HEAT FLUX $359000 \mathrm{~B} / \mathrm{HR} \mathrm{FT}^{2}$

MASS FLUX $3.17 \mathrm{LB} / \mathrm{HR} \mathrm{FT}^{2}$

FIGURE 40. HEAT TRANSFER RESULTS FOR RUN XE 25 


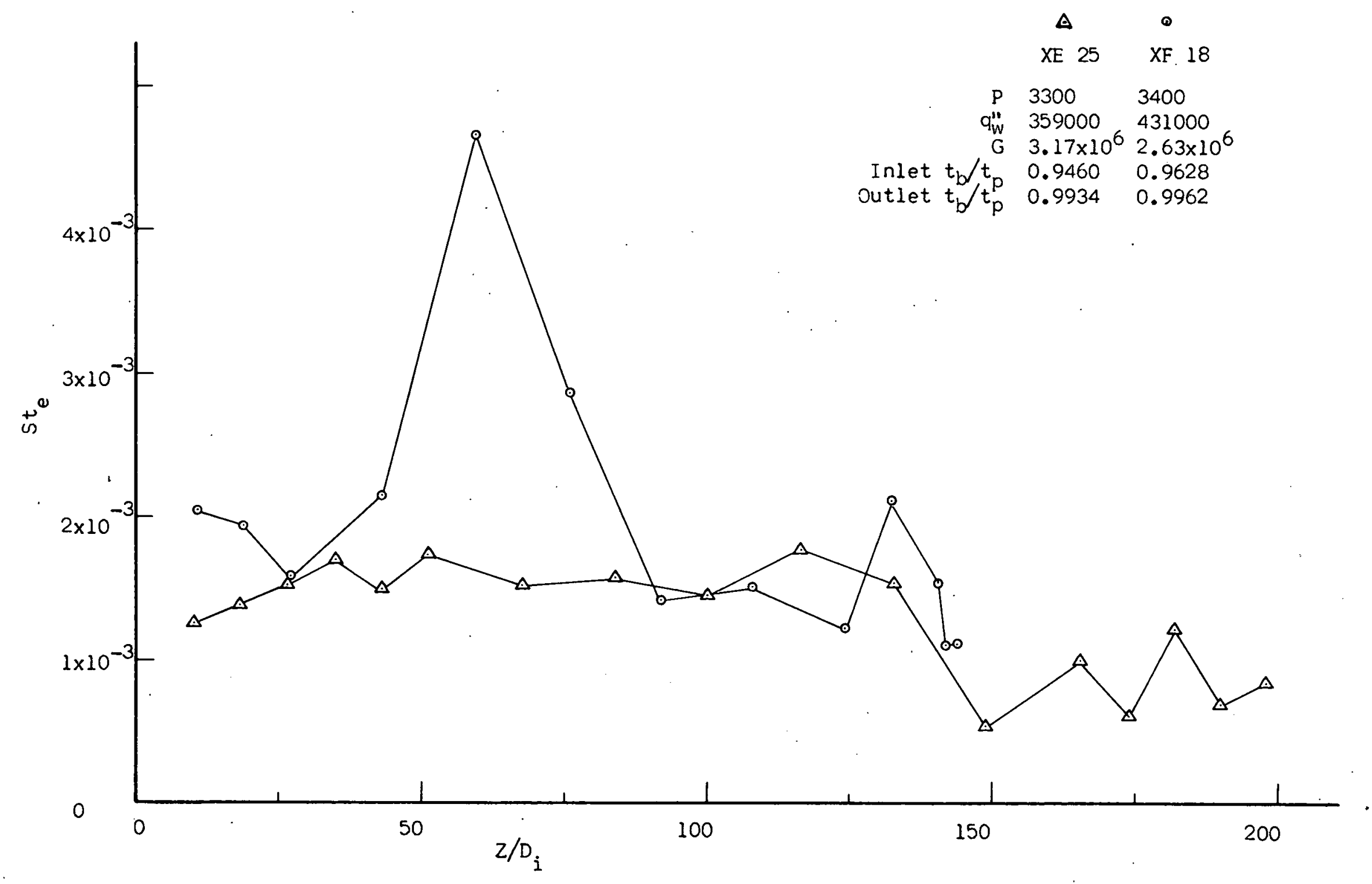

FIGURE 41. STANTON NUMBER PROFILES FOR RUNS XE 25, XF 18 
were excluded. This included the runs having small film temperature drops.

Figure 42 illustrates one possible method of correlation proposed in this work. The average Stanton number, previously defined as

$$
\overline{s t} \equiv \frac{\overline{\mathrm{h}}}{\overline{c_{p}} \mathrm{G}}
$$

was plotted against $\frac{\bar{t}_{b}}{\bar{t}_{p}}$ which signifies the ratio of average fluid temperature between stations $z+\Delta z$ and $z$, and the peak temperature corresponding to the prevailing average pressure. At $\frac{\bar{t}_{b}}{\bar{t}_{p}}$ less than 0.93 the Stanton number may be considered as constant for a limited range of variables. The data scatter was within \pm 10 per cent of the mean for $\frac{\bar{t}_{b}}{\bar{t}_{p}}$ not exceeding 0.98 . Beyond this limit the average. Stanton number decreased rapidly and larger scatter was observed. This correlation provides a simple method for presenting the near critical data. It may be improved and extended in range by adjusting the ordinate for the Reynolds number effect. This is not done here since a better method of correlation is presented later.

Another useful and simple correlation is presented in Figure 43, where the average stanton number was plotted against $\frac{\bar{t}_{p}-\bar{t}_{b}}{\bar{t}_{w}-\bar{t}_{b}}$. Again, to obtain a better fit and a wider range proper adjustment for the Reynolds number effect must be provided. However, in their present forms the above correlations included most of the data within ten to fifteen per cent. The "specific heat-like" behavior in the proximity of the peak temperature, arising from the definition of $\overline{S t}$, seemed to be the main disadvantage of the correlations. 


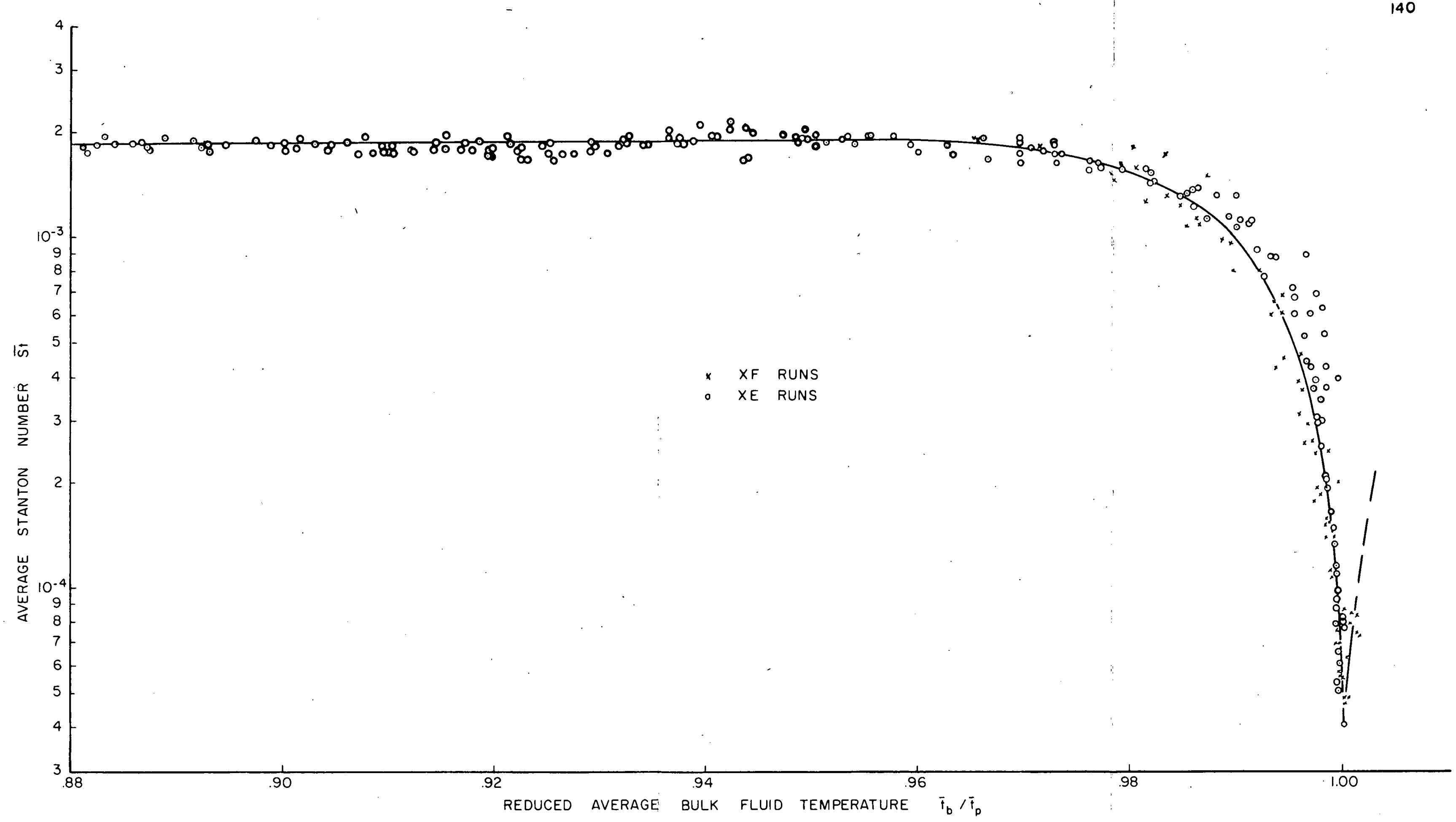

FIGURE 42. AVERAGE STANTON NUMBER VERSUS REDUCED BULK FLUID TEMPERATURE. 


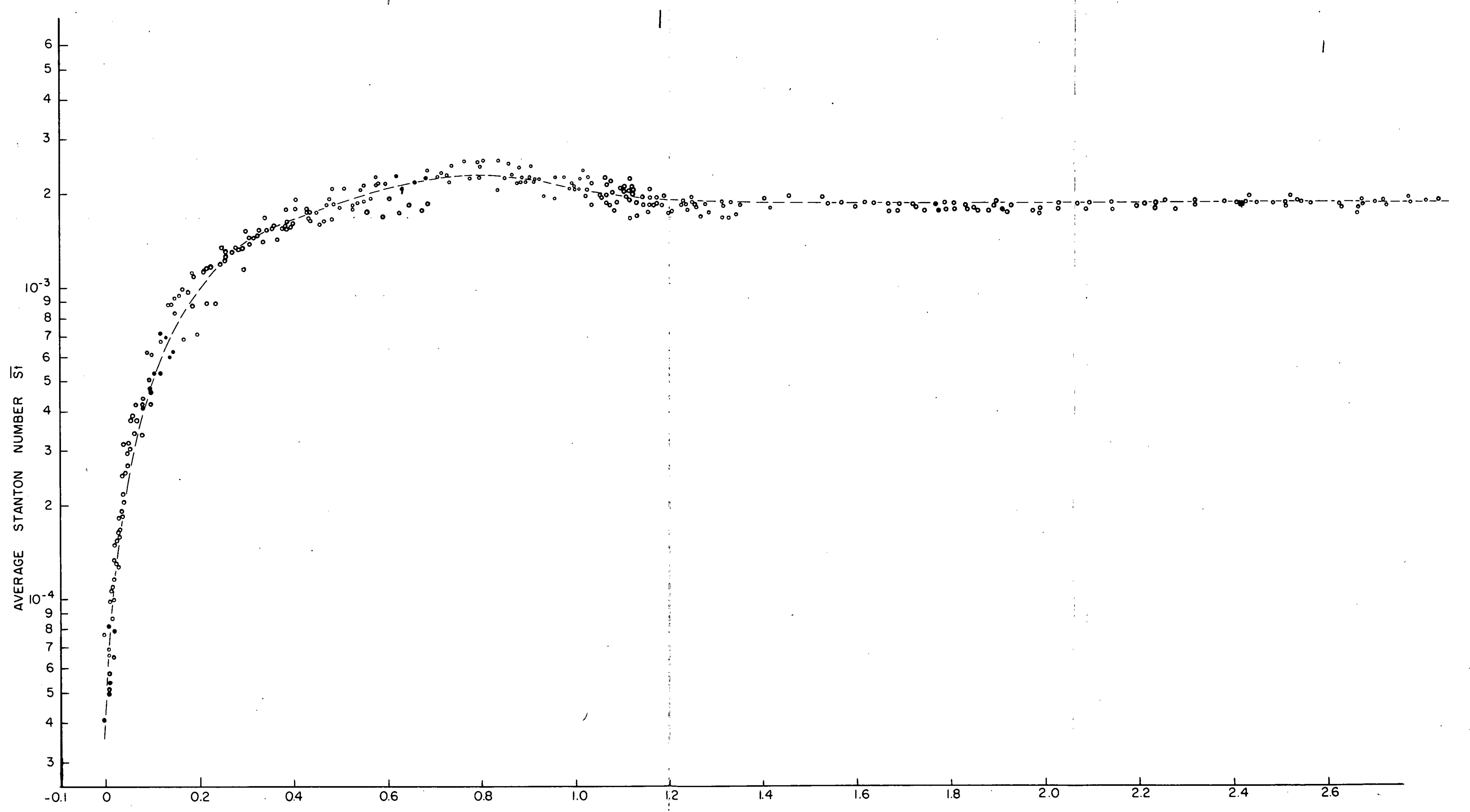

FIGURE 43. AVERAGE STANTON NUMBER VERSUS $\frac{t_{p}-\bar{t}_{b}}{\bar{f}_{w}-\bar{t}_{b}}$ 
Figure 44 presents two correlations for heat transfer to water in the critical region. It is seen that the upper plot, based on bulk fluid properties, correlates nearly all the data within $\$ 16$ per cent. Some scatter at lower enthalpy values was primarily due" to small film temperature drops. The lower plot was based on properties. evaluated at the wall temperature, and correlated most of the data. within $\$ 15$ per cent. The correlation equations are:

$$
\begin{aligned}
& S t_{e} \operatorname{Re}_{b}^{0.2}=0.0068 \exp \left[0.242\left(H_{b}-725\right) \times 10^{-2}\right] \\
& S t_{e} \operatorname{Re}_{w}^{0.2}=0.0080 \exp \left[0.169\left(H_{w}-1010\right) \times 10^{-2}\right]
\end{aligned}
$$

The data shown in Figure 44 are for 3300 psia pressure; however, the above equations also correlated the data of other pressures in the range $3220-3400 \mathrm{psia}$. The data from the entire length of the tube except for about eight diameters at the inlet and outlet were included. This was done to eliminate the possible effect of heat loss from the ends. At present the range of the equations is limited to the extent of data shown in Figure 44. The lower limit of $H_{b}=725 \mathrm{~B} / 1 b_{m}$ and $H_{w}=1010 \mathrm{~B} / 1 b_{m}$ must be observed.

The range and validity of the correlations may be increased somewhat by using $H_{p}$ to non-dimensionalize the enthalpy term in the exponent. An estimate of the peak enthalpy may be obtained from Figure F-1. Under this transformation equation (63) changes to:

$$
S t_{e} \operatorname{Re}_{b}^{0.2}=0.0068 \exp \left[2.19\left(\frac{H_{b}}{H_{p}}-0.801\right)\right]
$$

The uncertainty in $\mathrm{H}_{\mathrm{p}}$ was estimated at less than two per cent. 

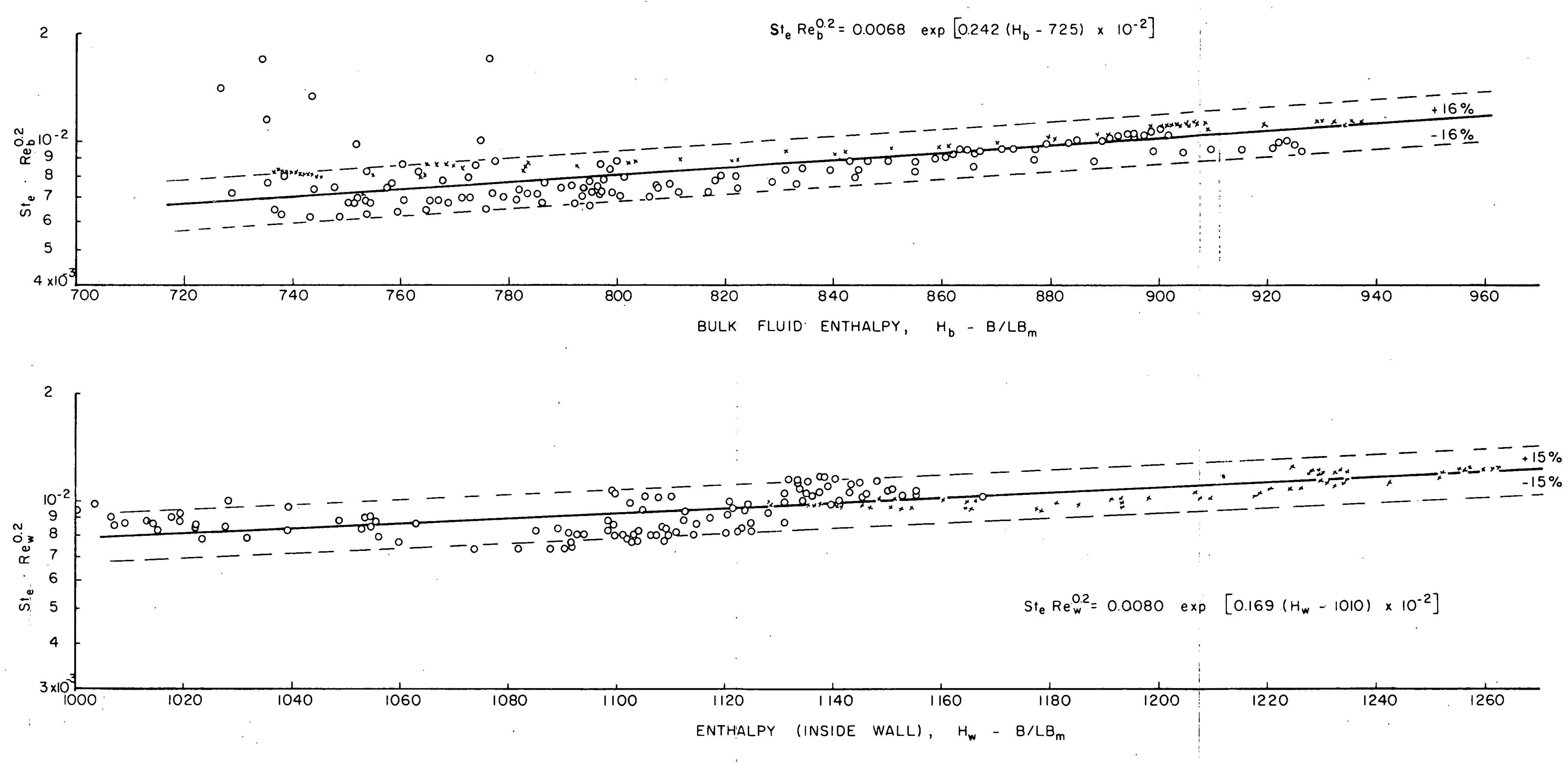

FIGURE 44. CORRELATION OF NEAR CRITICAL HEAT TRANSFER DATA 
Some experimental heat transfer results for carbon dioxide taken from the works of Koppel, Wood, and Smith were compared with values computed from equation (65). Despite inadequate knowledge of $\mathrm{H}_{\mathrm{p} \text { g }}$ good agreement (well within the limits given in Figure 44) was obtained. An attempt was made to extend the range of the Dittus-Boelter equation which satisfactorily correlated the low temperature data where the value of the Prandtl number did not exceed 1.2. The parameter $\xi_{b}=\frac{s t_{e} R_{b} 0.2 \mathrm{Pr}^{0.6}}{0.0243}$, where $c_{p_{h}}$ was used in the bulk fluid Prandtl number, was plotted against $P_{I}, \frac{v_{b}}{v_{w}}$, and other pertinent variables. No direct relationship between the above parameter and $\frac{v_{b}}{v_{w}}$ could be found, but the parameter was found to be related to the Prandtl number for $\mathrm{Pr}>6$, where a large increase in the value of $\xi_{b}$ with increasing Prandtl numbers could be seen. Figure 45 shows a plot of $\xi_{b}$ versus Px. A slight Reynolds number dependency is evident since the data with low mass fluxes fell below the minus ten per cent ine. Concerning the heat transfer coefficient in the supercritical region, it should be stated that the results of this investigation showed a decrease in the heat transfer coefficient with increasing heat fluxes. This was in agreement with the findings of other investigators. 


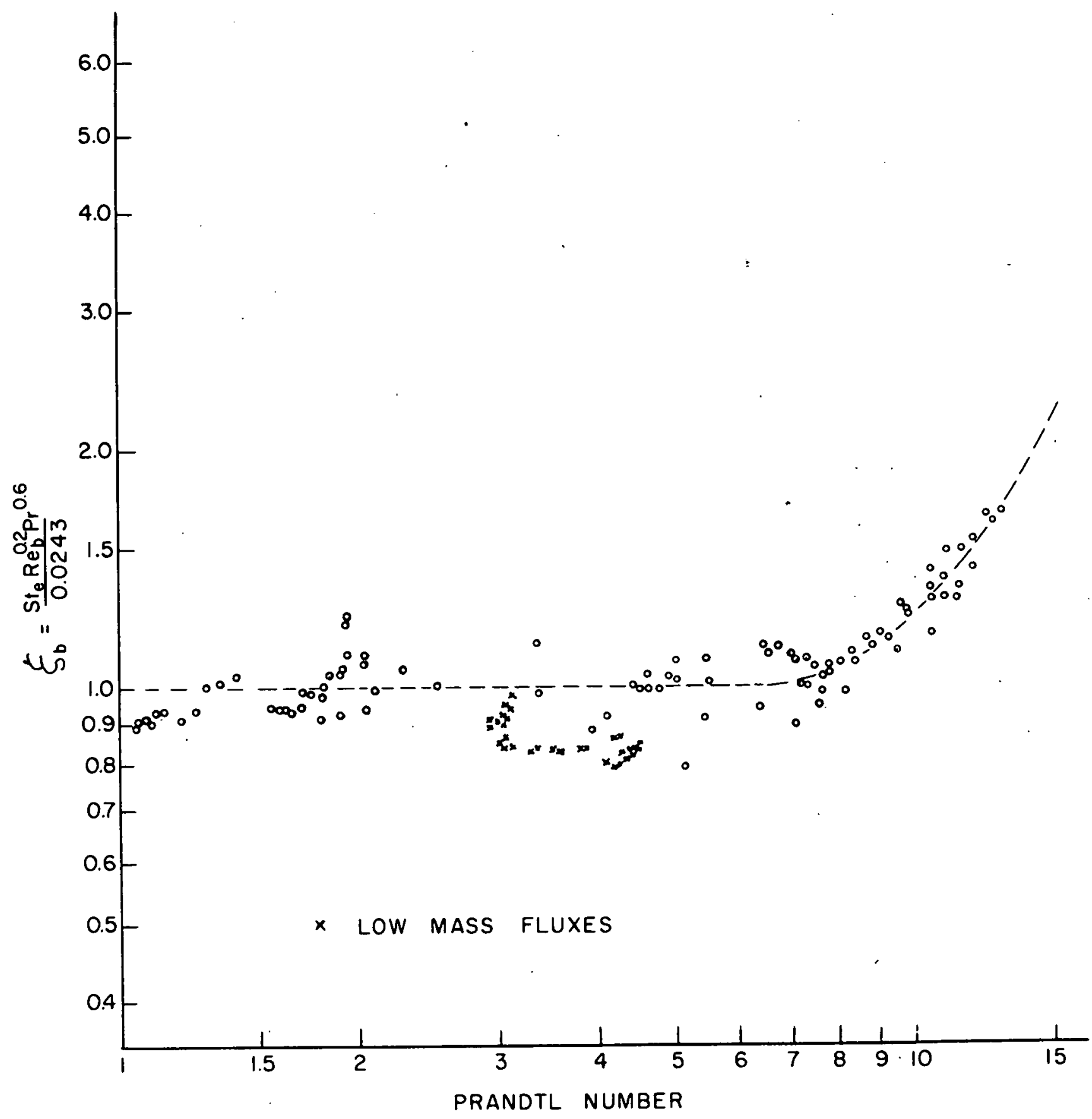

FIGURE 45. DEPENDENCE OF $\xi_{b}$ UPON THE PRANDTL NUMBER 


\section{CONCLUSIONS AND RECOMMENDATIONS}

Consideration of the experimental observations and the results led to the following conclusions:

1. Large heat transfer coefficients can be expected for heat transfer to critical water in turbulent upward flow through tubes. Very large heat transfer coefficients are obtained at small wall-to-bulk fluid temperature differences; however, uncertainty in the computation of the inside wall temperature does not allow a better understanding of heat transfer under such conditions. Such data could not be employed in the correlations and/or presented with any degree of certitude.

2. The Dittus-Boelter equation was proved to be inadequate for use with water at temperatures above $650 \mathrm{~F}$ or $\operatorname{Pr}_{b}=1.20$. The upper limit beyond which the equation may again be found useful can not be determined from the results of this investigation.

3. The recent correlation of Swenson et al. proved adequate up to around $690 \mathrm{~F}$ in general. It showed progressive deviation for temperatures closer to the peak temperature.

4. For applications up to $650 \mathrm{~F}$ the Dittus-Boelter equation would be preferred.

5. The failure of equations of the Dittus-Boelter type in the near critical region is associated with their inadequacy to 
respond to large variations in the Prandtl number. In other words, in the critical region the Nusselt number is strongly dependent on the properties which undergo large changes rather than the Reynolds number alone.

6. The use of Stanton number, $S t_{e}$, appears to be quite promising. However, more extensive data must be obtained in order to arrive at a firm conclusion. Rediced enthalpy seems to be a good parameter to be used in the correlations involving the near critical region.

7. A correlation of the type

$$
S t_{e} R e^{a}=c e^{b\left(H_{b} / H_{p}\right)}
$$

is recommended for use in conjunction with critical water. It is hoped that with the use of $\mathrm{H}_{\mathrm{b}} / \mathrm{H}_{\mathrm{p}}$ the range of the above correlation may be widened.

In view of the present work the following recommendations are presented.

1. For any further investigations of this nature the High Flux Heat Transfer Loop of the School of Mechanical Engineering must be modified to provide for: 1) a much better and more flexible preheater, 2) a rapid sequential thermocouple potential measuring device, and 3) better fluid immersed thermometry.

2. An extensive investigation must be conducted to pin-point the cause and effect of the fluid vibrations present in the system. 
3. With the above two items taken care-of, investigations must be carried out in the region above the peak temperature.

4. The possibility of initiating extensive measurements of the temperature and velocity profiles in the near critical fluids must be considered seriously. This would provide a firm foundation for future analytical studies and a good understanding of this mode of heat transfer.

5. The possibility of additional investigations of heat transfer to near critical fluids under small wall-to-bulk fluid temperature differences must be considered.

6. Investigations should be undertaken to determine the correctness of the hypothesis that the free convection pressure instabilities have their origin in the small flow fluctuations observed in this work. 
BI BLIOGRAPHY 


\section{BIBLIOGRAPHY}

1. Deissler, R. G., "Heat Transfer and Fluid Friction for Fully Developed Turbulent Flow for Air and Supercritical Water with Variable Fluid Properties", ASME Trans., vol. 76, Jan. 1954, pp. 73-85.

2. Eckert, E. R. G. and Drake, R. M., Introduction to Heat and Mass Transfer, McGraw Hill Book Co., Inc., New York, Second Edition, .1959.

3. Goldmann, K., "Heat Transfer to Supercritical Water and Other Fluids with Temperature Dependent Properties", Chem. E. Progress Symposium, Series 50, 1954, pp. 105-113.

4. Goldmann, K., "Heat Transfer to Supercritical Water at 5000 psia Flowing at High Mass Flow Rates through Round Tubes", International Developments in Heat Iransfer, Part III, ASME, 1961, pp. 561-568.

5. Hsu, Y. Y., and Smith, J. M., "The Effect of Density Variation on Heat Transfer in the Critical Region", ASME paper 60-HT-8, presented at the ASME-AIChE Heat Transfer Conference, August 15, 1960.

6. Bringer, R. P., and Smith, J. M., "Heat Transfer in the Critical Region", AIChE Journa l, No. 3, 1957, pp. 49-55.

7. Ojalvo, M. S., "Combined Forced and Free Turbulent Convection in a Vertical Tube", Ph.D. Thesis, Purdue University, Jan., 1962.

8. Lykoudis, P. S., "Analytical Study of Heat Transfer in Liquid Metals", Ph.D. Thesis, Purdue University, Jan., 1956.

9. McAdams, W. H., Kennel, W. E., and Adams, J. N., "Heat Transfer to Superheated Steam at High Pressures", ASME Trans., No. 72, 1950 , pp. $421-428$.

10. Kreith, F., and Summerfield, M., "Heat Transfer to Water at High Flux Densities with or without Surface Boiling", ASME Trans., Vol. 71, 1949, pp. 805-15.

11. Miropolskii, L., and Shitsman, M. E., "Heat Transfer to Water and Steam at Variable Specific heat in Near Critical Region", Soviet Physics, Technical Physics, Translated into English by the American Institute of Physics, Vol. 2, No. 10, Oct. 1957, pp. $2196-2208$. 
12. Dickinson, W. L., and Welch, C. P., "Heat Transfer in Supercritical Water", ASIIE Trans., Vol. 80, 1958, pp. 746-752.

13. Touba, R. F., "Heat Transfer to Critical Water Flowing through a Heated Vertical Tube Under the Effects of Combined Forced and Free Convection", M.S. Thesis, Purdue University, June, 1962.

14. Swenson, H. S., Kakarala, C. R., Carver, J. R., "Heat Transfer to Supercritical water in Smooth Bore Tubes", ASME paper 64-WA/HT-25, presented at the Winter Annual Meeting, New York, N. Y., Nov, 29Dec. 4, 1964.

15. Hess, H. L., and K.unz, H. R., "A Study of Forced Convection Heat Transfer to Supercritical Hydrogen", ASME paper 63-WA-205, presented at the Winter Annual Meeting, Nov., 1963.

16. Powel1, W. B., "Heat Iransfer to Fluids in the Region of Critical Temperature", Jet Propulsion, Vol. 27, No. 7, 1957, pp. 776-783.

17. Petukhov, B. S., Krasnoschekov, E. A., and Protopopov, V. S., "An Investigation of Heat Iransfer to Fluids Flowing in Pipes Under Supercritical Conditions", International Developments in Heat Iransfer, Part III, ASME, New York, 1961, Pp. 569-578.

18. Koppel, L. B., and Smith, J. M., "Turbulent Heat Transfer in the Critical Region", International Developments in Heat Transfer, part III, ASME, 1961, pp. 585-590.

19. Wood, R. D. and Smith, J. M., "Heat Transfer in the Critical Region-Temperature and Velocity Profiles in Turbulent Flow", AIChE Journa 1, March 64, pp. 180-186.

20. Hallman, T. M., "Combined Forced and Free Convection in a Vertical Tube", Ph.D. Thesis, Purdue University, May, 1958.

21. Sparrow, E. M., Eichhorn, R., and Gregg, J. L., "Combined Forced and Free Convection in Boundary Layer Flow", The Physics of Fluids, No. 3, May-June, 1959, pp. 319-328.

22. Hawkins, G. A., Ihermodynamics, Second Edition, John Wiley and Sons, Inc., New York, 1957.

23. Fritsch, C. A., "Free Convection Heat Iransfer to a Supercritical Fluid - An Analytical and Experimental study", Ph.D. Thesis, Purdue University, January 1962.

24. Nowak, E. S., Grosh, R. J., Liley, P. E., "Smoothed PressureVolume-Temperature Data for Water in the Critical Region Derived from Experimental Measurements", School of Mechanical Engineering, Purdue University 
25. Nowak, E. S., Grosh, R. J., "The Coefficient of Volume Expansion for Water and Water Vapor in the Critical Region", Technical Report No. 6 to Atomic Energy Commission, School of Mechanical Engineering, Purdue University, July 1961.

26. Nowak, E. S., Grosh, R. J., "An Analysis of Specific Heat Data for Water and Water Vapor in the Critical Region", Iechnical Report No. 8 to Atomic Energy Commission, School of Mechanical Engineering, Purdue University, Aug. 1961.

27. Nowak, E. S., Grosh, R. J., "An Investigation of Enthalpy Data for water and Water Vapor in the Critical Region", Technical Report No. 10 to Atomic Energy Commission, School of Mechanical Engineering, Purdue University, Sept. 1961.

28. Fritsch, C. A., Grosh, R. J., "A Description of Thermal Conductivity and Dynamic Viscosity of Water in the Critical Region", Argonne National Laboratory, ANL-6238, Cct, 1960.

29. Focken, C. M•, Dimensional Methods and Their Applications, Edward Arnold and Co., London, 1953.

30. Dix; R. C., "High Flux Heat Transfer Studies", M. S. Thesis, Purdue University, 1958.

31. Van Putte, D. A., Grosh, R. J., "Heat Transfer to Water in the Near Critical Region", Iechnical Report No. 4 to Argonne National Laboratory, School of Mechanical Engineering, Purdue University, August 1960.

32. Tokar, John V., "The Construction of an Experimental Heat Transfer Loop and a Review of Nucleate Boiling", M. S. Thesis, Purdue University, August 1961.

33. Wallace, R. B., "Single and Two Phase Heat Transfer to Near Critical Water Under Forced Convection in an Electrically Heated Vertical Tube", Ph.D. Thesis, Purdue University, June 1964.

34. Kreith, F., and Summerfield, M., "Investigation of Heat Iransfer at High Heat Flux Densities, Experimental Study with Water-Friction Drop and:Forced Convection with and without Surface Boiling in Tubes", Progress Report No. 4-68, Jet Propulsion Laboratory, California Institute of Technology, Pasadena, California.

35. National Bureau of Standards, Tables of Circular and Hyperbolic Sines and Cosines for Radian Arguments, Applied hathematics Series 36, Issued Nov. 30, 1953.

36. Keenan, J. H., and Keyes, F. G., Thermodynamic Properties of Steam, First Edition, John Wiley and Sons, Inc., New York, N. Y., 1956. 
37. Koch, Werner, Schmidt, Ernst, VDI-Wasserdampf ta feln Mit einem Molier $(i, s)-D i a g r a m m$ bis $800^{\circ} \mathrm{C}$ und einem T,S-Diagramm, 6th Revised and Amplified Edition, Springer Verlag, Berlin, 1963.

38. Babcock and Wilcox Co., Atomic Energy Division, "Enthalpy, Entropy, and Specific Volume of Water and Superheated Steam as a Function of Pressure and Temperature", N. Y., 1963.

39. Vuka lovich, M., Thermodynamische Eigenschaften des Wassers und des Wasserdampfes, 6th Edition, VEB Berlag Technik, Berlin, 1958.

40. Timrot, D. L., "Tables of Thermodynamic Properties of Water and Water Vapor", First Edition, Moscow, 1952, Leningrad, Iranslated into English by Land Turbine Engineering Division, Westinghouse Electric Corp., South Philadelphia W'orks, 1954.

41. Quinn, B. E., "Class Lecture Notes", ME 567-667, Dynamic Problems in Machine Design, School of Mechanical Engineering, Purdue University, Lafayette, Ind., Fall 1961 and Spring 1962. 
APPENDICES 


\section{APPENDIX A}

\section{LIST OF SYMBOLS}

Non-Dimensional Parameters

Gr $\quad=\quad$ Grashof number $\frac{\rho^{2} \beta g \Delta t D^{3}}{2}$

$\begin{array}{rll}\mathrm{Nu} & = & \text { Nusselt number } \frac{h D}{k} \\ \mathrm{Pr} & =\quad \text { Prandtl number } \frac{\mu c_{p}}{k}\end{array}$

Ra $=\quad$ Rayleigh number $\frac{\rho^{2} \beta g c_{p} D^{4}}{16 \mu k} \frac{\partial t}{\partial z}$

Re $\quad=\quad$ Reynolds number $\frac{G D}{\mu}$

$S=$ Strouhal number $\frac{f D}{\text { velocity }}$

st $=$ Stanton number $\frac{h}{c_{p} G}$ (basic form)

\section{Latin Alphabet (capitals)}

$\begin{array}{lll}\text { A } & = & \text { area } \\ \text { Ac } & = & \text { tube wall cross sectional area } \\ \text { Al } & = & \text { area along the axis } \\ B & = & \text { constant } \\ D & = & \text { tube diameter }\end{array}$




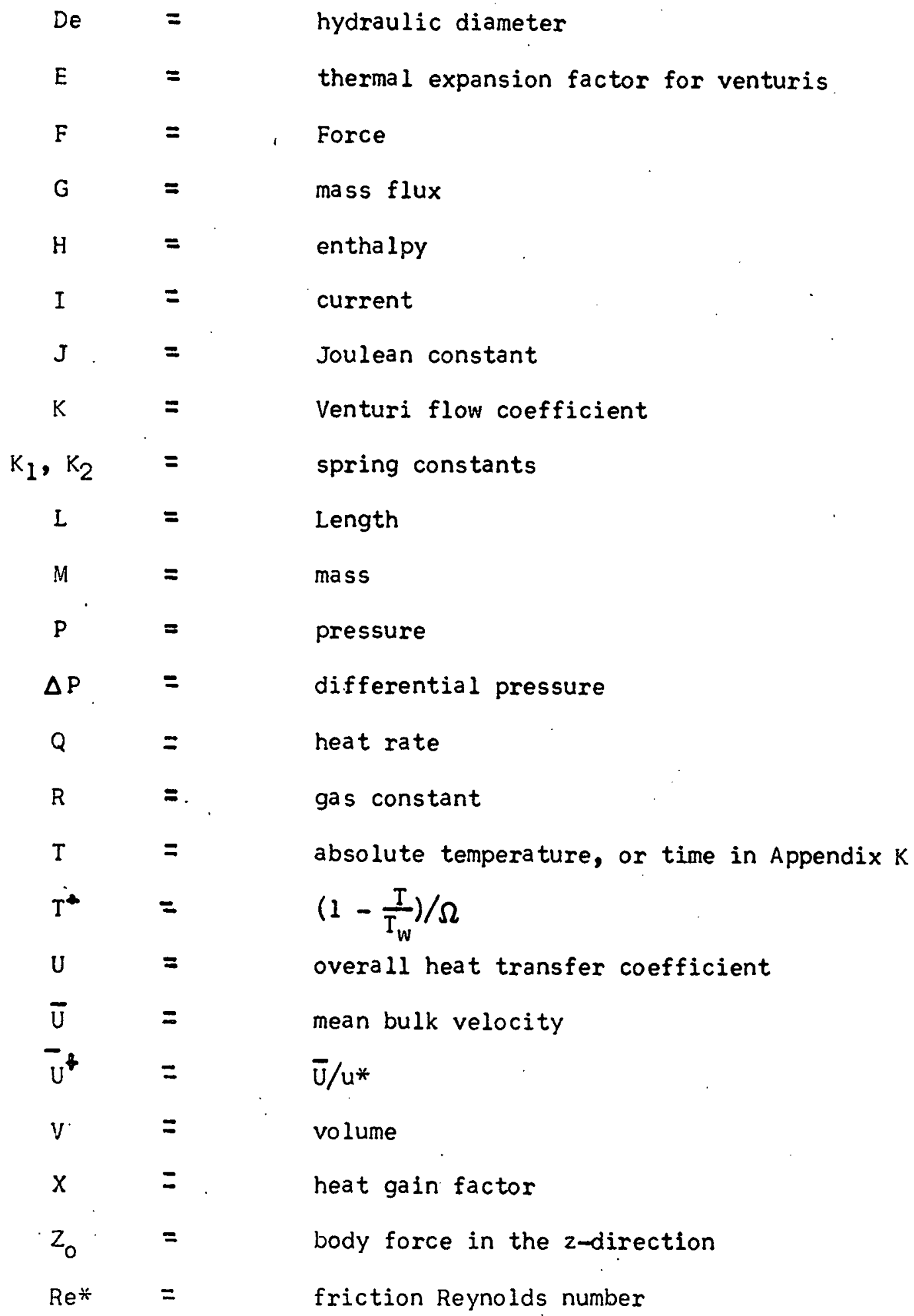




\section{Latin Alphabet (lower case)}

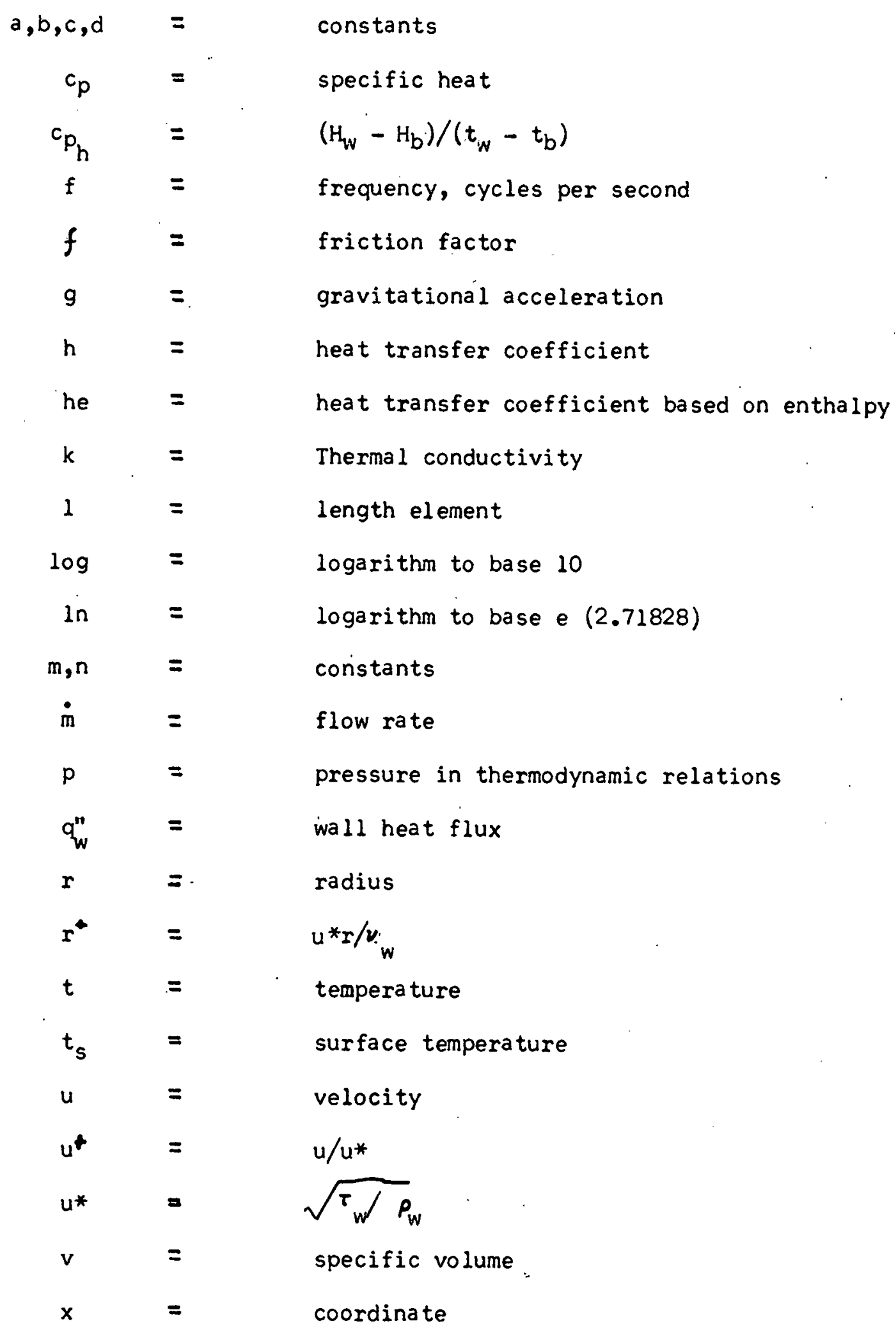




$\begin{array}{rll}y & = & \text { perpendicular distance from wall } \\ y^{*} & = & u^{*} y / \nu_{w} \\ z & = & \text { axial direction of tube } \\ \Delta z_{p} & = & \text { distance between pressure taps }\end{array}$

Greek Alphabet

\begin{tabular}{|c|c|c|}
\hline a & $=$ & $\begin{array}{l}\text { temperature coefficient of electrical } \\
\text { resistivity }\end{array}$ \\
\hline $\boldsymbol{\beta}$ & $=$ & volume expansion coefficient \\
\hline$\gamma$ & $=$ & temperature coefficient of thermal conductivity \\
\hline$\Delta$ & $=$ & differential \\
\hline 6 & $=$ & coefficient of eddy diffusivity for momentum \\
\hline${ }^{\epsilon} h$ & $=$ & $\begin{array}{l}\text { coefficient of eddy diffusivity for heat } \\
\text { transfer }\end{array}$ \\
\hline$\eta$ & $=$ & $2 r / D_{i}$ \\
\hline$\theta$ & $=$ & angular direction, time in Appendix $K$ \\
\hline$x$ & $=$ & Von Karman constant \\
\hline$\mu$ & $=$ & dynamic viscosity \\
\hline$\nu$ & $=$ & kinematic viscosity $\mu / \rho$ \\
\hline$\pi$ & $=$ & 3.14159 \\
\hline$\rho$ & $=$ & density \\
\hline$\rho_{e}$ & $=$ & electrical resistivity \\
\hline$\Sigma$ & $=$ & indicates summation \\
\hline 5 & $=$ & $\frac{t_{r e f}-t_{b}}{t_{w}-t_{b}}$ \\
\hline$\tau$ & $=$ & time, lag value in Appendix $K$ \\
\hline$\tau_{W}$ & $=$ & wall shear stress \\
\hline
\end{tabular}




$$
\begin{array}{ll}
\Omega \quad & q_{w}^{\prime \prime} u * / c_{p_{w}} g \tau_{w} T_{w} \\
\omega & =\quad \text { frequency, radians per second }
\end{array}
$$

\begin{tabular}{|c|c|c|}
\hline b & $=$ & bulk \\
\hline c & $=$ & critical, used with the properties \\
\hline$f$ & $=$ & friction, or film when appropriate \\
\hline g & $=$ & gas \\
\hline i & $=$ & inside \\
\hline 1 & $=$ & large \\
\hline $\mathrm{m}$ & $=$ & mean \\
\hline o & $=$ & outside, or initial \\
\hline $\mathrm{p}$ & $=$ & peak, in conjunction with the properties \\
\hline$I_{p}$ & $=$ & constant pressure \\
\hline $\mathbf{r}$ & $=$ & r-direction \\
\hline ref & $=$ & reference \\
\hline $\mathbf{s}$ & $=$ & sma ll \\
\hline$t$ & $=$ & transducer \\
\hline$v$ & $=$ & venturi \\
\hline$w$ & $=$ & wa 11 \\
\hline 2 & $=$ & $z$-direction \\
\hline$\theta$ & $=$ & $\theta$-direction \\
\hline$\infty$ & $=$ & ambient conditions \\
\hline
\end{tabular}

\section{Subscripts}

\section{Superscripts}

$\begin{array}{lll}-\quad & = & \text { averaged quantity } \\ - & = & \text { fluctuating quantity }\end{array}$


158

APPENDIX B

DENSITY CORRECTION IN TEST SECTION PRESSURE DROP MEASUREMENTS

Consider the transducer circuit given in Figure B-1 in conjunction with the simple derivation presented below. The work is self explanatory.

$$
\begin{aligned}
P_{A} & =P_{1}+\rho_{\infty}\left(z_{1}-z_{0}\right) \\
P_{B} & =P_{2}+\rho_{\infty}\left(z_{2}-z_{0}\right) \\
\left(P_{A}-P_{B}\right) & =\left(P_{1}-P_{2}\right)-\underset{\infty}{\rho_{\infty}}\left(z_{2}-z_{1}\right)
\end{aligned}
$$$$
\mathrm{B}-1
$$

$\mathrm{B}-3$

But, $\quad P_{2}=P_{1}-\Delta P_{f}-\bar{\rho}_{b}\left(z_{2}-z_{1}\right)$

$B-2$

Substituting for $P_{2}$ and transposing,

$$
\begin{array}{ll}
\Delta P_{f}=\left(P_{A}-P_{B}\right)+\left(z_{2}-z_{1}\right)\left(P_{\infty}-\bar{P}_{b}\right): & B-5 \\
\Delta P_{f}=\Delta P_{t}+\Delta z_{p}\left(P_{\infty}-\bar{P}_{b}\right) & B-6
\end{array}
$$

or 


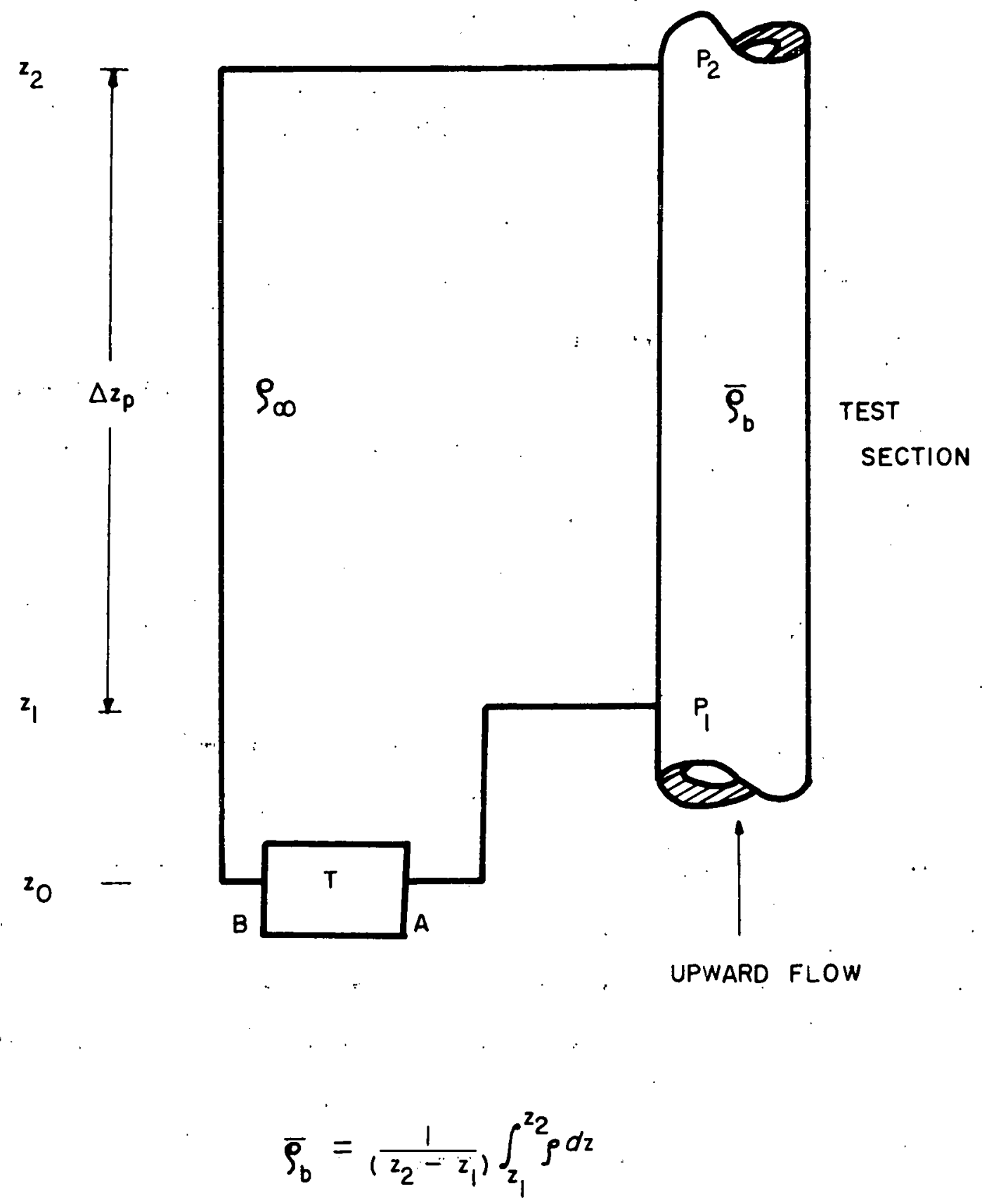

FIGURE B-I SIMPLE SCHEMATIC OF TRANSDUCER CIRCUIT 


\section{APPENDIX C}

POSSIBLE SOURCES OF UNCERTA INTIES AND THEIR EFFECT

ON THE CALCULATION OF INSIDE WALL TEMPERATURE

Inside wall temperatures were computed from the KreithSummerfield equation (46) using outside wall temperatures and the current flow through the section. Basically, there are three possible sources of error. Put in question forms

1. Are thermal conductivity and electrical resistivity for a material like stainless steel linear functions of temperature?

2. Is $\frac{t_{s}-t_{w}}{2} \stackrel{?}{=} \frac{1}{r_{0}-r_{i}} \int_{r_{i}}^{r_{0}} t(r) d r$ ?

3. How does error in varlous independent variables of the equation affect $\Delta t ?$

As far as the first question goes, indeed precision measurements have shown that the electrical resistivity and the thermal conductivity are not linear in an extended region. However, these functions may be linearized in a narrow region and used in equation (46) with good accuracy. Figure 21 attests to this. The errors which are then introduced in the process of linearization belong to the domain of the third question.

To facilitate further discussions, the form of equation (46) is modified as follows. 


$$
R=\frac{M \Delta x^{2}}{\left(1+y t_{s}\right)\left(1+a t_{s}\right)}
$$

$$
=\frac{I^{2} p_{\text {es }}}{2 \pi^{2} j K_{s}\left(2 r_{0}-\Delta x\right)^{2}} \frac{\left(1+a t_{m}\right)^{2}}{\left(1+a t_{s}\right)^{2}}
$$

Since

$$
A_{c}=\pi\left(r_{0}^{2}-r_{i}^{2}\right)=\pi \Delta x\left(2 r_{0}-\Delta x\right)
$$

and

$$
\rho_{\text {emz }}=P_{\text {es }} \frac{\left(1+a t_{m}\right)}{\left(1+a t_{s}\right)}
$$

Equation (46) may be then written as:

$$
\begin{aligned}
t=t_{s}-t_{w} & =R\left[1+\frac{\Delta x}{3 r_{0}}+\frac{\Delta x^{2}}{4 r_{0}}\right] \\
& +R^{2} \frac{\left(3 a+4 a \gamma t_{s}+\gamma\right)}{6\left(1+\gamma t_{s}\right)\left(1+a t_{s}\right)}
\end{aligned}
$$

The magnitude of the second term on the right harid side of equation $(c-2)$ was found to be less than 1.6 per cent of the total at highest currents used in this work. Therefore, the magnitude of the uncertainty that this term may introduce in $\Delta t$ is quite limited. In the following the effect of various uncertainties in the first term on the right hand side of $(C-2)$ is considered. Equation $C-2$ has been now reduced to:

$$
\Delta t=\frac{I^{2} P_{s s}}{2 \pi^{2} \cdot j K_{s}^{\prime}} \frac{\left(1+a t_{m}\right)^{2}}{\left(1+a t_{s}\right)^{2}} \frac{1}{\left(2 r_{0}-\Delta x\right)^{2}}\left[1+\frac{\Delta x}{3 r_{0}}+\frac{\Delta x^{2}}{4 r_{0}^{2}}\right] \quad c-3
$$


Taking logarithms and differentiating, the following expression is obtained:

$$
\begin{aligned}
\frac{\Delta(\Delta t)}{\Delta t}= & \frac{2 \Delta I}{I}+\frac{\Delta \rho_{\text {es }}}{\rho_{\text {es }}}-\frac{\Delta k_{s}}{k_{s}}+2 \frac{\Delta a t_{m}}{1+a t_{m}}-2 \frac{\Delta a t_{s}}{1+a t_{s}} \\
& -2 \frac{2 \Delta\left(r_{0}\right)-\Delta(\Delta x)}{\left(2 r_{0}-\Delta x\right)}+\frac{\Delta\left(\frac{\Delta x}{3 r_{0}}+\frac{\Delta x^{2}}{\left.4 r_{0}^{2}\right)}\right.}{\left(1+\frac{\Delta x}{3 r_{0}}+\frac{\Delta x^{2}}{4 r_{0}^{4}}\right)}
\end{aligned}
$$

Equation $(C A)$ shows how uncertainties in the variables may reflect in $\Delta t$. Table C-I displays an estimate of various uncertainties (which are based on measurements) for both test sections.

\section{TABLE C - I}

Estimates of Uncertainty in the Variables

(based on measurements)

Variable

Current, I

Electrical resistivity, Pes

Thermal conductivity, $k_{s}$

Tube outside radius, $r_{0}$

Tube wall thickness, $\Delta x$

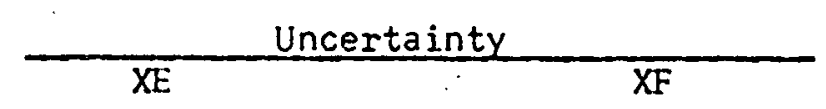

$\$ 0.5$ per cent

$\$ 0.5$ per cent

t0.20 per cent

$\$ 0.16$ per cent

$\$ 2.5$ per cent

-2.5 per cent

$\$ 0.0004$ inch

\pm 0.0002 inch

\pm 0.0012 inch 
The effect of uncertainty in the temperature coefficient of electrical resistivity, $a$, is negligible since the two terms in which it appears are nearly equal and of opposite sign.. Also very little error may be expected in a since the equations describing the electrical resistivity were in good agreement with the experimentally determined values over a sufficiently large range.

Table C-II, prepared from the values presented in Table $\mathbf{C}-\mathbf{I}$, shows the effect of uncertainty in individual variables and the sum of their absolute magnitudes upon $\Delta t$. It is observed that about 50 per cent of the total absolute uncertainty is due to the thermal conductivity.

\section{TABLE C-II}

Estimates of Possible Uncertainty Introduced by Each Variable into $\left(t_{s}-t_{w}\right)$

$\begin{array}{ccc}\text { Variable } & \text { XE } & \text { XF } \\ \text { I } & 1.0 \text { per cent } & 1.0 \text { per cent } \\ P_{\text {es }} & 0.20 \text { per cent } & 0.16 \text { per cent } \\ k_{s} & 2.50 \text { per cent } & 2.50 \text { per cent } \\ r_{0} & 0.55 \text { per cent } & 0.19 \text { per cent } \\ \Delta x & 1.05 \text { per cent } & 0.63 \text { per cent } \\ \text { solute uncertainty } & 5.30 \text { per cent } & 4.48 \text { per cent }\end{array}$

Total absolute uncertainty

5.30 per cent

4.48 per cent

Since the total uncertainty was computed on the accumulative basis, it may be expected that the actual uncertainties would be lower. 
Question two can also be answered from equation $(\mathrm{C}-3)$. If all variables except $t_{m}$ are held constant, then

$$
\frac{\Delta(\Delta t)}{\Delta t}=2 \frac{a \Delta t_{m}}{1+a t_{m}}
$$

Consider the typical case of $t_{s}=900 \mathrm{~F}$ and $\Delta t=100 \mathrm{~F}$, where $t_{\mathrm{m}}=850$. Supposing that the value of $t_{\mathrm{m}}$ was in error by $20 \mathrm{~F}$, the error in $\Delta t$ would be

$$
\frac{\Delta(\Delta t)}{\Delta t}=\frac{2 \times 0.000371(20)}{1+0.000371(850)}=0.0113
$$

Therefore an error of about one per cent may be expected if $t_{m}$ deviated by about 20 per cent from the true mean.

Summarizing this analysis it may be concluded that accumulative uncertainties of about five per cent may be present in the wall temperature drop computations. A better knowledge of the tube parameters together with better thermophysical data are required for more accurate computations. Also, future studies should be conducted to determine the deviation of $t_{m}$ from the correct mean temperature. Furthermore, it should be noted that a small error in the outside wall thermocouple reading does not significantly influence $\Delta t$ through the thermophysical properties. The error is directly transferred to the inside surface temperature $t_{s}$. 


\section{A PPENDIX D}

\section{ELECTRICAL RESISTIVITY MEASUREMENT}

An apparatus was designed and operated to obtain accurate data on the electrical resistivity of Type 347 stainless steel tube. The purpose of this appendix is: i) to show the method of measurement; and 2) to contribute to the literature. Ironically, the data obtained in this investigation was in complete agreement with the data reduced from voltage and current measurements on the test section XF of this investigation which was of the 304 type. Thus, the measurements reported here were used in conjunction with the main experiment. Furthermore, wallace (33) reported good agreement between his measured values for stainless steel Type 321 and this work.

A twenty inch long piece of tube (0.375 inch O.D. and 0.245 inch I.D.) was used as a test section. The ends of the tube were fitted with proper current taps. The middle eight inches of the tube were instrumented for electrical resistivity measurements, with $5-1 / 2$ inches on each side serving as guard heaters. The tube was covered with electrical Sauereisen cement, wound with Nickrom heating wires, and covered with another layer of the cement. Thermocouples were mounted to control the guard heaters and to monitor the test section temperature. Special yokes were designed to assure point contacts at the test section. To these the potential taps were connected. Figure D-l shows the details 


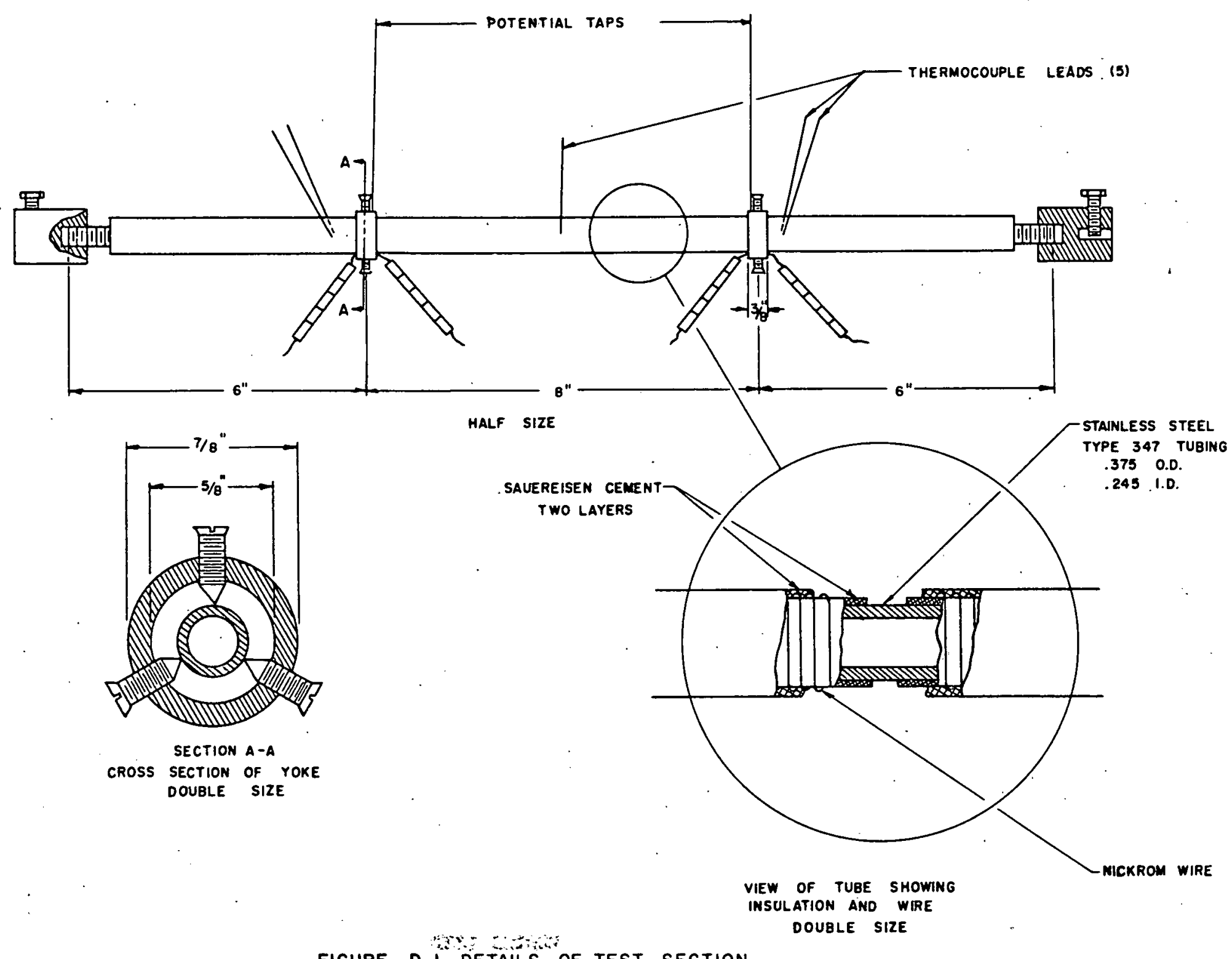


of the test section construction. Proper thermal insulation with several layers of glass wool were provided. Powerstat type heater controls were used.

Instrumentation for electrical resistivity measurements consisted of a Leeds and Northrup Kelvin bridge, appropriate ratio box and two current circuits connected to three six volt heavy duty automobile batteries arranged in series. When satisfactory test section temperature control was achieved, the low current circuit carrying about three amperes was used to balance the bridge roughly. The current was then increased to ten amperes and the bridge was further balanced. Finally, to obtain a precision balance, the high current circuit was operated momentarily with currents up to 70 amperes. This procedure was adapted to avoid Joulean heating of the test section with consequences of unallowable temperature drifts. Large currents are necessary for accurate measurements of this kind, and having two different current circuits allowed prebalancing of the bridge at low currents and only a very brief use of high currents. Figure D-2 shows the complete circuit diagram.

A second degree polynomial least squares curve was fitted to the data. The normalized absolute deviation of the curve from the experimental points was less than 0.083 per cent. The data ranged all the way from room temperature to about $1220 \mathrm{~F}$. Altogether 44 data points were obtained and entered in the curve fit. Unfortunately, due to a premature failure of one of the guard heaters and scarcity of time the work could not be continued at high temperatures. 


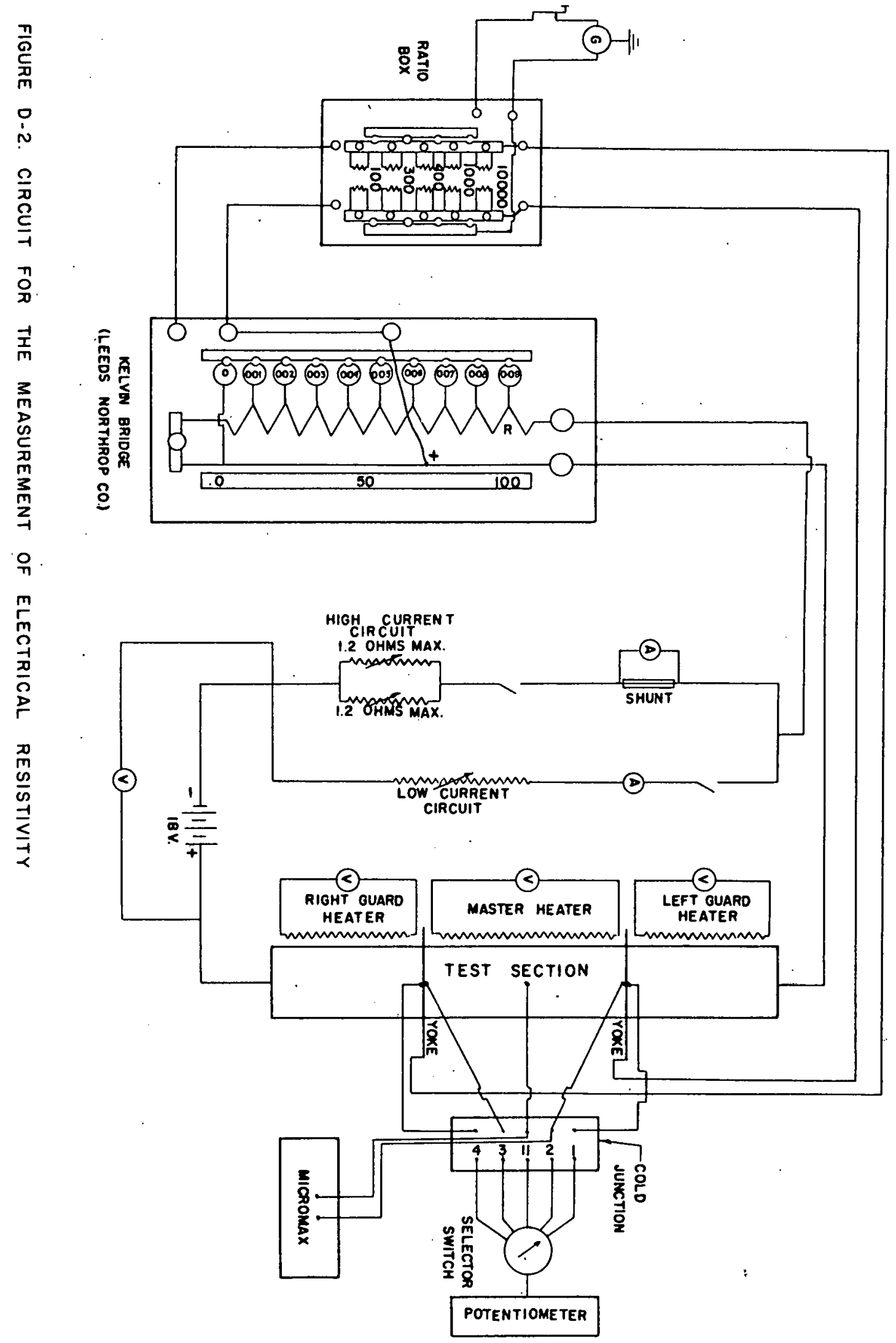


Figure D-3 shows the results of this measurement together with other data taken from the literature. 


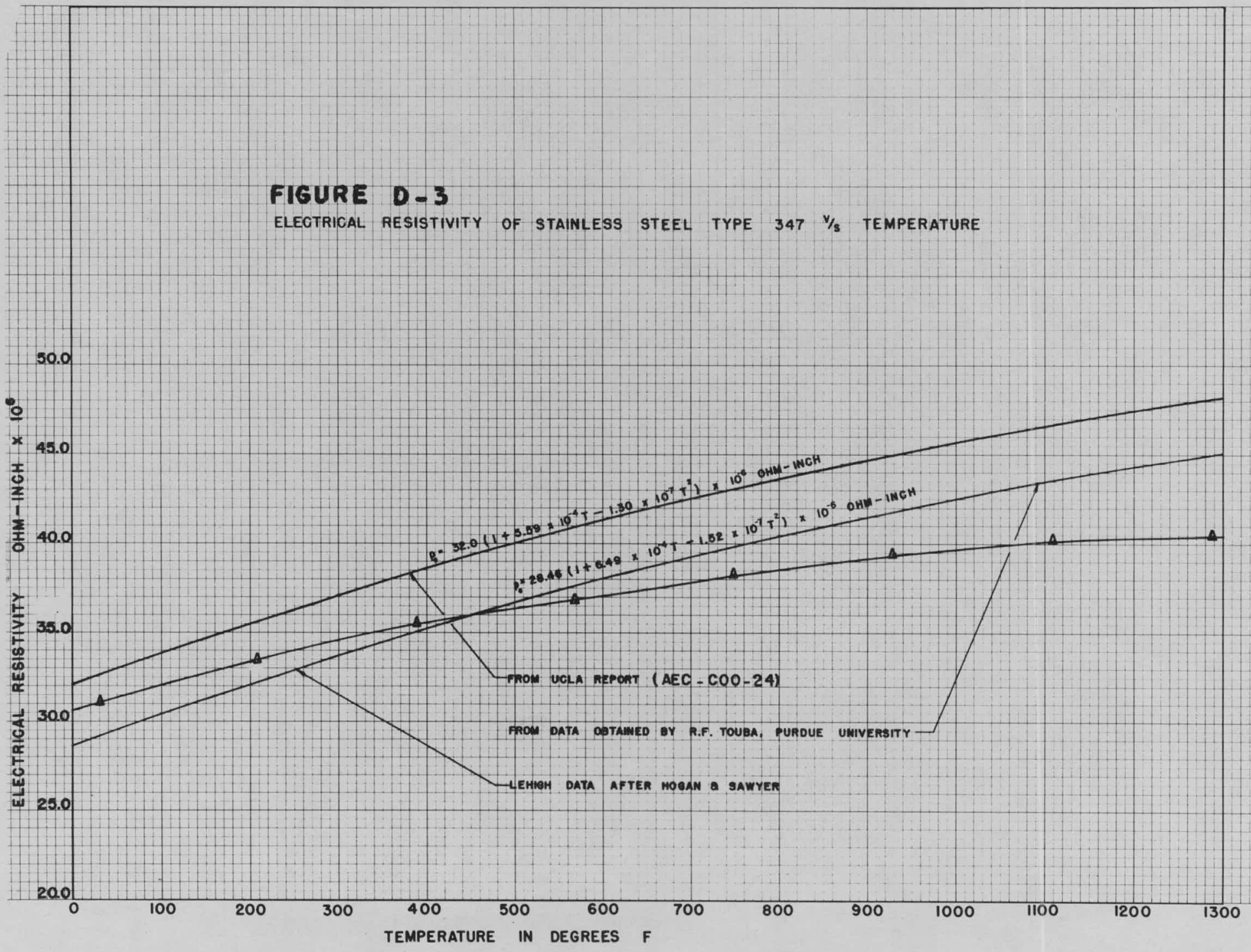




\section{APPENDIX E}

ENTHALPY-PRESSURE-TEMPERATURE TABLES

FOR NEAR CRI TICAL WATER 


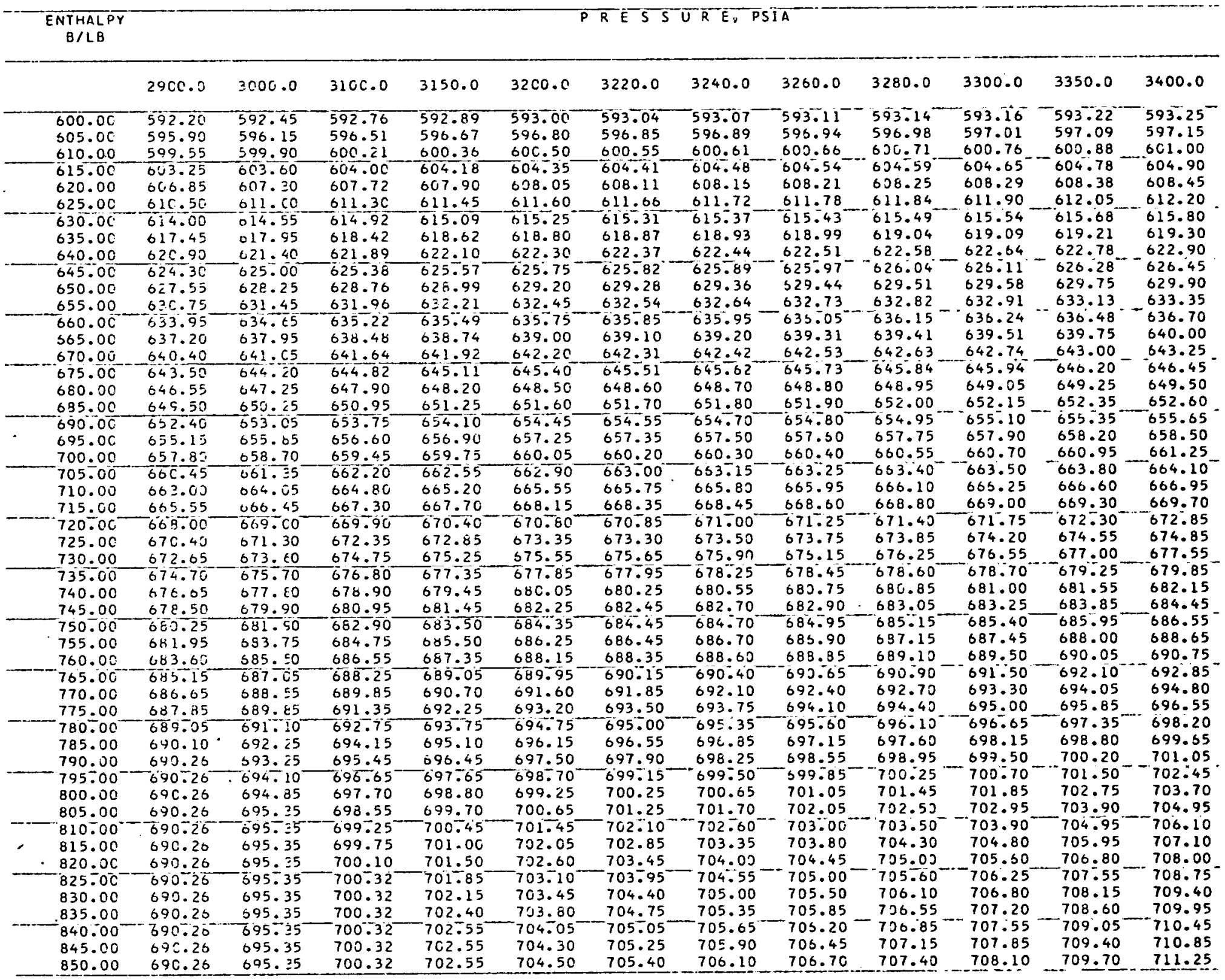




\begin{tabular}{|c|c|c|c|c|c|c|c|c|c|c|c|c|}
\hline 855.00 & 690.26 & 695.35 & 700.32 & 702.55 & 704.70 & 705.50 & 706.25 & 705.90 & 707.60 & 708.35 & 710.00 & 711.60 \\
\hline 860.00 & 690.26 & 695.35 & 700.32 & 702.55 & 704.85 & 705.60 & 706.35 & 707.05 & 797.80 & 708.55 & 710.30 & 711.95 \\
\hline 865.00 & 690.26 & 695.35 & 700.32 & 702.55 & 705.00 & 705.70 & 706.45 & 707.15 & 707.95 & 708.70 & 710.50 & .712 .25 \\
\hline 870.00 & 690.25 & 695.35 & 700.32 & 702.55 & 705.10 & 705.75 & 706.55 & 707.30 & 728.10 & 708.85 & 710.75 & 712.55 \\
\hline 875.00 & 690.25 & 095.35 & 700.32 & 702.55 & 705.10 & $705.80^{-1}$ & 706.60 & 707.35 & 708.20 & 709.00 & $710.95^{\circ}$ & 712.85 \\
\hline 880.00 & 690.26 & $095 . \pm 5$ & 700.32 & 702.55 & 705.10 & & 706.68 & 707.45 & 738.25 & 709.15 & 711.15 & 713.10 \\
\hline 885.00 & 690.26 & 595.35 & 700.32 & 702.55 & 705.10 & 705.89 & 706.72 & 707.50 & 708.35 & 709.25 & .711 .30 & 713.30 \\
\hline 890.00 & 690.26 & 695.25 & 700.32 & 702.55 & 705.10 & 705.92 & 706.77 & 707.60 & 708.45 & 709.35 & 711.40 & 713.45 \\
\hline 895.00 & 690.26 & .695 .35 & 700.32 & 702.55 & 705.10 & 705.95 & 706.80 & 707.65 & 708.50 & 709.40 & 711.55 & 713.55 \\
\hline 900.00 & 690.26 & 095.35 & 700.32 & 702.55 & 705.10 & 705.99 & 706.85 & 707.70 & 708.55 & 709.50 & 711.65 & 713.75 \\
\hline 905.00 & 690.26 & 095.35 & 700.32 & 702.55 & 705.10 & 706.00 & $706.90^{\circ}$ & 707.80 & 708.62 & 709.60 & 711.75 & $713.90^{\circ}$ \\
\hline 910.00 & 690.26 & 695.25 & 700.32 & 702.55 & 705.10 & 706.02 & 706.95 & 707.85 & 708.70 & 709.70 & 711.85 & 714.05 \\
\hline 915.00 & 690.26 & 695.35 & 700.32 & 702.55 & $705.1 \mathrm{C}$ & 706.04 & 706.98 & 707.90 & 708.75 & 709.75 & 712.00 & 714.20 \\
\hline 920.00 & 690.26 & 695.55 & 700.32 & 702.55 & 705.10 & 706.06 & 707.02 & 708.00 & 708.85 & 709.85 & 712.10 & 714.35 \\
\hline 925.00 & 690.26 & 595.35 & 700.32 & 702.55 & 705.10 & 706.09 & 707.06 & 708.05 & 708.90 & 709.95 & 712.20 & 714.50 \\
\hline 930.00 & 690.26 & 695.25 & 700.32 & 702.55 & 705.12 & 706.12 & 307.10 & .708 .10 & 739.00 & 710.00 & & 714.65 \\
\hline 935.00 & 690.26 & 595.35 & 700.32 & 702.55 & 705.14 & 706.16 & 707.17 & $708.20^{-}$ & $709.10^{-1}$ & 710.10 & 712.45 & $714.80^{\circ}$ \\
\hline 940.00 & $69 c .26$ & 695.35 & 700.32 & 702.55 & 705.18 & 706.20 & 707.22 & 708.25 & 709.20 & 710.20 & 712.55 & 714.95 \\
\hline $945.0 \mathrm{C}$ & 390.26 & 695.35 & 700.32 & 702.55 & 705.20 & 706.25 & 707.30 & 708.35 & 739.30 & 710.25 & & .10 \\
\hline 950.00 & 690.26 & 635.35 & 700.32 & 702.55 & 705.25 & 706.30 & 707.35 & 708.45 & 709.40 & $710.35^{\circ}$ & 712.85 & 715.25 \\
\hline 955.00 & 690.20 & 695.35 & 700.32 & 702.55 & 705.30 & 706.37 & 707.45 & 708.55 & 709.50 & 720.45 & & .40 \\
\hline $960.0 \mathrm{C}$ & 690.25 & 695.35 & 700.32 & 702.55 & 705.37 & 706.45 & 707.55 & 708.55 & 709.63 & 710.50 & 713.20 & 715.60 \\
\hline 965.00 & 540.26 & 095.35 & 700.32 & 702.55 & 705.45 & 706.55 & 707.65 & 6 & 709.77 & & .40 & .80 \\
\hline 970.00 & 690.26 & 695.25 & 700.32 & 702.60 & & 705.65 & 707.80 & 709.70 & 709.90 & 710.90 & & \\
\hline 975.00 & 699.25 & 695.35 & 700.32 & 702.70 & 705.70 & 706.80 & 707.90 & 709.05 & 710.08 & 711.10 & 713.80 & 716.20 . \\
\hline 980.00 & 690.25 & .695 .35 & 700.32 & 702.85 & 705.80. & 706.95 & 708.10 & 709.22 & 710.28 & $711.30^{\circ}$ & 714.05 & .45 \\
\hline 985.00 & 692.26 & 695.25 & 700.32 & 703.05 & 70 & .15 & 70 & 709.42 & 710 & 711 & 30 & .70 \\
\hline 990.00 & 69 & 695.35 & 700 & & 70 & 70 & & 709 & 71 & 71 & & 00 \\
\hline 995.00 & 690.26 & 695.35 & 700.50 & 703.50 & 706.40 & 707.55 & 708.75 & 709.90 & 711.00 & 712.05 & 714.85 & 717.35 \\
\hline 1000.00 & 690.26 & 095.25 & 700 & & 70 & 707.85 & 709.05 & 710.17 & 711.30 & 712.35 & 715.20 & .75 \\
\hline $1005.0 \mathrm{C}$ & 690.25 & 695.35 & 701.05 & 704.10 & 707 & 708.25 & 709.45 & 710.50 & 711.68 & 712.70 & 715.60 & 718.15 \\
\hline $1010.0 \mathrm{c}$ & 690.26 & 695.35 & 701.35 & 704.45 & 707.40 & $708.60^{\circ}$ & 709.80 & $710.90^{-}$ & 712.10 & 713.15 & $716^{\circ} .00$ & .65 \\
\hline 2015.00 & 690.26 & 095.35 & & & & & & 7 & & 60 & & \\
\hline 1020.00 & 690.26 & 695.65 & 702.15 & 705.30 & 708.30 & 709.50 & 710.75 & 711.85 & 713.00 & 714.10 & 717.00 & 719.70 \\
\hline 1025.00 & 690.26 & 696.10 & 702.60 & 705.80 & 708.80 & 710.00 & 711.30 & 712.40 & 713.53 & 714.65 & 717.55 & .25 \\
\hline 1030.00 & $69 C .26$ & 696.40 & 703.10 & 706.35 & 709.35 & 710.60 & 711.90 & 713.00 & 714.10 & 715.25 & 718.20 & .90 \\
\hline 1035.00 & 600.26 & 696.85 & 703.65 & 706.90 & 70 & 71 & 71 & 71 & 714 & 71 & 85 & .60 \\
\hline $1040.0 \mathrm{C}$ & 690.55 & 607.35 & 704.25 & 707.50 & 710 & 711.95 & -71 & & 715.43 & & 600 & 40 \\
\hline 1045.00 & 691.02 & 697.50 & 704.85 & 708.20 & 711.15 & 712.65 & 713.95 & 10 & 716.12 & & .40 & .15 \\
\hline 1050.00 & 691.55 & 698.50 & 705.55 & .90 & & 45 & 75 & & & & & 00 \\
\hline 1055.00 & 692.15 & 699.15 & 706.35 & 709.70 & 712.70 & 714.25 & 715.55 & $70^{-}$ & 717.67 & & 10 & $724^{\circ} .90$ \\
\hline $1060.0 \mathrm{C}$ & 692.85 & 599.85 & 707.15 & 710.55 & & $7 ! 5$ & 71 & & 55 & & & \\
\hline 1065.00 & 693.65 & 700.70 & 708.00 & 711.45 & 714.50 & 716.10 & 717.35 & 718.50 & 719 & 720 & & 726.85 \\
\hline 1070.00 & 694.55 & $7 0 1 \longdiv { 5 5 }$ & 708.95 & 712.40 & 715.45 & 717.10 & 718.30 & 717.40 & 720.45 & -721.75 & 725 & 727.85 \\
\hline 1075.00 & 695.45 & 702.50 & & 713.45 & & 718.15 & & & & & & .95 \\
\hline 1080.00 & 696.45 & 703.55 & 710.90 & 714.55 & 717.55 & 719.20 & 720.45 & 721.50 & 722.60 & 724.00 & 727.20 & 730.05 \\
\hline 1085.00 & 697.45 & 704.65 & 712.00 & 715.70 & 718.70 & 720.35 & $721.60^{-}$ & 722.65 & 83 & $20^{-}$ & .35 & .25 \\
\hline $1090.0 \mathrm{C}$ & 698.60 & 705.75 & 713.20 & 716.95 & 719.90 & 721.55 & 722.80 & 723.90 & 725.05 & 726.50 & 729.50 & 732.45 \\
\hline 1095.00 & 699.83 & 707.00 & 714.45 & 718.25 & & 722.85 & 724.05 & 725.15 & & & & 733.75 \\
\hline 1100.00 & 701.05 & -708.25 & 715.80 & 719.55 & 722.45 & 724.15 & .40 & 725.47 & 727.70 & 729.20 & 732.10 & 735.10 \\
\hline 1105.00 & 702.42 & 709.55 & 717.20 & 721.05 & 723 & 725.55 & 726.75 & 727.85 & 729.10 & 730.60 & & 736.55 \\
\hline 1110.00 & 703.80 & 710.95 & 718.65 & 722.50 & & & & & & & & \\
\hline 1115.00 & $70 \leq .40$ & $7 ! 2.45$ & 720.15 & 724.00 & 726.75 & 728.35 & 729.65 & 730.75 & $732.00^{\circ}$ & 733.75 & $736.80^{\circ}$ & 75 \\
\hline 1120.00 & 707.00 & $71 \div .05$ & 721.75 & 725.45 & & & & & & & & \\
\hline 1125.00 & 708.75 & 715.75 & 723.50 & 727.0 .0 & 729.90 & 731.45 & 732.65 & 733.92 & 735.35 & 737.35 & 740.35 & 743.30 \\
\hline 1130.00 & 710.50 & -717.60 & 725.20 & 728.55 & 731.55 & 733.15 & 734.40 & $735.70^{\circ}$ & 737.20 & 739.20 & 742.20 & 745.15 \\
\hline 1135.00 & 712.35 & 719.60 & 727.00 & 730.25 & 733.35 & 735.00 & 736.25 & 737.65 & 739.25 & 741.10 & 744.05 & 747.00 \\
\hline 1140.00 & 714.25 & 720.65 & 728.05 & 732.05 & 735.25 & 736.95 & 738.25 & 737.70 & 741.25 & 743.00 & 745.90 & 748.80 \\
\hline 1145.00 & 716.25 & 723.75 & -730.65 & $-734.00^{-}$ & 737.35 & 739.10 & $740.40^{-}$ & $741.80^{-}$ & 743.30 & 744.90 & $747.75^{\circ}$ & 750.55 \\
\hline 1150.00 & 718.30 & 725.80 & 732.50 & 736.05 & 739.60 & 741.30 & 742.65 & 743.95 & 745.35 & 746.80 & 749.65 & 752.50 \\
\hline 1155.00 & 720.50 & 727.85 & 734.60 & 733.40 & 741.85 & 743.55 & 744.95 & 746.10 & 747.45 & 748.75 & 751.50 & 754.60 \\
\hline
\end{tabular}




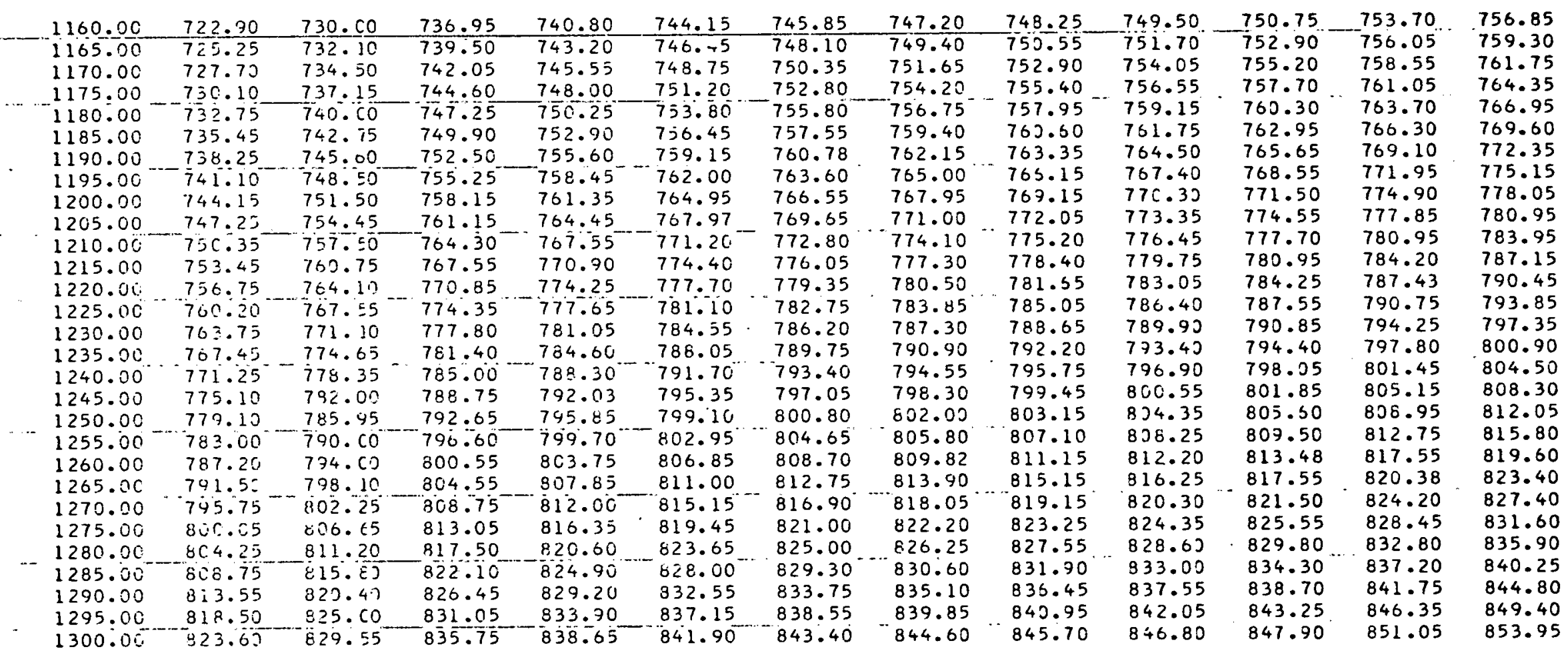




\section{APPENDIX F}

\section{CALCULATIONS FOR PEAK ENTHALPY}

Peak enthalpy was computed by several different methods with efforts to obtain more consistent results. Nowak and Grosh (27) reported that the inflection of the isobars of the product of enthalpy and temperature versus enthalpy were always found to occur at enthalpy values from 900 to $920 \mathrm{~B} / \mathrm{lb}$. This is very close to the value of the enthalpy at the critical point, $H_{C}=900 \mathrm{~B} / 1 \mathrm{~b}$. In (27) it was also reported that the uncertainty in this latter value could be as high as two or three per cent. It is, therefore, quite reasonable that the computation of $H_{p}$ should present difficulties.

One method of obtaining $H_{p}$ was by direct reference to the enthalpy-pressure-temperature plots prepared in conjunction with the present study. A second method was to fit a least squares straight line to the $H x t$ versus $H$ data in the range $H=890$ to $925 \mathrm{~B} / 1 \mathrm{~b}_{\mathrm{m}}$, and to compute $\mathrm{H}_{\mathrm{p}}$ from the coefficients obtained therefrom. Thus, if

$$
\text { Hxt. }=\mathrm{a}+\mathrm{bH} \quad \mathrm{F}-1
$$

then

$$
H_{p}=\frac{a}{t_{p}-b}
$$

Although the maximum deviation of the straight lines from the data was less than 0.015 per cent, with a much lower rms deviation, the results 
were not smooth. Figure $F-1$ shows the results obtained from this and the first method. It is observed that the values are well within the range described by Nowak and Grosh.

A third possible method was to derive the value of $H_{p}$ starting from another point. The change in the enthalpy may be expressed as

$$
d H=\left(\frac{\partial H}{\partial p}\right)_{t} d p+\left(\frac{\partial H}{\partial t}\right)_{p} d t
$$

which upon the substitution of the expression

$$
v-T\left(\frac{\partial v}{\partial t}\right)_{p}=\left(\frac{\partial H}{\partial P}\right)_{t}
$$

and integration becomes:

$$
\Delta H=\int_{r_{1}}^{P_{2}}\left[v-T\left(\frac{\partial v}{\partial t}\right)_{p}\right] d p+\int_{t_{1}}^{t_{2}} c_{p} d t
$$

The integration of the first term does not present any difficulties. However, the method runs into many difficulties precipitated by the specific heat term.

Another method took into account the non-linearity of the Hxt versus $H$ curve removing the linearity restriction imposed on the second method. By successive differentiation it may be shown that:

$$
\left(\frac{\partial(H t)}{\partial H}\right)_{p}=t+\frac{H}{c_{p}}
$$




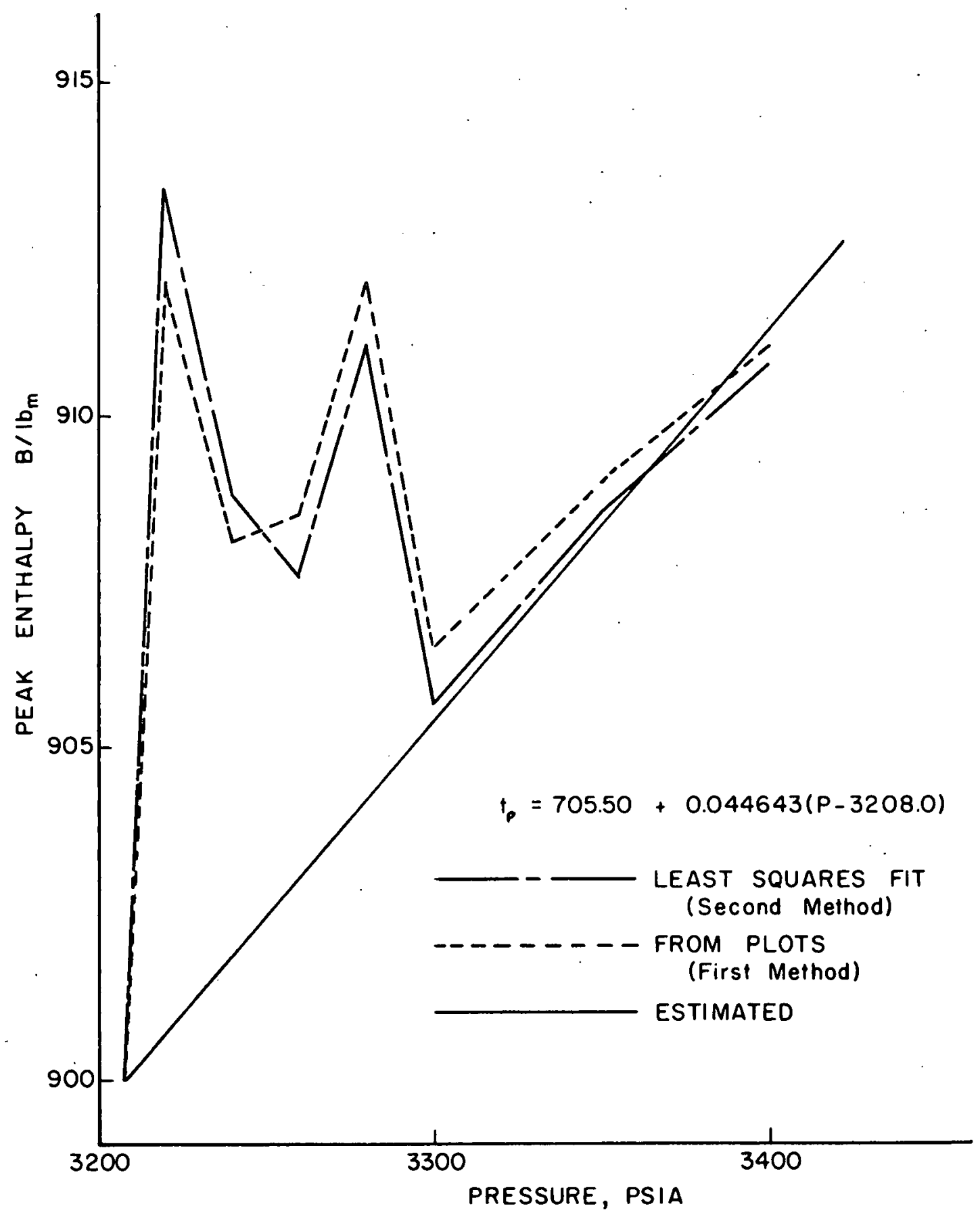

FIGURE F-I. PRESSURE AND ENTHALPY CORRESPONDING TO PEAK ENTHALPY ALONG ISOBARS 


$$
\left(\frac{\partial^{2}(H t)}{\partial H^{2}}\right)_{p}=\frac{2}{c_{p}}-\frac{H}{c_{p}^{3}}\left(\frac{\partial^{c} p}{\partial t}\right)_{p}
$$

and so on. The fact that $\left(\frac{\partial c_{p}}{\partial t}\right)_{p}$, which has a large magnitude near the peak temperatures, enters the derivatives makes it necessary that higher degree polynomials ar equations be employed. However, polynomial curve fits are known to be inadequate for thermodynamic data.

Thus, no accurate values for $H_{p}$ could be obtained, and the best guess would be the approximate straight line shown in Figure F-1. This was based on the assumption that accuracy could be better at higher supercritical pressures where the magnitude of $\left(\frac{\partial c_{p}}{\partial t}\right)_{p}$ becomes smaller.

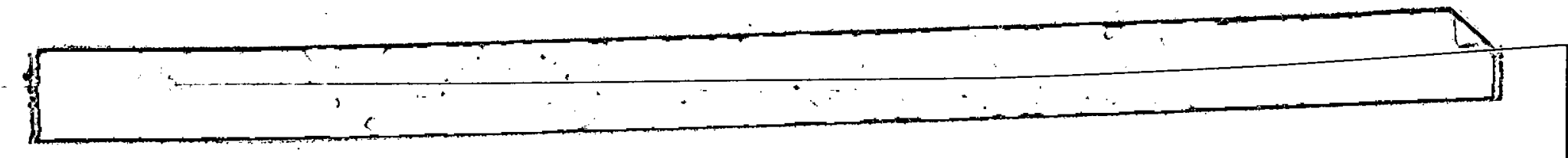


APPENDIX G

\section{IBM}

7094 FORIRAN II

COMPUTER PROGRAMS 


\section{Heat Balance Program}

Input:

M6 Number of enthalpy-temperature values

in Number of pressures

$P(J 2) \quad$ Pressures

Hor starting enthalpy value

$\mathrm{ET}(\mathrm{Jl}, \mathrm{J} 2)$ Temperature data spaced every $5.0 \mathrm{~B} / 1 \mathrm{~b}_{\mathrm{m}}$ starting at HOT for various pressures.

TML Starting temperature for thermocouple tables

TiN Entire matrix of $(21,6)$ giving millivolt values for temperature spaced every $5.0 \mathrm{~F}$., Same order as Leeds and Northrup tables.

$Z L, Z(I)$ Distance between pressure taps, pressure drop lengths, in inches.

M3 Test run number

M4 $00=$ last set of data, 01 = continue, more to come

M8 $\quad 00=$ venturi pressure drop in psi, $01=$ pressure drop in inches of mercury

M9 Number of times to iterate for venturi discharge coefficient

L System pressure code corresponding to the order of enthalpypressure-temperature data made available

VTM Venturi surface; preheater inlet, outlet; test section inlet, outlet temperatures in millivolts

SVV Specific volume at venturi

A.MPS Test section current

VOLTS Test section voltage

DPVI Large venturi pressure drop 


$\begin{array}{ll}\text { DPI } & \text { Test section pressure drop } \\ \text { PI } & \text { System pressure at test section inlet } \\ \text { VISV } & \text { Viscosity at venturi, will compute if VISV }=0.0 \\ \text { DPV2 } & \text { Small venturi pressure drop, same units as DPVI }\end{array}$


SID 3105\#003*050\#05O\#\#R -F.TOUBA - DATA REDUCTION-- XF
SEXECUTE FORTRAN

* $\quad X \subseteq Q$

* BIN

* DUMP

* LABEL

C P3O3 DATA REDUCTION - HEAT BALANCE COMPUTATIONS

DIMENSION ET $(160,12), P(12)$

DIMENSION VTWM(40), TMV $(21,6)$

DIMENSION VTM(5), TM(5), HSI(2), HS(5), H(5), Z(5)

DIMENSION TWM(5), TS(5), TMI(5)

READ INPUT TAPE 5, 53, MG, M7

READ INPUT TAPE 5, 56, (P(J2), J2=1, M7)

READ INPUT TAPE 5, 55, HOT

READ INPUT TAPE 5, 56, ( $(E T(J 1, J 2), J 1=1, M 6), J 2=1, M 7)$ ?

READ INPUT TAPE 5, 55, TMVL

READ INPUT TAPE 5, 55, TMV

READ INPUT TAPE 5, 55, ZL, $(Z(1), I=1,4)$

303 READ INPUT TAPE 5. 54, M3

READ INPUT TAPE 5, 54, M4, MB, M9, L

READ INPUT TAPE 5, 55, VTM

READ INPUT TAPE 5, 56. SVV, AMPS, VOLTS, DPVI, DPT, PI, VISV, DPVZ

DO $100 \quad I=1,5$

$V T W M(I)=V T M(I)$

$J=1$

$I I=1$

229 IF (VTWM(I)-TMV(II,J) 230, 231,232

$232 J=J+1$

GO TO 229

$230 \mathrm{~J}=\mathrm{J}-1$

235 IF (VTWM(I)-TMV (II,J) 233, 231, 234.

234 II $I=I I+1$

GO TO 235

$233 \quad 11=I 1-1$

$231 \quad A J=J-1$

$A I=I I-1$

TWM(I) $=A J * 100.0+(A I+(V T W M(I)-T M V(I I . J)) /(T M V(I I+1 . J)-T M V(I I$.

$1 J) 1 * 5.0+T M V L$

TMI (I) = TWM(I)

100 CONTINUE

$T M(1)=T M I(1)$

$T M(2)=T M I(2)-(5.58+0.00444 *(T M I(2)-626.9))$

$T M(3)=\operatorname{TMI}(3)-(5.58+0.00444 *(T M I(3)-626.9))$

$T M(4)=T M !(4)-6.85$

$T M(5)=T M(15)-6.85$

IF (VISV) $237,237,238$

237 VISV $=((37.94 E-10) *(1.0 /$ SVV $) * 1.57+(0.04788 E-08) * T M(2)+$

$1(14 \cdot 79 E-08)) * 115920 \cdot 0$

$2.38 \mathrm{TV}=T M(1)$

$E=0.9985+0.00002 * T V$

IF (MB) $210,210,211$

210 FRS $1=0.01489 * E * S Q R T F(D P V 1 /(0.455 * S V V))$

FRS2 $=0.004350 * E * S O R T F(D P V 2 /(0.455 * S V V))$

GO TO 212

211 FRS $1=0.01489 * E * S O R T F(D P V 1 / S V V)$

FRS2 $=0.004350 * E * S O R T F(D P V 2 / S V V)$

212 FRSA1 = FRS 1

FR.SA2 = FR.S2

$N=M 9$

200 REV $1=268300.0$ HFR $1 /$ VISV 
REV2 $=496100.0: \%: / \mathrm{VIVV}$

$D C 1=0.8270+0.07400 *$ RREV +1.0$) * 0.07$

DC2 $=0.408+0.0426$ H LOGF (RLVL + 1.1 )

FRS $1=$ FRSAI $\because$ L $1-1$

FRS2 = FRSAZ *DC2

$N=N-1$

IF (N) 201,201,200

$201 \mathrm{FRH1}=\mathrm{FRS} 1 * 3600.0$

$F R H 2=F R S 2 * 3600.0$

$F R H=F R H 1+F R H 2$

$J=5$

$00109 \quad 1=1,4$

$T S(1)=T M(1+1)$

$J 5=0$

$00108 K=1.2$

$N J=L-J 5$

IF(TS(I)-ET(J,NJ)) $220,221,222$

$220 J=J-1$

$I F(T S(I)-E T(J, N J)) 220,221,221$

$222 J=J+1$

IF (TS(I)-ET(J,NJ)) $223 \cdot, 221,222$

$223 J=J-1$

$221 \quad A J=J-1$

$H S I(K)=H O T+(A J+.(T S(1)-E T(J \cdot N J)) /(E T(J+1 . N J 2-E T(L) N J) S . .25 .0$

$108 \quad J 5=J 5+1$

OHS $(1)=H S I(2)+((P I-D P T * Z(1) / Z L)-P(L-1)) /(P(L)-P(L-1)) *(H S I(1)-$

$1 \quad H S I(2))$

$H(1)=H S(1)$

109 CONTINUE

QATS = FRH* $(H(4)-H(3))$

QGTS = AMPS $*$ VOLTS*3.4128

HBERR $=($ QGTS-QATS $) /$ OGTS*100.0

$Q A P H=F R H *(H(2)-H(1))$

$H O=H(3)$

WRITE OUTPUT TAPE 6,81

WRITE OUTPUT TAPE 6, 65, (M3).

WRITE OUTPUT TAPE 6,82

WRITE OUTPUT TAPE 6, 83, (VTM(I), TMI(1), TM(I), $1=1,5$ )

WRITE OUTPUT . TAPE 6. 70. (FRH . FRH. \&..FRH2) .

WRITE OUTPUT TAPE 6. 84. (QGTS, QATS, HEERR, QAPH, PI, VISV)

WRITE JUTPUT TAPE 6. 85, (DPV1, DPT, TV, HO, SVV, DPVZ)

PUNCH 93, (DPVI, DPT, TVI.HO, SVV, VISV,.RI .DPVZ)

81 FORMAT $(1 H 1,7 \times, 28 H$ HEAT BALANCE COMPUTATIONS//)

65 FORMAT $(31 X, 8 H$ RUN $X F, 12 / / / /)$

82 FORMAT $(10 \times$, GHVTM,MV, $10 \times, 5 H T M I, F, 10 \times, .4 H T M, F, \ldots, \ldots) \ldots$

83 FORMAT (1OX, F6.3, 8X, F7., $8 \times, F 7.2)$

70 FORMAT $1 / / / / 1$ 10X, $14 \mathrm{H}$ FLOW RATE $=1 \mathrm{~F} 11.1 .9 \mathrm{H} \quad$ LBS/HR//. $-1$

2

$10 \times, \ldots 14 \mathrm{H} \mathrm{FRH1} \ldots \ldots=\ldots . \mathrm{F} 11.1 . .9 H \ldots \ldots$.... $1 . . \mathrm{HS} / \mathrm{HR} /$.

......

2

2

3

5

85 FORMAT (4F15.2, F15.5. F15.2)

93 FORMAT (8F10.5)

IF (M4) 206, 206, 303

206 CALL EXIT

53 FORMAT $(214)$

54 FORMAT $(514)$

58 FORMAT $(7 F 10.0)$

-6 FORMAT (BF 10.0)

END 


\section{Data Reduction and Analysis Program}

Input:

(Includes symbols not covered previously)

$K(J) \quad$ Number of intervals between thermocouples evenly spaced. For example XE test section $8,2,6,2,8$

$D Z(J) \quad$ Length of the above intervals in inches

For example XE test section $0.50,3.0,6.0,3.0,0.50$

DO Tube outside diameter, inches

DI Tube inside diameter, inches

WT Tube wall thickness, inches

ALFA

BETA

RHOEO

eo

TKO $k_{0}$

$\mathrm{RHO}, \mathrm{RH} 1, \mathrm{RH} 2$ coefficients of second degree electrical resistivity equations

B Iteration accuracy for $t_{m}$ in Kreith Summerfield equation

B1, B2 Thermocouple calibration constants equation (1)

B3, B4 Thermocouple calibration constants equation (2)

HG $x$, Heat gain factor

N2 Number of test section thermocouples

M5 Thermocouple number where calibration shifts from equation

(1) to (2). Numbering starts at start of heating, inlet. If not needed $1,15=M$.

VTNM(I) Measured millivolts of test section thermocouples entered from inlet up.

DPVI,DPT, TV, HO ,SVV, VISV,PI,DPV2 This card is punched out by the Heat Balance Program

IV Venturi surface temperature, $F$

HO Test section inlet enthalpy 


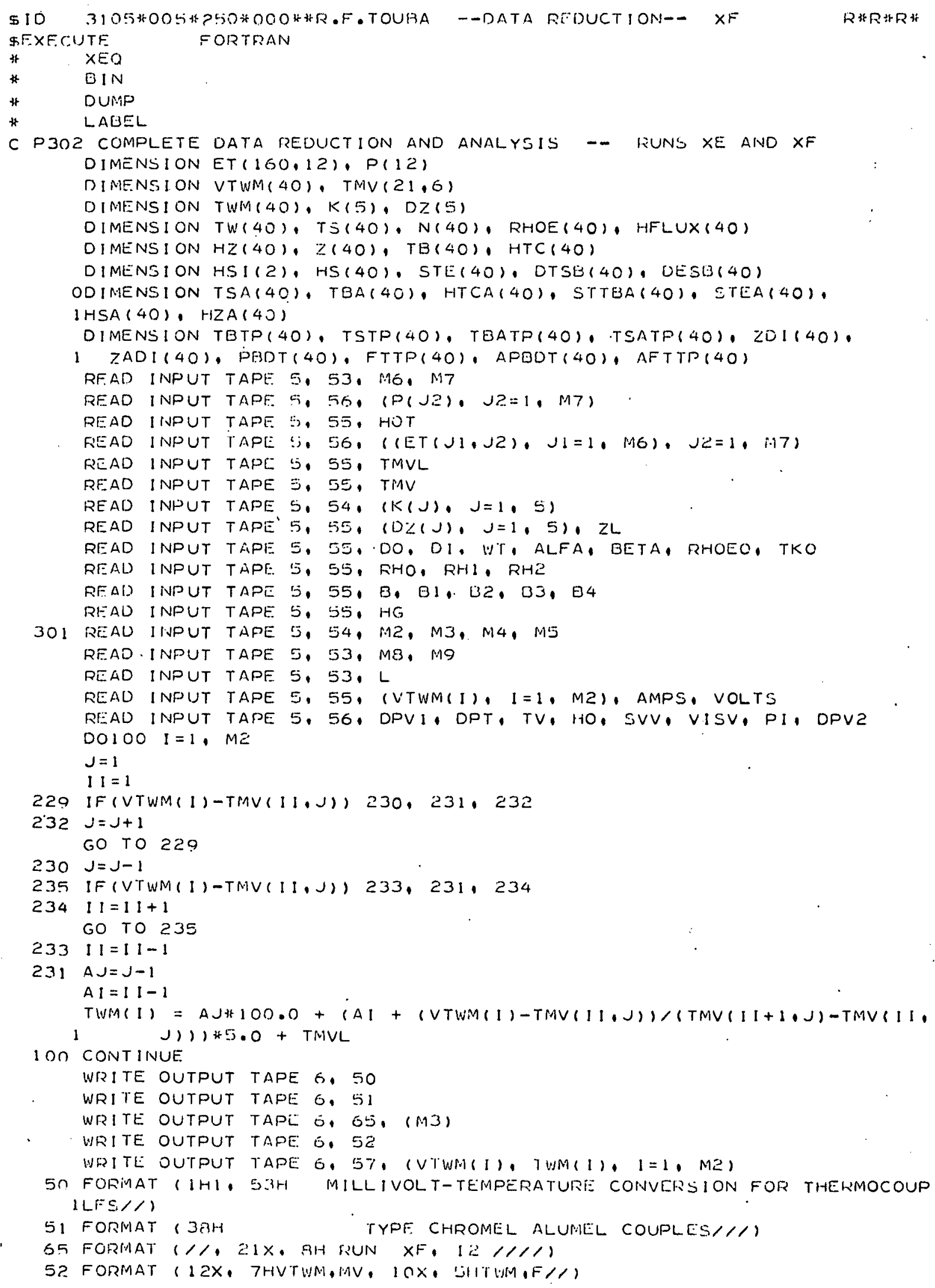




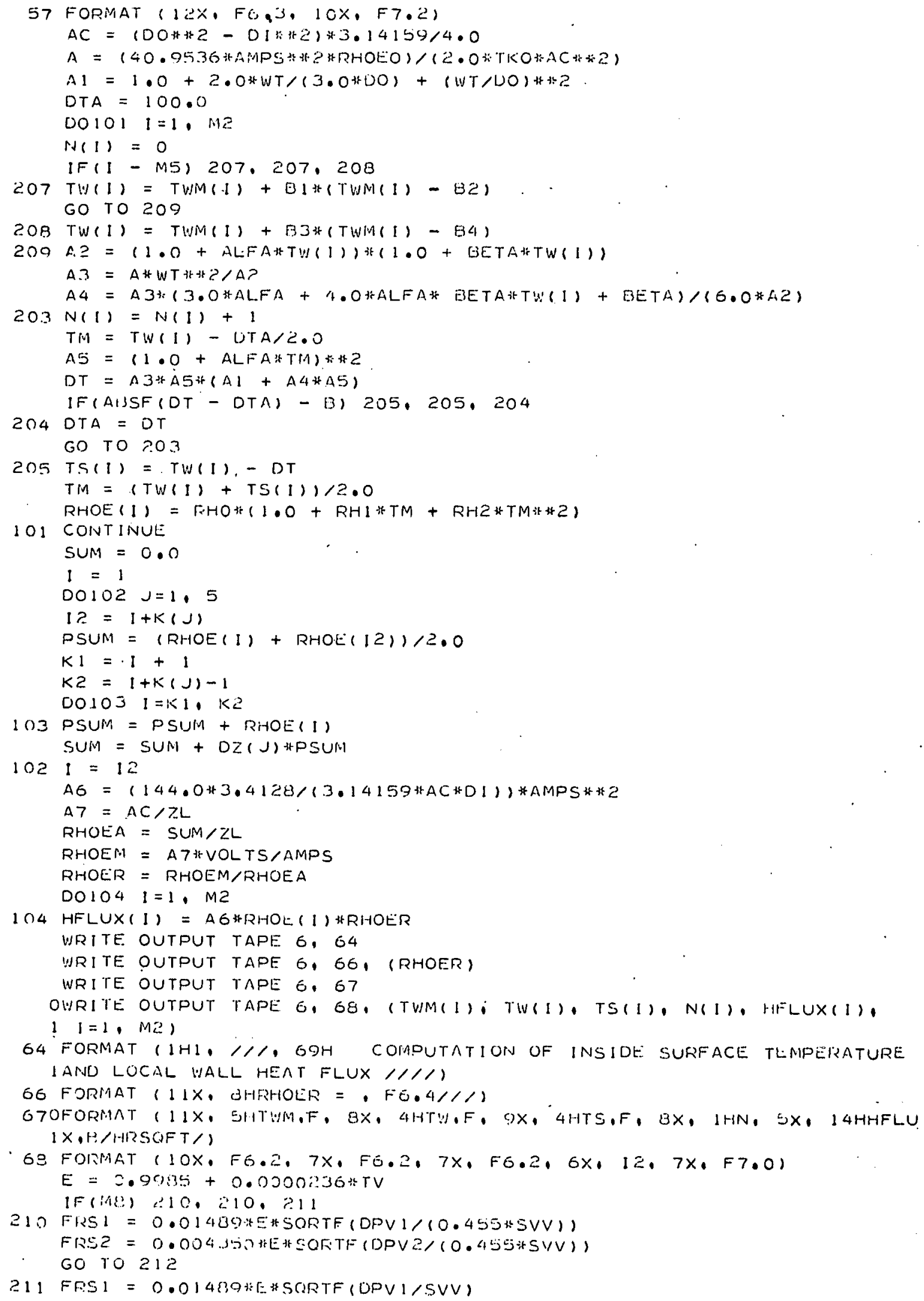




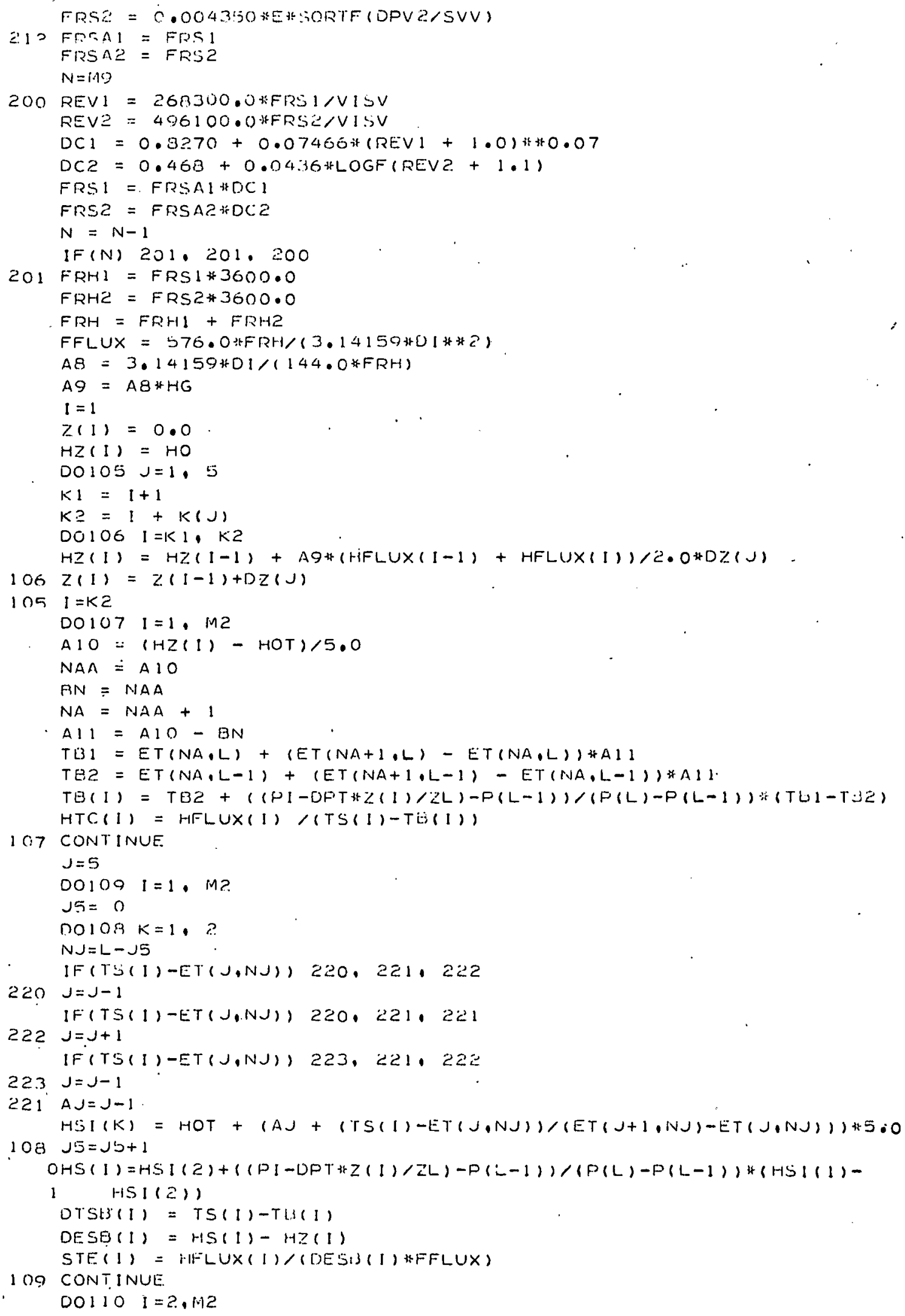


$\operatorname{TSA}(1)=(\operatorname{TS}(1)+\operatorname{TS}(1-1)) / 2 \cdot 0$

$\operatorname{TEA}(1)=(\operatorname{TE}(1)+\operatorname{TH}(1-1)) / 2 \cdot 0$

$H S A(1)=(H S(1)+H S(1-1)) / 2.0$

$H Z A(1)=(H Z(I)+H Z(1-1)) / 2 \cdot C$

HTCA (I) = (HFLUX(1) + HFLUX(1-1)) $(2.0 *(T S A(1)-T B A(1))$

STTESA (1) = HTCA (1)/(HZ(1)-HZ(1-1))/(TiS(1)-TQ $(1-1)$ KFFLUX)

STEA $(1)=($ HFLUX(1) + HFLUX $(1-1)) / 2.0 *(H S A(1)-H Z N(1))$ HFFLUX)

110 CONTINUE

WRITE OUTPUT TAPE 6.69

WRITE OUTPUT TAPE 6.70. (FRH, PI)

WRITE OUTPUT TAPE 6,71 , (FFLUX)

WRITE OUTPUT TAPE 6.72

WRITE OUTPUT TAPE E. 73, (Z(1), TH(1), TS(I), HZ(1), HS(1),

$1 H T C(1), S T E(I), 1=1, M 2)$

69 FOFMAT (IHI, $/ 1,19 \times$, BOH LOCAL TEMPERATURES, ENTHALPILS. HLAT TR

I ANSFER COEFFICIENTS, AINL STANTON. NUMBERS////)

70 FORMAT $(11 X, 14 H$ FLOW RATE $=$. F11.1. 9H LBS/HF, $10 X$.

1 I 1 PH PRESSURE $=$, FG.1.7H PSIA $/ 11$

71 FORMAT $(11 \times, 14 \mathrm{H}$ WASS FLLUX $=1$. 1 PE $11.4,13 \mathrm{H}$ LUS/HRSOFT///)

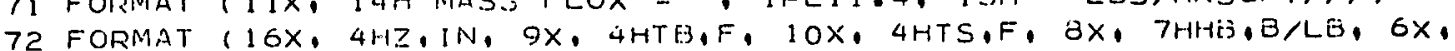

1 THHS, H/LR, $4 X, 13 H H T C, E S H R S O F T F, 7 X, 3 H S T E / 11$

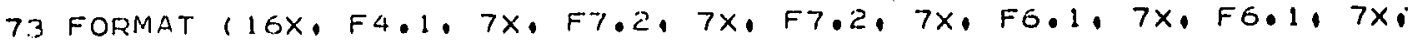

IF7.0.7X.FB.6)

WRITE OUTPUT TAPL 6.74

WRITE OUTPUT TAPE 6.75

WRITE OUTPUT TAPE 6.76, (Z(1), TS(1), TO(1), HS(I), HZ(1),

1 DTSB(1), DESB(1), $1=1, \mathrm{MZ})$

74 FORMAT $(1 \mathrm{HI}, 1 / 1,30 \times$, GOHLOCAL SURFACE AND BULK TEMPERATURE, AND IENTHALPY DIFFFPFNCFS////)

75 FORMAT (17X, 4HZ, IN, 9X, 4HTS,F, IOX, 4HTB,F, 3X.7HHS, B/LB, 6X,

1 7HHB, B/LB, 7X, GHDTSE,F, 6X, 9HDESB, B/LB//1

76 FOFMAT (17X, F4.1, 7X, F7.2, 7X, F7.2, 7X, F6.1. 7X, F6.1.7X,

] F7.2, $7 \times, F 7.2$ )

WRITE OUTPIJT TAPE 6,77

WRITE OUTPUT TAPE 6,78

WRITE OUTPUT TAPE 6.79, (TSA(1), TEA(1), HSA(1), HZA(1), HTCA(I), 1 STTEA (1), STEA (1), I =?, MZ)

77 FORMAT $(1 \mathrm{H}, 1 / 1,16 \mathrm{X}, 87 \mathrm{HLOCAL}$ AVERAGE TEMPERATURES, ENTHALPIES. 1HEAT TRANSFER COEFFICIENTS, AND STANTON NUMIEERS////)

78 FORHAT ( $14 X$, 5HTSA,F, 9X, 5HTBA,F, 7X, BHHSA, B/LB, 6X, BHHSA,B/LC, $14 X, 14 H H T C A, H / H F S O F T F$, 5X, SHSTTHA, $10 X, 4 H S T E A / / 1$

79 FORMAT (13X, F7.2, 7X, F7.2, 7X,F7,

$1 F B .6,7 \times, F B .0)$

IF (PI-320B.0) 241, 241, 240

240 DO111 $1=1$. 1.12

ZDI 11$)=Z(1) / D I$

$T T=705.50+0.044643 *($ (PI - DPTHZ(I)/ZLI - 3208.00)

$T B T P(1)=T(3)(1) / T T$

$T S T P(1)=T S(1) / T T$

PUDT (1) $=(T T-T H(1)) /$ CTSO (1)

$F T T P(1)=(T S(1)+T H(I)) /(2 \cdot O H T T)$

111 CONTINUE

DO112 $1=2$, MZ

$Z A=(Z(1)+\angle(1-1)) / 2.0$

$7 A D I(1)=Z A / O I$

TTA $=70 \% .40+0.04469 .3 *($ (PI-DPT*ZA $27 L)-3206.20)$

THATP(I) = THA(I) TTTA

TSATP(I) = TSA (I) TTAA

APHOT $(1)=(T T A-T H A(I)) /(T S A(I)-T H A(1))$

$A F T T P(1)=(T S A(I)+T i A A(I)) /(A \bullet O * T T A)$ 
11? CONT INUE.

WRITE OUTPUT TAPE 6,30 WRITE OUTPUT TAPE 6. 31 , (ZDI(1), TITPP(1). TSTP(1). PUUT(1).

1 FTTP(I), HTC(I), STE (I), I $=1, M 2)$

BO FORMAT (IHI. $/ 1 /$. 30X, GOH LOCAL PARAMETERS VERSUS NORMALIZEO OISIA

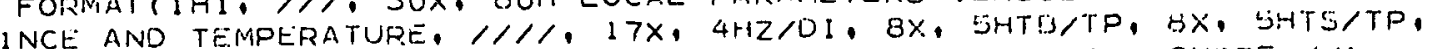
2 BX, SHPQ/DT, BX, SHFT/TP, 6X, I 3HHTC, B/HRSQFTF, 6X, 3HSTE //1

(3) FOPMAT $\left(17 X, F 5.1: 7 X, F 6.4,7 X, F 6.4,6 x, F 7.4,7 X, F 6.4,6 x_{1}\right.$ $1 F 8.0,7 \times, F(.6)$

WRITE OUTPUT TAPE G. B?

WRITE OUTPUT TAPE G, B3, (ZADI(I), TDATP(I), TSATP(1), APUUT(I), 1 AFTTP(I). HTCA(I), STTEA(I), STEA(I), I=2. MZ)

82 FORIMATIIHI, $/ /$, ZGX, GBH AVERAGL LOCAL PABAMETERS VERSUS NORMALIZ IED DISTANCE ANO TEMPERATURE, $/ 1 / 1,10 X, 5 H Z A / 01.7 \times, 6 H T B A / T P, 7 X$, 2 GHTSA/TP, 7X, GHAPB/DT, 7X, GHAFT/TP, 4X, 14 HHTCA, B/HRSQFTF, 5X, 3 SHSTTDA, $10 X$, $4 H S T E A / / 1$

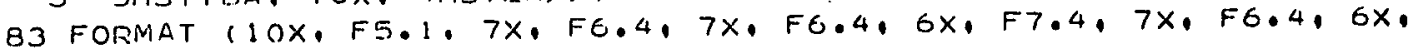

$1 F 8.0 .7 \times, F B .0 .7 \times . F 8.6$,

241 IF (M4) $200,206,301$

206 CALL EXIT

53 FORMAT (214)

54 FORMAT (514)

55 FORMAT (7F10.0)

56 FORMAT $(8 F 10.0)$

END 


\section{APPENDIX H}

\section{SAMPLE COMPUTATIONS}

Three sets of sample computations are presented in the following. The data shows the behavior and the magnitude of several parameters of interest under various conditions of operation. Run XF 9 had low film temperature drops. The symbols are explained below.

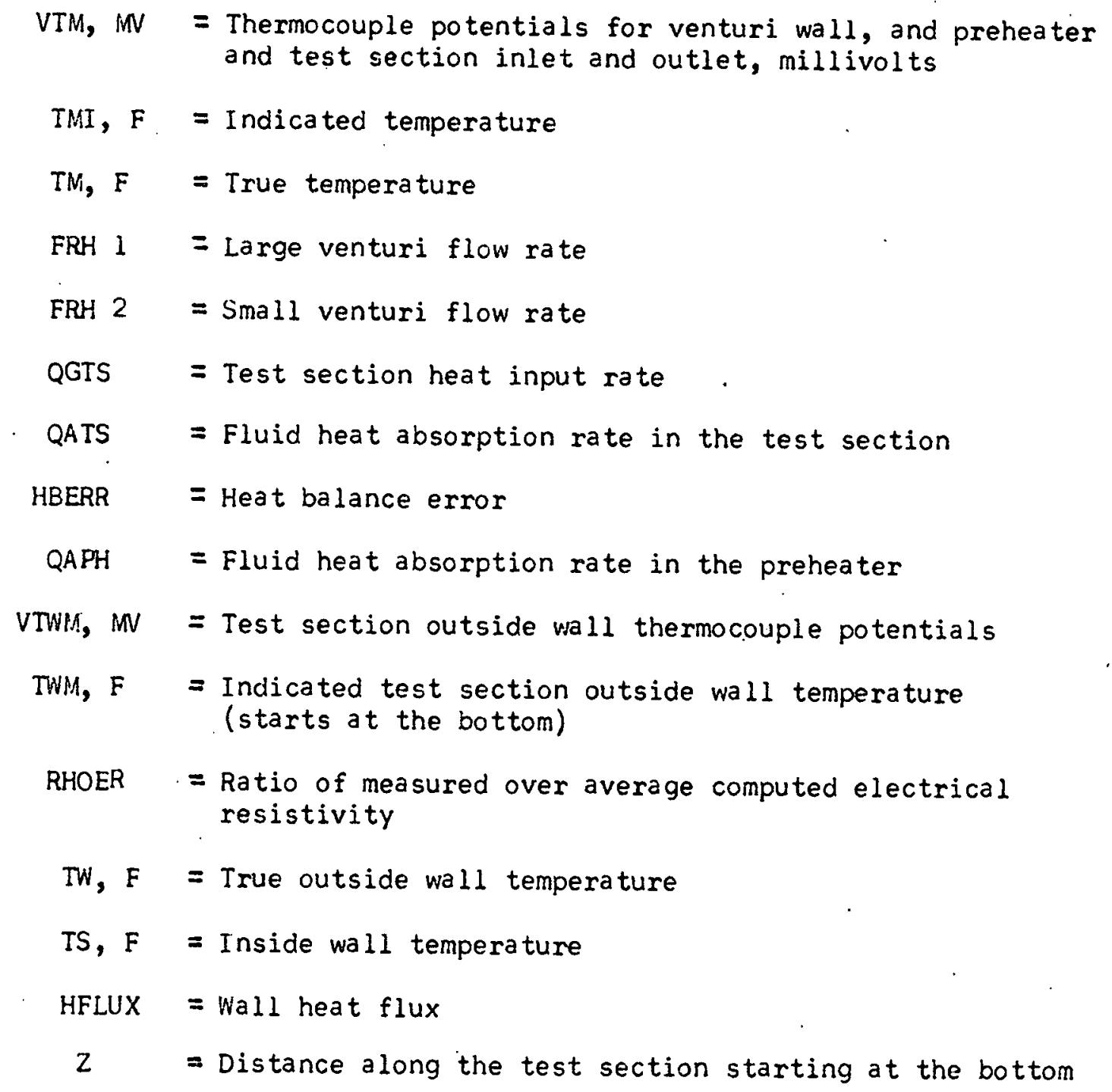




$$
\begin{aligned}
& T B, F=t_{b} \\
& T S, F=t_{w} \\
& \mathrm{HB}, \mathrm{B} / \mathrm{LB}=\mathrm{H}_{\mathrm{b}} \\
& H S, B / L B=H_{W} \\
& \text { HIC }=\text { Heat transfer coefficient } h \\
& \text { STE }=\text { stanton number } S t_{e} \\
& \text { DTSB, } F=t_{w}-t_{b} \\
& \text { DESB, } B / L B=H_{w}-H_{b} \\
& \text { TSA, } F=\bar{t}_{w} \\
& \mathrm{TBA}, F=\bar{t}_{\mathrm{b}} \\
& H B A, B / L B=\bar{H}_{b} \\
& H S A, B / L B=\bar{H}_{w} \\
& \text { HTCA }=\bar{h} \\
& \text { STTBA }=\overline{s t} \\
& \text { STEA }=\overline{s t}_{e} \\
& z / D I=\text { Tube length to diameter ratio } \\
& \mathrm{TB} / \mathrm{TP}=\frac{t_{\mathrm{b}}}{t_{\mathrm{p}}} \\
& \mathrm{TS} / \mathrm{TP}=\frac{t_{w}}{t_{\mathrm{p}}} \\
& P B / D T=\frac{t_{p}-t_{b}}{t_{w}-t_{b}} \\
& \text { FT/TP. } \quad=\frac{t_{w}+t_{b}}{2 t_{p}}
\end{aligned}
$$


HEAT BALANCE_COMPUTATIONS

RUN XE 4

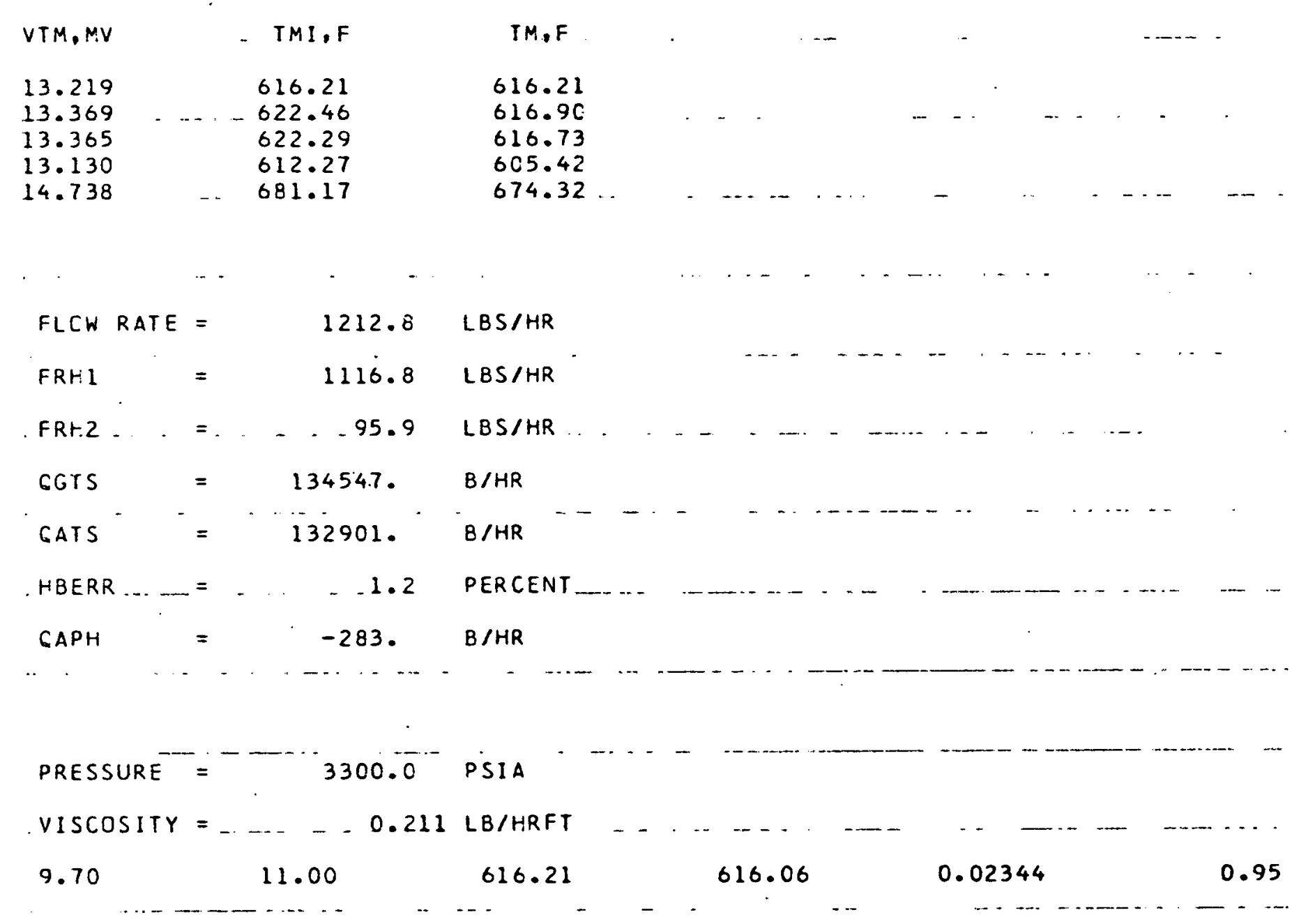


COMPUTATION OF INSIDE SURFACE TEMPERATURE AND LOCAL hALL HEAT FLUX

RHOER $=1.0037$

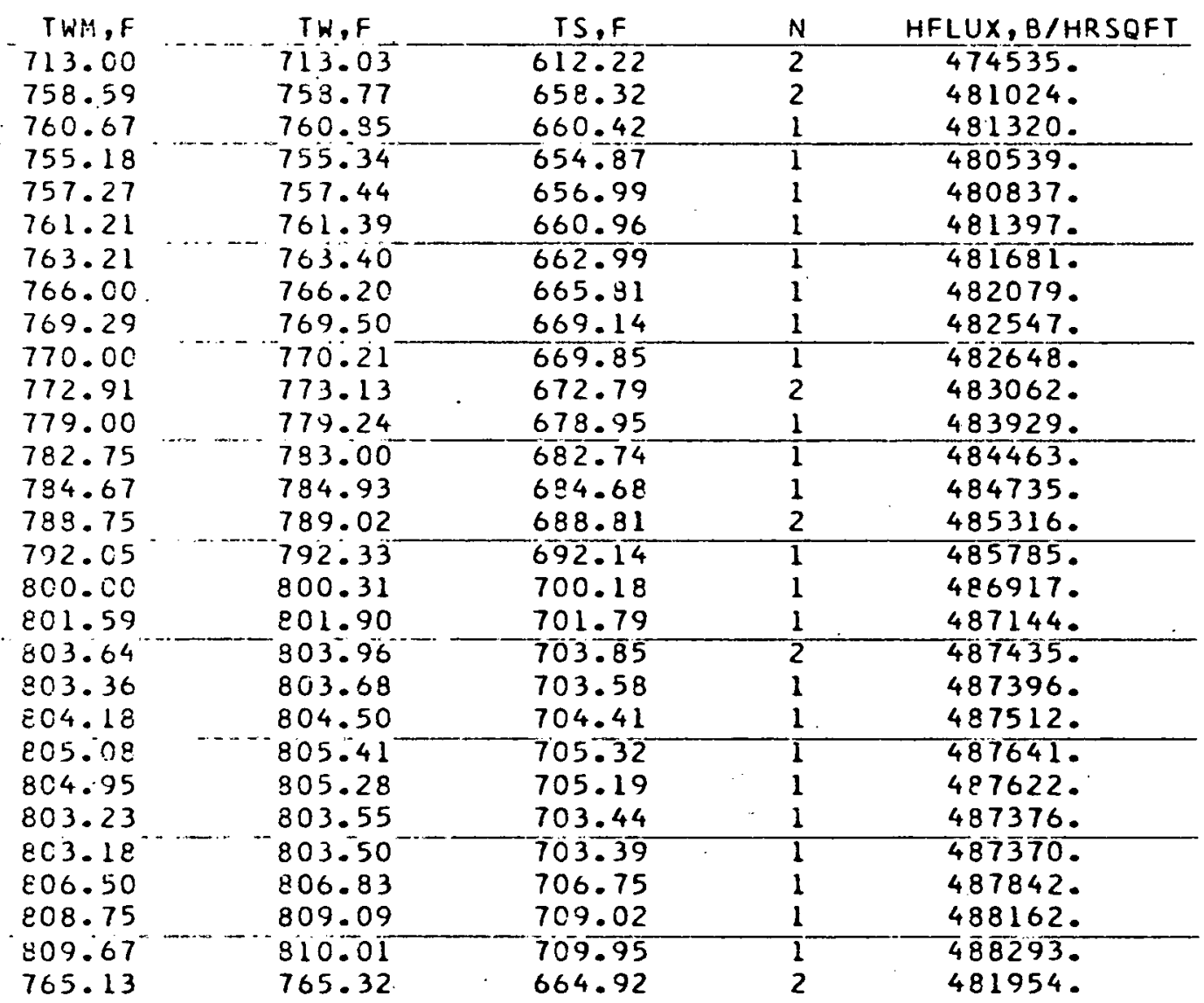


LOCAL TEMPERATURES, ENTHALPIES, hEAT TRANSFER COEFFICIENTS, AND STANTON NUMBERS

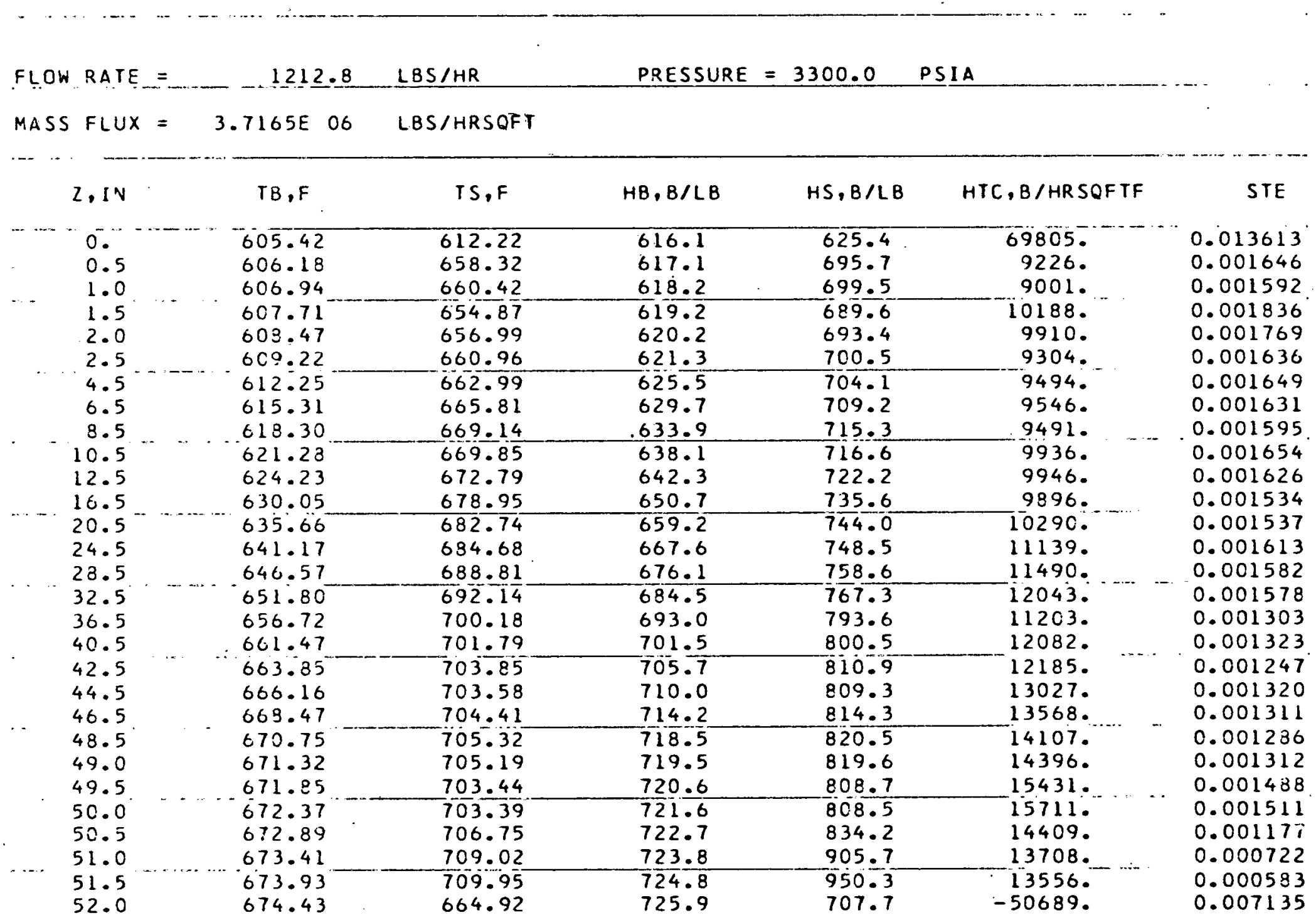


LOCAL SURFACE AND BULK TEMPERATURE, AND ENTHALPY DIFFERENCES

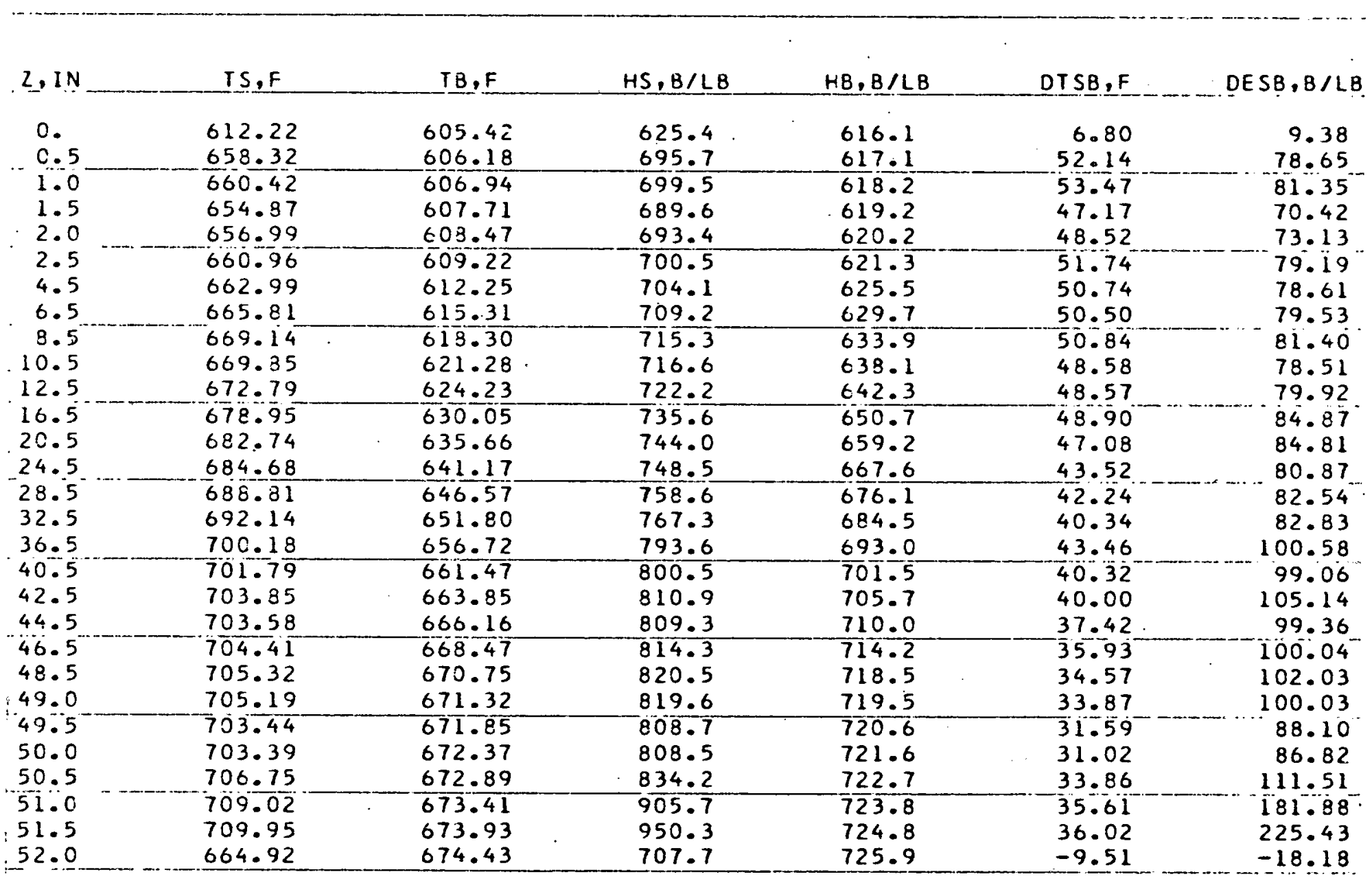


LOCAL PARAMETERS VERSUS NORMALIZED DISTANCE AND TEMPERATURE

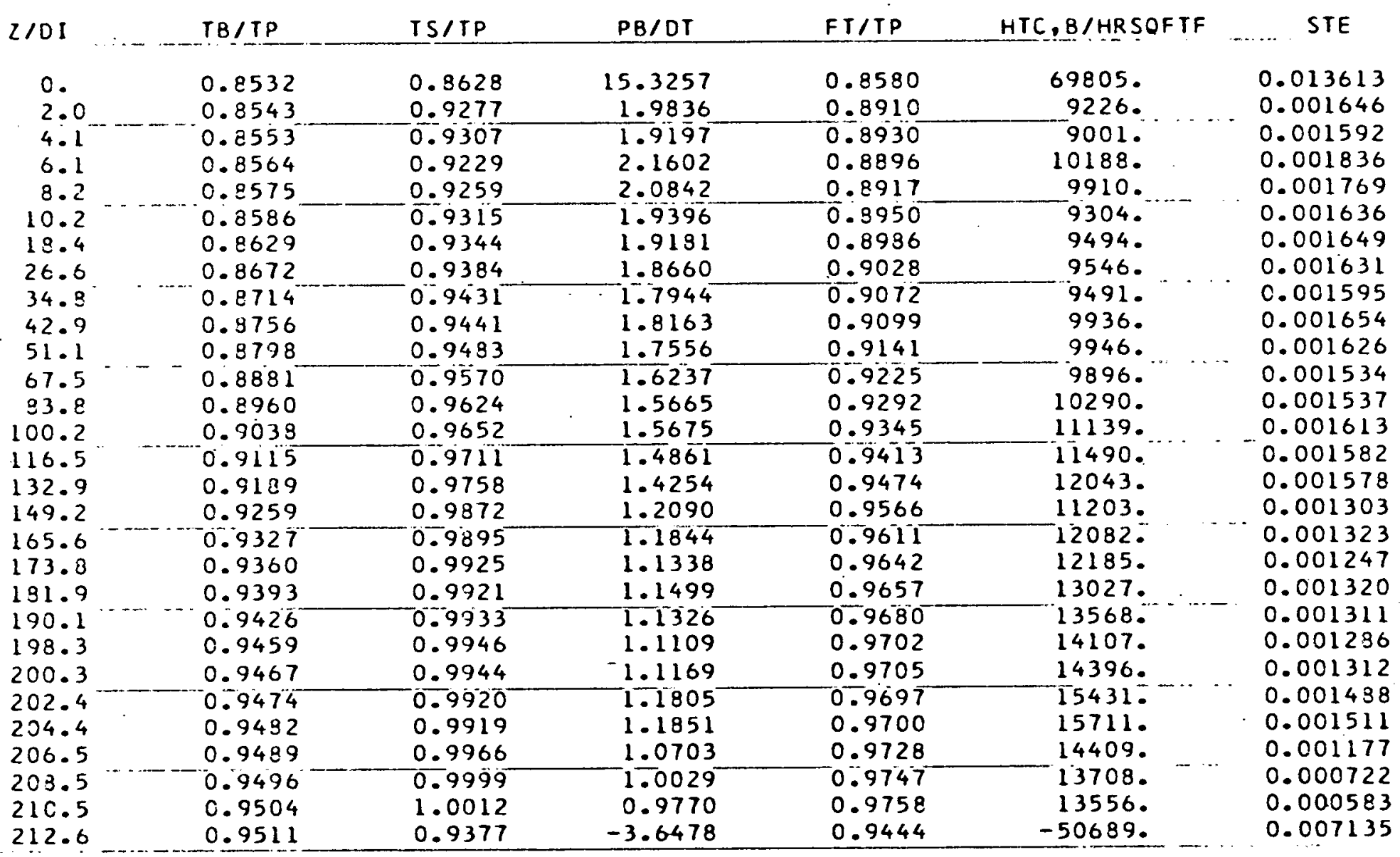


AVERAGE LOCAL PARAMETERS VERSUS NORMALIZEO DISTANCE AND TEMPERATURE

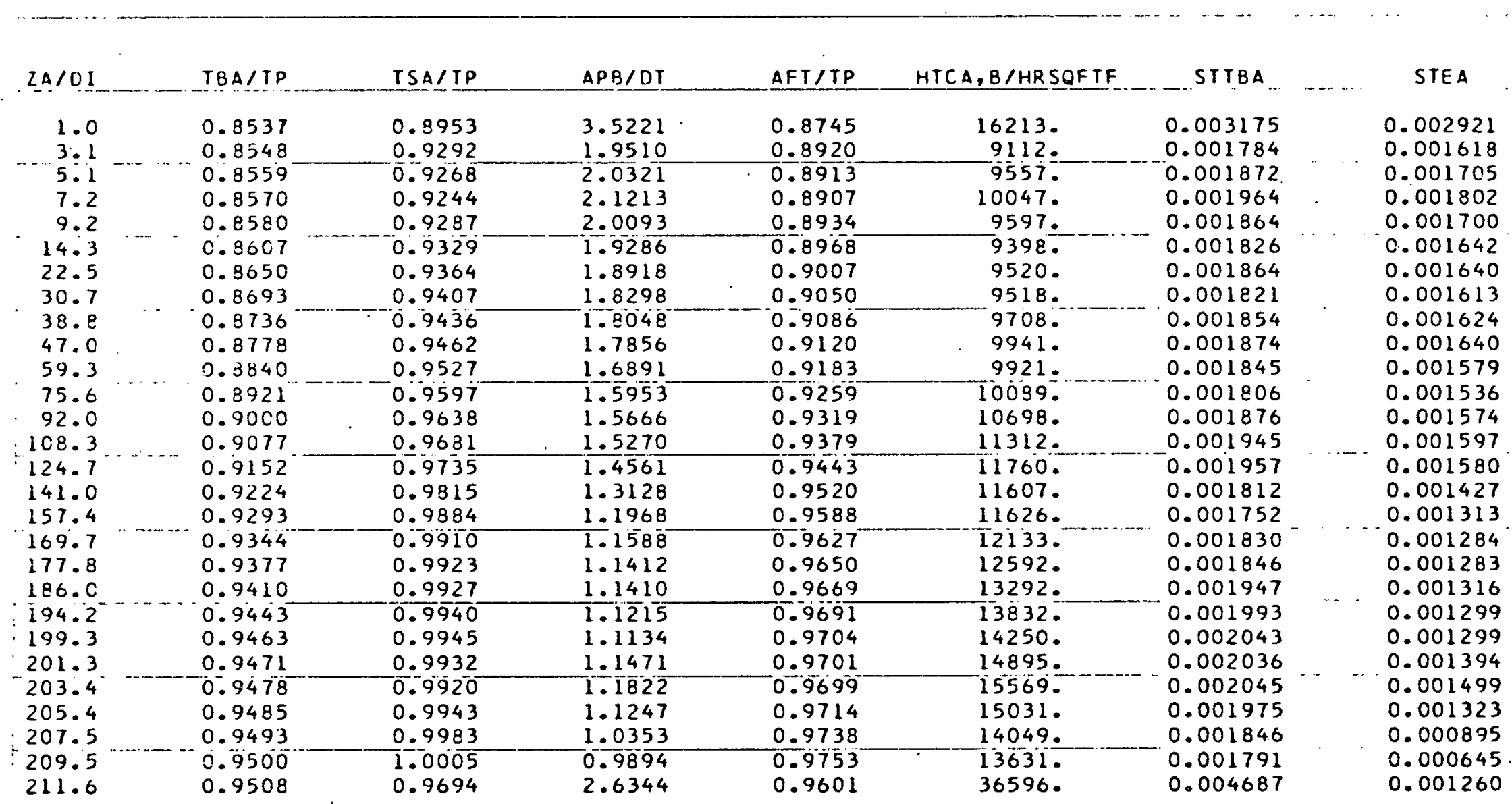


HEAT_BALANCE CONPUTATIOAS

RUN XF 9

$\begin{array}{lll} & \\ V T M, M V & T M I, F & \\ & 668.21 & 668.21 \\ 14.437 & 673.88 & 668.09 \\ 14.572 & 677.27 & 671.47 \\ 14.650 & 672.50 & 665.65 \\ 14.540 & 654.42 & 6.87 .57 \\ 15.046 & \end{array}$

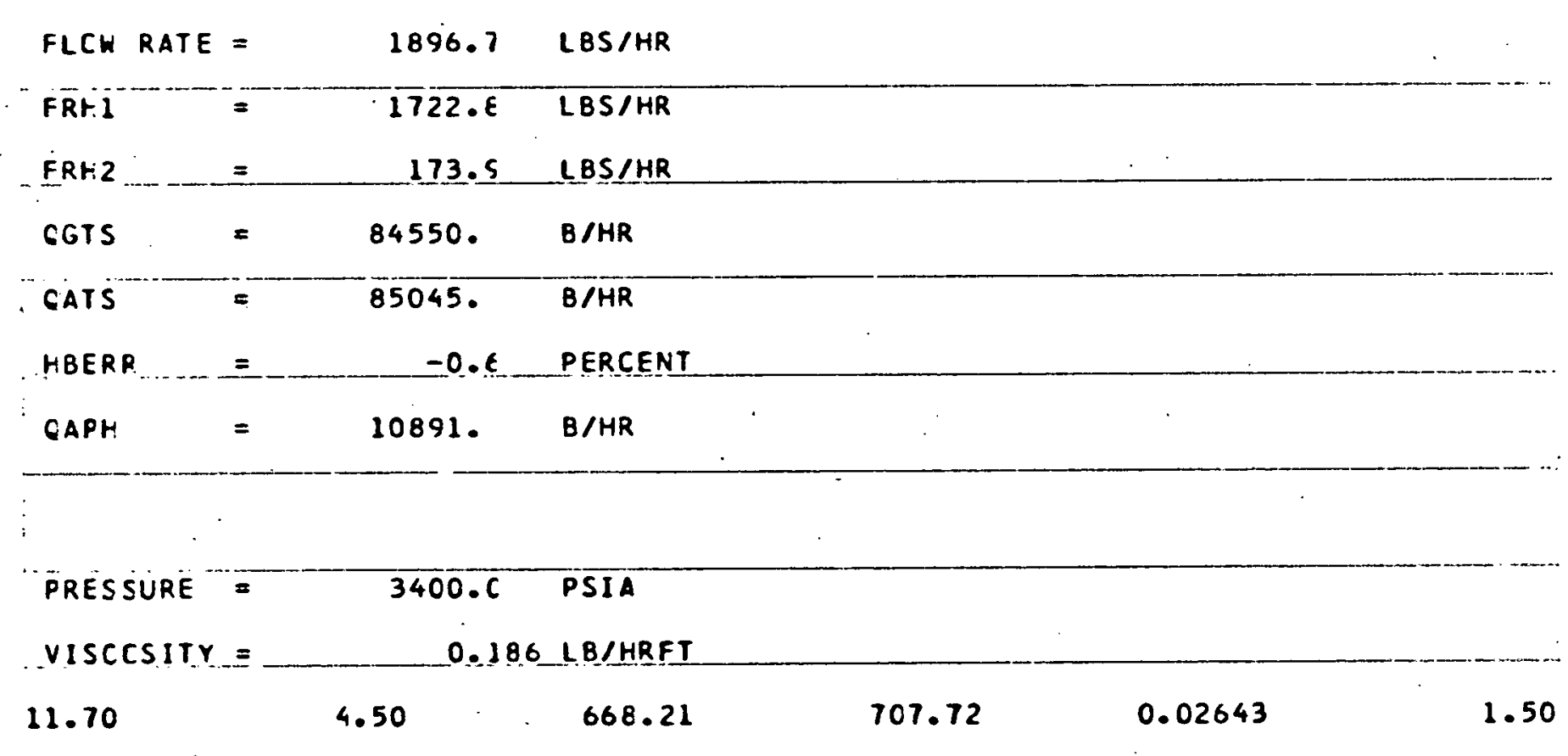


CCNPUTATIUN CF IJIUE SLPFÁCE TEMPERATURE AND LOCAL WALL HEAT FLUX

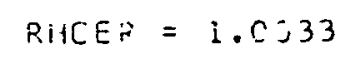

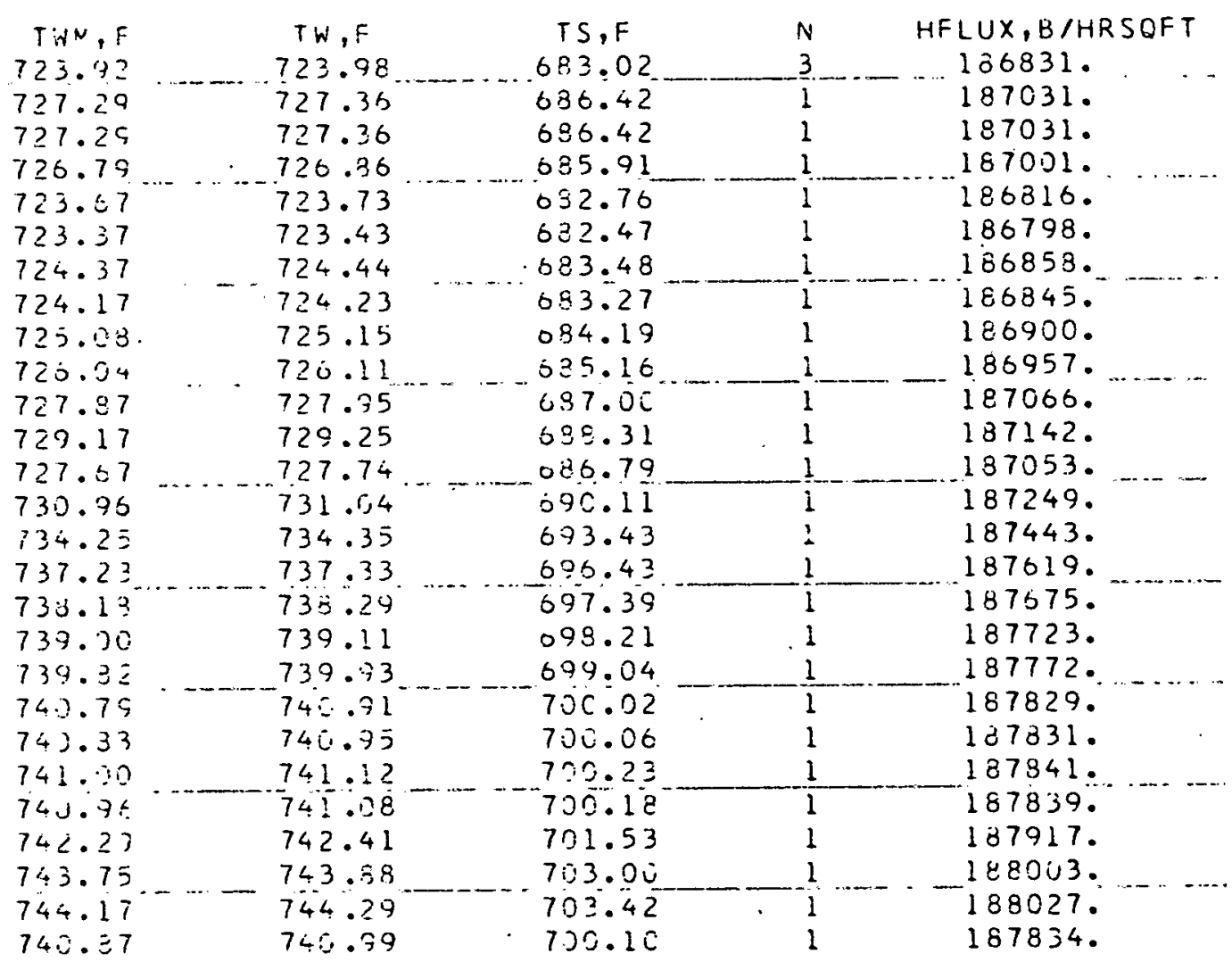


LOCAL TEMPERATLRES, ENTHALPIES, HEAT TRANSFER COEFFICIENTS, AND STANTON NUMBERS

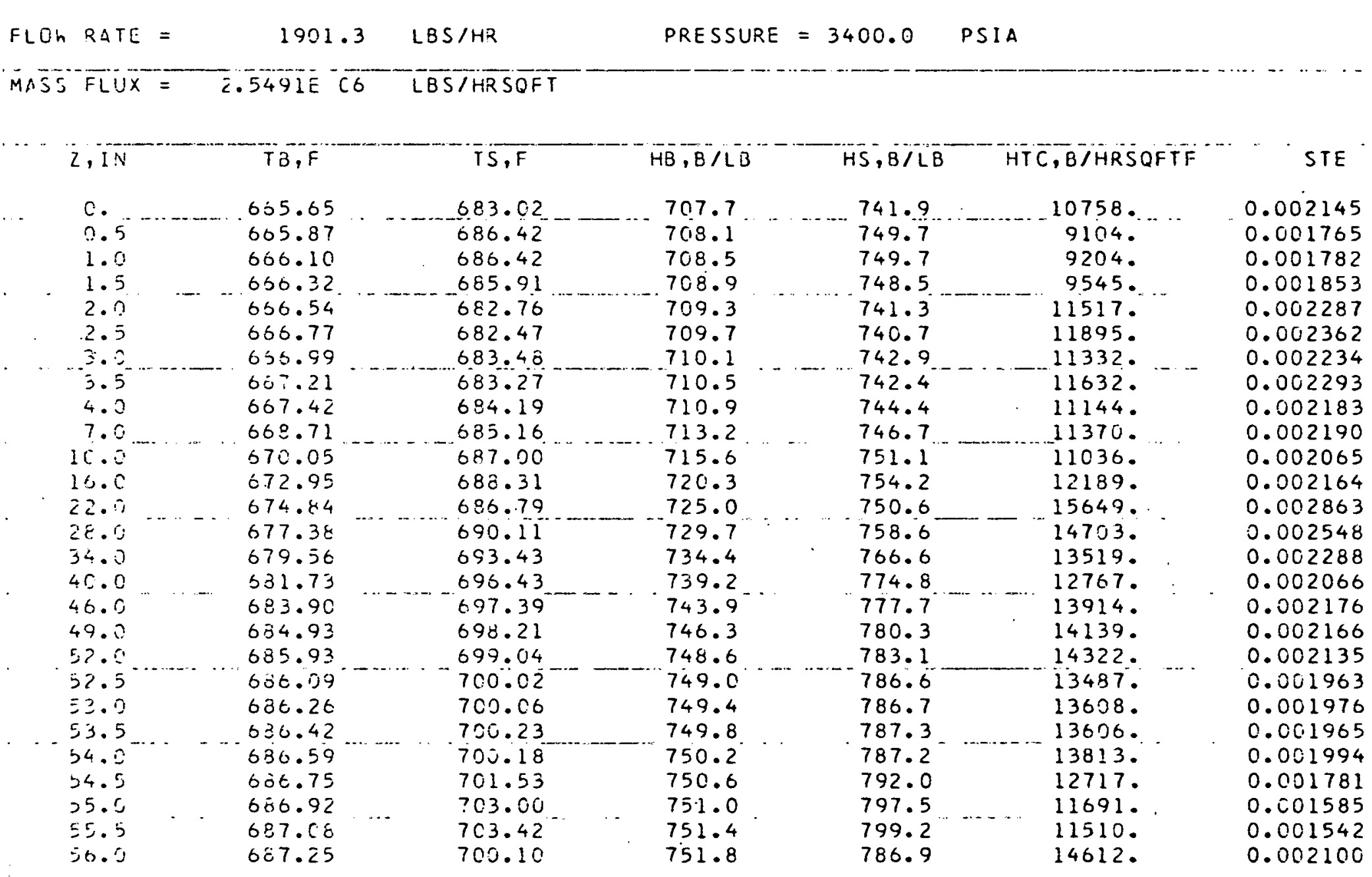


LÖCÁL SURFACE AND BULK TEMPERATURE, AND ENTHALPY DIFFERENCES

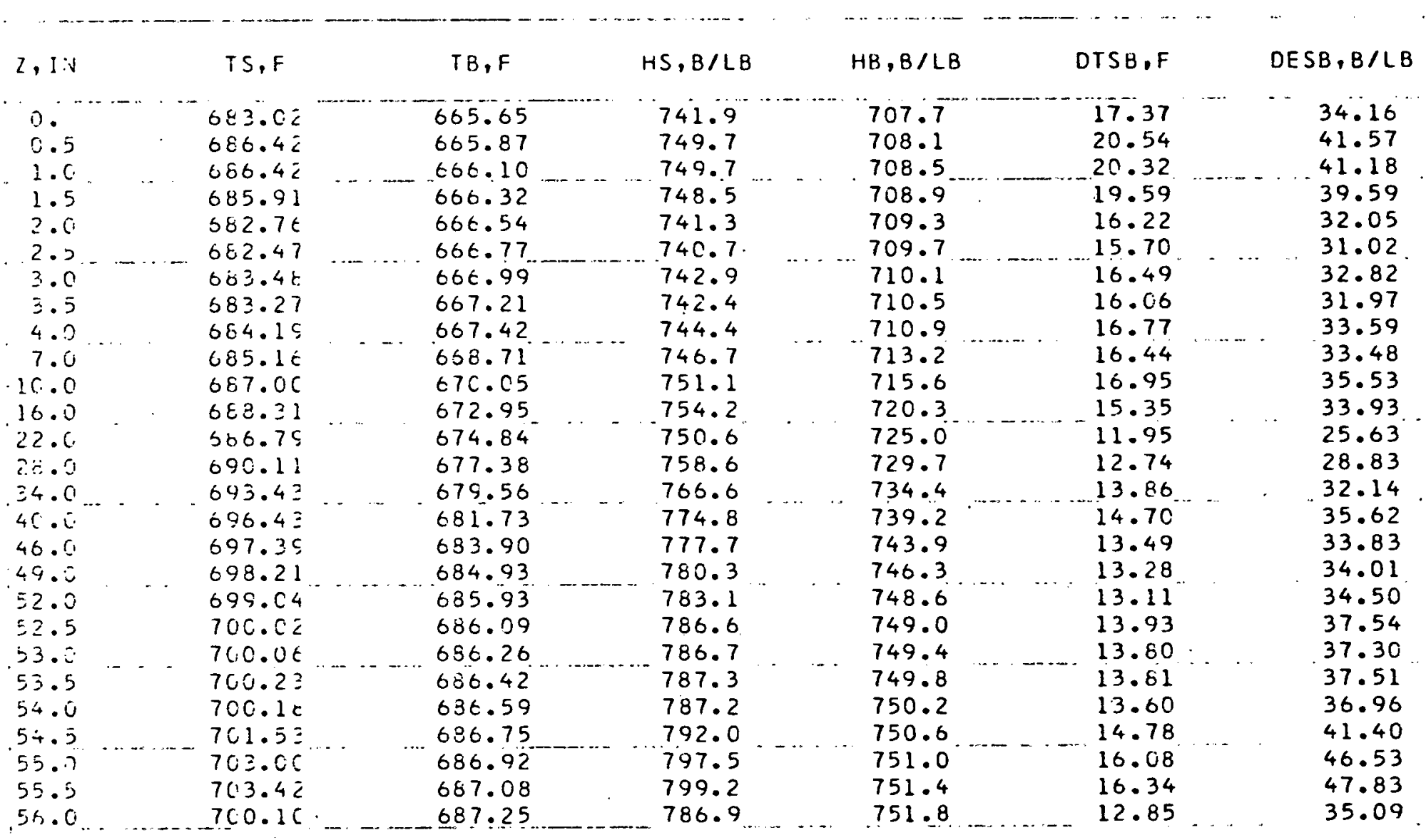




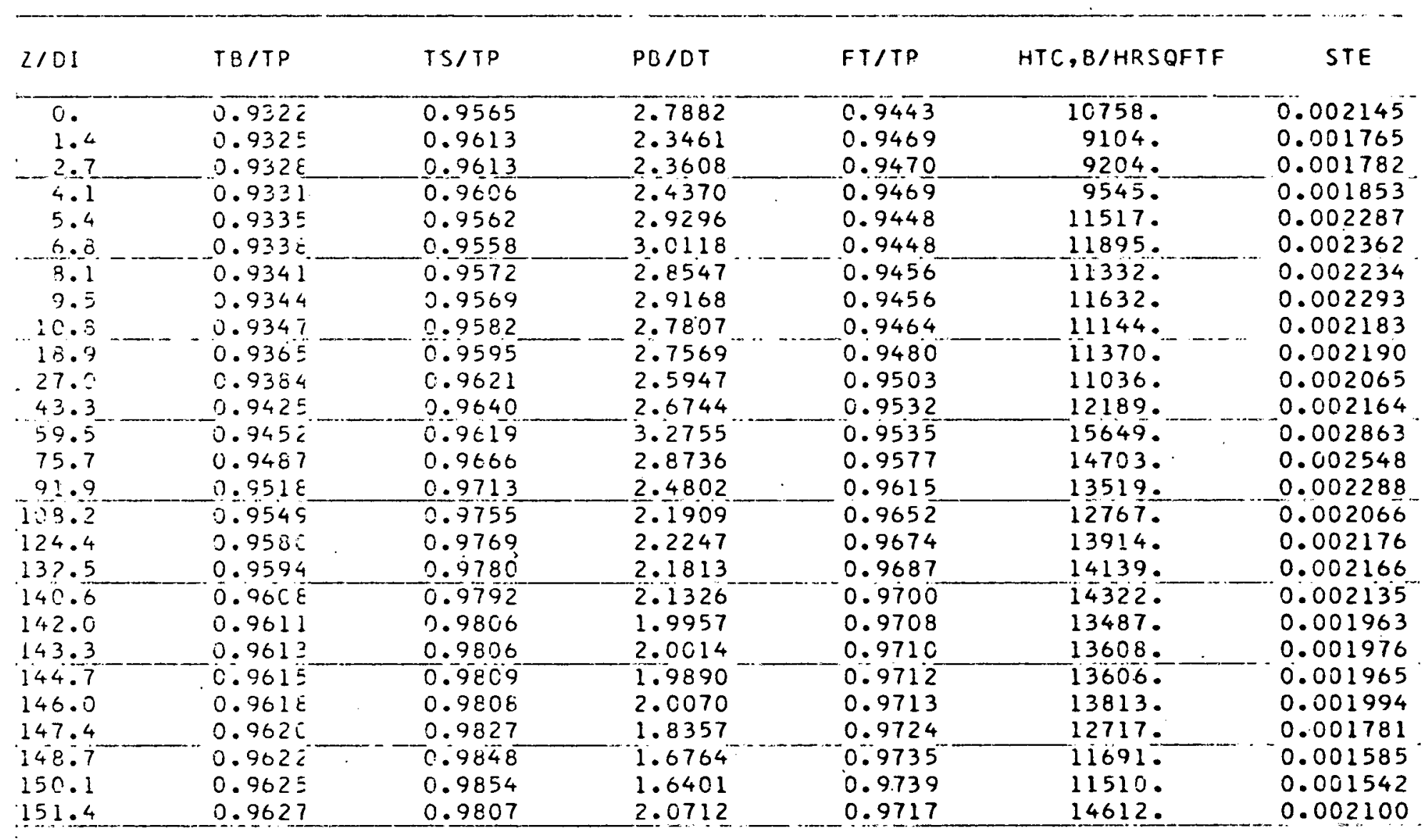




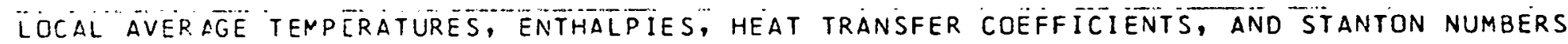

\begin{tabular}{|c|c|c|c|c|c|c|c|}
\hline$S A, F$ & $T B A, F$ & $H S A, B / L B$ & $H B A, B / L B$ & HTCA, B/HRSOFTF & STTBA & & STEA \\
\hline 684.72 & 665.76 & 745.78 & 707.92 & 9862 . & 0.002203 & & 0.001936 \\
\hline 686.42 & 665.99 & 749.68 & 708.31 & 9154. & 0.002044 & & 0.001773 \\
\hline 686.16. & 666.21 & 749.09 & 708.70 & 9371. & 0.002093 & & 0.001817 \\
\hline $68<.34$ & 666.43 & 744.91 & 709.09 & 10438 . & 0.002331 & & 0.002047 \\
\hline 082.62 & 660.66 & 741.02 & 709.49 & 11703 & 0.002614 & & 0.002324 \\
\hline$\varepsilon 2.97$. & 660.88 & 741.80 & 709.88 & 11607. & 0.002575 & & 0.002296 \\
\hline 633.37 & 657.10 & 742.67 & 710.27 & 11480 & 0.002473 & & 0.002263 \\
\hline 083.73 & 667.31 & 743.44 & 710.66 & 11383 & 0.002452 & & 0.002236 \\
\hline 084.07 & 668.07 & 745.57 & 712.04 & 11256 & 0.002425 & & 0.002187 \\
\hline 686.08 & 669.38 & 748.90 & 714.39 & 11200 & 0.002498 & & 0.002126 \\
\hline 687.05 & $.5 \mathrm{C}$ & 75 & 717.93 & 11584. & 0.002792 & & 0.002113 \\
\hline 607.5 .5 & 673.90 & .75 & 722.65 & 13703. & 0.002155 & & 2465 \\
\hline 028.45 & 676.11 & 754.59 & 727.36 & 15161. & 0.003195 & & 0.002696 \\
\hline 091.77 & 678.47 & .57 & 732.08 & 140 & 0.0 & & 2411 \\
\hline 694.93. & 680.65 & . 69 & 736.81 & $13132^{\circ}$ & 0.002363 & & 0.002171 \\
\hline $696.9=$ & 682.81 & 776.26 & 741.54 & 13316. & 0.002397 & & 0.002120 \\
\hline 697.30 & 634.42 & 779.00 & 745.08 & 14026 & 0.002407 & & 0.002171 \\
\hline 098.52 & 635.43 & 781.70 & 747.45 & 14230. & 0.002338 & & 0.002150 \\
\hline 699.53 & 680.01 & 784.85 & 748.83 & 13892. & 0.002282 & & 0.002045 \\
\hline 700.04 & 656.17 & 786.64 & 749.22 & 13547. & 0.002226 & & 1969 \\
\hline 700.14 & 686.34 & 787.02 & 749.62 & $13607=$ & 0.002235 & & 0.001970 \\
\hline 100.21 & 606.50 & 787.25 & 750.01 & 13709. & 0.002250 & & 0.001979 \\
\hline 700.36 & 686.67 & 789.59 & 750.41 & 13242 & 0.002171 & . & 0.001881 \\
\hline 26. & 680.83 & 794.77 & 750.80 & 12182 & $c .001997$ & & 0.001677 \\
\hline $703.2 \mathrm{i}$ & 687.00 & 798.38 & 751.20 & 11600. & 0.001902 & & 0.001563 \\
\hline $7 \mathrm{Cl} 1.76$ & 687.16 & 793.05 & 751.59 & 12876 & 0.002111 & & 0.001778 \\
\hline
\end{tabular}




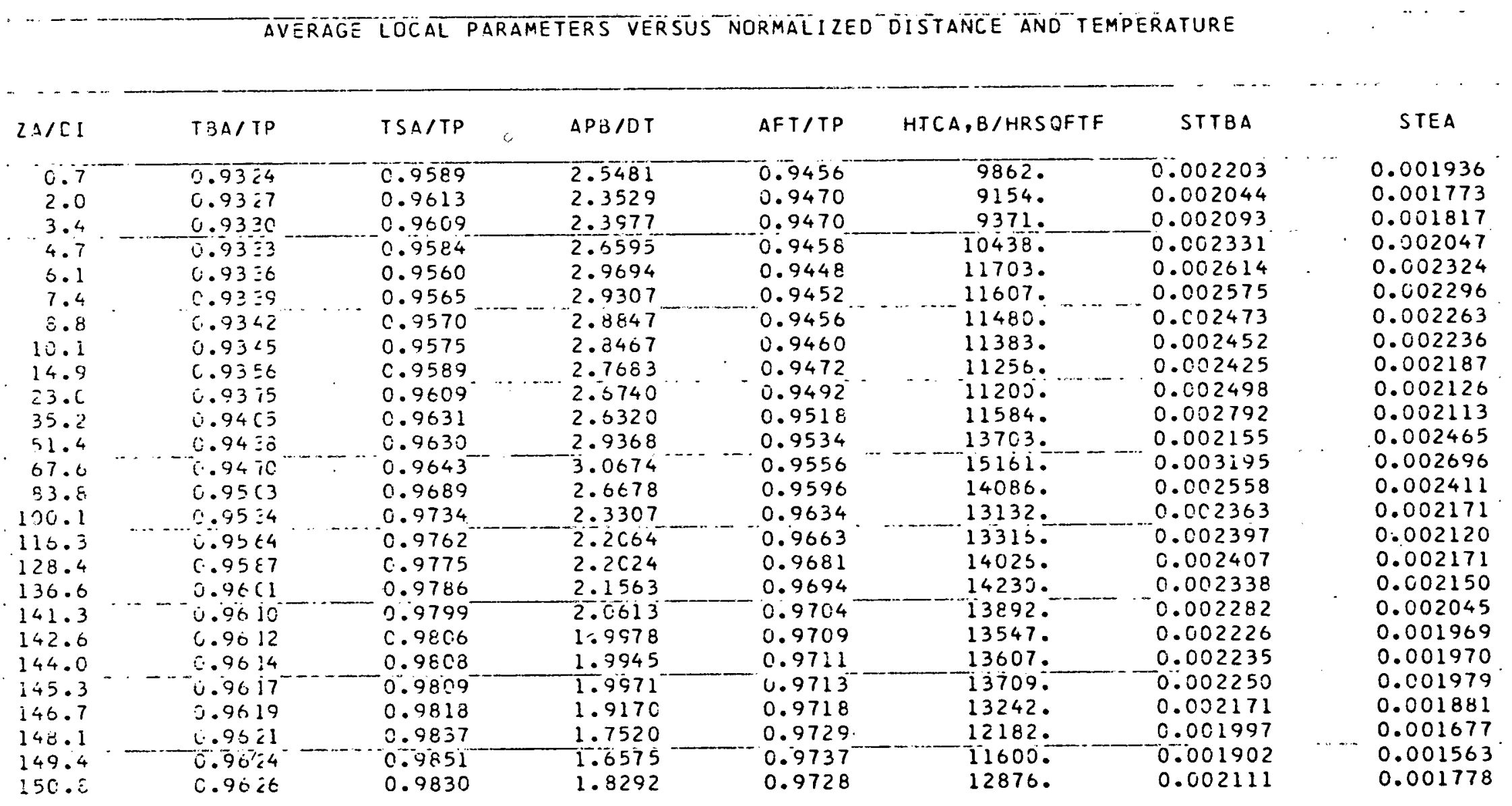


... HEAT_BALANCE_COMPUTAIIONS

RUN XEII

$\begin{array}{lll} & \\ \text { VTM,MV TMI.F } & \\ & & \\ 14.694 & 679.27 & 679.27 \\ 14.863 & 686.50 & 680.66 \\ 15.070 & 695.42 & 689.53 \\ 14.879 & 687.23 & 680.38 \\ 15.527 & 715.29 & 708.44\end{array}$

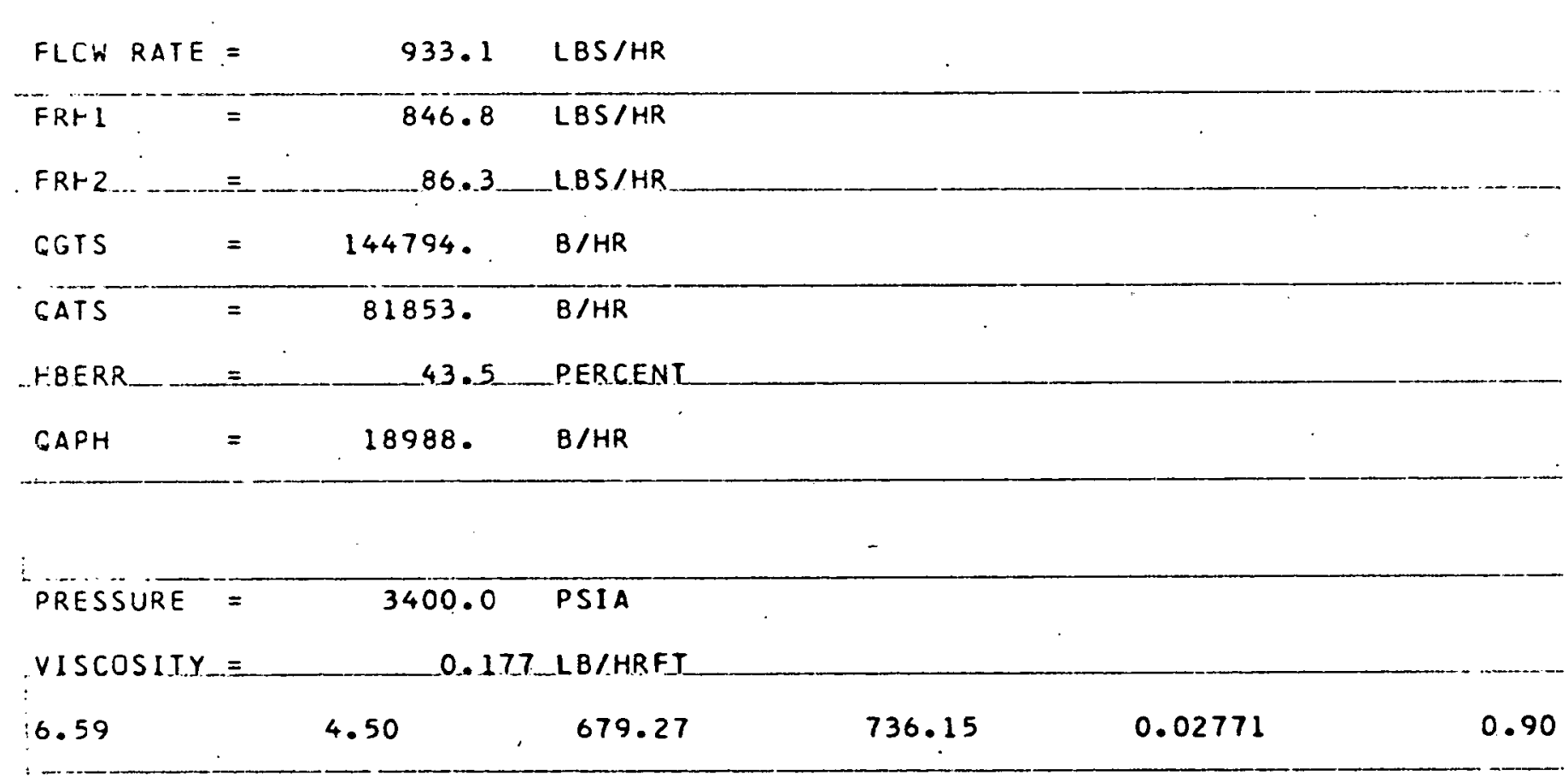


MILLIVOLT-TEMPERATURE CONVERSION FOR THERMOCOUPLES

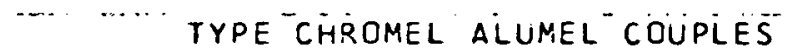

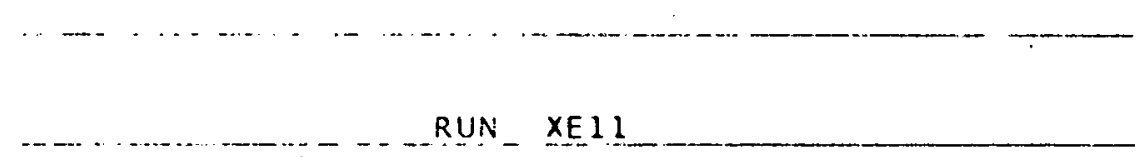

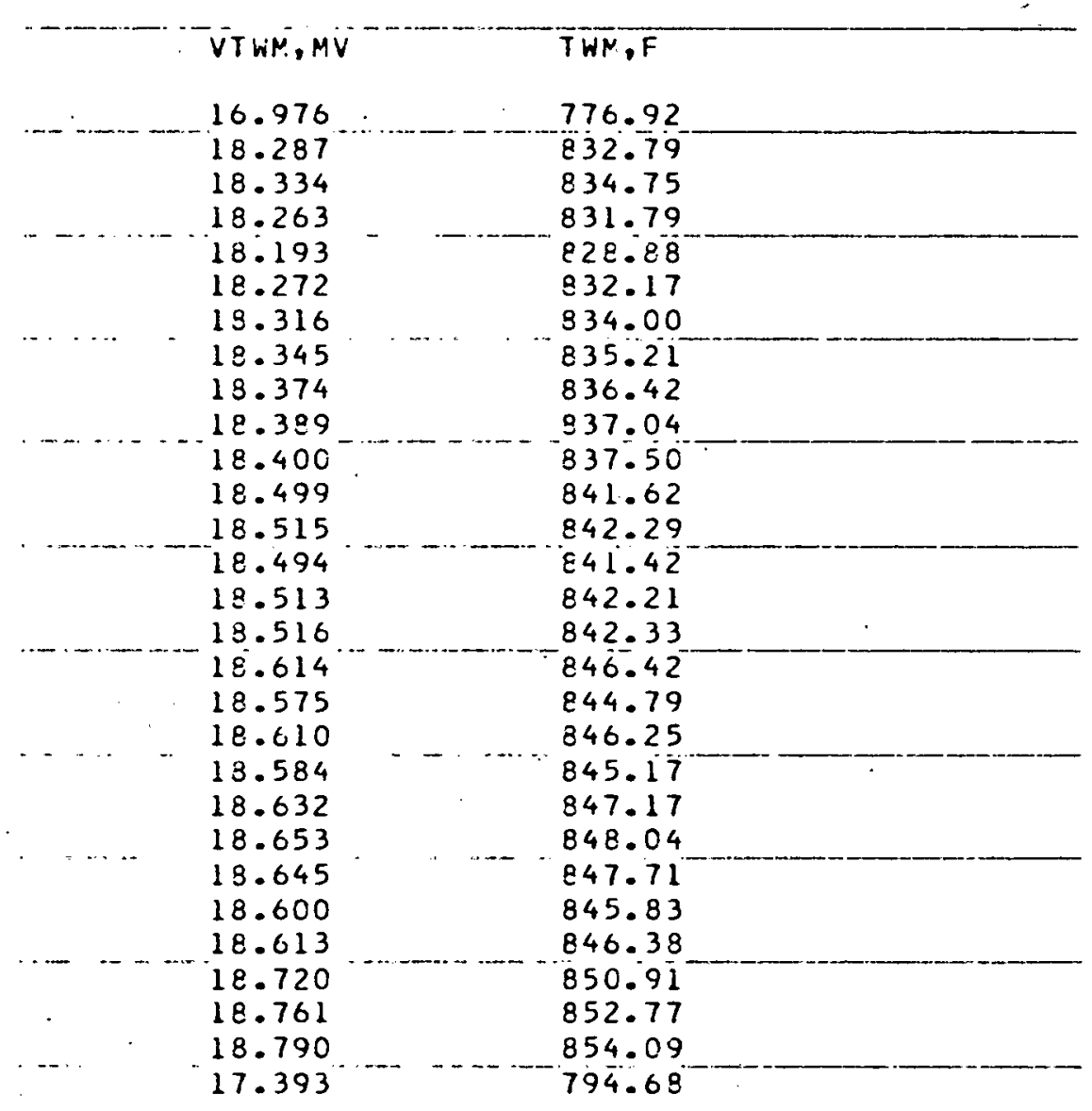


COMPUTATION OF INSIDE SURFACE TEMPERATURE AND LOCAL WALL HEAT FLUX

RHOER $=0.999 ?$

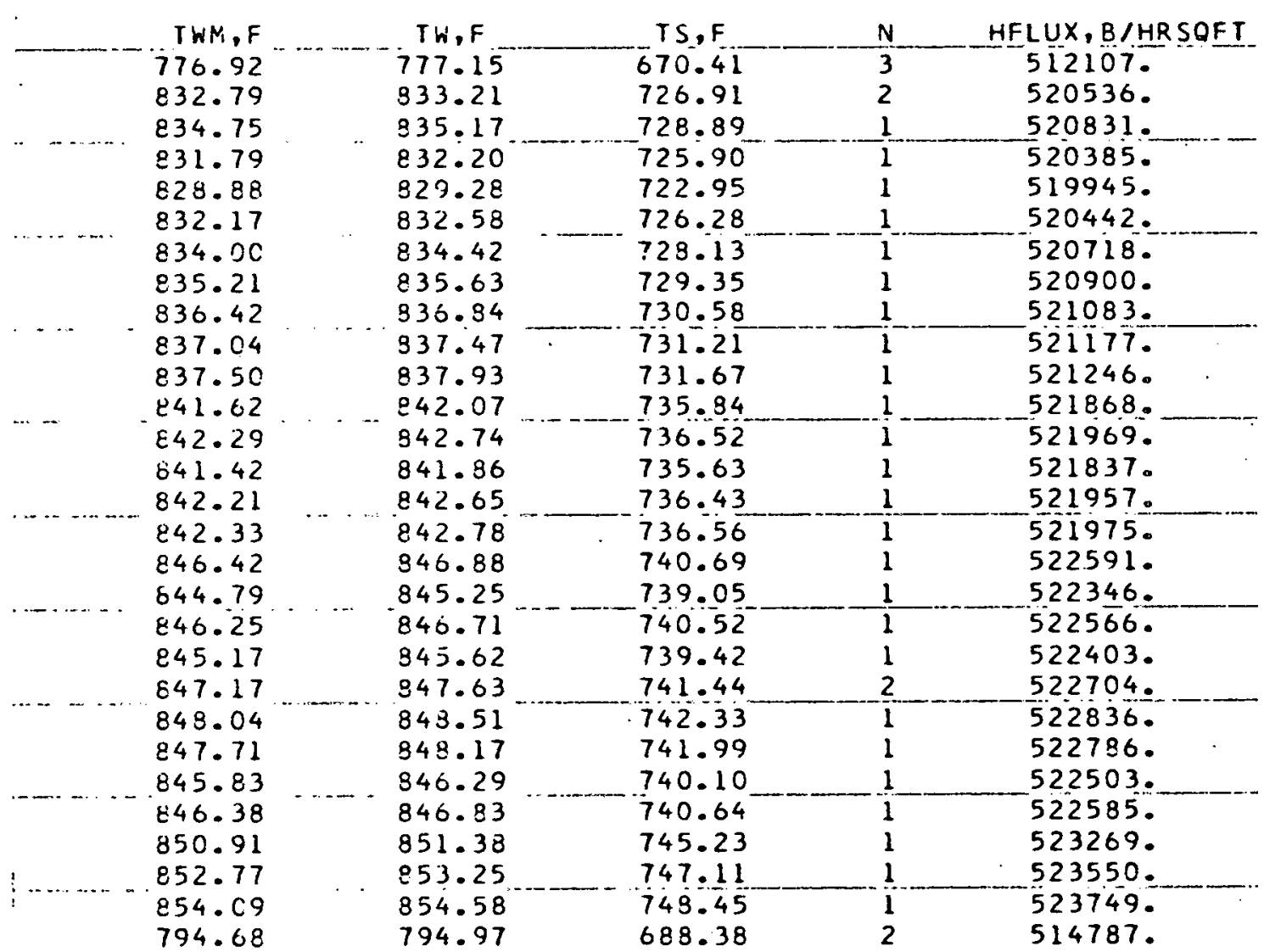


LOCAL TEMPERATURES, ENTHALPIES, heAT TRANSFER COEFFICIENTS, AND STANTON NUMBERS

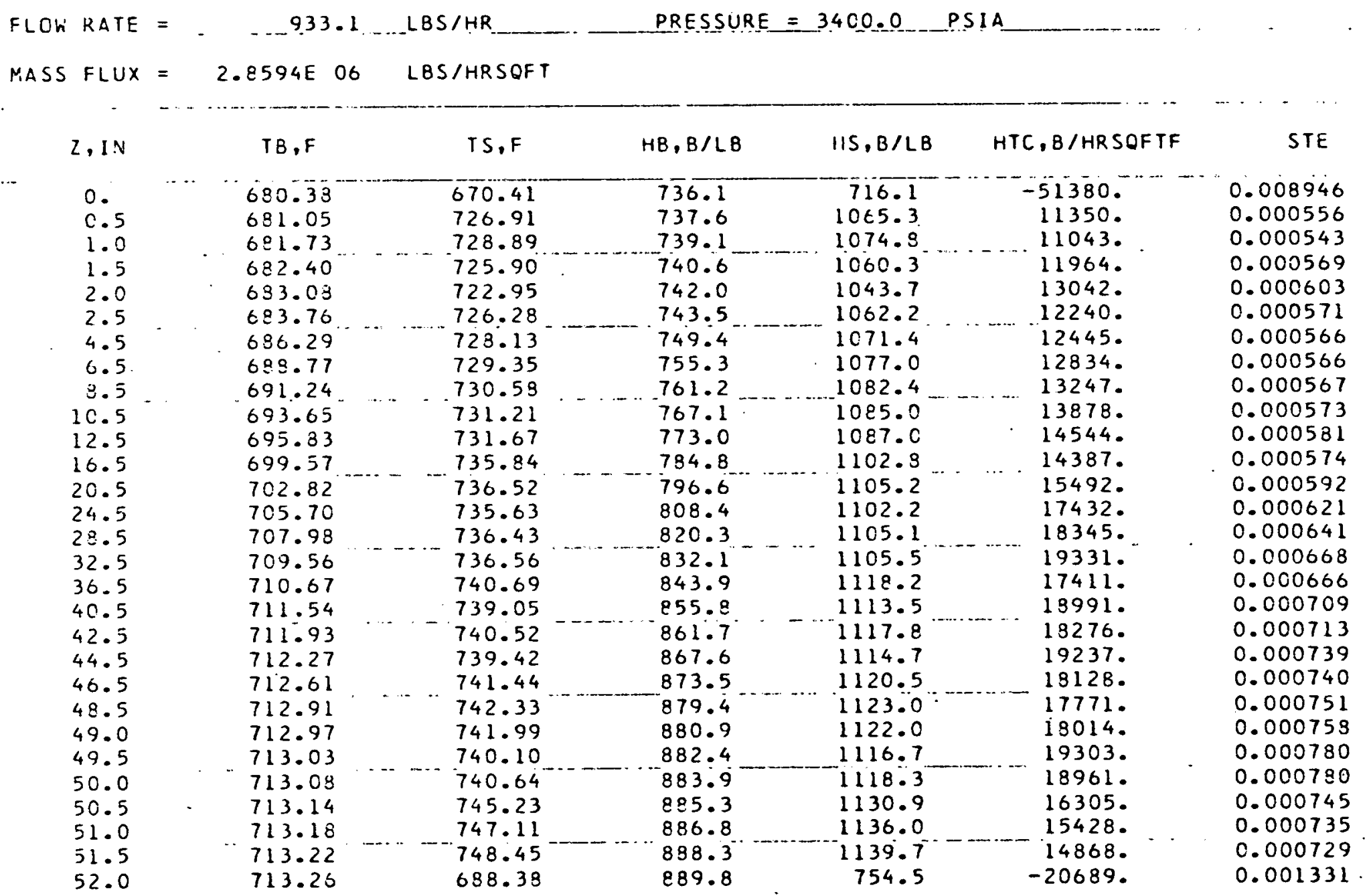


LCCAL SURFACE AND BULK TEMPERATURE, AND ENTHALPY DIFFERENCES

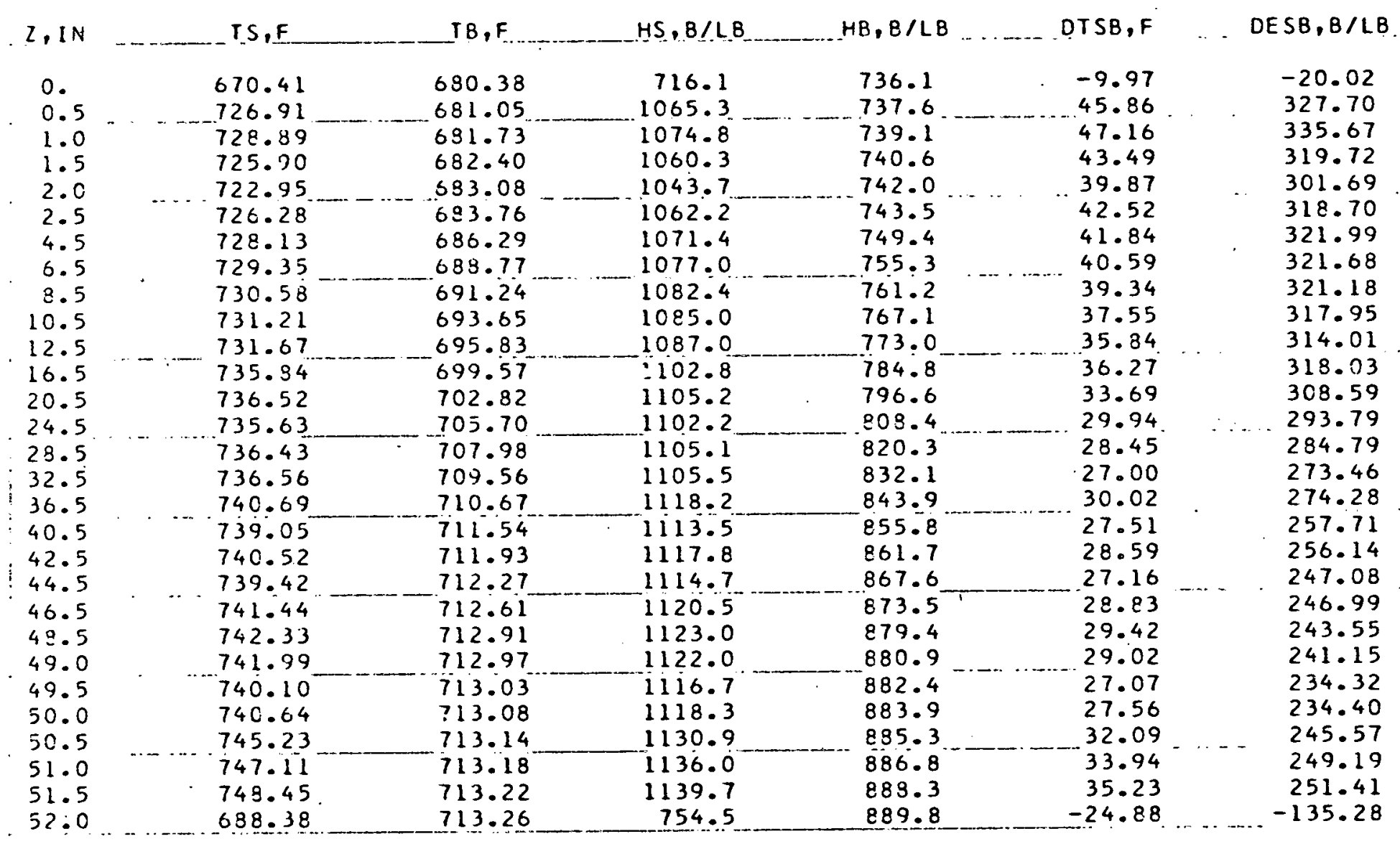




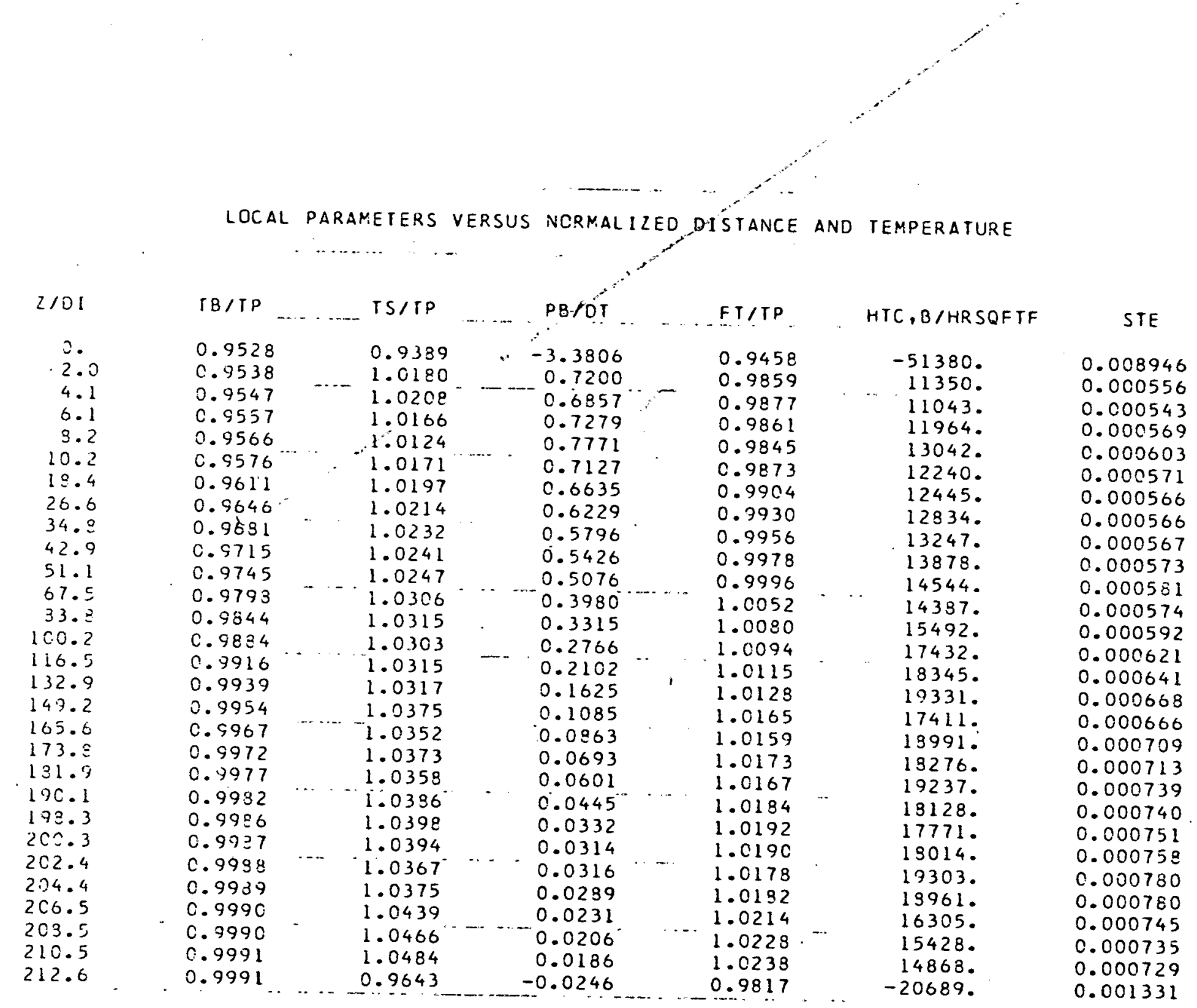




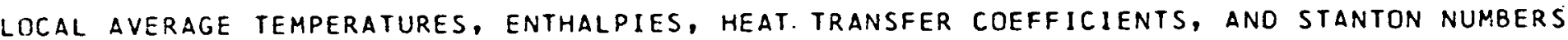

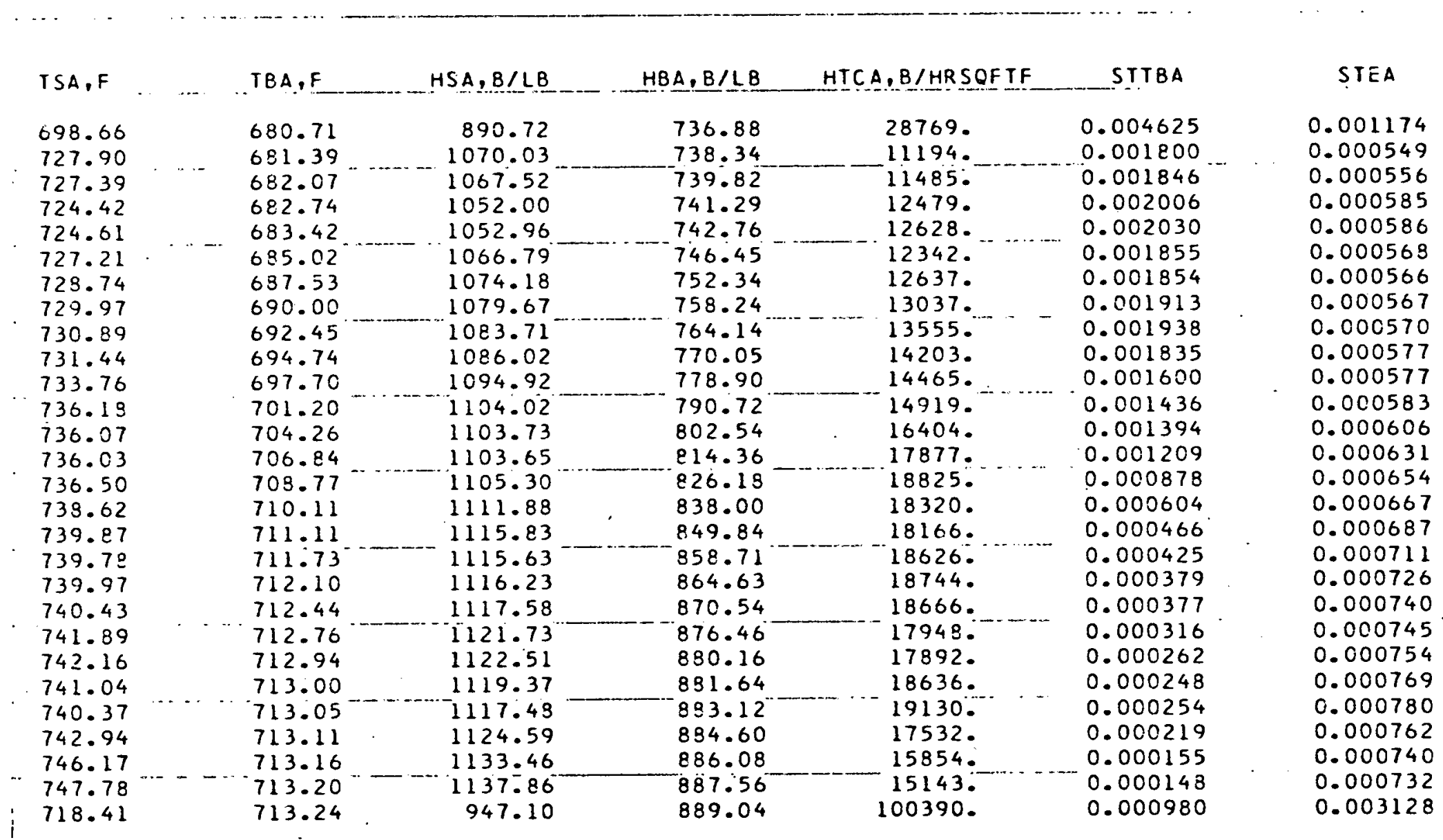


AVERAGE LOCAL PARAMETERS VERSUS NORMALIZED DISTANCE AND TEMPERATURE

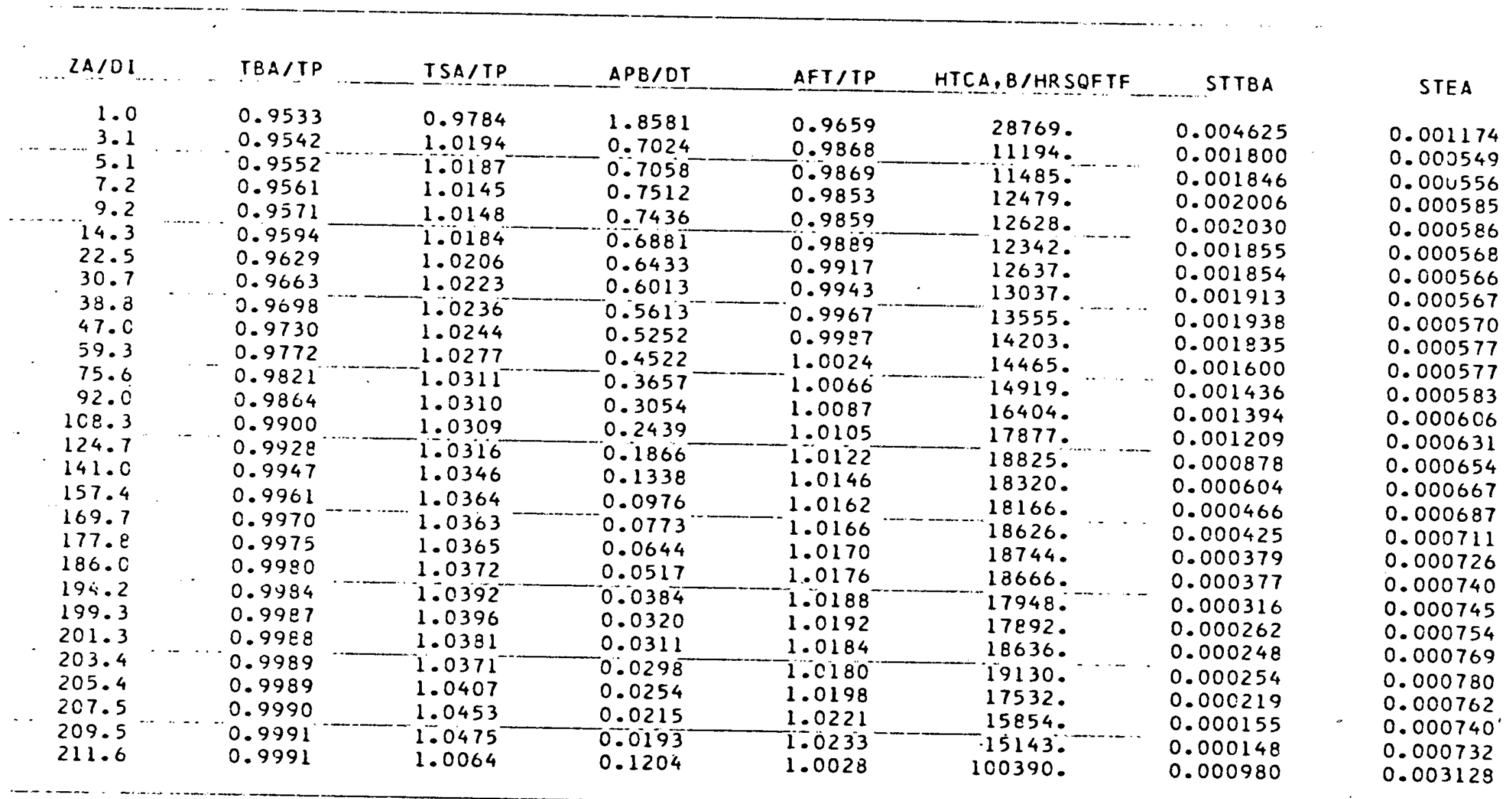




\section{APPENDIX I}

\section{EXPERIMENTAL DATA}

Nine sets of experimental data are presented in the following. The data appears in the following sequence.

1. Run number

2. $01=$ Venturi pressure drop in inches of mercury $00=$ Venturi pressure drop in psi

3. Test section outside wall thermocouple potentials as indicated. 29 for XE and 27 for XF

4. Test section current and voltage

5. Large venturi pressure drop, test section pressure drop in psi, venturi wall temperature, test section inlet enthalpy, fluid specific volume at the venturi, fluid viscosity at the venturi, test section inlet pressure, and small venturi pressure drop. 


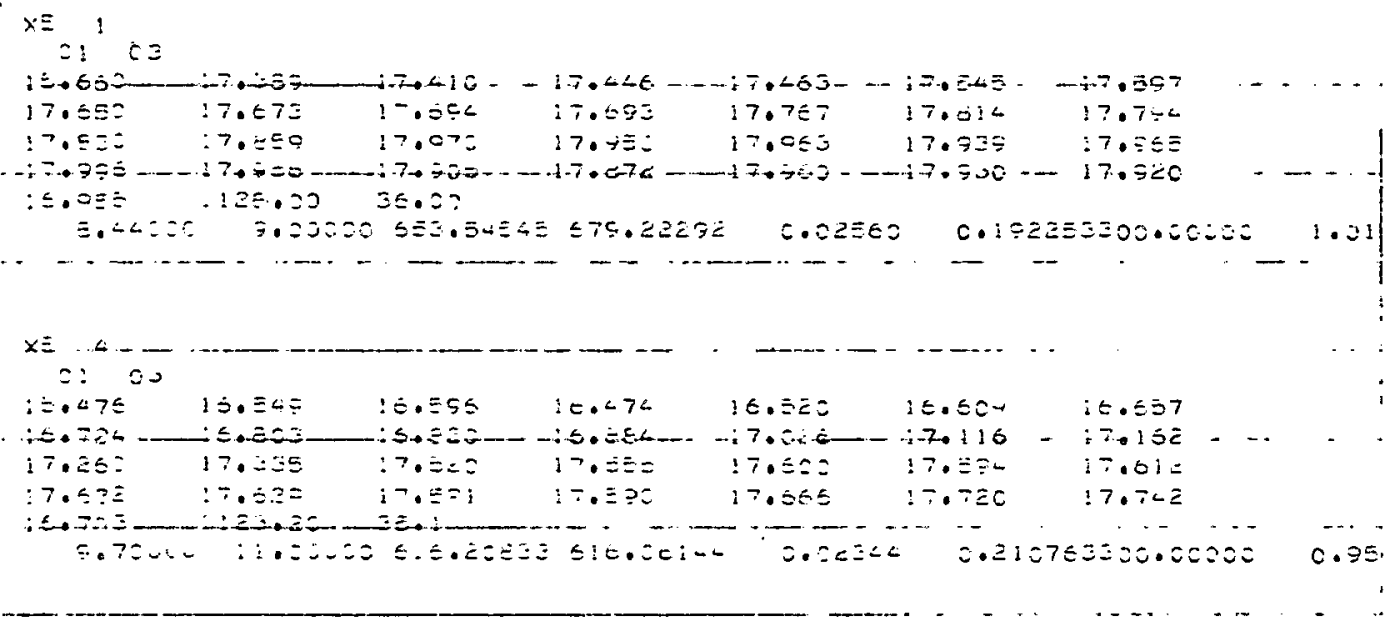

\begin{tabular}{|c|c|c|c|c|c|c|}
\hline$\therefore \therefore \quad \therefore=$ & --- & $\ldots-\ldots$ & - & ---- & $\cdots$ & $\cdot$ \\
\hline$\vdots \equiv . \approx=?$ & : ・・フミ & $: 7,: \leq 4$ & $: 7.1=0$ & $:-.: こ Z$ & : 7.こEL & $17 . \Xi \leq E$ \\
\hline$: 7 \cdot 2=5$ & $: 7 \cdot=\div$ & $: 7.555$ & $:-.=-6$ & $17 .-4 \equiv$ & $17.49=$ & 17.256 \\
\hline$\exists . . \Xi: \Xi$ & $\therefore ニ$ $\therefore=-$ & 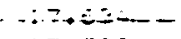 & $-\dot{a}= \pm \leqslant i$ & $-1=0=$ & $-17.60=-1$ & $i=0.630$ \\
\hline $\begin{array}{l}:-\because \leqslant \equiv \equiv \\
\vdots: \vdots \equiv: \vdots\end{array}$ & 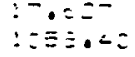 & 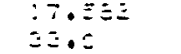 & $: 7 . \equiv 55$ & $: 7 .=7 三$ & $: 7.7: 5$ & $: 7.7 \div=$ \\
\hline
\end{tabular}

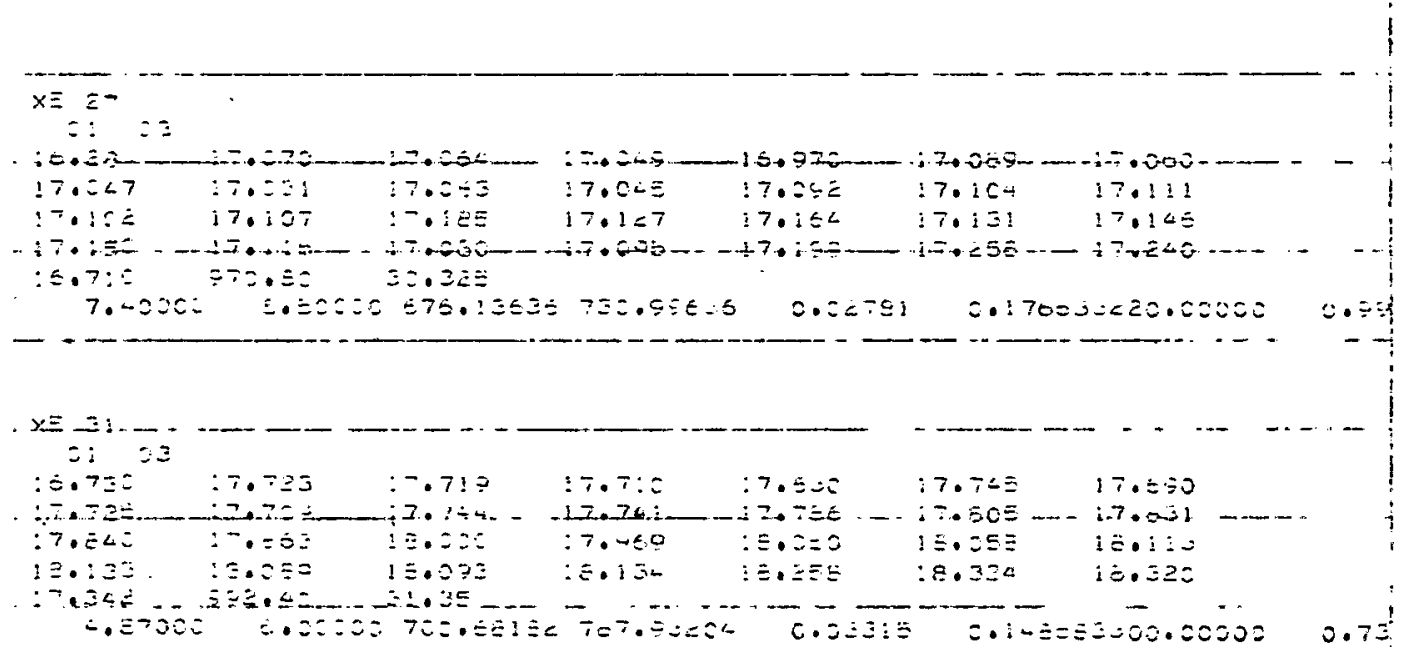




\begin{tabular}{|c|c|c|c|c|c|c|}
\hline 15.734 & 15.815 & 15.515 & 15.803 & 15.723 & 15.721 & 15.745 \\
\hline $15.7<0$ & $15 \cdot 762$ & 15.785 & 15.829 & 15.360 & 15.824 & 15.003 \\
\hline$i=0.982$ & 26.049 & $16.0>0$ & $-16 \cdot 038$ & $-160: 06$ & $-16 \cdot-129$ & $-16 \cdot 130$ \\
\hline $\begin{array}{l}16 \cdot 134 \\
24 \cdot 75\end{array}$ & 16.133 & 16.165 & $10 . \tilde{c 00}$ & 16.210 & $1 \in .131$ & $100 \approx .0$ \\
\hline
\end{tabular}

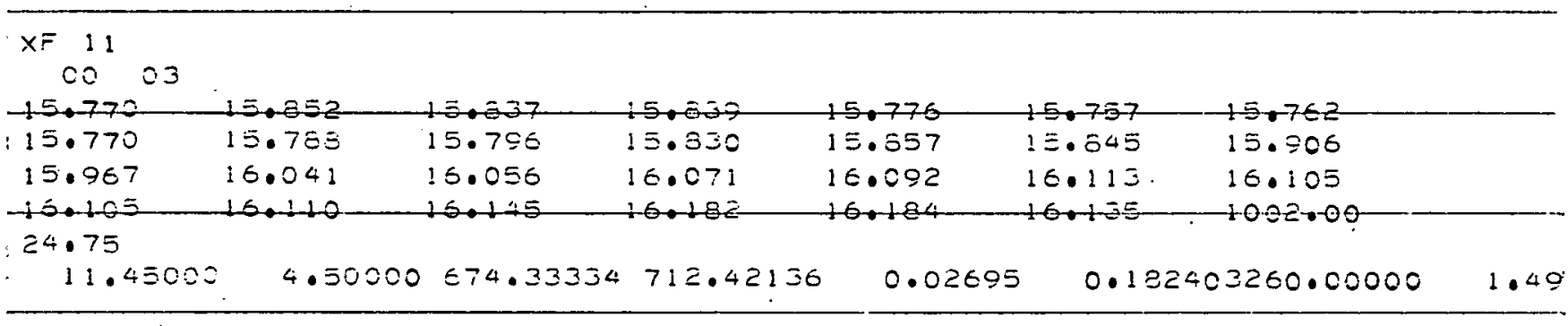

\begin{tabular}{|c|c|c|c|c|c|c|c|}
\hline \multicolumn{8}{|l|}{0103} \\
\hline$\cdot 16.328$ & 17.501 & 17.519 & 17.692 & 17.730 & 17.715 & 17.200 & \\
\hline 47.265 & 17.349 & $10003=$ & $1-160.185$ & -18.257 & $-1-2 \cdot-324$ & $-5 \cdot 306$ & \\
\hline$i 5.773$ & 15.949 & 19.120 & 19.124 & 19.201 & 10.150 & $19 \cdot 2 \overline{25}$ & \\
\hline 10.270 & 19.301 & 19.314 & 19.270 & 19.200 & 18.004 & $12=6.0$ & \\
\hline$\equiv .46000$ & C. & 695.70165 & 760.16664 & $\begin{array}{l}0.03207 \\
.\end{array}$ & $c \cdot 1:$ & 73300.00000 & o. \\
\hline
\end{tabular}

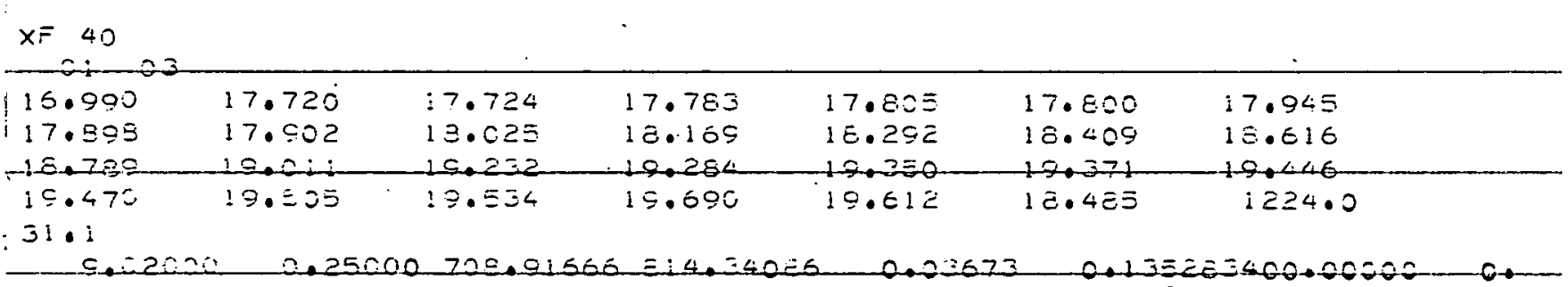




\section{APPENDIX $\mathrm{J}$ \\ POSSIBLE UNCERTAINTIES IN THE COMPUTED PARAMETERS}

The possible extent of uncertainties in the thermodynamic and transport properties, and in the computation of the inside surface temperature have been already discussed in the previous sections. The object here is to relate the uncertainties in various parameters of interest to the above mentioned basic values. The maximum possible uncertainty in a parameter is obtained by forcing the uncertainties in its various terms to accumulate. This gives an upper limit to the possible uncertainty in a parameter, but it is improbable that all error would always add up.

The flow rate uncertainty was estimated at around one per cent, based on the scatter in the venturi flow coefficient. The error due to thé venturi pressure drop measurements should not have exceeded 0.02 inch of mercury which for a pressure drop of 5.0 inches of mercury amounted to only 0.2 per cent. Since usually higher pressure drops were measured, this error was considered insignificant. At near critical temperatures the uncertainty may have increased another two or three per cent due to the steeper specific volume-temperature gradient.

The major source of error in the heat transfer coefficient was the wall-to-fluid temperature difference. It has been already estimated that a 4-5 per cent uncertainty may enter the inside wall tempera- 
ture computations. Therefore, for $80 \mathrm{~F}$ outside wall-to-inside wall temperature drop, and a reliability of about $0.5 \mathrm{~F}$ in the readings of the outside wall thermocouple, a $4.5 \mathrm{~F}$ temperature uncertainty may exist for the inside wall temperature. This is the reason why sufficiently large wall to fluid temperature differences must be maintained to alleviate the effect of this uncertainty upon the heat transfer coefficient and the related parameters. Hence, for $t_{w}-t_{b}=20 \mathrm{~F}, a$ 22.5 per cent maximum uncertainty may be expected in the heat transfer coefficient. The heat flux error could not exceed one per cent since the volt-ammeter was guaranteed at one half of one per cent.

The uncertainty for the Stanton number was expected to be around 25 per cent under the above conditions. This assumed a two per cent uncertainty in the enthalpy values. However, in the critical region $s t_{e}=\frac{q_{w}^{\prime \prime}}{\left(H_{W} H_{b}\right) G}$ may have been subject to higher uncertainties because of the non-linearity of the isobaric enthalpy-temperature curves. The estimation of such an uncertainty becomes very difficult. The same comment holds for other parameters such as the Reynolds, Prandtl, and Nusselt numbers.

Because of the careful calibration of the thermocouples, the uncertainty in the measured temperatures should not have exceeded $0.5 \mathrm{~F}$ in general.

The good agreement with the available well established correlations in the appropriate regions indicated that the extent of uncertainties was less than the above predicted values. The heat transfer coefficient for temperatures up to about $650 \mathrm{~F}$ was well within ten per cent of the value computed from the Dittus-Boelter equation. 
APPENDIX K

\section{A DISCUSSION OF FLID VIBRATIONS}

The object here is to outline the various tests which were performed to determine the origin of the perturbations in the differential pressure measurements across the test section and the venturi meters. Needless to say, efforts also included as their objective the elimination of the fluctuations whether their course was understood or not. The scope of this appendix unfortunately does not permit full description of the many trials which lasted for over four months.

It was thought that the perturbations indicated by the differential pressure transducer could be due to three basic sources:

1. Fluid vibrations.

2. Mechanical vibrations affecting the transducer.

3. Transducer noise and instability caused by (1) or (2) above.

\section{Experimental Methods}

Preliminary examinations indicated that the perturbations would cease as soon as the system circulation pump was shut down. On restarting the pump the vibrations would start again. When, with the pump off, the pump casing was struck with a wrench or hammer the noise would appear on the transducer recorder. This effect could al so be produced by striking any part of the system piping, although at some locations harder blows were necessary for the noise to be seen by the recorder. 
The test section was the most susceptible piece. A slight touch or plucking of the test section could produce appreciable indications. For a moment then it seemed that mechanical vibrations were responsible for the perturbations.

It is very difficult to mechanically isolate sections of a system which are normally connected together by heavy welds or large bolted flanges. Special wooden clamps were made to help tie down the test section and the transducer lines at several locations in order to impede their mechanical vibrations. Also a special spring mounted base was installed under the pump and was bolted to the floor. However no progress was made.

During the next phase, for trial purposes low pressure flexible hose was installed in the pressure lines leading to the transducer, completely isolating it from other metal pieces. The hose would allow operations at pressures up to 200 psia. Appreciable reduction in the amplitude of the fluctuations was achieved at 50 psia system pressure. However, as the pressure was raised the amplitude increased too, probably due to the stiffening of the flexible lines. The hose could have also provided damping against fluid vibrations. For further study high pressure flexible rubber hose of $1 / 4$ inch diameter was installed at the test section inlet and outlet, and at the transducer. The test section and the transducer were then completely isolated from the system. Again low pressure operations showed reductions in the amplitude of the vibrations, but no improvements were. - achieved at higher pressures. A series of vibration and dynamic tests were then carried out using a vibration pick-up. The object was to determine if it were 
possible for the pump vibration to carry through to the test section and the transducer. The pick-up was first installed on the pump to detect its vibrational modes. The known pump frequency together with a beat of four to five cycles per second could be observed. Loading the pump with 250 pounds decreased its effective frequency to one half the motor frequency. The effect of pump coolant flow was to add higher frequencies to the normal pump frequency.

The pick-up was then moved to the test section, the frequency of which was compared to the pump vibration output. It was found that the test section main frequency was around 10 cps. Pump cooling did not affect the test section frequency. When the pick-up was attached to other locations in the system and the framework, a frequency about one half the pump frequency was recorded. It must be mentioned that the pick-up was very sensitive and could detect minute perturbations.

The natural frequency of the transducer was obtained from transient tests clamping the plck-up to the transducer, and striking 1t. The recorded frequency was around $18.7 \mathrm{cps}$, and it demonstrated good damping characteristics. Comparison was also made between the oscllloscope traces of the pick-up mounted on the transducer and the transducer record of pressure drop across the test section. The pick-up reading gave the half pump frequency, while the transducer recorded other frequencies. As a matter of interest and record figures $k-1$ and $K-2$ show some of the findings of the above investigation. In figure $k-2$ lower traces in the top two pictures show differential pressure transducer output. Figure $k-3$ shows the various instruments employed in the dynamic analysis. From left to right Consolidated Electrodynamics 
PUMP FREQUENCY $=57.5 \mathrm{CPS}$

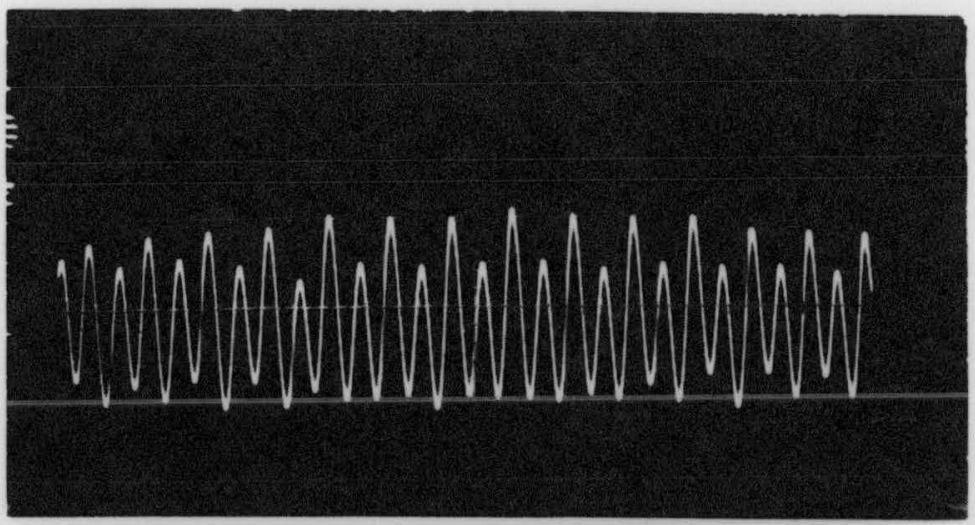

$\Sigma$
J
W
용

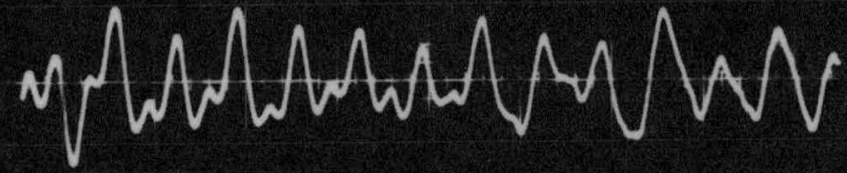

点

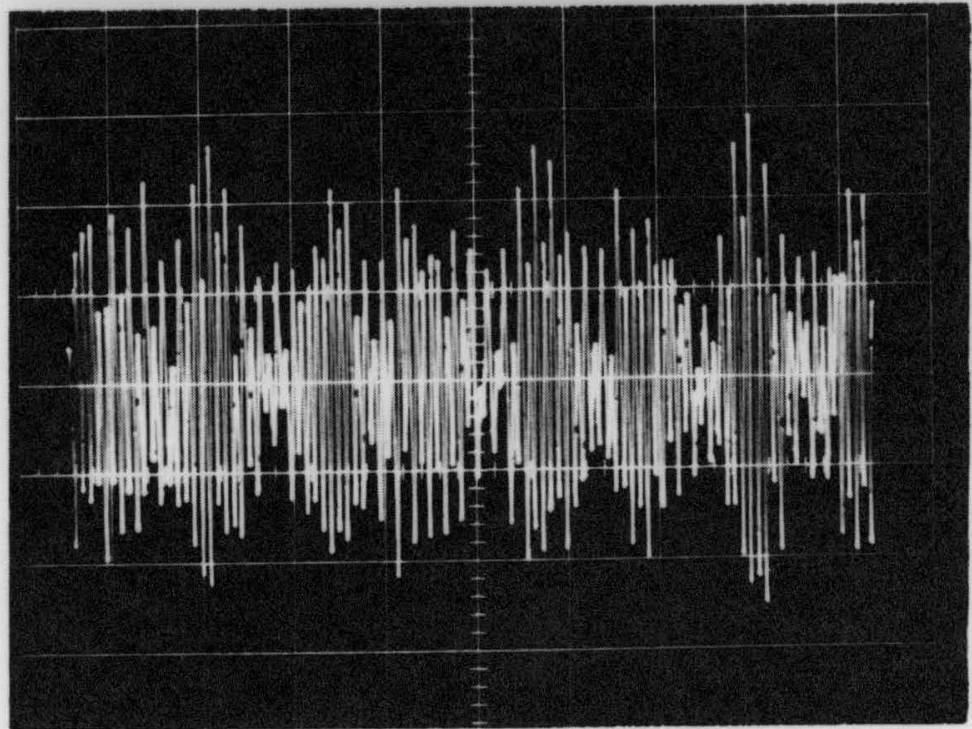

$\Sigma$
Ù
w
N
0

PUMP BEAT FREQUENCY $=4.3 \mathrm{CPS}$

$\sum_{\omega}^{\infty} \frac{\omega}{\Sigma} \frac{w}{\Sigma}$

FIGURE K-I. PUMP FREQUENCY 


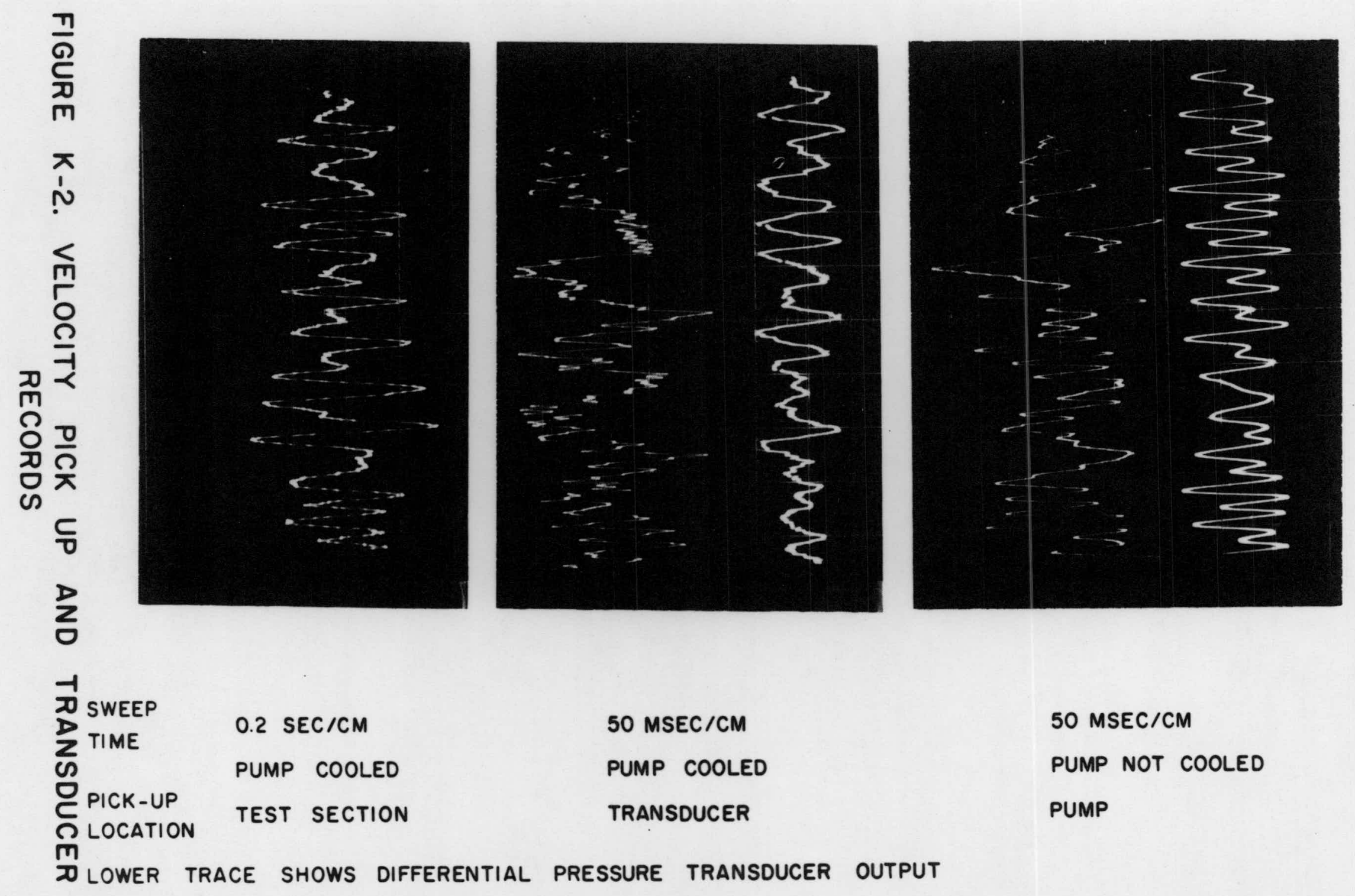




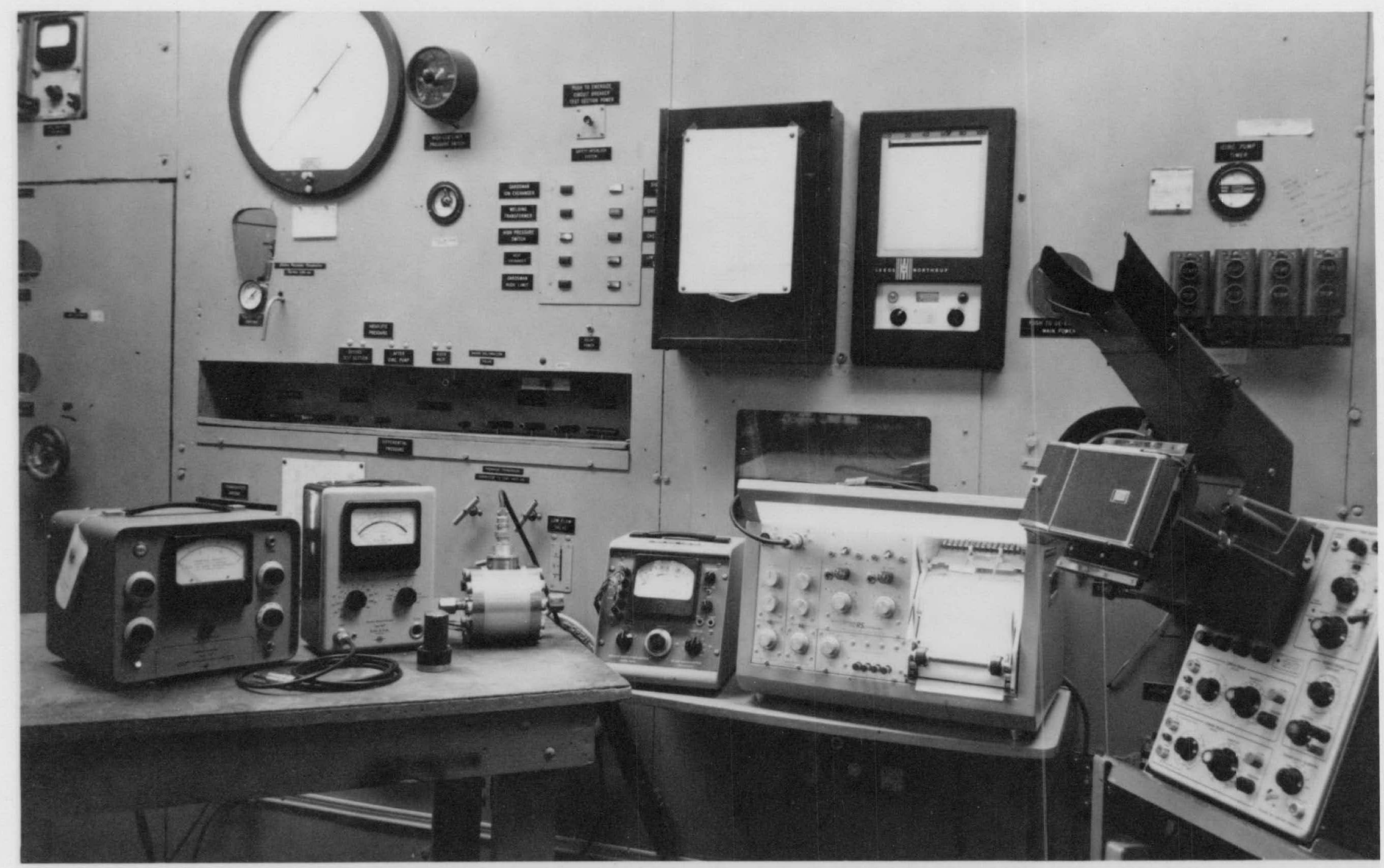

FIGURE K-3. EQUIPMENT USED IN DYNAMIC ANALYSIS 
Corporation's Type 1-117 Vibration Meter, Brüel and Kjoer 2-20,000 cps Random Noise Voltmeter, CEC Velocity pick up, Statham differential pressure transducer, Ellis Bridge Amplifier Meter, Offner Type RS Dynograph, and Tektronix 502 dual-beam oscilloscope. The random noise voltmeter was used to obtain rms values of the pressure drop measurements on the transducer. The output signal of this instrument appeared steady when the input signal was integrated for 100 seconds. In general, dynamic analysis ruled out the possibility of mechanical vibrations creeping into the transducer output. It was found that the natural frequency of the transducer was not close to the frequencies of the mechanical vibrations to which it was being subjected. Also, a strike on the transducer body did not produce any noise output. However, when lines contalning fluid were manipulated, appreciable signals were observed on the transducer output. This furthered the belief that fluid vibrations were the cause of the perturbations. In the following, various tests carried out in conjunction with the problem of fluld vibrations in the system areidiscussed.

Fluid vibrations could be of three types: 1) Spring-mass type vibration; 2) wave type vibration where a pressure front travels through the system; and 3) vibration due to travelling eddies or vortices. To start with, restrictions consisting of five hypodermic needles were installed in the transducer lines to damp out vibrations. No results beyond slowing the response of the transducer were obtained. These were then augumented by needle valves installed in the lines to make possible variations in the length of the transducer circuit. Finally the transducer was moved and installed very close to the pressure 
taps. There were no improvements, and it was concluded that no springmass type vibration was possible in the transducer circuit.

To investigate the possibility of eddies being responsible for the perturbations, the entrance of each tube was packed with several one inch long, 0.109 inch I.D. thin wall Monel tubes to act as flow straightners. The XE test section accommodated three and the $X F$ seven tubes. No noticeable gain was made. Either there were no such eddies present or the tubes were not small enough to influence them.

The next series of tests were conducted to determine whether an optimum accumulator size, which would damp out the vibrations, could be determined. The two accumulators available with the system were ineffective at all pressure and temperature levels.

For this purpose an eight-gallon cylinder capable of handling pressures up to 400 psi was mounted directly above the test section where vacuum pump connections were ordinarily made. Pressurization was provided from a commercial nitrogen cylinder. The tests were run at 200 psia starting with the tank full of water. The effect of an accumulator full of water located above the test section and connected to it through a $1 / 4$ inch tube, or a No. 18 hypodermic needle serving as an orifice, was first studied. No improvements were noticeable. The tests were continued by successive bleedings of $1 / 4$ or $1 / 2$ gallon of water from the tank which was replaced by nitrogen. Thus, the tests were ended with the tank (accumulator) fully charged with nitrogen. No significant improvements were. accomplished. These tests also ruled out the hypothesis that during the filling process some air cavity was left that worked like a loose spring. Figure $k-4$ 


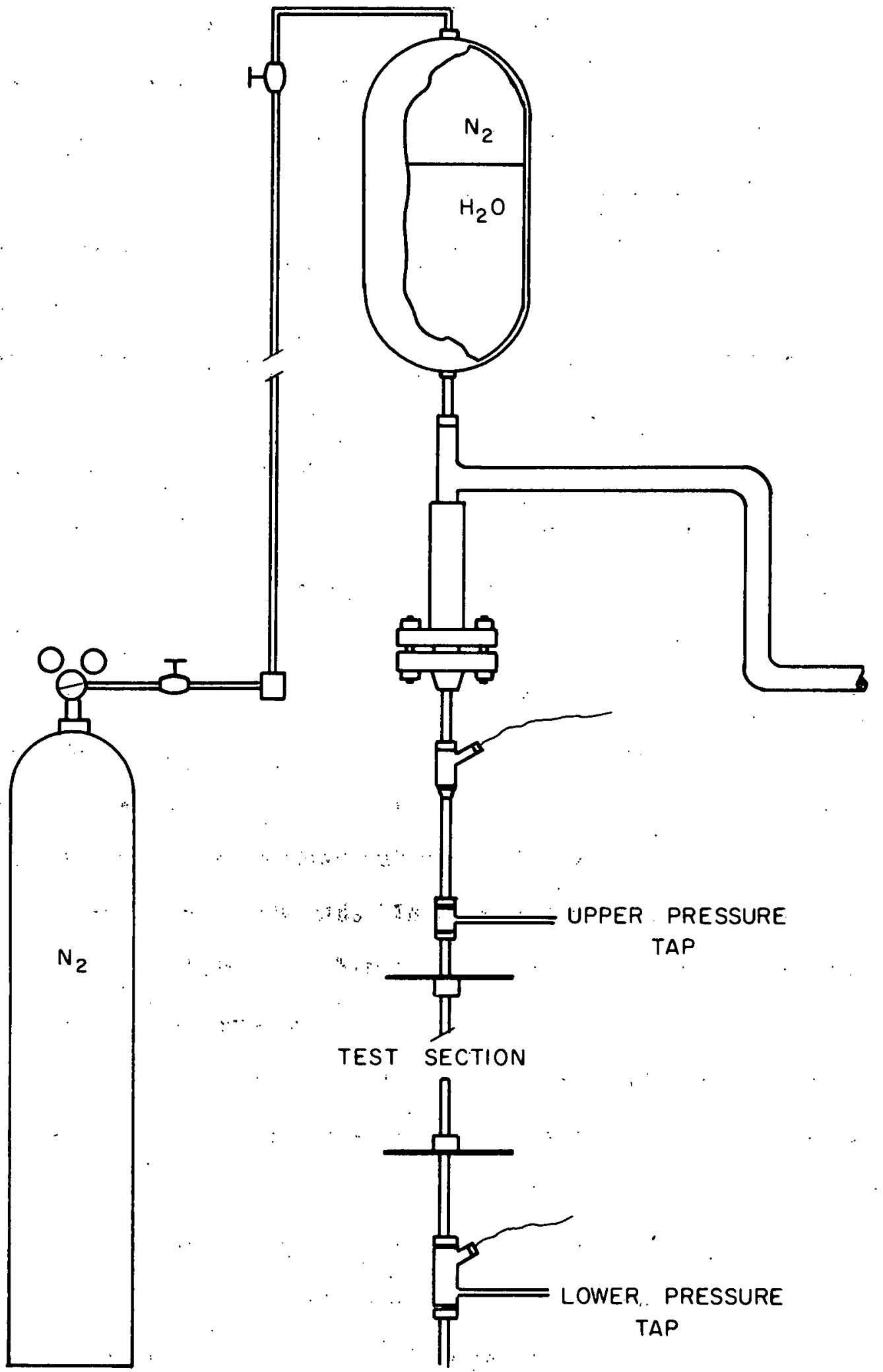

FIGURE K-4. EXPERIMENTAL SET UP FOR ACCUMULATOR, TESTS 
shows the experimental set-up for the above tests. In Figure $K-5$ some recorder traces of the transducer output are shown. It is observed that the gas to water ratio in the accumulator did not affect the amplitude of the vibrations to any appreciable extent. The frequency seems to have changed somewhat; however, such records must be examined over a longer period of time one second as is shown in Figure $K-5$. The mean value of the pressure drop was around 7.8 psi with about 0.6 psi perturbation amplitude. Percentage-wise this amounted to about 7.7 per cent.

The amount of air dissolved in the water was always a source of: concern since it could perhaps be the cause of some voids in the fluid, and influence the smooth running of the pump. It was safe to assume that the water being admitted into the system was properly degasified, but the effect of the small amount of air left in the system due to incomplete evacuation could not be determined. In the section on Experimental Apparatus it was pointed out that vacuums better than 29.3 inches of mercury were rarely attained. In conjunction with this it should be said that it is doubtful if other investigations of this nature ever used a more air-free water.

In closing this part it must be mentioned that the test section tube diameter did not affect the perturbations noticeably. While amplitude of the fluctuations could be compared easily, it was difficult to pinpoint the frequency with any accuracy. In the following part a description is given of certain analytical and statistical methods employed concurrently with the experimental work. 


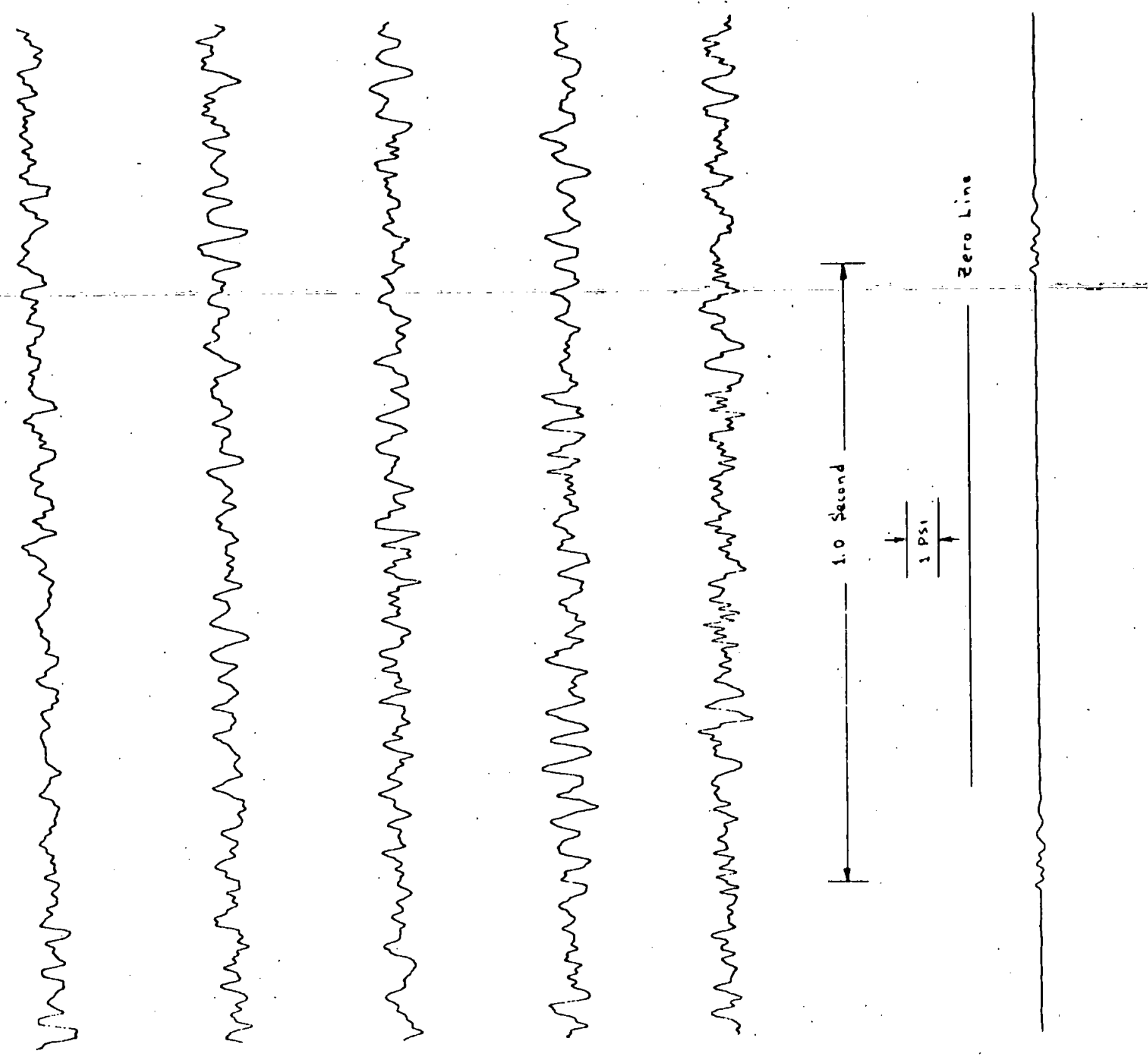

FIGURE K-5. SOME RECORDS OF THE ACCUMULATOR EXPERIMENTS 


\section{Analytical and Statistical Methods}

As a first approximation the ideal problem of non-damped vibration of a system consisting of two gas volumes and a leg of water (liquid) was considered. It was hoped that some estimate could be made of the frequency of such a system. The magnitude of the frequency would then help in deciding whether a vibration similar to a spring-mass system was at all possible. In this conjunction consider Figure K-6 which describes the system being considered. The system consists of two gas volumes $V_{g_{1}}, V_{g_{2}}$ and a liquid volume of mass $M_{0}$ Originally a pressure $p_{0}$ prevails in the system. If the gas volume $v_{g_{1}}$ is given a volume displacement of $v_{1}$, a displacement $v_{2}$ manifests itself in $V_{g_{2}}$. The displacements are not necessarily equal since the liquid $M$ may itself experience a volume change. A force balance gives:

$$
F=A\left(p_{g_{1}}-p_{g_{2}}\right)=M \frac{d^{2} x}{d t^{2}}
$$

where $\mathrm{p}_{g_{1}}$ and $\mathrm{p}_{g_{2}}$ are the pressures of $\mathrm{v}_{\mathrm{g}_{1}}$ and $\mathrm{v}_{\mathrm{g}_{2}}$ after the displacement. It is assumed that the gas volumes do not contribute appreciably to the system mass to be accelerated. The pressures $p_{g_{1}}$ and $p_{g_{2}}$ may be computed from an equation of state. Thus

$$
\begin{aligned}
& p_{g_{1}}=\frac{C_{1} M_{g_{1}} R_{1} I_{1}}{V_{g_{1}}+V_{1}} \\
& p_{g_{2}}=\frac{C_{2} M_{g_{2}} R_{2} I_{2}}{V_{g_{2}}-V_{2}}
\end{aligned}
$$




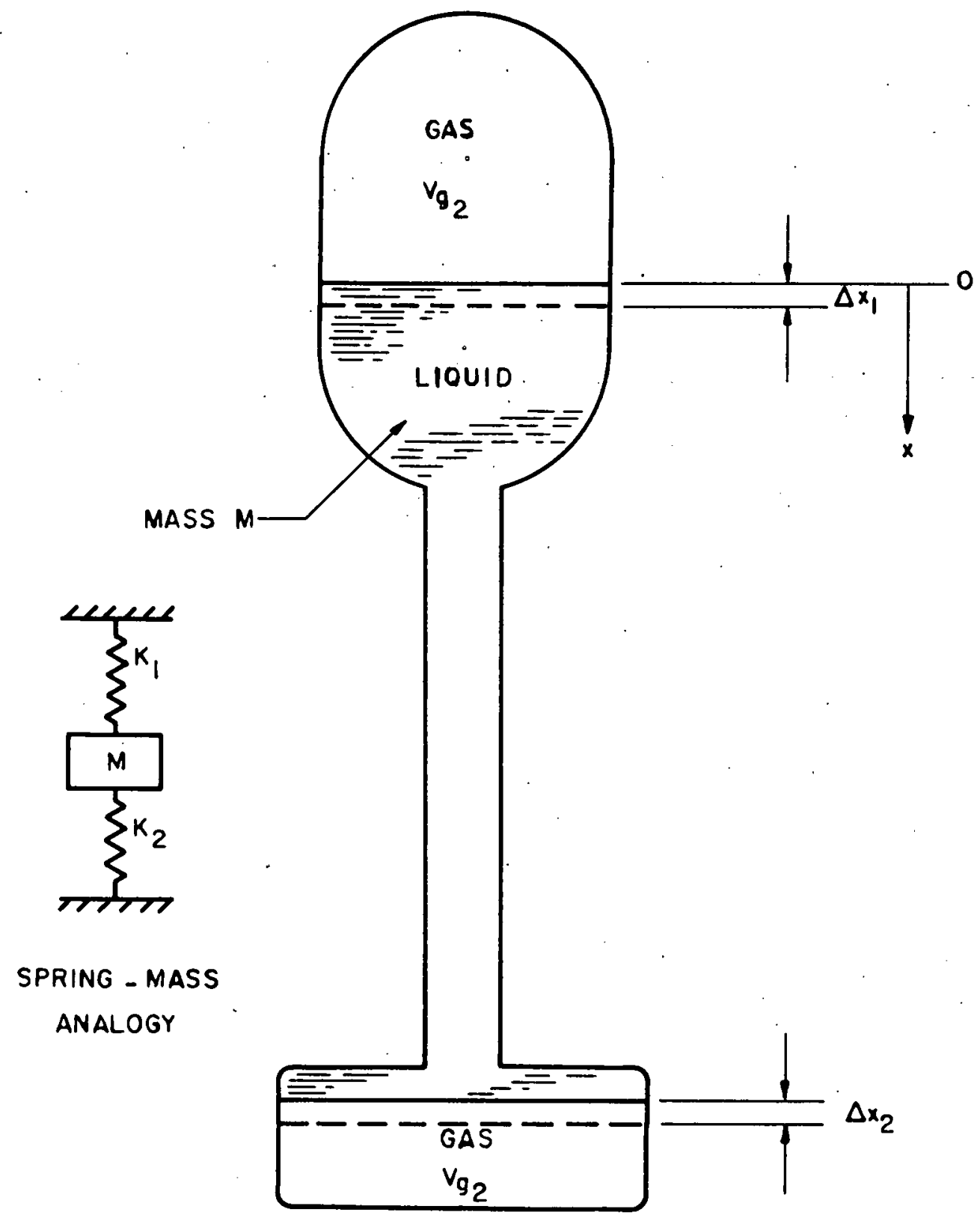

FIGURE K-6. LIQUID MASS ENTRAPPED BETWEEN TWO GAS VOLUMES 
However, originally

$$
p_{0}=\frac{C_{1} M_{g_{1}} R_{1} T_{1}}{v_{g_{1}}}=\frac{C_{2} M_{g_{2}} R_{2} T_{2}}{V_{g 2}}
$$

Assuming that $C_{1} R_{1} T_{1}=C_{2} R_{2} T_{2}=C R T$, then

$$
\frac{M_{g_{1}}}{V_{g_{1}}}=\frac{M_{g_{2}}}{V_{g_{2}}}
$$

and

$$
\text { A. } \frac{p_{0} V_{g_{1}}}{M_{g_{1}}}\left(\frac{M_{g_{1}}}{V_{g_{1}}-V_{1}}-\frac{M_{g_{2}}}{V_{g_{2}}-V_{2}}\right)=M \frac{d x^{2}}{d \tau^{2}}
$$

Furthermore, on the assumption that $v_{1}=v_{2}=v$ the following equation is obtained.

$$
M \frac{d v^{2}}{d t^{2}}=\frac{A^{2} p_{0} v_{g_{1}}}{M_{g_{1}}} \frac{-V\left(m_{g_{1}}+M_{g_{2}}\right)}{\left(v_{g_{1}}+v\right)\left(v_{g_{2}}-V\right)}
$$

Where $V=A X$. Equation $K-7$ is non-linear and it is futile to attempt to solve it when none of the terms $M_{g_{1}}, M_{g_{2}}, v_{g_{1}}, v_{g_{2}}$ are known. Therefore, to give it a more manageable form let it be assumed that $v_{g_{1}}=v_{g_{2}}=v_{g}$ and $v^{2}<<v_{g}^{2}$. Equation $k-7$ then reduces to:

$$
-\frac{d V^{2}}{d \tau^{2}}=\frac{2 A^{2} p_{0}}{V_{g} M} V
$$

which has the solution 


$$
V=B \sin \sqrt{\frac{2 A}{2} p_{O}} \frac{T}{M g}
$$

Frequency is given by

$$
f=\frac{1}{2 \pi} \sqrt{\frac{2 A^{2} p_{0}}{M N_{g}}}
$$

where the term $\frac{A^{2} p_{0}}{V_{g}}$ may be looked upon as the system equivalent spring constant. It is interesting to note that equation $\mathrm{k}-10$ shows a pressure dependence for frequency, which has been observed.

For a sample case consider:

$$
\begin{array}{ll}
p_{0}=200 \text { psia } & \\
M=83.3 \mathrm{lb}, & 10 \text { gallons } \\
A=0.442 \mathrm{in}^{2} & \text { based on system piping diameter } \\
V_{g}=1.0 \mathrm{in}^{3} & \text { assumed }
\end{array}
$$

Then,

$$
f=3.0 \text { cycles per second. }
$$

Such low frequencies were not observed. Another fact that throws doubt into the creditability of equation $k-10$ is that the frequency is expected to decrease with increasing gas volumes, a point which was repudiated by the experiments. Admittedly such equations are too simple to predict a complex phenomenon.

A statistical method was used to obtain a better estimate of the frequencies that were predominant. Three hundred data points, spaced every 0.01 second, were obtained from a transducer record of 
the test section pressure drop fluctuations at 200 psia and room temperature. Unfortunately the spacing of data only permitted evaluation of the frequencies up to 50 cycles per second, thus denying observations close to the circulating pump speed.

The autocovariance and power spectral density functions were evaluated. These functions are basically defined by the following relations:

Autocovariance Function:

$$
c(\tau)=\lim _{T \rightarrow \infty} \frac{1}{2 T} \int_{-T}^{T} x(\theta) \cdot x(\theta-\tau) d \theta
$$

Power Spectral Density Function:

$$
P(\omega)=\frac{1}{\bar{\sigma}} \int_{-\infty}^{+\infty} c(\tau) e^{-i \omega \theta} d \theta \quad k-12
$$

or

$$
P(\omega)=\frac{2}{\pi} \int_{0}^{\infty} c(\tau) \cos (\omega \theta) d \theta
$$

where $T$ is the time, $x(\theta)$ is the variable, $\omega$ is the frequency, and $T$ is the so called lag value.

Without sophistication, the autocovariance function will give:

1) a measure of randomness, 2) the mean square value of a random function, and 3) an indication of any periodicity in the record. The power spectral density function shows to what extent various frequencies are important. As defined in equation $(K-12)$ it is the Fourier trans- . 
formation of the autocovariance function. Investigation and computation procedure followed the methods given in reference (41).

The autocovariance function was determined from Tukey's computational form, viz.

$$
c\left(r_{r}\right)=\frac{1}{n-r} \sum_{i=1}^{n-r} x_{i} \cdot x_{i+r}
$$

where $\mathrm{n}$ is the number of data points. The power spectral density function was then computed from

$$
P\left(f_{h}\right)=2 \Delta \theta\left[c(0)+2 \sum_{r=1}^{r=m-1} c\left(r_{r}\right) \cos \left(\frac{\pi h r}{m}\right) \cdots\left(\tau_{m}\right)(-1)^{h}\right] \quad k-15
$$

where $\mathrm{m}=\frac{\tau \max }{\Delta \tau}$.

Figure $k-7$ shows three records illustrating pressure dependence of the frequency. Figure $k-8$ gives the final result of the statistical analysis for the 200 psia run. The average value of the pressure drop was around $8.0 \mathrm{psi}$. It should be mentioned that the average value was subtracted from the data which were analyzed. Figure $K-8$ shows that at 200 psia the predominant frequencies were around 15 cycles per second. The autocovariance function gave no indication of periodicity. A word of caution is in order. Although statistical methods are accurate, to be significant they require a large number of data. The amourit of data used for these analysis were rather modest and per se the results should not be taken for granted. Some work was carried out considering wave propagation in the system. However, these methods are quite complex and beyond easy 


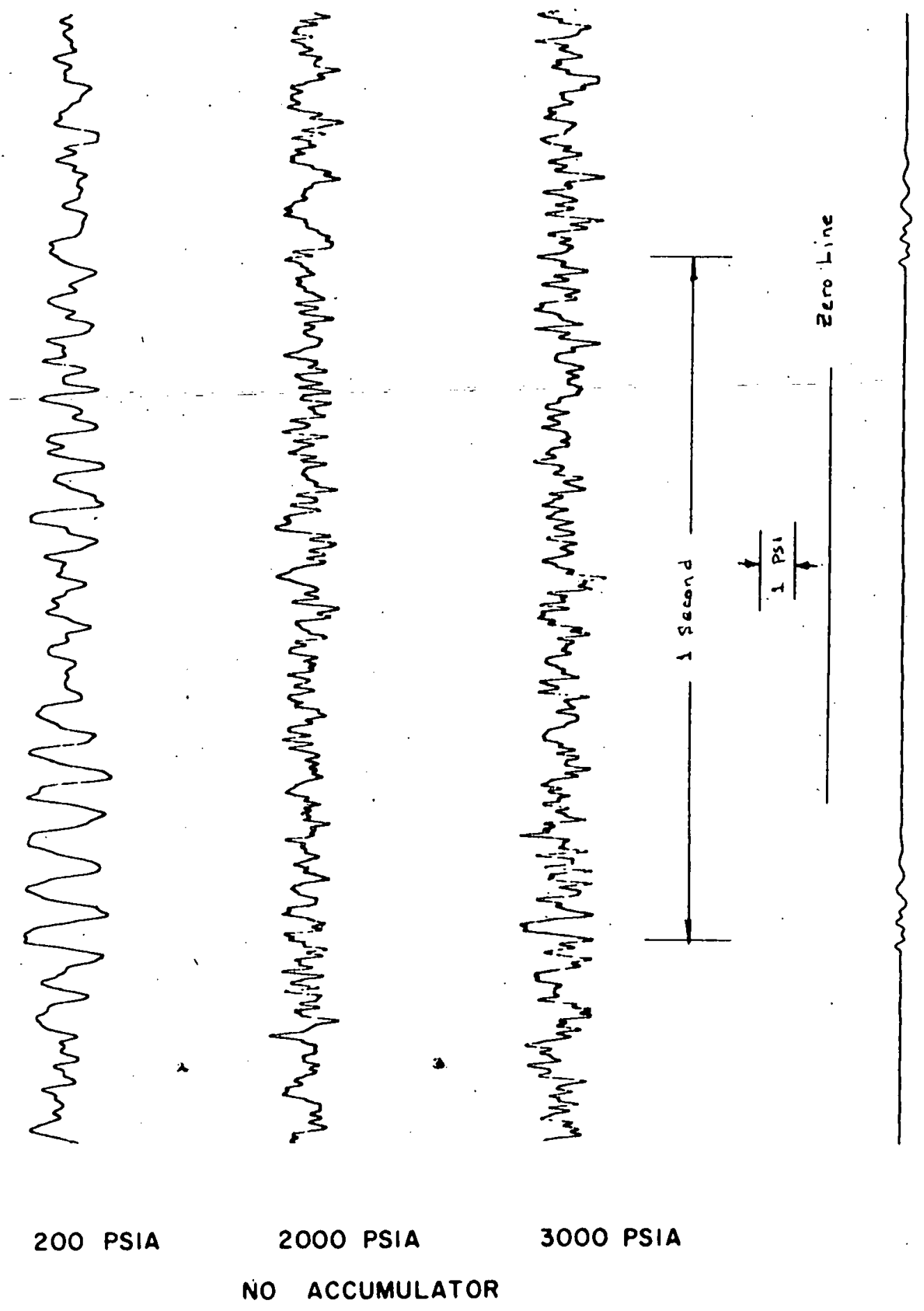

FIGURE K-7. PRESSURE DEPENDENCE OF THE FREQUENCY 


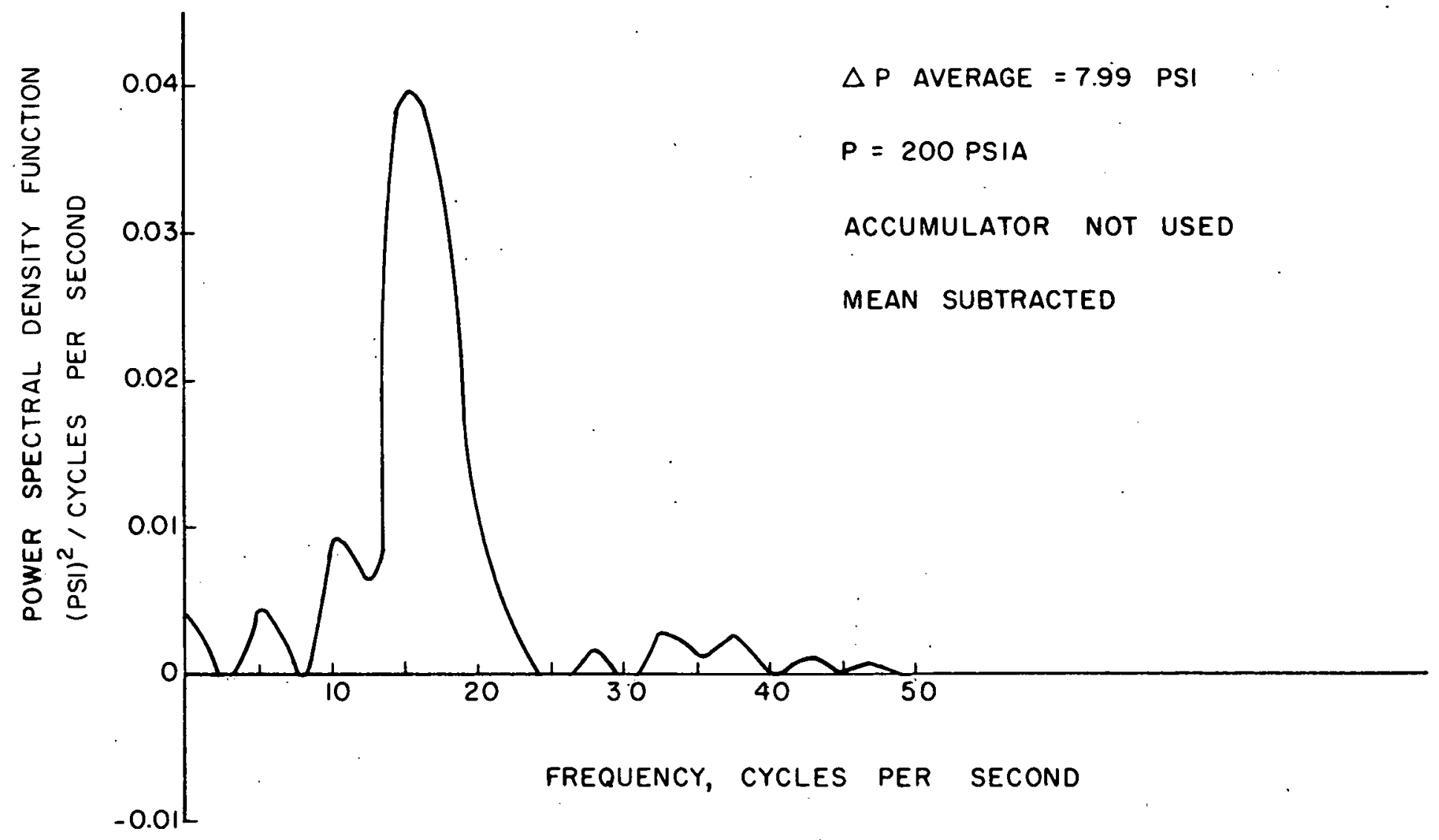

FIGURE K-8. POWER SPECTRAL DENSITY FUNCTION 
reach. Time did not permit any further investigations. In general the work has led to the following conclusions:

1. It is quite improbable that mechanical vibrations per se influence the differential pressure transducer readings.

2. The possibility of spring-mass type vibrations could be ruled out.

3. Pressure wave propagation within the system or the presence of eddies and vortices seem to be the likely cause of the perturbations.

The latter point is substantiated by the fact that the amplitude of the fluctuations is larger across the test section than the venturi where the pressure taps are located closely. A wave or eddies traveling within the tube would first affect one pressure tap and some time later the other, the time and thus the differential amplitude being a function of the distance, and wave and/or fluid velocity. Furthermore, it has been observed that the displacement pump action influences the differential amplitude across the test section severely (see Figure $\mathrm{k}-9$ ), while the venturi record is affected little. Undoubtedly, such pump action could be classed as wave propagation. There seem to be two possible ways in which pressure waves could be generated: 1) pulses from the circulation pump action, and 2) mechanical vibration of loose components of the system such as long small diameter tubes. The latter has been experimentally proved. A small displacement in such long tubes causes a volume change in nearly incompressible water and therefore a pressure wave. This may also explain the increase in the frequency of the perturbations with in- 

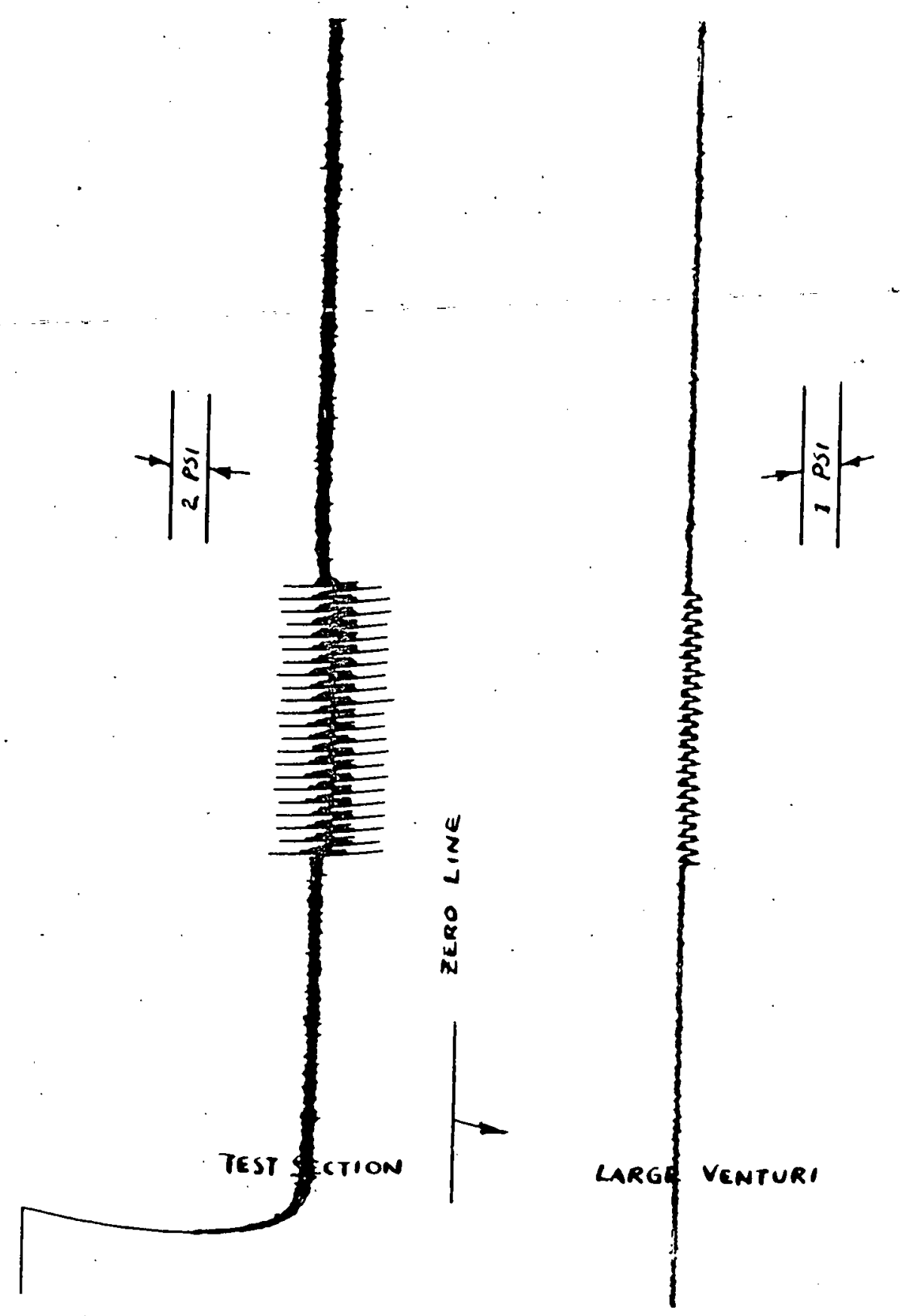

FIGURE K-9. RECORDED EFFECT OF THE DISPLACEMENT PUMP ACTION 
creasing pressure. At high pressures these components could become taut, and vibrate at higher frequencies. It is doubtful that the small increase in the modulus of elasticity of water with pressure could cause such changes in frequency.

The presence of eddies or vortices was not detected, but could be assumed. These could be shed by the sharp bends in the flow path or by certain boundary layer separation effects. The author has recently learned that the venturi walls were not smooth, but more like steps. This could be a cause, though it must be proved.

By the farthest stretch of imagination, if the frequencies with which vortices are shed in a Kármán vortex street behind a circular cylinder are applied to this problem, it is found that a frequency range of 30-70 cps may be expected. Since, at high Reynolds number

$$
\begin{aligned}
& \text { or (Stroulial Number) }=\frac{f D_{0}}{\bar{U}}=0.21 \\
& \text { frequency }=\frac{0.22 \times \bar{H}}{D_{0}} \\
&=\frac{0.21}{\frac{0.750}{12}} \times \bar{U}=3.36 \times \bar{U}
\end{aligned}
$$

The calibration curves for the venturis (Figure 19) show uncommon scatter which probably indicates unsmooth, high turbulence flow. Eddies and Kármán vortices may; therefore, result from the venturis. 